\title{
GIS Assisted Problem Analysis of Trail Erosion in Monongahela National Forest
}

Steven J. Storck

West Virginia University

Follow this and additional works at: https://researchrepository.wvu.edu/etd

\section{Recommended Citation}

Storck, Steven J., "GIS Assisted Problem Analysis of Trail Erosion in Monongahela National Forest" (2011). Graduate Theses, Dissertations, and Problem Reports. 3427.

https://researchrepository.wvu.edu/etd/3427

This Dissertation is protected by copyright and/or related rights. It has been brought to you by the The Research Repository @ WVU with permission from the rights-holder(s). You are free to use this Dissertation in any way that is permitted by the copyright and related rights legislation that applies to your use. For other uses you must obtain permission from the rights-holder(s) directly, unless additional rights are indicated by a Creative Commons license in the record and/ or on the work itself. This Dissertation has been accepted for inclusion in WVU Graduate Theses, Dissertations, and Problem Reports collection by an authorized administrator of The Research Repository @ WVU.

For more information, please contact researchrepository@mail.wvu.edu. 


\title{
GIS Assisted Problem Analysis of Trail Erosion in Monongahela National Forest
}

by

\author{
Steven J. Storck
}

\author{
Dissertation submitted to the \\ Davis College of Agriculture, Natural Resources and Design \\ at West Virginia University \\ in partial fulfillment of the requirements \\ for the degree of \\ Doctor of Philosophy \\ in \\ Forest Resources Science
Approved by Dr. Chad Pierskalla, Ph.D., Committee Chairperson
Dr. Robert Burns, Ph.D.
Dr. Steve Selin, Ph.D. \\ Dr. David Smaldone, Ph.D. \\ Mr. Charles Yuill
Department of Recreation, Parks and Tourism Resources
Morgantown, West Virginia 2011

Keywords: Trail Erosion, Recreation Ecology

Copyright 2011 Steven J. Storck 


\section{Abstract \\ GIS Assisted Problem Analysis of Trail Erosion \\ in Monongahela National Forest}

Steven J. Storck

This research investigates the frequency and patterns of trail erosion on purposefully selected natural surface trails in Monongahela National Forest. Trail erosion is considered a non-self-limiting process which degrades trail beds making them unattractive, difficult to travel on, and has the potential to impact local streams with the introduction of silt. Recreation ecology research delineates factors which influence the rate of erosion on a trail into three broad categories: recreational use, environmental conditions, and managerial actions. This study tests the relationship of variables from each of these categories to the local patterns of erosion. Three sampling strategies are used to document the presence of erosion and to characterize recreational use, environmental conditions, and management parameters. Point samples taken at 600 -foot intervals along 63 miles of trail provide information on maximum incision, and a problem census of erosion greater than five inches in depth for ten or more feet document the presence and extent of erosion on study trails. Use of over 500 high-quality field reference points collected with a Global Positioning System (GPS) allowed the placement of wheel distances for eroded segments onto trail routes in a Geographic Information System (GIS) for analysis with other secondary GIS data sets. This approach allowed each trail to be segmented into 600 -foot linear segments providing a third sampling frame for consideration with the amount of linear erosion per segment as the dependent variable. These equal sized segments provide a manageable landscape scale unit of analysis. Additionally, GIS elevation data enabled the calculation of two independent variables which are new to trail erosion research, Topographic Relative Moisture Index (TRMI) and Estimated Upslope Flow Length (EUFL).

The results of this study indicate trail erosion on the study trails is comparatively lower than other resource areas with occurrences limited to a subset of trails. Regression models show the primary factors influencing erosion rates for the Forest are recreational use, trail grade, low trail alignments, mid-slope trail positions, open canopies, mean annual precipitation, decreased winter temperature, TRMI, and EUFL yet the best model only predicted $26 \%$ of the occurrences of erosion. Of all the independent variables, average EUFL for linear trail segments described the most variance in the incidence of erosion. The significance of this finding is that there is a great need for shortening the distances water is allowed to travel on a trail with either water diversion structure installation and maintenance or trail rerouting. EUFL was also influential in the finding that low-gradient trails with limited use displayed disproportionately higher rates of erosion than other trails, a finding not well documented in previous research. As four of the eight significant predictor variables were GIS based, this study shows the usefulness of utilizing GIS in trail erosion research as it provides insights into landscape scale variables that are not easily measured in the field. Furthermore, this approach integrates well with GIS based trail inventory management systems informing maintenance regimens and facilitating long-term trail degradation monitoring. 


\section{Acknowledgments}

The author wishes to thank the many individuals and organizations who contributed to the completion of this research. Foremost, I would like to thank Dr. Chad Pierskalla and Monongahela National Forest for the creation of this research opportunity. Dr. Pierskalla supported my ideas, was involved in my field work, helped target my analysis, questioned my interpretation, and served as the chair of my committee for more than 6 years. Thank you for hanging in there. In addition to thanks for the financial support during my field work, I would like to thank the recreation managers and GIS staff of Monongahela National Forest for their accessibility and for sharing their knowledge and data with me without any of which this study would not have been possible.

The community at West Virginia University has been very supportive of my completion of this degree. Specific thanks to my committee members, Dr. Dave Smaldone, Dr. Steve Selin, Dr. Robert Burns and Mr. Charlie Yuill, for their long-standing support of my academic work. Much appreciation to my field partners Jason Stancil and Dr. Jason Siniscalchi for helping me refine my field methods and for the long hours on bent knees measuring minute losses of soil throughout the state. I would also like to thank the staff of the College of Agriculture and Forestry's Dean's Office for helping me through the logistics and costs of this degree. Particular thanks go to my GIS mentors Mr. Charlie Yuill and Dr. Mike Strager for inspiring me to expand my thinking of databases and geospatial analysis and for fielding my many questions regarding GIS techniques and the interpretation of my data. The friendship and mentorship of my statistics professor Dr. Sebastian Diaz was also of great importance in the structuring of my analysis and the final push towards completion.

I would like to acknowledge and thank Dr. Jeff Marion of Virginia Polytechnic Institute and State University for his leadership in the recreation ecology field and for his guidance in crafting this study. Dr. Marion's correspondence and sharing of resources are testament to his collaborative nature and professionalism in mentoring future recreation ecologists. Special thanks go to Dr. Jerry Vaske, Professor of Human Dimensions of Natural Resources, Colorado State University Warner College of Natural Resources for introducing me to recreation research and for sharing his wisdom and expertise in the field.

In the final push to finish this dissertation the flexibility and support of my supervisor and co-workers at NOAA and my employer, Earth Resources Technology, Inc., were greatly appreciated. I would like to thank the staff of NOAA's Office of Education for their support of my extended absences and particular 
thanks go to Christos Michalopoulos for the extra push when I needed it most. I was further inspired to finish this work by the writings and professional pursuits of my newly discovered cousin Dr. Rita Nyizsalovszki, Senior Lecturer in the Department of Tourism and Regional Development, Károly Róbert College, Gyöngyös, Hungary.

Finally, I would like to thank my family for doing without while I wrestled this document and degree into submission. I look forward to life with you on the other side of this endeavor. 


\section{Table of Contents}

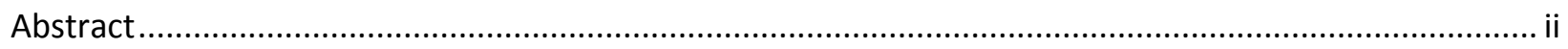

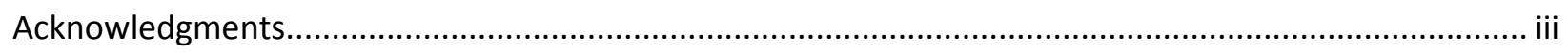

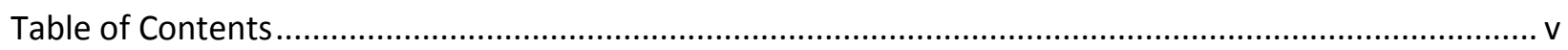

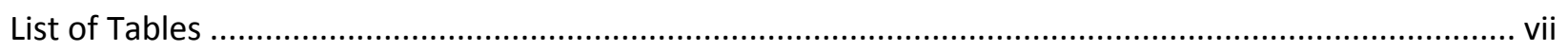

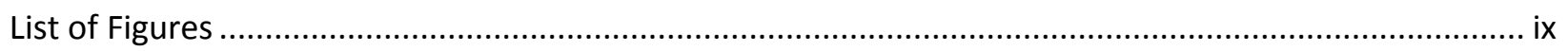

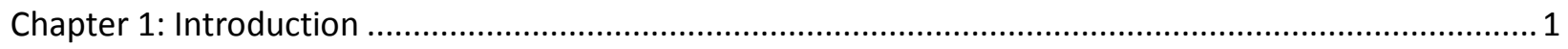

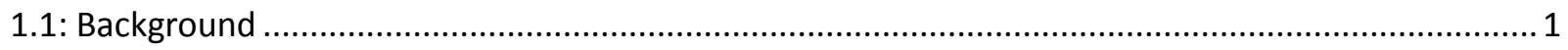

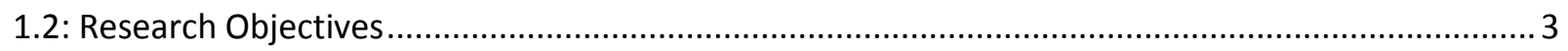

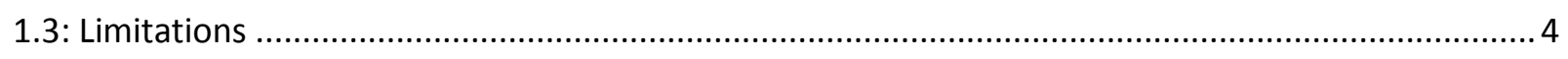

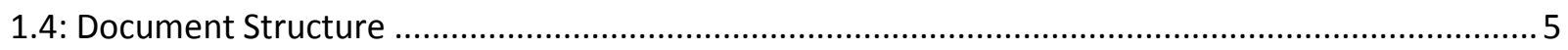

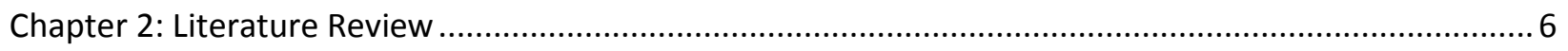

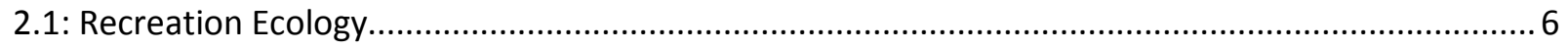

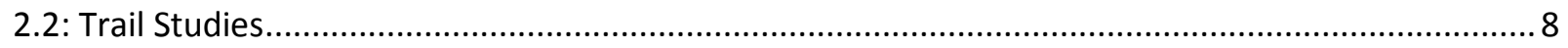

2.3: Trail Assessment Field Methodologies …........................................................................... 11

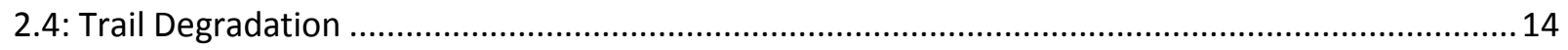

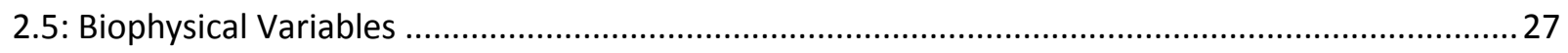

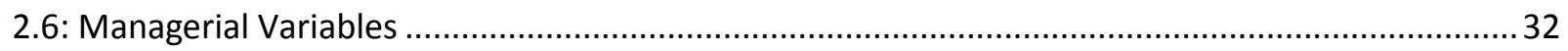

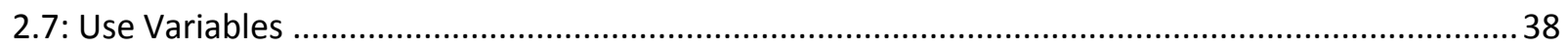

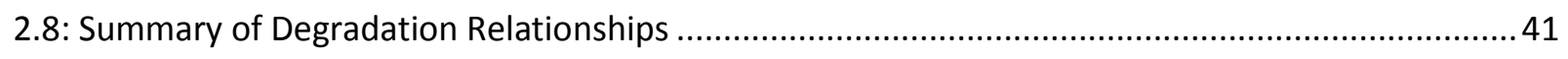

2.9: Application of Geographic Information Systems in Trails Research ....................................... 42

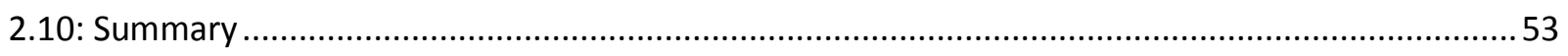

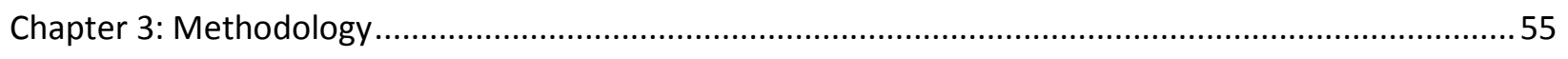

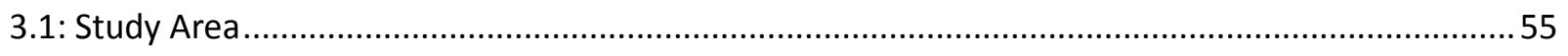

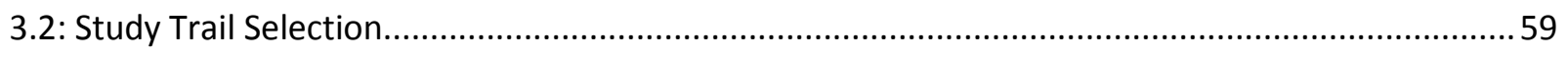

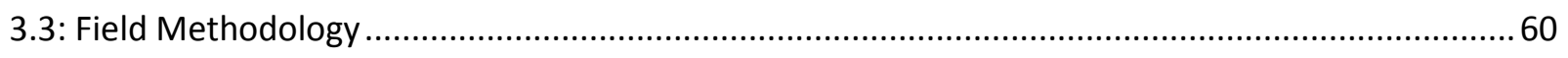




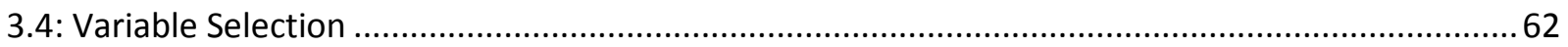

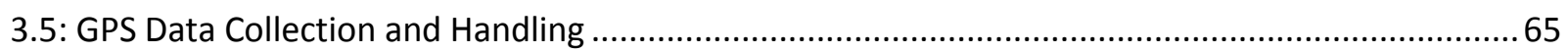

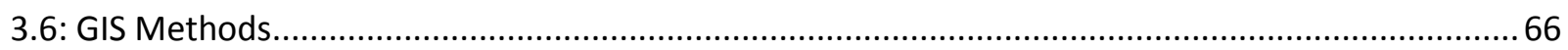

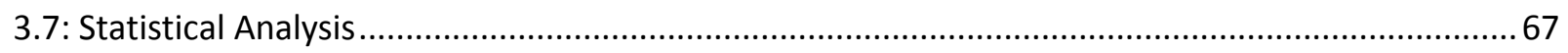

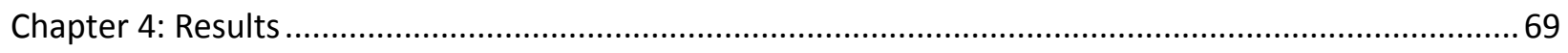

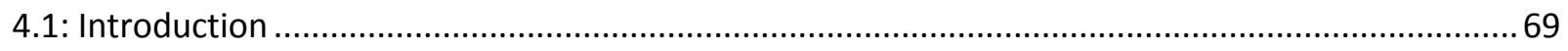

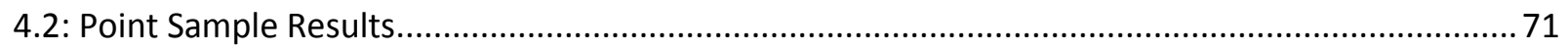

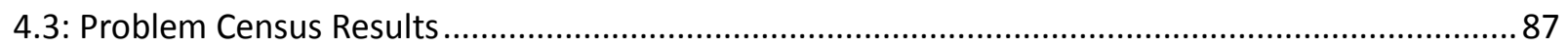

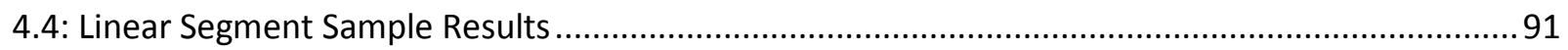

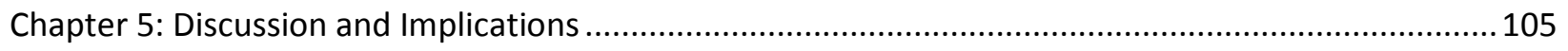

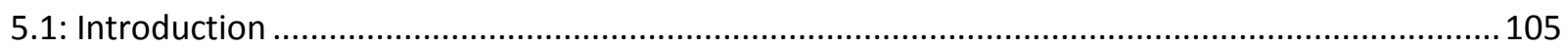

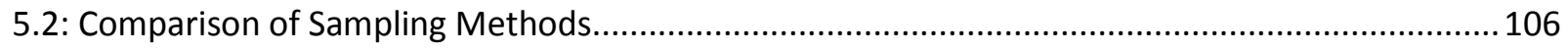

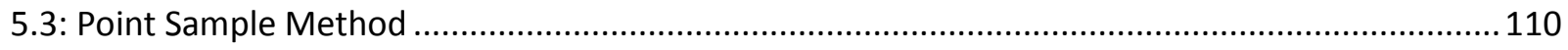

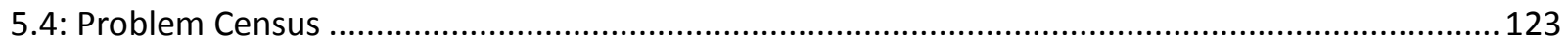

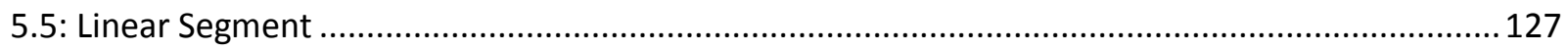

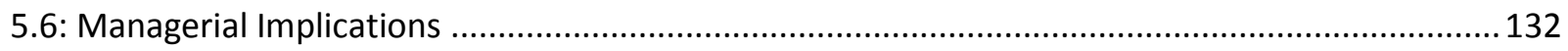

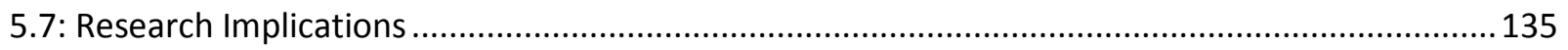

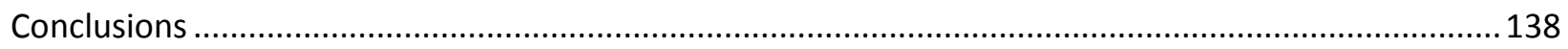

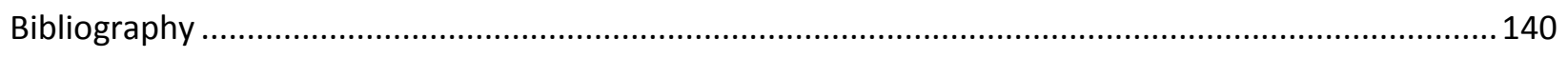

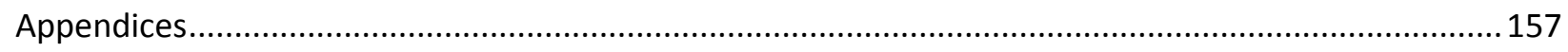

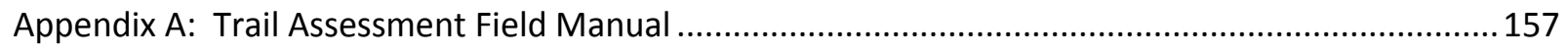

Appendix B: Estimated Upslope Flow Length (EUFL) Derivation in ArcGIS ..................................... 162 


\section{List of Tables}

Table 1 A Classification of Trail Research Terms Based on the Scope of Trail Problems Included..............10

Table 2 Trail Study Sample Lengths by Assessment Methodology ....................................................... 14

Table 3 Trail Degradation Study Variables and Statistical Methods. .....................................................24

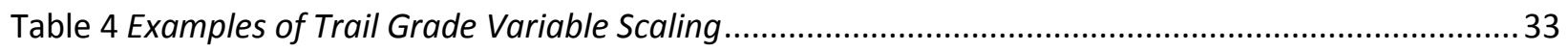

Table 5 Most Popular Recreational Activities Reported by 2004 NVUM Respondents (USFS, 2004). .........57

Table 6 Field Collected, GIS Extracted, and GIS Derived Independent Variable List for Point Sample

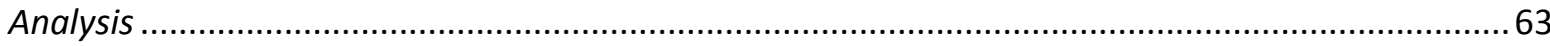

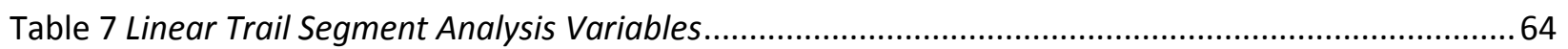

Table 8 Point Sample Distribution by Trail With Trail Usage and Maximum Incision................................. 73

Table 9 Analysis of Variance in Maximum Incision for Recreational Use Volume Categories .....................74

Table 10 T-Test Results for Maximum Incision of High and Low Recreational Use Volume Categories..... 75

Table 11 Analysis of Variance of Maximum Incision for Trail Grade Categories ....................................... 76

Table 12 Mean Maximum Incision by Trail Alignment Categories. ......................................................... 77

Table 13 Mean Maximum Incision by 25' Estimated Upslope Flow Length (EUFL) Groupings...................79

Table 14 Mean Differences in Maximum Incision by Forest Canopy Type............................................... 80

Table 15 Mean Maximum Incision by Ecological Land Unit................................................................... 82

Table 16 Individual Independent Variables Regressed with Maximum Incision for Point Samples............ 83

Table 17 Multiple Regression Model Results for Recreational Use, Managerial, Biophysical Factors, and Combined Model (Standardized Beta Coefficients) Regressed with Maximum Incision .....................85

Table 18 Comparison of Explained Variance in Maximum Incision for Field and GIS Extracted Variables. 86 Table 19 Cumulative Lengths and Percentages of Trail Erosion in Major Ecological Land Unit Categories

Table 20 Distribution of Eroded Segments by Trail (Mean All Segments) ................................................92

Table 21 Biophysical Variable with Significant Differences for Trail Segments with and Without Erosion 95

Table 22 Distribution of Linear Segment Erosion Categories by Ecological Land Unit ............................. 96

Table 23 Distribution of Eroded Segments by Trail (Mean Eroded Segments Only) .................................97

Table 24 Cumulative Linear Feet of Erosion per 600' Trail Section x Mean Grade of 600' Trail Section .... 99

Table 25 ANOVA Results for Mean Differences in Trail Segment Cumulative Linear Erosion by 25'

Estimated Upslope Flow Length (EUFL) Groupings .................................................................... 99 
Table 26 Pearson Correlations for Environmental Variables with Cumulative Length of Erosion per 600'

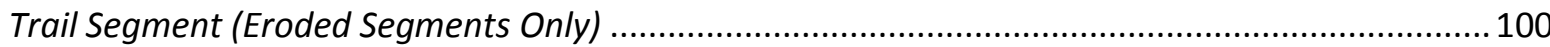

Table 27 Distribution and Mean Length of Eroded Trail Segments by Ecological Land Unit ....................101

Table 28 Individual Independent Variables Regressed with Cumulative Linear Feet of Erosion on 600-foot

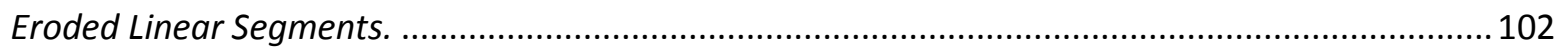

Table 29 Multiple Regression Model Results for Recreational Use, Managerial, Biophysical Factors, and Combined Model (Standardized Beta Coefficients) Regressed with Mean Cumulative Linear Erosion

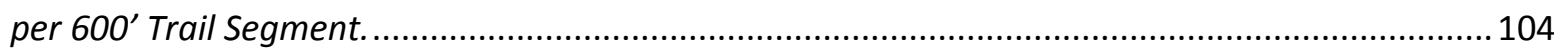

Table 30 Percentage of Observed Erosion Greater Than 5 Inches by Sample Type ................................ 107

Table 31 Comparison of observed erosion of $>5$ inches for problem census, point sample, and linear

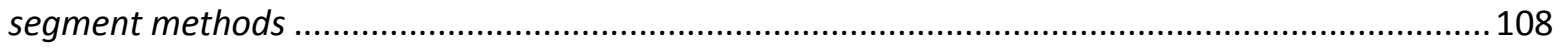

Table 32 Comparison of Point Sample and Linear Segment Regression Models ...................................109 


\section{List of Figures}

Figure 1: Interrelationships between environmental, use-related, and managerial factors affecting trail

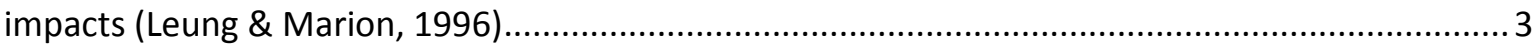

Figure 2. Trail tread erosion process. Adapted from T. S. Parker (2004)............................................... 18

Figure 3. Seven-step cycle of recreational impact on soils (Manning, 1979) ......................................... 19

Figure 4 Trail slope alignment impact characteristics (Aust et al., 2005)............................................... 35

Figure 5: General relationship between amount of use and recreational impacts on campsites. (Source:

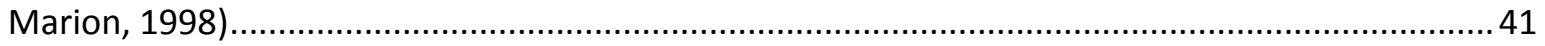

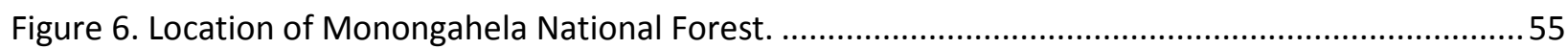

Figure 7. Suitability of soils for trail development in MNF (USDA-NRCS, 2010)........................................56

Figure 8. Monongahela National Forest Ranger Districts. ...................................................................58

Figure 9. Distribution of Point Sample Maximum Incision values in inches for Monongahela National

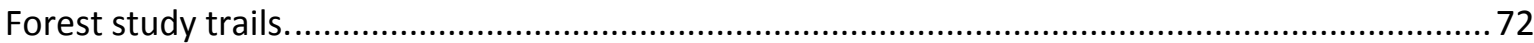

Figure 10. The influence of trail grade and trail slope alignment on soil erosion, as measured by maximum incision.

Figure 11. Comparison of trail alignment and trail grade relationships with erosion indicators on MNF and Big South National Recreation Area (NRA) trails. 


\section{Chapter 1: Introduction}

\section{1: Background}

The trail, "a track made by passage, a course followed or to be followed" ("Trail," 2003), is the single most unifying unit of the outdoor recreation experience. Regardless of activity, each user of an outdoor resource must transit across or through the resource by some type of trail. Hunters to their tree stands, hikers to the overlook, horse packers to their camp, and paddlers to the river's edge. As part of the mandate to enhance recreation on public lands, resource managers have developed networks of trails to connect the public to these resources. The placement, design, and condition of these trails help shape the experience of the user and the level of disturbance of the surrounding natural environment. The natural environment, recreational use, and management practices also influence the condition of the trail. This circular, inter-relationship of environment, user, management, and trail is complex. Extensive research in the field of recreation ecology focuses on these relationships. This research builds on this foundation to further advance the understanding of trail morphology.

Trail condition is most commonly evaluated by the existence of various types of "impacts" that were not part of the original trail design. Trails most closely resembling the route when construction was completed have few impacts; those with the most un-managed modifications are more heavily impacted. The word impact is a neutral term indicating change from some catalyst, but in most contexts, it has a negative connotation. In the case of trails, the existence of impacts indicates a reduced utility. This process of increasing impacts on trails is also referred to as trail degradation (Cole, 2004). The definition of "utility" depends greatly on the user, their reason for being there, their background and experience, and their expectations. Exploring these definitions and their salience to resource management is an important focus of visitor satisfaction and environmental psychology research but is not a focus of this study. What is taken from this literature is support for the fact that resource impacts can negatively affect visitor experiences and maintenance of high-quality trail systems is a key contributing factor to this experience (Aust, Marion, \& Kyle, 2005; Lynn \& Brown, 2003; Manning et al., 2004; Pierskalla et al., 2006).

In addition to the potential detriment to visitor satisfaction, trail impacts can also pose threats to the safety of visitors and the health of the local environment. Public safety is a primary mandate for resource managers, trails with hazardous surfaces, those sliding down steep slopes, or a trail with many 
dead trees overhead are threats to the user. In the United State's National Forests, these conditions would not meet the national trail quality standards for public safety (USFS, 2006a). From an environmental perspective, trails, and their subsequent human use, are alterations to the natural environment. Previous research indicates that these disturbances have led to sedimentation of sensitive aquatic habitats, slope failures, and scouring of streambeds contributing to local flash flooding (Bratton, Hickler, \& Graves, 1979; Chatterjea, 2007; Leung \& Marion, 2000; Olive \& Marion, 2009). While looking at the causal relationship of any one of these problems is beyond the scope of this study, modeling the relationship of the contributing factors, recreational use, environmental conditions, and management action, for a specific precursor to several of them (trail erosion) is.

In the arena of trail impact research, erosion is of primary importance as it removes the soil that forms the base of the majority of trails. Trail erosion is considered non-self-limiting as the amount of soil removed from a trail increases over time once initiated (Cole, 1983). The primary cause of erosion is an interaction between soil, water, and gravity. On a geologic scale, the power of water to alter the topography of the land over the millennia is well documented. The role and influence of recreational trail use, environmental factors, and management action make the science of modeling erosion on trails complex. The conceptual model in Figure 1 illustrates the potential pathways of these relationships. Once these processes begin on a trail they will progressively increase the level of impact observed and few natural phenomenon will stop the process. Thus, human intervention, managerial action, is required if the alterations are diminishing the utility of the trail to undesirable levels.

Surfacing trails into solid platforms with low permeability is one long-term solution to the impact of erosion, but the majority of trails in the world are unsurfaced due to budgetary and aesthetic considerations (Giles, 2002). Without a hardened surface, the remaining millions of miles of trail are more quickly susceptible to the forces of water. The rate of trail deterioration is a highly localized phenomenon and leaders in the field have encouraged examination of each unique setting. In Wildland Recreation (Hammitt \& Cole, 1998) the authors write:

"There is no doubt that environmental factors profoundly influence amount of impact. The problem is that so many of the relationships between environment and impact are highly site specific. Relationships that apply in one place may not apply in another.... Ultimately, each area will have to develop its own guidelines for where to develop facilities." 
The consideration of these concepts and relationships form the underpinnings of recreation ecology research. Although a relatively new science, studies of impacts in natural resource settings cover a broad spectrum of geography and ecosystems spanning some eighty years. The methods used are still under refinement and, as in many fields, calls for standardized metrics are frequent (Monz, Cole, Leung, \& Marion, 2009).

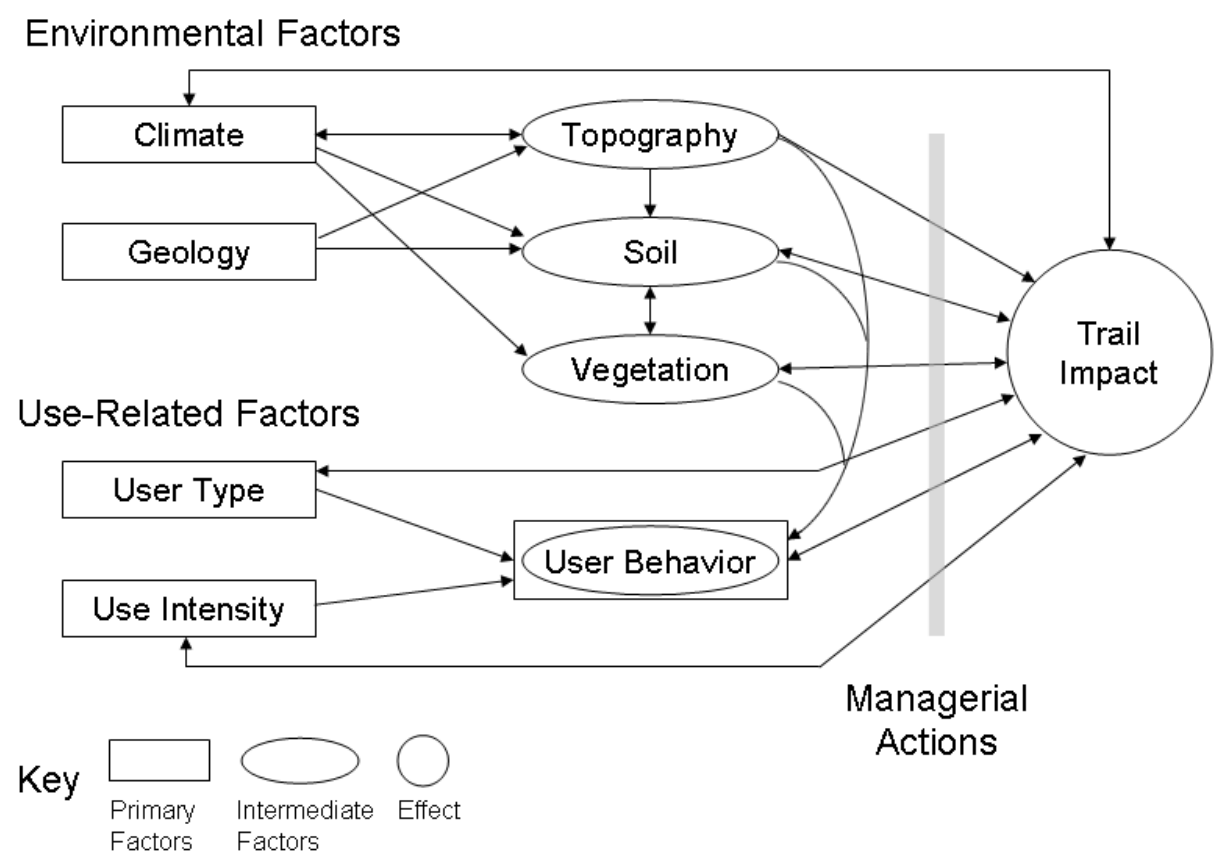

Figure 1: Interrelationships between environmental, use-related, and managerial factors affecting trail impacts (Leung \& Marion, 1996)

\section{2: Research Objectives}

The purpose of this study is to examine trail erosion patterns in the Monongahela National Forest (MNF) to advance the understanding of the localized influences of visitor-use, environmental, and managerial variables on trail conditions. This type of study had not previously been conducted for this resource area. Findings from this study aim to provide further evidence to support the growing body of recreation ecology literature on the nature of trail degradation processes. In addition, this study seeks to more fully integrate Geographic Information Systems (GIS) into the analysis of trail erosion than 
previously had been done in trail degradation research. This approach attempts to advance the field with a more modern tool of analysis and to provide additional insights into landscape level trail erosion modeling. Four specific objectives are established for this research:

1. Identify and characterize trail erosion patterns of purposefully selected trails in Monongahela National Forest using field data and traditional impact modeling statistical analysis;

2. Describe and model trail erosion patterns of purposefully selected trails in the Monongahela National Forest using GIS extracted data from secondary data sources and GIS derived data;

3. Model trail erosion of purposefully selected trails in the Monongahela National Forest using a combination of field data, GIS extracted data from secondary data sources, and GIS derived data; and,

4. Compare and contrast the findings, analytical methods, and merits of field based, GIS based, and GIS-Field mixed method approaches to trail erosion modeling.

\section{3: Limitations}

Several factors limit the extent to which the findings of this research can be generalized to other settings. Foremost, the trails investigated in this study were purposefully selected to provide a sampling of natural surface trails from each district within the Monongahela National Forest. This sampling incorporated a random component but findings cannot be generalized to all natural surface trails in the Forest and caution should be used in considering these findings in comparison with those of trails in other resource areas with different recreational use patterns, environmental conditions, and managerial processes. Recreational use levels for trails in this research were compiled by trail manager estimates, a common method in trail degradation research. As estimates were not based on a numeric standard, comparison with other studies for this variable is limited. Additionally, all trails in the Forest are designated non-motorized. This is significant as trail degradation patterns for motorized-use trails are significantly different from non-motorized and are not comparable to these findings. Finally, integration of GIS variables is relatively new to trail erosion research although the literature review reveals that these techniques are more common in the closely related research of forest road erosion. Two primary limitations exist with using GIS data: first, each GIS data set has inherent errors in both the base data and the geographic positional data that are not controlled by the researcher; and second, GIS is effectively used for landscape scale modeling, estimation of micro-topographic processes is limited to only the highest resolution data sets. Given these limitations of GIS data, it is prudent to use caution in applying the results of this research to high-risk decisions. Also for this study, the derivation of 
Estimated Upslope Flow Lengths (EUFL) on trails is an adaptation of other non-trail GIS techniques and should therefore be considered exploratory requiring further field verification beyond the scope of this study.

\section{4: Document Structure}

This document is divided into several sections beginning with a literature review of the relevance of trail erosion research to natural resource management and the field of recreation ecology. Additional literature review topics include an examination of established trail degradation assessment techniques, overview of factors that influence trail degradation, and the use of GIS in trail and forest road studies. A detailed statement of Methods, Results, Discussion, and Conclusions follow the Literature Review. The Results and Discussion chapters are organized by sample method, point sample, problem census, and linear trail segment. A comparison of the findings and merits of each approach is considered in the discussion. 


\section{Chapter 2: Literature Review}

This literature review begins with an overview of recreation ecology to contextualize this research in the broader framework of natural resource management science. As recreation ecology itself is a diverse area of study, the review specifically discusses the scope of trail studies within this field. Trail studies are further narrowed to the focus of this research, trail tread degradation, and specifically trail erosion. In order to establish a strong foundation for this study, this review examines conceptual frameworks, methodological practice of field and analytic techniques, and research findings of thirty-seven trail degradation studies covering a 40-year time span. Although only a small sampling of all trail degradation studies, this review provides a strong representation of published studies on this topic from around the globe. Specific attention is given to studies which seek to establish causal relationships between environmental factors, trail use, management practices including trail design, and trail erosion.

A secondary review of research and professional literature which incorporate the use of Geographic Information Systems (GIS) in trail planning, impact assessment, and impact modeling is provided. This review is separate as this technology is a new addition to the recreation ecology research toolbox and has not yet been well integrated. Promising GIS techniques from non-trail related literature are also presented to gain a better understanding of the potential and limitations of these tools in this and future trails research.

\section{1: Recreation Ecology}

Recreation ecology can be defined as the field of study that examines, assesses, and monitors visitor impacts, typically to protected natural areas, and their relationships to influential factors (Hammitt and Cole 1998; Liddle 1997; Marion 1998). In Marion \& Leung, 2000.

The field of study known as recreation ecology has a brief but fruitful history. By many accounts, the field is no more than 80-years old, with most accepting its formal conception in the late 1960s (Cole, 1987; Liddle, 1991; Hammitt \& Cole, 1998, Cole, 2004). The growth of recreation ecology research is closely aligned with the increase in recreational demand for outdoor recreation after World War II through the late 1990 s. Cole (2004) comments that “... the literature on this subject is voluminous and 
is a challenge to thoroughly review," and, Monz, Cole, Leung, and Marion (2009), "several recent reviews of the state of knowledge of recreation ecology indicate that more than one thousand recreation ecology articles have been published in the past few decades." This expanse of research covers diverse geographic settings, varied methodological approaches, and a multitude of analysis methods.

The emergence of recreation ecology science is also closely tied to the evolution of the concept of resource carrying capacity in the natural resource management field. Carrying capacity began as an ecological concept emphasizing the ability of the land to absorb use by visitors and migrated to its present theoretical model of managing the resource to keep impacts to an acceptable level (Graefe, Kuss, \& Vaske, 1987; Hendee, Stankey, \& Lucas, 1990; Manning, 2001; Wagar, 1964). This new conceptualization provides a three dimensional approach to recreation carrying capacity where environmental, managerial, and social variables interact or can be selected and/or manipulated to maximize the capacity of the resource. Implementation of this strategy requires a broader understanding of the interactions between these dimensions, how new management regimens support the mandates of natural resource protection, and the long-term effects of this approach to recreational use management on the resource, the recreational infrastructure, and the visitors. With this new perspective on management, it was necessary to identify and monitor indicators of impacts and to create research methodologies which would allow for analysis of the causal relationships if possible. In this approach, recreation ecology provides information on the environmental impacts of the recreational activities and helps to identify appropriate indicators; social science identifies socially acceptable standards for the level of impact for each indicator; and management sciences create or modify systems and environmental conditions that influence these indicators, balancing both resource protection and recreation provision mandates (Manning, 2007). Recreation ecologists rose to the challenge of this new managerial need with a broad range of research on recreation impacts on soils, vegetation, wildlife, water quality, and recreation infrastructure (particularly trails and campsites) (Hammitt \& Cole, 1998; Leung \& Marion, 2000; Monz et al., 2009). Field methodologies, analysis techniques, and sampling designs that were developed to support this research have been integrated into management practices and emerging management frameworks (Hill \& Pickering, 2009; Leung \& Marion, 2000) such as Limits of Acceptable Change (LAC) (Stankey, Cole, Lucas, Petersen, \& Frissell, 1985), Visitor Impact Management (VIM) (Graefe, Kuss, \& Vaske, 1990), and Visitor Experience and Resource Protection (VERP) (Manning, 2001), as well as recreation resource impact, assessment, and monitoring (IA\&M) systems (Fancy, Gross, \& Carter, 2009; USFS, 2006a), and trail planning and 
constructions systems (AMC, 2008; Birkby, 2006; Felton, 2004; Hesselbarth, Vachowski, \& Davies, 2007; T. S. Parker, 2004).

Although the research in recreation ecology is prolific, a recent review of the body of work notes an inconsistency in approach, lack of theoretical integration, and isolation of findings (Monz et al., 2009). This review, written by four of the leaders in the U.S. recreation ecology field, calls for a modernization of methodological approaches and the expansion of research to incorporate spatial patterns of recreation impacts. Additionally, the authors emphasize that the incorporation of ecosystem variables and spatial patterns will help make the field "more robust and effective." Six areas of emphasis for future recreation ecology research are encouraged: advancing conceptual and theoretical development, particularly in the examination of the stress-response models of resource impacts; improving the ability of models to predict environmental changes; partnering with other resource sciences to develop models of synergistic effects with other stressors beyond recreation; and, broadening the scope of traditional recreation ecology to incorporate new settings particularly front-country and modified recreation settings and new forms of recreation.

This research is in the traditional mold of past recreation ecology studies as it investigates relationships of environmental, visitor use related, and management variables on unsurfaced trails in backcountry settings. Through adherence to emerging standards in methodology and analysis, this study responds to the criticism of Monz, Cole, Leung, and Marion (2009) by building on past knowledge and presenting findings in a way that can be compared with past and future studies. Beyond these traditional approaches, this study seeks to develop an understanding of spatial relationships to ecological landscape variables and to build new techniques utilizing emerging technologies to help standardize these processes for future studies.

\section{2: Trail Studies}

Historically, recreation ecology has predominantly focused on recreation in backcountry settings with only recent work being conducted in more developed areas. As such, trails and campsites are the primary recreation resources studied, since they are the most common "developed" or managed infrastructure in these settings. Within the scope of trails research, the focus of this study, a variety of approaches and emphases in the literature are apparent. A brief discussion of the different approaches is beneficial as it places the current study in a context of what it is and what it is not, allowing readers to easily identify and group the findings with other theoretically similar research. 
Three fundamentally different approaches in trails research are identified in the literature. The first two fall within the field of recreation ecology: 1) Trampling Studies, this research focuses on the impact of introducing recreational activity of various types and intensity on vegetation and soils of undisturbed landscapes; and 2) Trail Impact Studies, this broad research area focuses on the impacts of the trail and its associated use on the surrounding environment as well as on the trail itself (Cole, 2004; Hammitt \& Cole, 1998; Leung \& Marion, 2000). A third approach to trails research, Trail User Perception Studies, focuses on the impact of the trail and its associated design, management, and usage on the recreational user. This research commonly falls outside of the recreation ecology literature and is theoretically based in social and environmental psychology.

Trampling and trail user perception studies, while not the focus of this research, are pertinent to the discussion of trail degradation as the former is related to the resistance and resilience of the trail settings which influence both user behavior and environmental impacts. User perceptions, in part, form a critical justification for conducting trail degradation research and have substantive implications for managing recreation resources. In addition, two components of user perception research, the analysis of user behavior patterns in response to impacts (Roggenbuck, Williams, \& Watson, 1993; Vaske, Graefe, \& Dempster, 1982), and user knowledge of appropriate trail etiquette (Marion \& Reid, 2007), have shown to strongly influence the impact users can have on trails.

Trail impact investigation, as mentioned previously, is a broad area of research and represents the largest body of trail study literature. Several attempts have been made to classify this literature in meaningful ways. Cole (2004) provides a two-tiered nomenclature with the top level considering the research design (descriptive studies, comparisons of used and unused sites, before-and-after natural experiments, and before-and-after simulated experiments) and the second level arranged by the presentation of the results (the nature and magnitude of impacts caused by different recreational activities, spatial aspects of impacts, and temporal patterns of impacts). Leung and Marion (1996) offer a classification system based on the scope of trail problems considered presented in Table 1 . This classification model provides a narrower interpretation of trail impact research than many current reviews; notable exclusions include impacts to wildlife, water quality, and culture (Buckley et al., 2006; Hill \& Pickering, 2009; Monz, Cole, Leung \& Marion, 2009). The model does clearly delineate a subset of trail impact problems that are commonly aligned to comprise a research focus termed Trail Degradation. One additional impact is commonly associated with trail degradation, soil structure modification, the most common being soil saturation (mud development) but displacement and porosity 
are also often included (Garland, 1990; Godwin, 2000). Soil compaction, trail widening, incision, soil loss, and soil modification are measured utilizing various methodologies discussed in more detail below but are generally considered dependent variables which are influenced by environmental factors, use related variables, and managerial actions including trail design. This research contributes to this focused slice of recreation ecology literature and more specifically the research methods and causal relationships of trail erosion on natural surface trails.

Table 1

A Classification of Trail Research Terms Based on the Scope of Trail Problems Included $\underline{\text { Trail Research Terms }}$

\begin{tabular}{|c|c|c|c|c|}
\hline Trail Problem & Trail Impact & Trail Deterioration & Trail Degradation & Trail Erosion \\
\hline Depreciative behavior & $\mathrm{v}$ & & & \\
\hline Trail proliferation & $v$ & $v$ & & \\
\hline $\begin{array}{l}\text { Vegetation cover loss } \\
\text { or compositional change }\end{array}$ & $v$ & v & & \\
\hline Soil compaction & $v$ & $v$ & $v$ & \\
\hline Trail widening & $\checkmark$ & $\checkmark$ & $v$ & \\
\hline Trail incision and soil loss & v & v & $v$ & v \\
\hline
\end{tabular}

Source: Leung \& Marion (1996)

An additional consideration in the characterization of recreation ecology research and more specifically trail degradation studies in their relationship to managerial inventories, assessments, and monitoring (IA\&M) of trail resources. Maintenance of aging trail infrastructure, increasing usage of trails, proliferation of "informal" trails, and more targeted policies governing resource impact management have increased the need for assessing the quantity and condition of trail systems worldwide (Monz et al., 2009). Many of the methods used for conducting recreation ecology trail impact studies, particularly in the area of trail degradation, are integrated into the trail IA\&M systems. Two primary differences exist between these inventory reports and a research approach to the topic. The first is the lack of theoretical consideration and statistically supported inferences of causal relationships in these reports. The second is the lack of stringent field methodological rigor and well structured sampling designs. There are many examples of applied research studies presented in this manuscript which were incorporated into resource management IA\&M projects, including this study. These approaches have successfully met the needed reporting and analytical requirements of resource management agency as 
well as the theoretical and methodological rigor of the research community. Trail inventory reports are often unpublished agency reports but a number of examples are available for comparison: Trail Condition Monitoring, West Trail Study Area, Boulder, CO (Middleton, Cseke, Gershman, \& Sherry, 2009); An Assessment of Trails, Watercourses, Soils, and Redwood Forest Health in Joaquin Miller Park, Oakland, CA (Koehler, Sowers, Mileham, \& Golec, 2000); and, Breckenridge Trail Condition Report, Cucumber Gulch, Breckenridge, CO (Pettebone \& Newman, 2008).

There is some consideration of this differentiation provided in the recreation ecology literature. Hill and Pickering (2009) classify trail assessments by management objectives: trail inventories provide the current status of trail condition which allow managers to identify and prioritize maintenance needs; trail monitoring is a component of adaptive management which samples trail inventories and monitors over time to provide indicators of the effectiveness of management actions; and recreation ecology studies are implemented when there is a need to further clarify causation of specific trail management issues. Leung and Marion (2001) treat trail inventories and trail maintenance studies separately and group recreation ecology studies and monitoring activities, as described by Hill and Pickering, as trail condition surveys. These studies seek to describe resource changes and their relationships with influential environmental, use-related, or managerial factors. Leung and Marion reference four specific objectives within this study type:

- Identify and quantify specific types of trail resource impacts.

- Summarize impacts by environmental, managerial, or use-related factors to detect and evaluate relationships.

- Aid in setting and monitoring management standards for trail resource conditions.

- Evaluate deterioration in trail resource conditions to suggest potential causes and effective management actions.

This study addresses the first two objectives outlined by Leung and Marion and falls clearly in the recreation ecology study type defined by Hill and Pickering.

\section{3: Trail Assessment Field Methodologies}

The field methodologies for assessing physical trail impacts vary greatly depending on the discipline of study, theoretical approach to trail problems, geographic area of study, and variable interdependencies 
under consideration. Field methods can be grouped in a number of ways based on the granularity of the analysis and the region under consideration.

\section{Spatial Scale of Field Methodologies}

Trail assessment and monitoring methodologies can be separated into two general categories based on their spatial scale:

In-depth, single occurrence and longitudinal studies of small segments of trail:

- Fixed-point Repeated Measures - descriptive analysis and monitoring of conditions at purposefully or randomly selected fixed points on a trail or trail network (fixed points may identify observation points and/or trail transect locations);

- Problem Analysis - in-depth analysis of the causal factors of impacts on purposefully selected trail segments which display trail impact problems; and,

- Paired Comparisons - a comparative analysis of on and off trail biophysical characteristics to test pre and post-use conditions.

Large scale spatial sampling or rapid census techniques for higher mileage trail lengths or trail networks:

- Interval-based Point Sample - impact indicator measurements are taken at systematic intervals along the entire distance of a trail;

- Problem Assessment Census - linear location, length, and severity of observable, predefined trail problems or conditions are recorded for the entire length of a trail; and,

- Trail Segment Condition Classification - utilizing an index of various observable trail impacts a descriptive, categorical value is assigned to a pre-determined trail segment length.

(Sources: Cole, 1983; Hill \& Pickering, 2009; Jewell \& Hammitt, 2000; Marion, Leung, \& Nepal, 2006)

Considering a smaller number of sampling locations allows a greater depth of analysis on the interaction of variables and allows for more complex measurements than allowed in the methods applied to large trail networks. Jewell and Hammitt (2000) conducted an expert panel analysis of the large scale spatial methods considering the level of training required, efficiency, precision, accuracy, and management utility. This study found that problem assessment census methods had the most management utility; interval-based point sample methods had the highest precision and accuracy; and, condition class was the most efficient but provided the lowest managerial utility. Leung and Marion (2001) compared point 
sampling to the problem assessment census method on a segment of the Appalachian Trail. They reported similar results noting the point sampling method provided the most efficient, accurate, and precise measures of trail width, tread incision, and tread composition while the problem assessment method yields data characterizing the frequency, lineal extent, and location of specific trail impact problems. Problem assessment was found to be more useful to managers, particularly in planning for maintenance, but authors noted that point sample methods would be useful if monitoring management indicators having a finer granularity such as soil loss.

\section{Sampling Strategies}

The scope of the trail impact assessment and the inferences the researcher is interested in making as part of the study analysis help to inform the researcher which sampling strategy to use. A number of strategies are present in the literature and several have been compared empirically.

\section{Regional and Trail Network Strategies}

Although the census strategy is the easiest to conceive it is often unrealistic to implement given the time requirements and cost of implementation. It is noteworthy that many U.S. natural resource agency trail inventory management systems require a full census of trail conditions for a park, forest, or protected area on a rotational planning time block of five or more years. Another limitation of a census approach is that the inference power is only to the trails within the resource area. Due to these limitations, only a handful of trail network impact census studies have been conducted in the last few decades with the Bratton, Hickler and Graves (1979) study in Great Smoky Mountains National Park most commonly noted. This study surveyed approximately $1200 \mathrm{~km}$ ( 745 miles) of trail employing three large scale methodologies (point sample, census, and condition classification). Table 2 provides a listing of reviewed trail impact studies by the type of assessment methodology employed. 
Table 2

Trail Study Sample Lengths by Assessment Methodology

\begin{tabular}{|c|c|c|c|}
\hline Methodology & $\begin{array}{l}\text { Sampling } \\
\text { Strategy }\end{array}$ & $\begin{array}{l}\text { Stratification } \\
\text { Variables }\end{array}$ & Studies \\
\hline \multicolumn{4}{|l|}{ Local/Regional Scale } \\
\hline $\begin{array}{l}\text { Fixed-point Repeated } \\
\text { Measures }\end{array}$ & $\begin{array}{l}\text { Purposeful, } \\
\text { Random }\end{array}$ & $\begin{array}{l}\text { Land Type, } \\
\text { Trail Age }\end{array}$ & $\begin{array}{l}\text { Cole 1989; Dixon, Hawes \& McPherson, 2004; } \\
\text { Goodwin, 2000; Goeft \& Alder, 2001; Yoda \& } \\
\text { Watanabe, 2000; Summer, 1986; Tinsley, } 1985\end{array}$ \\
\hline Problem Analysis & Purposeful & & Gager \& Conacher, 2001; Koehler et al., 2000 \\
\hline Paired Comparisons & $\begin{array}{l}\text { Purposeful, } \\
\text { Random, } \\
\text { Systematic }\end{array}$ & $\begin{array}{l}\text { Land Type, } \\
\text { User Type, } \\
\text { Use Intensity, } \\
\text { Slope Class }\end{array}$ & $\begin{array}{l}\text { Deluca, Freimund \& Cole, 1998; Goodwin, 2000; } \\
\text { Harden, 2001; Leung \& Neller, 1995; Liddle \& } \\
\text { Smith, 1975; Sutherland et al., 2000; Törn et al., } \\
\text { 2007; Wilson \& Seney, 1994; Chatterjea, } 2007\end{array}$ \\
\hline \multicolumn{4}{|l|}{ Large scale } \\
\hline Interval-based Point Sample & $\begin{array}{l}\text { Purposeful, } \\
\text { Systematic, } \\
\text { Stratified } \\
\text { Systematic }\end{array}$ & $\begin{array}{l}\text { Trail Use Type, } \\
\text { Trail Use, } \\
\text { Travel-time } \\
\text { Estimation, } \\
\text { Intensity, } \\
\text { Vegetation } \\
\text { Type, Land } \\
\text { Type, } \\
\text { Ecological } \\
\text { Regions }\end{array}$ & $\begin{array}{l}\text { Bayfield 1971, Bratton et al, 1979, Bryan 1977; } \\
\text { Chatterjea, 2007; Coleman 1981, Dale \& Weaver, } \\
\text { 1974; Dixon, Hawes \& McPherson, 2004; Farrell } \\
\text { \& Marion, 2002; Garland, 1990; Jubenville \& } \\
\text { O'Sullivan, 1997; Leung \& Neller, 1995; Liddle \& } \\
\text { Smith, 1975; Manning, Jacobi \& Marion, 2006; } \\
\text { Wood, Lawson \& Marion, 2006; Aust, Marion \& } \\
\text { Kyle, 2005; Olive \& Marion, 2009; Obua \& } \\
\text { Harding, 1997; White et al., 2006; Wilkerson \& } \\
\text { Whitman, 2010; Marion \& Leung, 2001; } \\
\text { Pettebone, Newman \& Theobold, } 2009\end{array}$ \\
\hline Problem Assessment Census & Purposeful & $\begin{array}{l}\text { Use Type, Use } \\
\text { Intensity, } \\
\text { Topographic } \\
\text { Position }\end{array}$ & $\begin{array}{l}\text { Bratton et al, 1979, Cole 1989; Farrell \& Marion, } \\
\text { 2002; Lanehart, 1998; Leung \& Marion, 1999; } \\
\text { Manning, Jacobi \& Marion, 2006; Aust, Marion \& } \\
\text { Kyle, 2005; Obua \& Harding, 1997; Wilkerson \& } \\
\text { Whitman, 2010; Marion \& Leung, } 2001\end{array}$ \\
\hline $\begin{array}{l}\text { Trail Segment Condition } \\
\text { Classification }\end{array}$ & $\begin{array}{l}\text { Purposeful, } \\
\text { Systematic }\end{array}$ & & $\begin{array}{l}\text { Bratton et al., 1979; Garland, 1990; Manning, } \\
\text { Jacobi \& Marion, 2006; Nepal \& Nepal, 2003; } \\
\text { Summer, } 1980\end{array}$ \\
\hline
\end{tabular}

\section{4: Trail Degradation}

The following review of the methodologies and generalized findings of trail degradation research is intended to underscore the current understanding of the degree and causal relationships of trail tread soil loss, widening, and soil modification as they relate to recreational use, environmental conditions, 
and managerial factors. Identification of best practices for conducting such studies is emphasized to provide a strong theoretical foundation for this research. Gaps in both research practice and knowledge are also explored to identify areas where this research can advance the field of recreation ecology.

For clarification, the term degradation, in respect to natural resource settings, has several closely related definitions from geologic, soil, and physical geographic sciences in addition to natural resource management. From a geologic perspective, degradation refers to the gradual wearing down and lowering of the earth's surface through erosional processes including wind and water (P. Parker, 2008). Soil scientists consider degradation as an adverse change in soil properties and processes which lead to reduced function, changes may occur through natural or anthropogenic processes (Lal, livari, \& Kimble, 2003). Physical geographers include noted changes in the "carrying capacity" of land revealed by, among other things, removal of vegetation and increased soil erosion (Mayhew, 2009). As there is a healthy mix of researchers from varying scientific backgrounds that have contributed to the trail degradation literature, it is possible that each believed they were describing a trail tread degradation process from the basis of their own scientific discipline. This etymology of the usage of the term degradation is of interest as it shows a potential evolution in the approaches to trail degradation research from one of strict focus on soil erosion to a broader managerial definition of the reduced functionality and "value" of the trail tread and trail infrastructure to the visitors and resource managers (Cakir, 2005; Leung \& Marion, 1996). This study considers the latter application of the term with consideration of the other approaches.

In defining trail degradation in managerial terms, trails are categorized as resource management infrastructure assets separate from, but highly interactive with, the natural landscape. Degradation is a process that begins at the accession of the trail into the management inventory, or more precisely the time at which the trail tread is constructed or repaired. With this perspective it is noted that while many of the impacts to vegetation and soils commonly studied in recreation ecology consider trails themselves as impacts on the landscape, trail degradation studies consider the trail as a necessity for resource protection which provides recreational users and managers with a hardened surface to transit across the land thus reducing broader impacts (Hammitt \& Cole, 1998; Leung \& Marion, 1996).

\section{Conceptual Model}

Various conceptual models of the relationships between independent environmental, recreational use, and managerial variables and dependent trail impact variables, including those incorporated in trail degradation studies, can be found throughout the literature (Cole, 2004, p. 53; Coleman, 1981; Leung \& 
Marion, 1996; M. Liddle, 1997, p. 329; Manning, 1979; Monz \& Leung, 2006; Wall \& Wright, 1977). Although each varies in the degree of detail, there is general agreement on the relationships established in the Leung and Marion (1996) model presented in Figure 1. One shortcoming of this degradation model, as noted by the Leung and Marion, is an understanding of the effectiveness of various managerial actions in mitigating trail degradation. Since the model's publication, additional research on trail management functions of layout and design, trail use rationing, and user education have been conducted. Two specific trail design variables have consistently been identified as influential in the amount of trail soil loss: trail grade (the steepness of the trail tread), and trail alignment (the downhill aspect of the trail in relationship to the surrounding slope) (Table 3). Trail widening has been found to be influenced by trail grade but not to the same degree as soil loss. Additional design and trail positioning parameters which have been suggested or tested in trail degradation studies include: topographic positioning (valley, midslope, ridge); use of trail surface hardening materials; and, trail tread watershed length (also called upslope length or distance from sample point to a functional uphill water management structure) (Aust et al., 2005; Gager \& Conacher, 2001; Kuss \& Morgan, 1986; Olive \& Marion, 2009; T. S. Parker, 2004, pp. 51-54). The predictive validity of any of these variables alone or in combination with other factors is inconsistent, as the relationships between environment, use, and management appear to be complex. Meta-analysis of these factors to establish patterns of each variable's influence on trail degradation are hampered by inconsistencies in field methodologies and statistical analysis methods (Monz et al., 2009).

\section{Trail Degradation Processes}

The process by which natural surface trails degrade from a newly constructed tread to an unsightly ravine, mud-hole, or wide-braided web of volunteer pathways has been well documented (Hammitt \& Cole, 1998; M. Liddle, 1997). The forces of nature which grind away the tallest mountains and form deep canyons are constantly at work moving soil from the mountains to the sea. Trail building techniques attempt to engineer a surface that will minimize this effect, but without the protection of hard, unnatural surfacing, the inevitability of soil movement will ultimately win out. Building balance between a trail that blends into the natural character of the land and one that maintains its utility as a recreational and management pathway across the land with minimal maintenance requires an understanding of soils and the forces at work on them. This knowledge will enable trail builders and managers to locate, design, and maintain the tread in concert with those forces (AMC, 2008; Hesselbarth et al., 2007; Marion \& Leung, 2004; T. S. Parker, 2004). 


\section{Trail Erosion}

"The whole point of trail work is to get dirt where you want it and to keep it there.

Water is the most powerful stuff in your world. Gravity is water's partner in crime.

Their mission is to take your precious dirt to the ocean. The whole point of trail work is

to keep your trail out of waters grip." USFS Trail Construction and Maintenance

Notebook (Hesselbarth, Vachowski, \& Davies, 2007)

Trail erosion is considered one of the most problematic forms of trail degradation as it is non-selflimiting; once it begins, it will only abate with physical intervention even if trail use is removed (Hammitt \& Cole, 1998; Hill \& Pickering, 2009). Figure 2 outlines the temporal process of an eroding engineered trail for a typical cross slope trail. The rate of compaction and subsequent erosion is influenced by a number of biophysical, managerial, and use related factors which are discussed in more detail in the following sections.

The erosivity of the mineral soil used for the trailbed is a primary factor in determining the durability of the tread. The sensitivity of soils to erosion in forest and agricultural lands has had extensive research due to the natural resource disasters such the Dust Bowl of the 1920s. As a result, indexes are available for the erosivity of major soil types in every state through the U.S. Department of Agriculture's Natural Resource Conservation Service. Although this model is useful, when conducting degradation research and assessments of large, historic trail networks the origins of the system trails are often not purposefully designed and sited as trails. Trails are often placed on old roadbeds, retired railroad grades, and historic animal tracks while others are informally developed pathways that have been adopted into the system. Those that were developed as trails are often dated with original construction being done through widespread public works projects of the 1930s such as the Civilian Conservation Corp. This is the case for many trails in MNF as well (McKim, 1970). 


\begin{tabular}{|l|l|l|}
\hline \multicolumn{1}{|c|}{ Original Trail Tread } & \multicolumn{1}{|c|}{ Compacted Tread } \\
\hline \multicolumn{1}{|c|}{ Original Tread Surface } \\
$\begin{array}{l}\text { 1. Typical cross-slope designed } \\
\text { tread with slight outslope to }\end{array}$ & $\begin{array}{l}\text { 2. Through recreational use tread } \\
\text { soils become compacted } \\
\text { lowering the central tread } \\
\text { surface with slight displacement } \\
\text { to the downhill edge creating a } \\
\text { berm that traps water on tread. }\end{array}$ & $\begin{array}{l}\text { 3. Over time, water trapped in } \\
\text { the trail tread erodes the soil } \\
\text { leaving larger stones and } \\
\text { pebles. This process will }\end{array}$ \\
reached or trail tread rebuilding \\
is done.
\end{tabular}

Figure 2. Trail tread erosion process. Adapted from T. S. Parker (2004)

Non-engineered trails generally do not have a hardened tread surface and often have a thick organic layer with integrated vegetation associated with them. This is also true of newly forming, visitor-created trails which the subject of a growing body of recreation ecology research on trail impacts (Marion et al., 2006). Although the erosion process is similar to that described for engineered trails, the rate of initial compaction is often quicker due to the thicker organic layer. The resistence and resilience of vegetation on these types of trails influence their erosion rates more so than on engineered trails which remove vegetation as part of the construction process. Trampling research has been conducted in many environments to assess the rate at which certain types of vegetation are removed from informally developed surfaces (Burden \& Randerson, 1972; Dale \& Weaver, 1974; Kuss, 1983; Sun \& Liddle, 1993; Whinam \& Chilcott, 2003). Manning (1979) presents a seven-step cyclic process that trampled soils undergo in the development of a bare soil pathway (Figure 3). This process is cyclic as organic materials are continually added to the impacted area and the area may expand as the trail widens. Compaction is reflected in steps three through five and erosion in steps six through seven. 


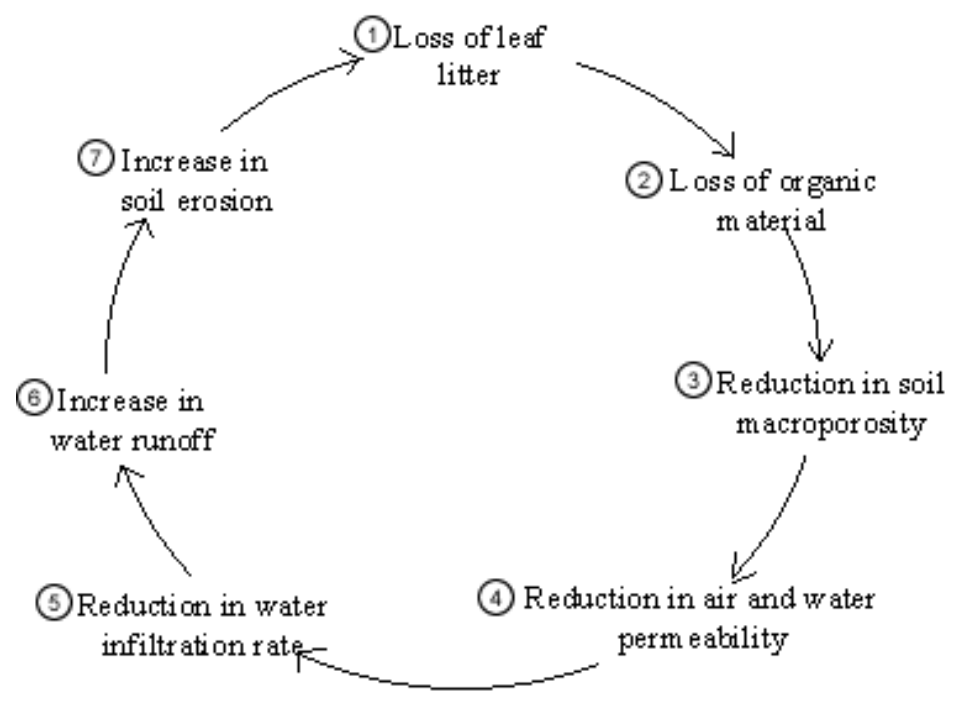

Figure 3. Seven-step cycle of recreational impact on soils (Manning, 1979)

The more detached and fine grained soil that is available to be transported away from the original tread location the greater the resulting erosion. Processes which disrupt the compacted surface include various anthropogenic forces, including the hooves of horses and lug soles of hiking boots (Deluca, Patterson, Freimund, \& Cole, 1998; Kuss, 1983; Weaver \& Dale, 1978), and natural forces, including the splash of raindrops, movement of small stones, and seasonal frost heave (Garland, 1990; Jubenville \& O’Sullivan, 1987; Yoda \& Watanabe, 2000).

Water is another primary component of the process. The volume of water, its downhill velocity, and the length of time it is contact with the soil are key elements in soil loss equations (K. N. Brooks, Ffolliott, Gregersen, \& DeBano, 2003; Yoder et al., 2001). The USFS Trails Management Handbook lists reducing the amount of time water is allowed to "operate on the surface" of the trail as one of the primary erosion management methods (Hesselbarth et al., 2007). The availability of water is closely related to the geology and climate of an area which influence rainfall amounts and how ground water moves through the system. The velocity of water is influenced by volume, resistance on the soil surface (often referred to as soil roughness), and the steepness of the surface on which it is traveling (i.e. trail grade). Catastrophic rain events or quick snow melts often result in trail scouring and severe gully erosion (Marion \& Olive, 2006; Summer, 1986). Although these events are not entirely predictable, historic climate patterns can show areas of high likelihood for these occurrences. These types of events can 
seriously impact entire trail networks as was the case in the Monongahela twice in the 1980s with two hurricane events (D. Saville, personal communication, May, 2006).

The review of the trail erosion process provides a number of tangible independent variables which are examined to varying degrees in the recreation ecology literature: soil properties, historic origins of a trail, trail design specifications, soil detachment agents, vegetation, overhead canopy which limits rain splash, length of time water is on the trail, trail grade, soil roughness, climate, geology, and sources of on-trail water. This interface of natural and human influenced systems is complex and the scale of predictability is often localized. A review of how these variables have been measured and their relationship to trail tread erosion is provided in the sections below.

\section{Trail Widening}

When a trail tread extends beyond the engineered surface, or managed surface for non-engineered trails, it becomes a degradation issue. Often it is an indicator of another form of degradation such as a badly eroded area or a muddy section of trail. Wide and multi-threaded trails also present a negative visual impact, can impact sensitive areas adjacent to the planned tread, and can lead to lost trail users as they get off the main tread into unmarked side trails. Although this degradation factor walks a fine line between the impact of the trail on the environment and the impacts on the utility of the trail it commonly appears in both research approaches. Trail width, from a management perspective, is defined within trail design specifications and is generally associated with a specific recreational opportunity spectrum (ROS) class associating a certain width with the "naturalness" of an area (USFS, 1991, sec. 2309.18,.14.2). Thus, the more primitive ROS classes have very narrow trail design widths; in fact, a newly designated Wilderness area in MNF has no trails of any width due to its remoteness and pristine condition. Trail widths are also associated with different types of trail users as hikers and mountain bikers have a narrower trail profile than do horseback riders.

Some trail width issues may result from trail slippage on steep side slopes, deposition from erosion, and expansion due to on-trail erosion spreading to off-trail areas, but trail use type, use intensity, and user behavior have been strongly correlated with widening trails (Cole, 1983; Coleman, 1981; Hill \& Pickering, 2009). As users spread from the managed tread, the forces described by Manning in the seven-step recreational impact model come into play: vegetation removal, compaction, runoff, and erosion. Mud development is also likely in wet, flat areas as the off-trail areas are not hardened. Positive relationships of maintaining trails within design parameters have been found in areas with steep side slopes (Aust et al., 2005) or thick resistant vegetation (Hammitt \& Cole, 1998, p. 341) as these form natural barriers to 
width expansion. Areas prone to expansion are flat areas in valley bottoms (Cole, 1983; Marion, 1994), meadows or forests with open understories (Cole, 2004; Törn, Tolvanen, Norokorpi, Tervo, \& Siikamäki, 2009), wet soils or seasonally wet areas, and at trail intersections and other points of interest (Leung \& Neller, 1995; Wood, Lawson, \& Marion, 2006). As with erosion, several prominent independent variables are apparent in the study of trail widening: vegetation type and density; soil wetness; trail usage type and intensity; user behavior; trail side slopes; and, trail features.

\section{Mud Development}

When the soils that comprise the tread surface become saturated with water they become muddy and can often lead to trail widening as users walk on adjacent surfaces to avoid the mud, or increased trail erosion as loose surface soils are more easily detached (Deluca et al., 1998). These related impacts are generally intermittent as the thin surface mud dries between wet weather or season events. A complete collapse of the soil support structures leading to a mud-hole or lengthy section of deep mud degrades a trail section beyond usability. Soil structure and geology are the primary variables associated with mud development on trails, particularly sensitive are soils with high clay or organic content, hard or fragipan soil layers near the surface or thin soils over impermeable bedrock (Bryan, 1977; Hammitt \& Cole, 1998). Horse trail use is another highly correlated independent variable with mud development (Bratton et al., 1979; Marion \& Olive, 2006). The deep incisions created by the horse hoof catch rain water and hold it, with the up and down pumping action of continued use water is worked into the surrounding soil creating mud. The increased impact pressure of a horse also leads to deeper compaction and lower water infiltration rates below detached and imprinted surface soils leading to a highly conducive environment for surface mud development (Aust et al., 2005). Like erosion, water is an important ingredient to mud development but greater impacts can be realized in a shorter time span with smaller amounts of water due to user avoidance of muddy soils (Leung \& Marion, 2000). Climate, geology, soil structure, slope, and use type are all prominent variables of interest in examining the relationship of trails and degradation from mud.

\section{Compacted Trail Treads}

Although compaction is a component of both erosion and mud degradation models, it is often considered a standalone degradation variable when either of these are not present. Compacted trail treads are often coupled with exposure of shallow root systems and protruding rocks and can be quite difficult to travel on (Hammitt \& Cole, 1998, p. 32). Examination of the presence of different soil horizons in the sample would allow a differentiation of compaction and erosion but most often both are 
present causing loss of soil horizons in addition to truncation (Garland, 1990; Godwin, 2000). Like mud development, soil structure and use variables are highly correlated with compacted treads. Compaction occurs through repeated use lowering the tread surface. The spaces between the soil particles (micro and macro-porosity), is greatly reduced and the compressed soil creates a semi-permeable barrier to water infiltration. Areas with thick organic layers compact quickly leaving deep channels with hardened soil bases that collect water. Like mud avoidance, trail users try to avoid standing water in trails and this can lead to multiple tread development or trail widening. Soils structure and use type and intensity are again primary study variables when considering soil compaction.

\section{Trail Degradation Study Variables}

Table 3 provides an index of the primary variables commonly considered in trail degradation research. The thirty-seven studies presented were selected based on their frequency in trail degradation literature citations and/or their usage of commonly accepted trail degradation study methods. Methodologies developed and refined by Bayfield, Coleman, Cole, Leung, Liddle, and Marion permeate the literature and have greatly influenced the selection and measurement techniques of variables under consideration. Studies generally fall into one of two categories: Relational studies, those studies that test hypotheses and explore relationships between independent biophysical, managerial, and use variables and dependent degradation measures; and, Descriptive studies, those studies which describe the spatial and/or temporal distribution of degradation indicators. Soil studies were included in descriptive studies as they describe the differences between on and off trail conditions. Trampling studies which took place on existing, active trail sections were also included. The following section will discuss the primary measurement techniques, Leung and Marion's (1999a) site scale component of sampling decisions, and general findings for each category of variable.

\section{Trail Erosion}

Direct measurement of the amount of trail tread soil lost to erosion across an entire trail network is an imperfect estimation process and has only been attempted in a limited number of studies (Olive \& Marion, 2009). Point sampling techniques that use proxy measures to estimate soil loss include the measurement of maximum incision, and the calculation or tracking of cross-sectional area (CSA) of the tread profile. A soil loss estimation technique used in agricultural settings, the Universal Soil Loss Equation, proposed for use in developing recreational carrying capacity estimations by Kuss and Morgan(1986), was used as a measure of soil loss in comparing graveled and un-graveled trails by Aust, Marion, and Kyle (2005). Descriptive studies record the lineal extent of incised sections of trail greater 
than a pre-defined depth and length; and classify sections of trail based on the presences of erosion features such as rill, gully, incision, and presence of exposed roots and rocks. Soil studies look at sediment yield from test plots and changes in the soil profile utilizing soil core samples (Bryan, 1977; Godwin, 2000; Harden, 2001; Sutherland, Bussen, Plondke, Evans, \& Ziegler, 2001). Several studies consider the changes to the tread profile over time using CSA measurements at fixed points (Cole, 1991; Summer, 1986; Yoda \& Watanabe, 2000), and one study conducted photographic comparisons of soil movement through the use of tracer materials (Rinehart, Hardy, \& Rosenau, 1978). Changes in frequency of erosion indicators in descriptive studies are not included in this list but are being used as indicators in visitor impact management systems (Manning, Leung, \& Budruk, 2005). More in-depth comparative reviews of erosion measurement methods are provided by Jewell and Hammitt (2000) and Marion, Leung, and Nepal (2006).

Of the studies reviewed, ten relational studies and five descriptive studies measured maximum incision as an estimate of erosion severity, with nine relational and five descriptive studies utilizing CSA. CSA provides a more detailed profile and volume estimate of soil loss but is more time consuming than maximum incision measurements limiting its applicability in large trail network assessments. Linear extent and erosion class are more commonly used in descriptive studies (or the descriptive portion of mixed method studies). Erosion class assignment generally has a subjective component which limits the replicability and long-term comparison for monitoring purposes, although several examples of class indexes generated from objective measurements are present in the literature (Bratton et al., 1979; Dixon, Hawes, \& McPherson, 2004; Garland, 1990). 
Table 3

Trail Degradation Study Variables and Statistical Methods.

\begin{tabular}{|c|c|c|c|c|c|c|c|c|c|c|c|c|c|c|c|c|c|c|c|c|c|}
\hline \multirow[b]{2}{*}{ Studies } & \multicolumn{7}{|c|}{ Degradation Variables } & \multicolumn{5}{|c|}{ Biophysical } & \multicolumn{5}{|c|}{ Managerial } & \multicolumn{2}{|c|}{ Use } & \multicolumn{2}{|c|}{ Stats. } \\
\hline & 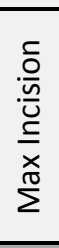 & گ్ర & 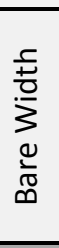 & 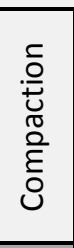 & 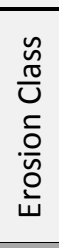 & 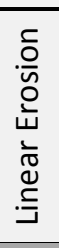 & $\stackrel{\overline{0}}{\bar{z}}$ & $\overline{\bar{n}}$ & 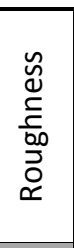 & 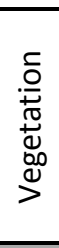 & 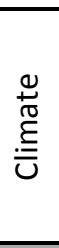 & 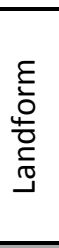 & $\frac{\check{0}}{\frac{0}{n}}$ & 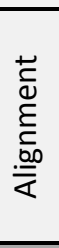 & 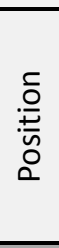 & 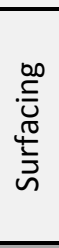 & 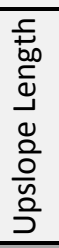 & $\stackrel{\Perp}{\stackrel{2}{\gtrless}}$ & 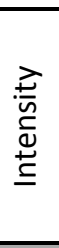 & 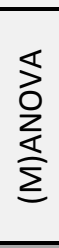 & 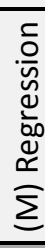 \\
\hline \multicolumn{22}{|l|}{ Relational Studies } \\
\hline Aust, Marion \& Kyle, (2005) & $\mathbf{S}$ & $\mathbf{S}$ & $\mathbf{S}$ & & & $\mathrm{x}$ & $\mathbf{S}$ & $x$ & & & & & $\mathbf{S}$ & $\mathbf{S}$ & $\mathbf{S}$ & $\mathbf{S}$ & $\mathbf{S}$ & & $\mathbf{S}$ & $\mathbf{S}$ & $\mathbf{s}$ \\
\hline Bayfield (1973) & & & $\mathbf{S}$ & & & & & $\mathbf{S}$ & $\mathbf{S}$ & $\mathrm{x}$ & & & $\mathbf{S}$ & & & & & & & & $\mathbf{s}$ \\
\hline $\begin{array}{l}\text { Bratton, Hickler \& Graves, } \\
\text { (1979) }\end{array}$ & $\mathbf{S}$ & & $\mathbf{S}$ & & $\mathbf{S}$ & $x$ & $\mathbf{S}$ & & & $\mathbf{S}$ & & $x$ & $\mathbf{S}$ & $\mathbf{S}$ & & & & $x$ & $x$ & $\mathbf{S}$ & \\
\hline Bryan, (1977) & & & & $x$ & & & & $\mathbf{S}$ & & $\mathrm{x}$ & & & $\mathrm{x}$ & $\mathrm{x}$ & & & & & $\mathrm{x}$ & $\mathbf{S}$ & \\
\hline Cakir, (2005) & $\mathbf{S}$ & & $\mathbf{S}$ & & & & & & & & & $\mathrm{x}$ & $\mathbf{S}$ & $\mathbf{S}$ & $\mathrm{x}$ & & & & & & $\mathbf{S}$ \\
\hline Cole, (1991) & $\mathbf{S}$ & $\mathrm{x}$ & $\mathbf{S}$ & & & & & & & & & & & & $\mathrm{x}$ & & & & & & \\
\hline Coleman, (1981) & $\mathbf{S}$ & & $\mathbf{S}$ & & $\mathrm{x}$ & & & $\mathbf{S}$ & & $\mathbf{S}$ & & $\mathrm{x}$ & $\mathbf{S}$ & & $\mathbf{S}$ & & & & $\mathrm{S}$ & & $\mathbf{s}$ \\
\hline Dale \& Weaver, (1974) & $\mathbf{S}$ & & $\mathbf{S}$ & & & & & & & $\mathbf{S}$ & & & & & & & & $\mathbf{S}$ & $\mathbf{S}$ & & $\mathbf{S}$ \\
\hline Deluca et al., (1998) & & & & $\mathrm{S}$ & & & & $\mathrm{x}$ & $\mathbf{S}$ & & $\mathrm{x}$ & & & & & & & $\mathrm{S}$ & $\mathrm{S}$ & $S$ & \\
\hline $\begin{array}{l}\text { Dixon, Hawes \& McPherson, } \\
\text { (2004) }\end{array}$ & $\mathbf{S}$ & & $\mathbf{s}$ & & & & $\mathrm{x}$ & $\mathrm{x}$ & & $\mathrm{x}$ & & $\mathbf{S}$ & $\mathbf{s}$ & & & & & & $\mathbf{s}$ & & $\mathbf{S}$ \\
\hline Farrell \& Marion, (2002) & $\mathrm{S}$ & & $\mathrm{S}$ & & & & $\mathrm{x}$ & $\mathrm{x}$ & & $\mathrm{x}$ & & & $\mathrm{S}$ & & $\mathrm{x}$ & & & $x$ & $\mathrm{~S}$ & $S$ & $\mathrm{x}$ \\
\hline Gager \& Conacher, (2001) & & $\mathrm{S}$ & & & $S$ & & & $\mathrm{~S}$ & & & & $S$ & $\mathrm{~S}$ & $\mathbf{S}$ & $\mathrm{x}$ & & $S$ & & & $S$ & $\mathrm{~s}$ \\
\hline Garland, (1990) & & $\mathrm{x}$ & & & $\mathbf{S}$ & & & & & & $\mathbf{S}$ & $\mathbf{S}$ & & & & & & & & & \\
\hline Godwin, (2000) & & $\mathrm{S}$ & & $\mathrm{S}$ & & & & $\mathrm{S}$ & & $S$ & & & $\mathrm{~S}$ & & & & & & & & $\mathrm{~s}$ \\
\hline Goeft \& Alder, (2001) & & $\mathbf{S}$ & & $\mathbf{S}$ & & & & $\mathrm{S}$ & & & & & $\mathbf{S}$ & & $\mathrm{x}$ & & & & & $S$ & \\
\hline Jubenville \& O'Sullivan, (1987) & & $\mathrm{S}$ & & & & & & $\mathrm{S}$ & & $\mathrm{S}$ & & & $\mathbf{S}$ & & & & & & & $\mathbf{S}$ & \\
\hline Liddle \& Greig-Smith, (1975) & & & & $\mathrm{S}$ & & & & $\mathrm{x}$ & & & & & & & & & & $\mathbf{S}$ & $\mathrm{S}$ & & $\mathrm{S}$ \\
\hline Obua \& Harding, (1997) & & $\mathbf{S}$ & & & & $\mathrm{x}$ & & & & $\mathbf{S}$ & & & $\mathbf{S}$ & & & & & & & & \\
\hline Olive \& Marion, (2009) & & $\mathrm{S}$ & & & & & $\mathrm{S}$ & $\mathrm{S}$ & & & & & $\mathrm{S}$ & $\mathrm{S}$ & $\mathrm{S}$ & $\mathrm{x}$ & $\mathrm{S}$ & $\mathrm{S}$ & $\mathrm{x}$ & $S$ & $\mathrm{~S}$ \\
\hline Sutherland et al., (2001) & & & & $\mathrm{S}$ & & & & $\mathrm{X}$ & $\mathbf{S}$ & & & & $\mathrm{x}$ & & & & & & $\mathbf{S}$ & $\mathbf{S}$ & \\
\hline Torn et al., (2009) & $\mathrm{X}$ & & $\mathbf{S}$ & & & & & & & $\mathbf{S}$ & & & $\mathrm{x}$ & & & & & $\mathbf{S}$ & $\mathrm{x}$ & $\mathbf{S}$ & \\
\hline White et al., (2006) & $\mathbf{S}$ & & $S$ & & & & & & & & & $S$ & $S$ & & & & & & & $S$ & \\
\hline
\end{tabular}




\begin{tabular}{|c|c|c|c|c|c|c|c|c|c|c|c|c|c|c|c|c|c|c|c|c|c|}
\hline \multirow[b]{2}{*}{ Studies } & \multicolumn{7}{|c|}{ Degradation Variables } & \multicolumn{5}{|c|}{ Biophysical } & \multicolumn{5}{|c|}{ Managerial } & \multicolumn{2}{|c|}{ Use } & \multicolumn{2}{|c|}{ Stats. } \\
\hline & 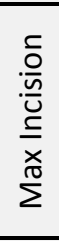 & $\overleftarrow{\mho}$ & $\begin{array}{l}\frac{c}{ \pm} \\
\stackrel{0}{0} \\
\frac{0}{3} \\
\frac{1}{\pi} \\
\infty\end{array}$ & 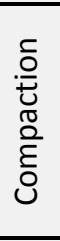 & 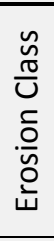 & 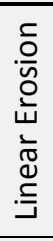 & $\stackrel{\text { D }}{2}$ & $\overline{\bar{o}}$ & 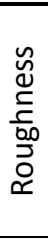 & 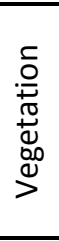 & $\begin{array}{l}\stackrel{\oplus}{\pi} \\
\stackrel{\Xi}{\Xi} \\
\end{array}$ & $\begin{array}{l}\varepsilon \\
\frac{\xi}{0} \\
\frac{0}{0} \\
\frac{1}{0} \\
\text { J }\end{array}$ & $\frac{0}{\frac{0}{n}}$ & 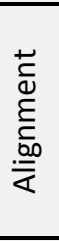 & 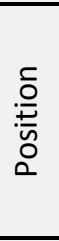 & 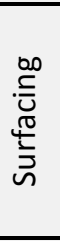 & 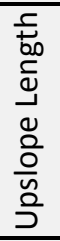 & $\stackrel{0}{2}$ & $\begin{array}{l}\stackrel{\vec{D}}{\bar{n}} \\
\stackrel{c}{d} \\
\stackrel{ \pm}{ \pm}\end{array}$ & 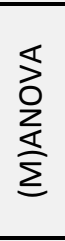 & 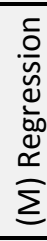 \\
\hline Wilson \& Seney, (1994) & & & & $\mathrm{X}$ & & & & $\mathbf{S}$ & $\mathbf{S}$ & & & & $\mathbf{S}$ & & & & & $\mathbf{S}$ & & & $\mathbf{S}$ \\
\hline \multicolumn{22}{|l|}{ Descriptive Studies } \\
\hline Chatterjea, (2007) & & & & $\mathrm{X}$ & & & & $\mathrm{X}$ & & $\mathrm{X}$ & & & & & & & & & & & \\
\hline Harden, (2001) & & & & & & & & $x$ & & & $\mathrm{X}$ & & & & & & & & & & \\
\hline Koehler et al., (2000) & & & & & $\mathrm{X}$ & $\mathrm{X}$ & & & & & & & & & & & & & & & \\
\hline Kuss, (1983) & & & & & & & & $\mathrm{X}$ & & & & & & & & & & $x$ & $\mathbf{S}$ & $\mathbf{S}$ & \\
\hline Lanehart, (1998) & & & $\mathrm{X}$ & & & $x$ & $\mathrm{x}$ & $\mathrm{X}$ & & & & $\mathrm{x}$ & $\mathrm{X}$ & $x$ & $\mathrm{X}$ & & & $\mathrm{X}$ & & & \\
\hline Leung \& Marion, (1999b) & $x$ & & $\mathrm{X}$ & & & & $\mathrm{x}$ & & & & & & & & & & & & & & \\
\hline Leung \& Neller, (1995) & & $x$ & $\mathrm{X}$ & $\mathrm{X}$ & $x$ & & & $\mathrm{X}$ & $x$ & & & & $\mathbf{S}$ & & $\mathrm{X}$ & & & & & & \\
\hline $\begin{array}{l}\text { Manning, Jacobi \& Marion, } \\
\text { (1998) }\end{array}$ & $x$ & $\mathrm{X}$ & $x$ & & & $x$ & $x$ & & & & & & & & & & & & $\mathbf{S}$ & & \\
\hline Marion \& Leung, (2001) & $x$ & & $\mathbf{S}$ & & & $x$ & $\mathrm{X}$ & & & & & & & & & & & & $\mathbf{S}$ & & \\
\hline Nepal \& Nepal, (2004) & $x$ & & $\mathrm{X}$ & $\mathrm{X}$ & $\mathbf{S}$ & $\mathrm{x}$ & $\mathrm{X}$ & $\mathrm{X}$ & & $\mathbf{S}$ & & & $\mathbf{S}$ & & $\mathrm{X}$ & & & $\mathrm{X}$ & $\mathrm{X}$ & & \\
\hline Summer, (1986) & & $x$ & $\mathrm{X}$ & & & & & $\mathrm{X}$ & & & & $\mathrm{X}$ & & & $\mathrm{X}$ & & & $\mathrm{X}$ & $X$ & & \\
\hline Wilkerson \& Whitman, (2009) & & $x$ & $\mathrm{X}$ & & & $\mathrm{X}$ & $\mathrm{X}$ & & & & & & & & & & & $\mathrm{X}$ & & & \\
\hline Wood, Lawson \& Marion, (2006) & $x$ & & $\mathrm{X}$ & & & & & $\mathrm{X}$ & & $\mathrm{X}$ & & & & & & & & $\mathrm{X}$ & $\mathrm{X}$ & $\mathbf{S}$ & \\
\hline Yoda \& Watanabe, (2000) & & $x$ & & & & & & & & $\mathrm{X}$ & & & $\mathrm{X}$ & & & & & & & & \\
\hline Frequency in Relational ( $n=23)$ & 10 & 9 & 11 & 7 & 4 & 3 & 5 & 15 & 4 & 12 & 2 & 7 & 18 & 6 & 8 & 2 & 3 & 8 & 12 & 12 & 12 \\
\hline Significant Relationships & 9 & 8 & 11 & 5 & 3 & 0 & 3 & 9 & 4 & 7 & 1 & 4 & 15 & 5 & 3 & 1 & 3 & 6 & 8 & 12 & 11 \\
\hline Frequency in Descriptive $(n=14)$ & 5 & 5 & 9 & 3 & 3 & 6 & 6 & 8 & 1 & 4 & 1 & 2 & 4 & 1 & 4 & & & 6 & 6 & 2 & 0 \\
\hline
\end{tabular}

Note: " $X$ " denotes a variable was considered, measured, and presented in the research study, an " $\mathrm{S}$ " denotes the variable was considered and is part of a significant relationship (<.05 significance level) in one or more models discussed in the study. 


\section{Trail Widening}

As original trail construction dimensions are seldom available for determining the deviation of present width from the original design specifications, establishing a standard for comparison of this degradation variable is difficult. Comparison to management classification standards is useful from a compliance standpoint but not from an environmental degradation perspective. Establishing the outer edges of a trail to determine the length to be measured is also a subjective process as intrusion of vegetation and multiple trail treads are often present. Generally two distinct trail width measurements are taken, bare width, the width of bare soil or rock with no plant or organic matter, and disturbed width, the width of trail including the outside extent of visible disturbance to soil or vegetation. In problem assessment studies the length of trail which exceeds the "typical" width by pre-defined amounts has been used as a degradation indicator (Leung \& Marion, 1999b) but this is not common, width is generally considered in erosion classification schemas. Leung and Neller (1995) compare their study site average width measurements with nine trail studies at other geographic locations but this again is not the norm as trail width is generally used as a descriptive element or monitoring indicator. The presence of multiple treads is a form of trail widening but as parallel treads often have large gaps from the official trail, it can be difficult to differentiate these from visitor-created trails. When it is evident that the parallel tread is being used to avoid an on-trail impact it is generally included in the trail width measurement and bare width is a cumulative measure for all treads.

Bare width was the most frequently assessed trail degradation variable in the studies reviewed. For relational studies, significant relationships with one or more independent variables were found in every instance. Correlations between bare width and use variables were most common, but vegetation, trail position, and landform relationships were also frequently cited. Bare width was also frequently reported in descriptive studies as a way to characterize the trail corridor. Box plots showing the deviation from the mean are an effective way of identifying problem areas along trail segments (Leung \& Marion, 1999a; Pettebone, Newman, \& Theobald, 2009).

\section{Mud Development}

Although mud related problems are common on backcountry trails, point sample methods can miss $50 \%$ or more instances of their occurrence (Leung \& Marion, 1999a). Thus, mud related degradation is more common in problem analysis and descriptive studies. Definitions for mud differ slightly throughout the literature: "a soil surface that moves when wet" (Bratton et al., 1979); "Seasonal or permanently wet and muddy soils that show imbedded foot or hoof prints from previous or current use" (Aust et al., 
2005). The inclusion of soil moisture and a description of wet soils are also present in the studies but it is often unclear if mud is the variable the authors are referencing. From the literature reviewed, mud development is common in wet soils, catchment landforms, valley trail positions, and with horse related recreational use but as limited studies identified significant relationships with other variables the statistical power of these relationships is not evident and may be an opportunity for additional research.

\section{Compacted Trail Tread}

Hardened or compacted trail treads form the durable surface that differentiates a trail from the surrounding environment. The thickness and depth of the compaction will determine the infiltration rates of water and the rate of trail tread runoff. Compaction is commonly measured using a penetrometer to determine a value of resistance (Chatterjea, 2007; Gager \& Conacher, 2001; Goeft \& Alder, 2001), through a laboratory bulk density test (Godwin, 2000; Kuss, 1983), or in microscopic soils analysis a laboratory assessment of the macro and micro porosity of soil core samples (Sutherland et al., 2001). The use of a penetrometer is the only viable option for a rapid assessment of large trail mileage due to the need to take core samples for all other methods yet, this method was only included in three of the fourteen descriptive studies reviewed. Compaction analysis is commonly applied using on and off trail paired comparison sampling (Bryan, 1977; Chatterjea, 2007). Five of seven relational studies that measured compaction reported significant relationships with other variables.

\section{5: Biophysical Variables}

Biophysical variables are the elements of the natural environment on and through which the trail traverses. From a terminology perspective, no differentiation is made in the literature between environmental factors, as referenced in the conceptual model, and the term biophysical factors used here. Both terms refer to the setting through which the trail travels and generally considers a larger region than the trail corridor.

\section{Soils}

Investigations of the relationship between soils and trail degradation had the highest frequency among the studies reviewed and can be found throughout recreation impact and management literature. The most prominent aspect of soils considered is soil texture, an analysis of the percentages of different sized soil particles (clay, silt, and sand) and stones which combine to form the soil. Textures are classified into soil types in a matrix with clay having the finest particle sizes, sandy soils the coarsest, silt 
medium size with little mass, and loams which are a combination of particle sizes. Each soil type responds differently to moisture and compaction with the development of mud, erosion, and dustiness occurring at different rates. General models of the suitability of different soils for trail construction are common in the trail design literature (AMC, 2008; Birkby, 2006; Felton, 2004; Hesselbarth et al., 2007; T. S. Parker, 2004) with soils having a balanced mixture being the preferred tread material. As most trails are built with local soils, or in the case of non-engineered trails form on the surface of native soils, trail degradation responses will vary accordingly. Soil depth, compaction, bulk density, porosity, stoniness, organic content, surface roughness, and wetness are other soil characteristics which are commonly investigated. Bryan (1977) discusses in depth the effect of pan structures in the soil on trail erosion; Dixon et al. (2004) classify soil impact susceptibility by soil moisture content. Surface roughness was specifically called out in the study review because when it was considered it was frequently found to be significant in relationships with erosion and widening (Bayfield, 1973; Deluca et al., 1998; Sutherland et al., 2001). Also, the Saleh chain method, a roughness estimation method (Saleh, 1993) used in several studies, has limited equipment requirements and may be applied in high mileage, rapid assessment trail studies.

The methodologies for characterizing soil type vary greatly depending on the research approach. Field methodologies utilize visual comparisons (T. S. Parker, 2004, pp. 46-49), and "texture by feel"(Cakir, 2005; Foth, 1990, p. 337; Lanehart, 1998; Olive \& Marion, 2009). Soils samples are also taken in the field using coring techniques for lab analysis (Gager \& Conacher, 2001; Jubenville \& O'Sullivan, 1987; Sutherland et al., 2001). Researchers often use secondary data sources such as U.S. Department of Agriculture's Natural Resource Conservation Service state and county soil maps (STATSGO) in the description of study sites. This data source includes variables indicating the erodibility of the soil type and the appropriateness of the soil for recreational trail development. This source is seldom used in relational studies as it is deemed too granular for point assessments although these maps are used extensively in other fields of study which model landscape level environmental processes.

In the studies reviewed and through other meta analysis reviews (Hammitt \& Cole, 1998; Hill \& Pickering, 2009; Leung \& Marion, 1996) a number of patterns are apparent in the soil-trail degradation relationship:

- Soils with high organic content are prone to mud development and trail widening.

- Trails with increased surface roughness are prone to trail widening; trails with high off-trail surface roughness tend to be narrower. 
- Trails constructed on soils with finer particles are more prone to compaction and incision.

- Trails constructed on thin soils or soils with pan structures near the surface tend to have persistent water on the trail and are prone to widening (multi-tread) and seasonal mud development.

\section{Vegetation}

Vegetation is the second most frequently considered biophysical variable and third overall in the studies reviewed. More often than not, research evaluates the impact of recreational use on plant diversity, vigor, and spread of invasive species rather than the relationship of vegetation to trail degradation. From a degradation standpoint the type of vegetation communities (forest, grassland, shrub, alpine), their understory density, and their resistance to breakage are the most prominent variables. Measurement of vegetation communities is used on a spatial scale for stratification (Jubenville \& O'Sullivan, 1987; S. K. Nepal \& Nepal, 2004) and on a local level utilizing general (Obua \& Harding, 1997; Wood et al., 2006) and specific field identification techniques (Bayfield, 1973; Coleman, 1981; Törn et al., 2009).

Vegetation had the strongest influence on trail width, contributing to nine predictive models of trail widening. Dense woody shrub vegetation or forests with dense understory vegetation had statistically narrower trails than those in open grasslands or alpine meadows. Two studies used the presence of dense woody plants in an assessment of a recreational site or trail's potential for expansion (Dixon et al., 2004; Wood et al., 2006), as this type of vegetation serves as an "expansion inhibitor." The presence of woody roots from trees or shrubs was found to reduce the amount of erosion on a trail (Dixon et al., 2004; S. K. Nepal \& Nepal, 2004). Some variability in the expected relationships between vegetation and erosion led researchers to examine interactions between slope and vegetation (Jubenville \& O'Sullivan, 1987; Obua \& Harding, 1997) or as an indicator of topographic and climate interactions (Coleman, 1981; Törn et al., 2009; Yoda \& Watanabe, 2000).

\section{Landform}

The landform category used in the study table is a composite of variables found in the research which cover topographic, geologic, and spatial environmental classifications of the land on which the trails are built. Although the decision to build a trail in these settings is managerial, this reviewer felt these variables belong in the biophysical category due to their large scale. Variables included in this grouping are elevation, aspect, terrain slope, lithology (rock formations), and curvature of landform. As the scale of these variables can be larger than the researcher can evaluate in the field, use of topographic maps or 
GIS to compute these values is common. For elevation, some studies used altimeters in the field (Bratton et al., 1979), and for slope, it is common to use a clinometer (Felton, 2004, pp. 70-71). Several authors note interaction effects between landform, soil, climate, and vegetation variables that make it difficult to assess the appropriate component to study (Bratton et al., 1979; Coleman, 1981; Jubenville \& O'Sullivan, 1987; Törn et al., 2009; Yoda \& Watanabe, 2000). Other studies used composite ecological land unit classification systems from secondary data sources (Arrowsmith \& Inbakaran, 2002; Garland, 1990; White et al., 2006), or created unique systems for the study site (Dixon et al., 2004; S. K. Nepal \& Nepal, 2004) instead of, or in combination with the component landform variables.

From a findings perspective it is difficult to isolate landform variables from other biophysical conditions. For example, higher elevations were found to be more sensitive to trail degradation, particularly erosion (Bratton et al., 1979; Hartley, 2000; S. K. Nepal, 2003; Yoda \& Watanabe, 2000) but sensitivity of vegetation, increased precipitation, and lack of canopy were indicated as possible explanations rather than the elevation itself. Arrowsmith and Inbakaran (2002) found trails at higher altitudes in better condition but suggested that this was due to the predominance of rock, their increased distance from the trailhead, and the effort required in getting there as all trails started at the bottom of the mountain. Elevation is also relative, ranging from trail studies in the Appalachians with 1000 to 5000 foot elevations (Bratton et al., 1979; Leung \& Marion, 1999b) to Mt. Everest approach trails at 9000 to over 12000 feet (S. K. Nepal, 2003). White et al. (2006) found significant differences in both incision and width in five common ecological regions (CER) for mountain bike trails in the southwest U.S. These regions are part of a regional composite classification schema that incorporates biotic and abiotic variables including elevation, precipitation, soils, and vegetation. Using this type of schema is somewhat experimental but shows promise as a method of integrating recreation resource management into broader ecosystem management processes.

Landform slope relationship to degradation was a little more direct. Slope was found to be a limiting factor in trail width expansion (Coleman, 1981; Leung \& Neller, 1995; Sutherland et al., 2001). Steep side slopes kept visitors on the trail tread while flat terrain allowed spread. Water drainage on flat terrain was limited with mud developing more frequently (Bratton et al., 1979; Leung \& Marion, 1999b), while on steep slopes overland flow would be caught in entrenched trails increasing erosion (Bryan, 1977; Coleman, 1981). However, these impacts may be more fully explained by soils, vegetation, and rainfall. 


\section{Climate}

Precipitation and temperature are the two primary variables included in the climate grouping. The timing, intensity, and duration of these variables can have substantive effects on all degradation variables. Only three of the studies reviewed included climate as a study variable indicating that these impact patterns are seldom measured in isolation. Due to the longitudinal aspect of these variables, field assessment is impractical in most settings. Secondary data from weather monitoring stations is widely available and was used by Garland (1990) in his degradation model; studies which utilize the USLE erosion model compute a rainfall/runoff factor $(R)$ which is also based on this data (Aust et al., 2005; Gaffer, Flanagan, Denight, \& Engel, 2008; Kuss \& Morgan, 1986). Soil and trampling studies have included field experiments that simulate rainfall events with wetting instruments (Deluca et al., 1998; Harden, 2001) to examine sediment yield potential of soils.

Precipitation provides water to transport detached trail tread soil, a key element of erosion. Depending on off-trail infiltration rates, incursion of the trail tread into sub-surface water flow, and landform curvature, the volume of water will be variable. Coleman (1981) notes the difficulty of identifying off and on-trail sources and measurement of on-trail water due to the temporal and spatial distribution of water sources. Chatterjea (2007) comments on the similarity of trail treads to ephemeral streams during heavy rainfall events highlighting the influence incised trails have on the hydrology of the landscape focusing water and its erosion potential on the tread. In addition, splash from raindrops striking the soil surface causes detachment of soil increasing its availability for transport (Harden, 2001); this process is intensified if there is no overhead canopy (Dissmeyer \& Foster, 1981). As mentioned, catastrophic rain events have been found to result in scouring and severe gully erosion on trails (Bailey \& Pilgrim, 1983; S. K. Nepal, 2003; Summer, 1986).

Temperature is mentioned anecdotally and in relation to other biophysical variables throughout the reviewed studies. Of specific concern are cold weather impacts, permafrost (Bryan, 1977; Jubenville \& O'Sullivan, 1987), frost heave, and the formation of sub-surface needle ice (Coleman, 1981; S. K. Nepal, 2003; Whinam \& Chilcott, 2003; Yoda \& Watanabe, 2000) as they increase the detachment of surface materials increasing the potential for erosion. Although not emphasized in four of the commonly referenced trail building manuals (AMC, 2008; Felton, 2004; Hesselbarth et al., 2007; T. S. Parker, 2004), these soil disturbing freeze-thaw cycles are in soil recreational suitability models (Bailey \& Pilgrim, 1983) and, Hammitt and Cole $(1998$, p. 52$)$ note that frost heave is more common on compacted, bare soils which form typical trail treads. In related research, Swift (1984) notes a doubling of erosion rates on 
bare tread of unsurfaced forest roads during winter freeze-thaw cycles in Southern Appalachia; and, winter run-off from bare soil agricultural fields is greatly increased during the thaw cycle although the Water Erosion Prediction Project (WEPP) model is unable to predict the scale of the increase consistently (Greer, Wu, Singh, \& McCool, 2006). As most trail degradation studies do not cover large geographic regions, it is not surprising that relational studies with climate are not more common as climate variability is generally limited within a single study area.

\section{6: Managerial Variables}

Trail degradation rates and extent are often studied in relation to decisions resource managers make. The predominant grouping of independent variables in this grouping reference trail design. This grouping of variables is important to the discussion of trail impact mitigation as they can be altered through management decisions although such structural changes to trailbeds can be cost prohibitive. In the conceptual model in Figure 1, authors suggest that these actions can moderate or mediate the influences of environmental and use related factors.

\section{Trail Design}

Trail design for this review incorporates the physical attributes of trail location and man-made structural elements of the trail.

\section{Trail Grade}

Across the studies considered for this review, trail grade (also referred to as trail slope and trail gradient) is the most frequently considered managerial variable. One possible reason is its consistency in contributing to the explained variance of trail erosion more than any other variable. Trail grade is also a key variable in soil erodibility models like USLE, WEPP, and NRCS soil surveys. In the set of studies in Table 3, trail grade had the highest frequency of significant relationships with degradation variables. For the relational studies, trail grade was found to be significant in $65 \%$ of the studies.

Measurement of trail grade was also one of the most consistent methodologies identified in the research which makes it unique in its ability to be compared across studies. A simple field survey technique using a clinometer to measure the percentage of rise or fall of a section of trail over a given distance provides the measure. Some care must be given to the value presented as some authors report grade in degrees while others use percentage (tangent (degree raw value) x 100). In a limited body of 
literature, trail grade is estimated using GIS in a post processing environment or for planning new trails (Cakir, 2005) but the field method is still dominant.

One limitation in comparing trail grade values in the literature is an inconsistency in the treatment of its measured value. While some studies consider it a continuous value from zero (flat) through ninety (straight vertical, the highest value reported was $~ 50 \%$ ), others create a categorical variable from the raw values, and others still use the raw or categorical value as part of a scaled, design suitability index. Low predictive values of a continuous variable with a skewness towards higher trail grade values when regressed against incision and CSA is one justification for creating the categorical values.

Table 4

Examples of Trail Grade Variable Scaling

\begin{tabular}{|c|l|}
\hline Variable type & Studies \\
\hline Continuous & $\begin{array}{l}\text { (Aust et al., 2005; Bratton et al., 1979; Cakir, 2005; } \\
\text { Coleman, 1981; Dixon et al., 2004; Gager \& Conacher, } \\
\text { 2001; Godwin, 2000; Goeft \& Alder, 2001; Olive \& } \\
\text { Marion, 2009) }\end{array}$ \\
\hline Categorical & \\
\hline $0-6.9 \%, 7-14.9 \%,>14.9 \%$ & (Jubenville \& O'Sullivan, 1987; Sutherland et al., 2001) \\
\hline $0-5 \%, 5.1-8.7 \%, 8.8-17.6 \%,>17.6 \%$ & (Bryan, 1977) \\
\hline $0-9 \%, 9.1-18 \%, 18.1-27 \%,>27 \%$ & (T. F. Farrell \& Marion, 2002) \\
\hline $0-36 \%, 36.1-58 \%,>58 \%$ & (Obua \& Harding, 1997) \\
\hline$<12.3 \%,>12.3 \%$ & (Törn et al., 2009) \\
\hline$<5 \%, 5-10 \%,>10 \%$ & (White et al., 2006) \\
\hline
\end{tabular}

Note: all grades were converted to $\%$ when degrees were provided, rounded to the nearest 10 th

Although trail grade is consistently a significant contributor to erosion models, the strength of this relationship and degree of explained variance varies greatly across studies. Jubenville and O'Sullivan (1987), and Godwin (2000) report grade explaining upwards of $30 \%$ of the variance in CSA; Olive and Marion (2009) highlight the limited contribution of $2 \%$ to CSA. Several studies find that trail grade effect is limited unless interacting with other variables: grade + alignment of the trail to the landscape (Bratton et al., 1979; Cakir, 2005); grade + use type (Coleman, 1981; T. F. Farrell \& Marion, 2002; Olive \& Marion, 2009); grade + soil type (Wilson \& Seney, 1994); and grade + ecological type (Obua \& Harding, 1997; 
Törn et al., 2009; White et al., 2006). When significant, the grade-soil loss relationship is positive, increased grade equates to increased soil loss, although not linearly. The relationship of grade to trail width is inconsistent, some positive (Bayfield, 1973; Bryan, 1977; Cakir, 2005) and some negative (Coleman, 1981). Grade was also found to relate to soil roughness positively, greater slopes equate to greater roughness (Sutherland et al., 2001). Even though the grade-erosion relationship is tested across a large body of research, there appears to be no definitive answers to the role of trail grade in the trail degradation model. There is more support that grade affect varies by environment and should be modeled accordingly in a multivariate process.

\section{Alignment}

Trail alignment is the angle at which a trail crosses the slope of the land on which it is built. The measure is calculated by subtracting the aspect of the trail in a downhill direction from the aspect of the terrain in a downhill direction. Measurements are taken in the field using a simple compass bearing and values range from 0 to 90,0 being directly in line, parallel, with the fall line of the terrain, and 90 being completely perpendicular to the fall line. Determination of the landform's predominating aspect has some subjectivity and can be difficult in areas with little slope or an undulating surface. This measure is referenced with different terms throughout the literature: trail orientation (Bryan, 1977); trail angle (Bratton et al., 1979); and, trail slope alignment angle (Leung \& Marion, 1996). Aust et al. (2005) outline an alignment classification schema with typical trail characteristics and degradation potential presented in Figure 4.

Bratton et al. (1979) found trail alignment to have significant correlation to all types of erosion except on bare rock. Their findings indicated that low trail angles ( 0 to 10 degrees) had the worst erosion ratings and trail angles between 80 and 90 degrees showing the least erosion. Bryan (1977) noted a similar relationship, "Where trails follow the fall-line severe water erosion hazard exists, regardless of slope angle. When trails parallel contours little damage will occur unless incision is sufficient to divert runoff." Gager and Conacher (2001) note that track alignment angle was highly correlated with CSA and erosion severity ratings. Olive and Marion (2009) also found a significant relationship but the magnitude of the effect was minimal, with each degree of deviation from 90 degrees accounting to a six $\mathrm{cm}^{2}$ increase in CSA. 


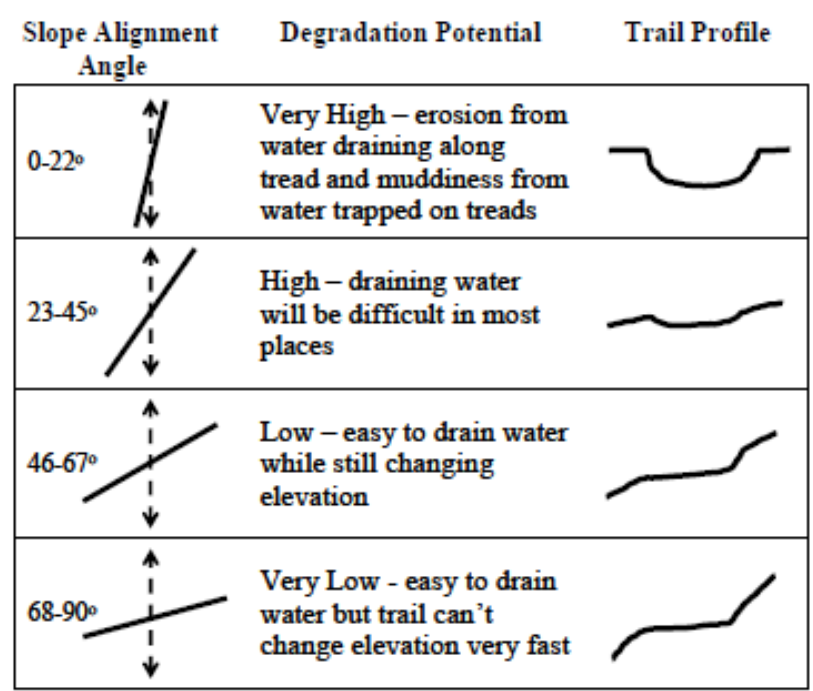

Note: Landform slope is dotted line, trail is solid line.

Figure 4 Trail slope alignment impact characteristics (Aust et al., 2005).

Trail building references warn against "fall line" trails due to their increased erosion potential but also note trail slope, alignment, and the length of a continuous alignment factors to be considered in combination (Felton, 2004; T. S. Parker, 2004). The interaction effect between alignment and slope is supported by field research as well. Aust et al. (2005) found that trails with slopes greater than $14 \%$ having high angle alignments (61-90 degrees) were highly correlated with increased CSA; Bratton et al (1979) found that $45 \%$ of trail segments with $<10$ degree trail angle and $>10$ degree slope were in the poorest erosion rating class. Olive and Marion's (2009) research on horse trails did not statistically support this interaction effect. Further investigation is needed to build evidence to support the persistence and magnitude of this relationship across varying environmental settings.

\section{Position}

Determining the trail destination and the path it follows are managerial function that involve decisions on the desired distances, difficulty, scenic qualities, and function (T. S. Parker, 2004). When considering scenery, trails following ridges, particularly those with open vista opportunities, and those in valleys following streams and rivers are popular with visitors. Both ridge and valley positioning and the space between, midslopes, have been examined in the trail impact research for their susceptibility to degradation. The delineation of each of these topographic positions in the field is somewhat subjective 
with the relative elevation change of the land on each side of the trail being the primary determinant (Leung \& Marion, 1999b). Cakir (2005) utilized a GIS process to create a systematic method of determining topographic position but still included subjective elements.

Some patterns are discussed in the studies. Valley bottom trails have an increased frequency of mud development and root exposure due to poor drainage and intrusion into seeps and subsurface water (Bratton et al., 1979; Coleman, 1981; S. K. Nepal \& Nepal, 2004). Olive and Marion (2009) found valley position trails with greater erosion but accounted for this by seasonal flooding events from adjacent streams. Trail width has also been found to increase in valley bottoms as they are generally flat with limited barriers to widening (Cole, 1991), in addition visitors frequently interact with water features along valley bottom trails increasing the impact zone (Serengil \& Özhan, 2006). Ridge trail degradation patterns are inconsistent in the literature and appear to be more a function of trail grade and presence of functional drainage features. Some findings include: trail width on sharp ridges is less (Leung \& Neller, 1995; Sutherland et al., 2001) due to steepness of side slopes; Bratton et al. (1979) found increased erosion on ridges; Coleman (1981) found less incision on ridges; Marion and Leung (2001) found ridge trails to be difficult to drain due to their limited slope, leading to increased erosion as water remained entrenched in the tread over long distances. Midslope trails are encouraged in trail building literature as they are more easily drained through proper design, but will erode rapidly if water is trapped in the tread; research also supports this (Aust et al., 2005; Bryan, 1977). With the exception of mud development it appears that topographic position is less of an influence on degradation than other trail design variables particularly upslope length. Compounding this finding is the common occurrence of different soil textures and sub-surface geology at different topographic positions (Koehler et al., 2000; Summer, 1986).

\title{
Upslope Length
}

\begin{abstract}
"Basically, trail surface erosion results from three factors: soil type; velocity of water along the trail; and length of time running water is allowed on the trail. By modifying any of these three items, erosion potential is changed. The most common modification is to reduce the length of time running water is allowed to operate on the surface material by increasing the number of structures designed to remove this water." USDA Forest Service Trail Management Handbook (1991, p. 24)
\end{abstract}

Although the trail degradation research has shown that the erosion potential formula is not a simple three variable equation as prescribed by the Forest Service, the length of time water is on the trail is a 
key factor frequently omitted from trail studies. Troy Scott Parker in Natural Surface Trails by Design (2004, pp. 51-54), discusses "tread length" as a critical element of the erosion potential in a "tread watershed" providing a hypothetical table of maximum tread lengths by soil type and grade. In a problem analysis of eroded trails, Gager and Conacher (2001) refer to this measurement as "upslope track length," the length of trail uphill from the study area that contributed runoff and find it the most significantly correlated variable in predicting erosion severity from a number of on and off-trail variables.

Another measurement found in the research which equates to upslope length is an evaluation of the distance of a point sample to an effective upslope water control structures, water bars, dips, and turnouts (Aust et al., 2005; Olive \& Marion, 2009). Olive and Marion (2009) found significant differences in CSA between sample points with functioning drainage structures within $7.6 \mathrm{~m}$ uphill and those without. Aust et al. (2005) found distance to functioning drainage structures to be the most influential factor in predicting CSA in a regression analysis. Bratton et al. (1979) propose a revision to their study variables to include an assessment of water bar frequency and condition to create a maintenance intensity variable to correlate to trail condition due to the strong observed relationships. In the related forest roads research, Luce and Black (2001) found road segment length for recently disturbed surfaces had a linear relationship with sediment yield while this length on undisturbed surfaces did not.

Given the research findings and emphasis in trail design literature, inclusion of upslope length in future trail degradation studies seem appropriate as it has the potential to improve the modeling of erosion rates of natural surface trails. This would be consistent with other landscape erosion prediction models, USLE, RUSLE, WEPP, which include this variable in various forms (Hickey, 2000). One potential difficulty with applying this measurement in a rapid assessment methodology is the added time to backtrack or go forward to capture the full contributing slope length. Post processing data points in a GIS, as done by Brooks et al. (2006), offers some potential here if the geographic locations of trail drainage design features are recorded in the field.

\section{Surfacing}

Although this is a study of natural surfaced trails, a brief discussion of trail surfacing effectiveness is included here as it has a substantial potential to provide false readings if present on study trails. Aust et al. (2005) found that moderate to high-use natural surface trails were significantly more eroded than graveled trail sections on the same grade and alignment. They also found lower CSA values on trail grades over $12 \%$ when gravel was applied. In addition, gravel application was effective in managing 
mud development even with horse use. Although gravel application was not significant in a regression analysis on trail erosion on Big South National Recreation Area, Marion and Olive (2006) compared CSA of graveled and natural surface sample points in a separate report finding significantly lower CSA and fewer instances of mud on trails with greater than $30 \%$ gravel coverage. Wilkerson and Whitman (2009) omitted all graveled sample points in their trail degradation study noting that these points were outliers in the CSA, trail width, and depth measurements.

Social science research on the acceptability of surfacing materials finds that some surfacing is acceptable in front country settings to protect the resource but is undesirable in more primitive settings (Aguirre, 2009; Dorwart, Moore, \& Leung, 2010; Giles, 2002). The sensitivity to surfacing varies with user type and activity specialization.

\section{7: Use Variables}

The third grouping of variables commonly considered in trail degradation is the attributes associated with the recreational user. The most common use variables considered are the method of transit used to travel on the trail tread (use type), the number of users over a given time period (use intensity), and, the different habits and practices of users as they interact with the trail environment (user behavior).

\section{Use Type}

In a review of trends in outdoor recreation Cordell (2008) references a variety of modalities related to trail use including hiking, bicycling, horseback riding, rock climbing, skiing, and off-road vehicles. Because each modality contacts the trail surface with a different "tread" (shoe sole, hoof, wheel, ski), a different degree of compacting force, and different width profiles, the types of impacts on the tread surface will differ (Buckley, 2004; Hammitt \& Cole, 1998; M. Liddle, 1997). For example Liddle (1997, p. 10) measured the compacting force of a human with hiking boots at $206 \mathrm{~g} / \mathrm{cm}^{2}$ as compared to a shod horse with rider at $4,380 \mathrm{~g} / \mathrm{cm}^{2}$. Several studies comparing horse and hiker use impacts have shown that the degree of soil compaction on trails with horse use is significantly deeper than trails used by hikers only (Deluca et al., 1998; Newsome, Cole, \& Marion, 2004; Weaver \& Dale, 1978). The relationship of increased frequency of mud development and increased soil erosion with horse use versus hiking and mountain biking, which behave similarly for these variables, has been supported in many studies (Aust et al., 2005; Bratton et al., 1979; Dale \& Weaver, 1974; Deluca et al., 1998; Leung \& Marion, 1999b; Pickering, Hill, Newsome, \& Leung, 2009; Törn et al., 2009). One notable study differs 
with this predominant viewpoint, Summer $(1980,1986)$, and points to landform and soils as the causal factors not horse use.

Trail widening due to user type had some inconsistencies in findings. Generally there was agreement that foot and bicycle use had similar width effects, but while Dale and Weaver (1974) found trails with horse and foot travel were narrower than foot traffic alone, Marion and Olive (2006) found horse trails to be twice as wide as mountain bike and hiking trails in the Big South NRA. Torn et al. (2009) found hiking trails to be wider on average than horse trails, although the author noted that these trails were significantly older than the horse trails under investigation.

Although use type was not considered in all studies that looked at user variables, several studies considering use intensities only studied trails with specific use types, primarily horse (Aust et al., 2005; Summer, 1986) and mountain bike (Goeft \& Alder, 2001; White et al., 2006).

\section{Intensity}

Of all the degradation influencing variables in the reviewed studies, Table 3, use intensity had the third highest frequency with more than $50 \%$ of the investigations indicating it played a significant role in one or more trail degradation processes. For this review use intensity refers to the number of visitors using the trail, other researchers have used intensity to describe the lateral spread of users across a trail tread. At least three inconsistencies exist in the values given for intensity in the reviewed studies:

- Units - the number of trail users are reported in the following ways: temporally, number per day, number per year, number per year over the life of the trail; as a density, number per distance, number of encounters per distance; number of passes with trampling studies; and percentage of a reference trail. Relative values without number assessments are also given in high, medium, and low categories.

- Data sources - determining a quality estimate of the number of users on a given trail has an entire body of research unto itself (Watson, Cole, Turner, \& Reynolds, 2000). Direct observation has been rated highly as a reliable source but is one of the most labor intensive of all methods. For the reviewed studies: 5 relied on expert estimates; 3 used visitor logs or registers; 2 used trail counters; 2 used observations; some used multiple sources; and at least 3 others did not provide a source for the values used.

- Categorical Data - many studies classify their intensity data into high, medium, and low-use categories. Comparing classifications across studies is difficult because no standard is used. A three level rating for a trail that gets more than 10,000 hikers per year (Dale \& Weaver, 1974) cannot be compared to a trail that receives 1000 users per year (Dixon et al., 2004; T. F. Farrell \& Marion, 2002). At least one categorical schema was highly skewed: low, 200-600 annual users; medium, 4000-6000 annual users; and, high, 6000-7000 annual users (Summer, 1986). 
From this range of treatments, it is difficult to gain reliable insights into the true relationships of use intensity and trail degradation. The most commonly listed significant finding is a relationship between use level and trail width, as use increases trail width increases (Aust et al., 2005; Coleman, 1981; Dale \& Weaver, 1974; Dixon et al., 2004; T. F. Farrell \& Marion, 2002; Marion \& Leung, 2001; Olive \& Marion, 2009). Although increased width is a general pattern, some studies indicated anomalies in the pattern associated with variables that confined the trail tread's expansion, vegetation, steep side slopes, trail edge structures, and rock outcrops. Several studies also found an increase in soil loss (maximum incision or (SA) associated with increased use levels, but this was more limited and often involved an interaction with a biophysical variable (Coleman, 1981; Dixon et al., 2004; T. F. Farrell \& Marion, 2002; Manning, Jacobi, \& Marion, 2006; Törn et al., 2009). Findings indicated that at low levels of use (<1000 annual users) bare width diminishes (Dale \& Weaver, 1974), and some authors offer that some level of use is a positive as it keeps the trail tread surface clear of vegetation (Bratton et al., 1979; Summer, 1980). There was also evidence that use impacts are cumulative over the history of the trail (Dixon et al., 2004; Törn et al., 2009) unless substantial low level use periods allow vegetation and soil organic layer to regenerate.

It has been a generally accepted principle of recreation ecology that there exists a curvilinear relationship between vegetation loss and use, Figure 5 . The general concept is that vegetation loss occurs rapidly at low levels of use then the rate levels off at a certain inflection point of use. The inflection point varies based on the resistance and resilience of the vegetation to trampling, soil compactibility, and use type. This model is most relevant to trail widening as widening is measured by the removal or disturbance of vegetation and organic matter at the edge of the trail. Although this model was originally derived for vegetation loss on pristine ground utilizing trampling studies it is extended to other impact relationships as well in the literature (Marion, 1998). Some longitudinal trail research and studies on trails with very high use levels, over 10,000 users per year, have shown that impacts continue to increase beyond the inflection point in frequency, lineal extent, and severity resulting in a larger cumulative effect (Dixon et al., 2004; Marion \& Leung, 2001). These long-term findings support the need for longitudinal trail monitoring, not only to assess visitor impacts from a managerial standpoint, but also to test the theoretical underpinnings of recreation ecology. 


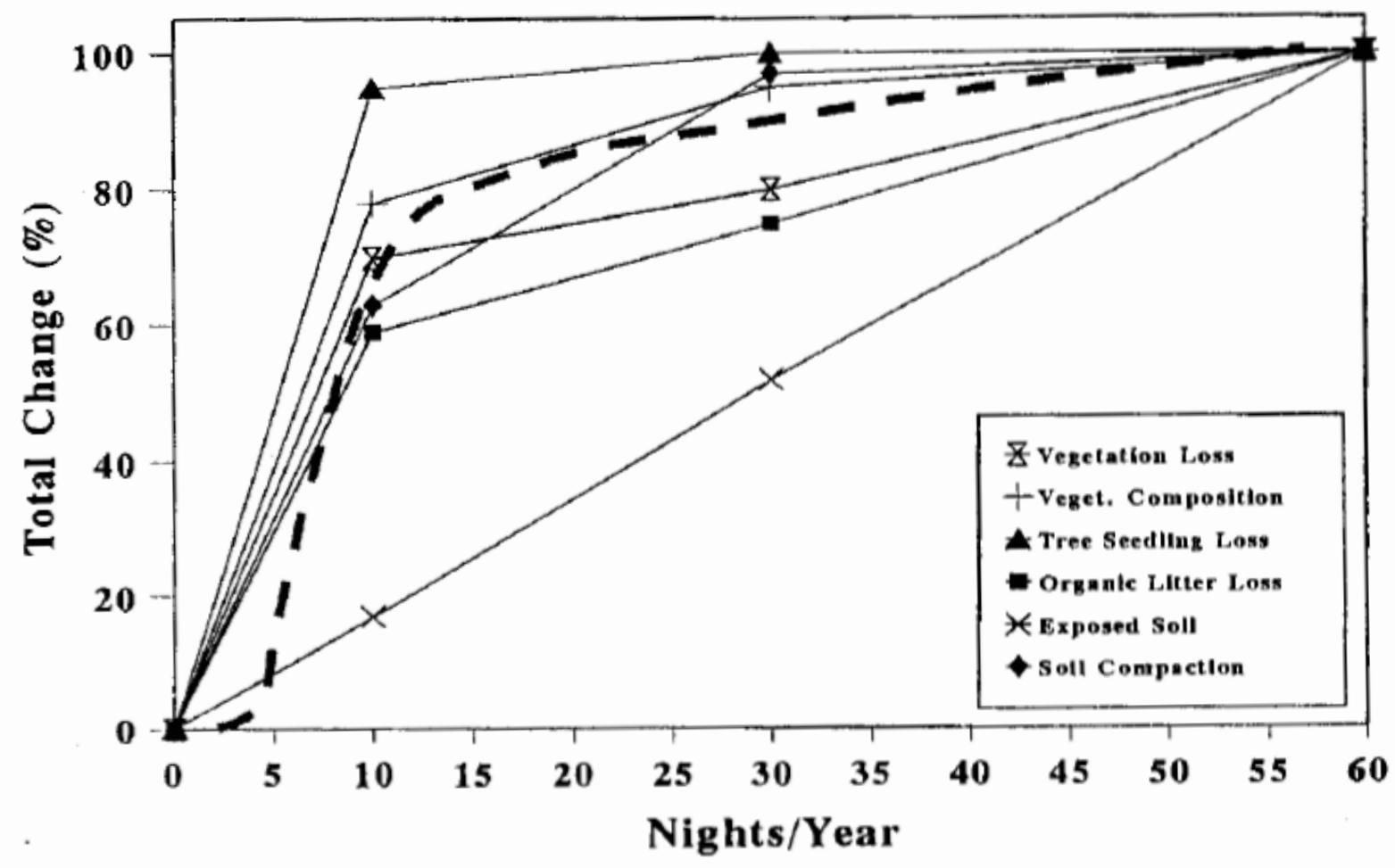

Figure 5: General relationship between amount of use and recreational impacts on campsites. (Source: Marion, 1998)

Note: Change is expressed as a percentage of change on high-use sites. Thus, approximately $70 \%$ of the vegetation loss that occurs on campsites receiving 60+ nights/year has already occurred on campsites receiving 10 nights/year usage. The generalized curvilinear use-impact relationship is depicted by the thicker black line.

\section{8: Summary of Degradation Relationships}

From this review, it is evident that some biophysical, use, and managerial variables have been found to have stronger influences on trail degradation severity than others do. These variables also appear to be highly inter-related with evidence of interaction effects skewing degradation rates at both the low and high ends of variable value ranges. As no consistent model has emerged which reliably accounts for a high percentage of variance in degradation rates, it appears that modeling is best done on a site or regional level due to the influences of micro-climate and micro-topography. Single trail or small regional assessments with relatively homogenous biophysical and use conditions show higher levels of explained variance for degradation. 


\section{9: Application of Geographic Information Systems in Trails Research}

While there is a plethora of studies on trail degradation, research integrating geographic information systems (GIS) in the examination of degradation is minimal. While other disciplines within natural resource management have fully embraced the integration of GIS into landscape and ecological modeling, the recreation resource field has been slow to adopt this technology (Harris, Gimblett, \& Shaw, 1995). Several editorials have been written regarding the need for better use of this technology. Some authors tout GIS as a panacea providing answers to all the recreation resource manager's wildest questions. Others, more grounded in the truth of the labor and cost involved in creating detailed GIS data sets and the limitations of remotely sensed or interpolated spatial data, put GIS more solidly in the realm of a decision support tool (Cole, 1989; Lee \& Graefe, 2004; Naber \& Leung, 2006). Hammitt and Cole (1998) are more hesitant in acceptance of GIS as a recreation-impact management tool. While noting its ability to provide sophisticated analytical options, they describe it as "novel" with more limited value in IA\&M than in other natural resource applications

The literature that is available on GIS integration into trails management can be divided into three general categories: Visualization, Planning, and Analysis. Only a limited number of reports are represented in refereed journals due to the applied nature of GIS, the majority of applications are presented in theses, technical reports, and unpublished management documents. A large portion of the content has been developed in the landscape architecture field whose early pioneer, lan McHarg, is credited with "creating" the geo-referenced overlays on which many GIS applications are based (Foresman, 1998).

\section{Trail Visualizations in GIS}

The most common, elementary, usage of a GIS is to allow for the visualization of points, lines, and polygons on a spatial surface. This approach uses GIS as an electronic map allowing the user to see spatially the location and extent of these features. The power of GIS is that each map element is stored in a database that is referenced on the map based on its geographic location, geo-referenced (McHarg, 1995). The database can be queried by selecting visual elements on the map providing easy access to managerial data regarding the feature. Multiple layers of information for a given geographic location can be accessed through this querying process. Trails are entered into a GIS as vectors connecting georeferenced points and are assigned attributes based on the purpose of the inventory. Many resource management agencies develop attribute libraries as well as GIS and global positioning system (GPS) data quality standards to insure the relative accuracy of these inventories. In addition to management 
features (signage, surfacing, facilities, water diversion structures, etc.), trail impacts are often included as part of the inventory database. The location and lineal extent of impacts collected through a problem assessment census, point sample data, or impact classification values of trail segments have all been mapped in a GIS for use with presenting trail degradation results in research (Cakir, 2005; Leung, 1998; S. K. Nepal, 2003). Frequencies, lengths, and other descriptive attribute reports are created using reporting tools built into the GIS utilizing these query methods.

One study, which falls into the visualization category, was conducted on the trekking trails of the Mt. Everest region in Sagarmatha National Park, Nepal by Sinjay and Stella Amor Nepal (S. K. Nepal, 2003; S. K. Nepal \& Nepal, 2004). A trail degradation classification schema was derived from problem assessment trail surveys and the information was entered as a layer into a GIS. A GPS was used during the survey to create trail vector data and record positions of degraded "hot spots" on the trails. In the GIS, trails were segmented based on their degradation class and combined with park boundary, topographic, vegetation, and settlement layers to allow for spatial visualization of degraded trail sections. Data was associated to lineal distances on measured trail vectors using a GIS process known as dynamic segmentation. The authors noted some difficulty applying problem assessment data to the vectors due to differences in the linear distances measured in the field with a measuring wheel and those calculated in the GIS. They note this as a common source of error in GISs due to the difficulty in representing three-dimensional distances in mountainous terrain using coarsely scaled digital elevation models (DEMs). Review of the articles on this research did not indicate further derivation of values from the secondary data sources for this study. The GIS was used for logistical purposes to organize the study and visualizations were referenced in descriptive and qualitative analysis of degradation patterns.

\section{Trail Planning with GIS Integration}

GIS has been utilized by researchers and managers to assist in the planning of trail locations and in modeling trail use for determining management strategies. A common GIS approach to trail planning is to develop a grid of values that represent the suitability of the enclosed grid cell for trail building. The following discussion provides a few examples of this approach. Some of the grid models are simple such as Garland's (1990) exploratory model in the Drakensberg Mountains of South Africa. The author computed values in raster grid cells of lithology, rainfall, and topographic slope from GIS layers scoring the cells based on the sensitivity of each factor to erosion. Unlike other studies, this "erosion sensitivity grid" was compared to actual conditions of existing trails and was found to correspond well with existing erosion rates. Xiang (1996) produced a similar grid but included many landscape and management 
feature variables providing a more complex approach to weighting of grid cells. Environmental variables in this model included: topography (elevation, slope, and aspect), hydrological features (watershed boundaries, lakes, and creeks), surface geology, soil types, land cover (vegetation categories, endangered species, and ecologically fragile areas), land use (existing trails, camping areas, climbing areas, safety buffer zones, power/gas and sewer lines), wetlands, and the two prominent peaks. Other user and management variables were also considered including the suitability of the landscape for a trail, the viewshed of the trail, cost of construction by terrain type, and barriers to trail development. Many of the environmental and management variables mirror those used in trail degradation research. The objective of Xiang's study was to provide potential corridors for trails which provide trail users with the highest level of enjoyment at the lowest possible costs (both ecological and economical) which goes beyond Garland's erosion potential modeling. To achieve this objective Xiang utilized the cost-path functions of GIS to establish least-cost paths across the grids from existing trails to desired destinations. Other authors have utilized similar approaches for developing optimal trail alignment corridors. Starr, Gratzer, and Lewis (1999) incorporated slope, land cover, soil drainage, wetlands, and land acquisition costs in their suitability grids for developing linking trails to existing trail networks in New York. Gül, Örücü, and Karaca (2006) included degree of slope, proximity to water resources, accessibility, elevation, vegetation, soil, climate, aspect, current cultural facilities, visual values. One commonality to these studies is that the suitability or sensitivity values associated with the variable categories were not derived from recreation ecology research. Most often values were allocated by expert opinion; Garland established scores "arbitrarily" based on personal professional knowledge; Xiang utilized a combination of state trail design criteria prioritization and expert opinion of a park manager utilizing a theoretical prioritization model; Starr, Gratzer, and Lewis utilized a Delphi Census of three resource area managers; and Gül, Örücü, and Karaca surveyed 30 "local experts" in park and recreation planning and management creating a rank order index.

Integration of user preferences into trail corridor suitability grids extends these planning models. While some studies use manager or researcher expert opinion on the recreational value of certain environmental, social, psychological, and visual attributes of geographic locations (Starr et al., 1999; Xiang, 1996) other studies employ user surveys to generate preference weighting factors for these attributes. For example, Gül, Örücü, and Karaca (2006) interviewed 400 park visitors to determine recreational setting and behavioral preferences, the results of the interviews were used to prioritize suitability zones for future development. Boers and Contrell (2007) created a visitor preference 
opportunity grid weighting desirable destinations as "zones of interest" matching three visitation priorities of cultural interests, general nature interests, and a specific nature preference of seeing birds. This information was combined with managerial and social trail density preferences to assist in the development of a sustainable tourism visitor transportation network in Sri Lanka. Kliskey (2000) developed a recreation terrain suitability index grid map quantifying terrain quality using recreation attributes considered important to the recreation user. User preferences were derived through principal component analysis of recreational user survey data creating a recreation attitudinal scale which was used to weight various topographical features including terrain, remoteness, access, and forest cover. These are three of many examples of integrating user preferences with GIS in supporting land-use planning decision.

A final grouping of GIS use in trail planning integrates current and historic trail use data layers to model potential user conflicts and threats to management objectives such as sensitive species protection. A general pattern in this line of research is to capture the trails used by study subjects either through ontrip journaling, post trip recall, in field GPS tracking, or field observation. This data is used to investigate a variety of management objectives. In an early study, Wing and Shelby (1999) created seasonal trail user density maps divided by user types based on post trip route recall information using the dynamic segmentation functions of GIS route features. Additionally, the study mapped frequency of user conflicts as well as perceived crowding issues on trail segments providing managers with a visual model of the social carrying capacity of trails in the resource area. Conflict and crowding was found to be minimal to moderate for the study area but the method demonstrates the potential for use of GIS in modeling the human dimensions of trail use in a spatial format. This methodology has been advanced in recent years through the development of agent-based modeling systems which when linked to GIS enable scenario testing, use encounters, crowding modeling, and relationships of use with trail impacts (H. R. Gimblett, 2005; S. R. Lawson, Itami, Gimblett, \& Manning, 2004, 2006). The impact of recreational use on resource protection objectives also has a growing number of studies. One example was conducted in Lolo National Forest (Schumacher, Redmond, Hart, \& Jensen, 2000) where authors mapped residential, recreational trail, and road human densities in combination with grid maps of terrestrial and aquatic species of concern, particularly the threatened bull trout. Resulting maps indicate where population pressure has the potential to impact sensitive habitats and cause stress to sensitive species. More directly linked to trail impact research, a number of studies of informal or social trail densities have been published. These studies map informal trails utilizing field based GPS (Leung, 
Shaw, Johnson, \& Duhaime, 2002; Manning et al., 2006; Wood et al., 2006) and heads-up digitizing utilizing high resolution geo-referenced aerial photography (Marion et al., 2006). These unplanned routes if unmanaged have the potential to cause severe ecological and visual impacts as they are not designed to shed water becoming muddy or eroded, and can travel through sensitive habitats. Mapping these trails allows managers to identify potential impact zones when combined with other resource management GIS layers.

All of the approaches mentioned inform management decisions for trail development, maintenance scheduling, trail rerouting, and possible user intervention such as educational messaging, signage, ranger patrols, and site rationing. As more spatial data on recreational use is available, the use of GIS in resource management and planning is sure to increase. Such integrated systems have been previously proposed (Avery, Clements, Harrison, Hughey, \& Thompson, 1997) but few have been documented with USFS GIS based Off-Road Vehicle IA\&M system (Meyer, 2002) as a noteworthy exception.

\section{Trail Analysis with GIS}

In editorials and texts on recreation ecology, several authors have noted a need to increase the scope of research to incorporate larger spatial scales and spatial relationships of degradation variables (Monz et al., 2009). This type of analysis investigates the interrelationship of spatial layers and the potential or realized degradation of the trail and/or the surrounding ecosystem. Many of the potential uses of GIS in predicting spatial patterns of trail degradation are hypothetical or exploratory (Naber \& Leung, 2006). Testing and validating these methodological approaches is an important step in moving the science of spatial recreation ecology forward. While a number of the planning models discussed in the previous section create hypothetical sensitivity grids which incorporate theoretical independent variables that influence trail degradation, a more limited body of literature is available which integrates the capabilities of GIS in analyzing the causes or spatial distribution of measured impacts.

Cakir's dissertation (Cakir, 2005) is one of the most extensive treatments of the utilization of GIS secondary data to predict trail degradation. Utilizing digital elevation models (DEMs) of various resolutions, Cakir explored the substitutability of in situ degradation influencing variables, trail alignment angle, trail grade, landform aspect, landform slope, landform position, and landform curvature, in the prediction of field collected data on trail maximum incision and width collected using the point sample method. Although each DEM performed differently, there were significant correlations between field data and the DEM generated equivalents for each variable. Final prediction models showed that only field data for landform position and landform slope performed better than GIS 
derived data for maximum incision; and, trail grade, and landform position field collected data performing better in the prediction of trail width. In both cases, the mixed data source regression models performed better than either field based regression models.

Arrowsmith and Inbakaran (2002) also used GIS acquired and derived variables in their multivariate analysis of trail impacts. In their study, GIS data on elevation, soils, vegetation, hydrology, historic structures, and management features, including trails and roads, provided values for independent variables in assessing their collective influence on observed trail conditions. Authors defined impact classes as the dependent variable in this study. Impact classes were a subjective value of 1 to 5 , with 1 being low levels and 5 being the highest, it was noted that zero was not a possible score as the existence of a trail tread indicated an impact on the natural landscape. Impact was a composite variable including trail width, evidence of erosion, and trampling of vegetation. Although not specified, the study appeared to use a type of point sample methodology recording trail parameters at 201 observation points along twelve trails. Like Bratton et al. (1979), observation point data was used to characterize a length of trail. Authors utilized principle component analysis to establish the set of GIS extracted and derived environmental factors that best described the impact ratings. The final model found that impact had significant positive correlations with elevation, distance from trailhead, and rainfall, and significant negative correlations with track surface, observed impact, and soil type although the best model only predicted $18 \%$ of the variance in the impact rating. Once the factors were established using both field and GIS based variables, this study shifted from a predictive-analytical modeling study to a planningsuitability modeling study. Despite the limited power of the model, authors used the established factors to create a "tourist impact resilience" grid for future trail development planning in the Grampian National Park resource area. The building of the GIS grid planning model based on original predictive degradation modeling fieldwork is a noteworthy deviation from the group of planning studies previously reviewed which relied primarily on expert opinion for grid weighting scores.

Agricultural soil loss modeling software which utilizes GIS has gradually become available since the late 1980s. GIS-based grid categorization of the soil loss potential of landforms based on the USLE and RUSLE formulas are available for many natural resource areas which support recreation due to interests in timber extraction although researchers can readily compute maps using add-on modules for current GIS software. Kuss and Morgan (1986) proposed a recreational carrying capacity model utilizing this information although their work was done before GIS was widely available and they relied on paper 
maps with transparent overlays for visual analysis. In a study of trail erosion rates of a military training base in Indiana, Gaffer, Flanagan, Denight, and Engel (2008) utilized the USLE GIS data as well as a GIS based WEPP model of road erosion to estimate soil loss from base trails. Authors categorized model generated GIS-based erosion prediction grids into low, medium, and high erosion potential. Qualitative field estimates of erosion were collected at 75 GPS geo-referenced field sites randomly located along trails at the basis for comparison with model generated grid data. The analysis showed that the erosion rates on trails were predicted correctly $51 \%$ of the time with USLE and $24 \%$ with the GeoWEPP GIS model. This study shows the ability of GIS to process data for large spatial areas while still providing good predictive validity for landscape dependent processes such as trail erosion.

One of the few trail impact studies to attempt to use remotely sensed information is a vegetation impact study conducted on Cadillac Mountain in Acadia National Park (Kim, Ednie, \& Daigle, 2006). In this study, vegetation adjacent to the short loop trails and extensive informal trail network at the summit of the mountain was mapped on a 1 meter $x 1$ meter grid from geo-referenced aerial photographs utilizing ERDAS software. Images from three different time periods were compared to establish changes in vegetative cover and species diversity. This information was combined with trail vector data of to investigate differences in vegetation within varying distance buffers from the trails. GIS data layers for trail vectors, signage, and other management features were acquired from existing data sets provided by the Park or with GPS field mapping. Geospatial analysis of the changes in vegetative cover over time allowed researchers and managers to view the effectiveness of management activities in preserving the naturalness of the area under heavy visitation. The lack of forest cover for this trail area makes it uniquely appropriate for this type of analysis although areas with seasonal leaf loss like MNF could also implement this methodology using late fall or early spring imagery.

\section{GIS in Forest Road Erosion Modeling}

In 2010, the USFS reported over 370,000 miles of roads in the National Forest Transportation System, the vast majority being unpaved forest roads originally developed to support logging activities (USFS, 2011). This mileage more than doubles the reported 152,000 miles of system trails on National Forests. Forest roads are a primary concern to resource managers as they are a primary contributor of sediment to streams and waterways second only to wildfire damage (Elliot, Foltz, \& Robichaud, 2009). As watershed protection is one of the primary purposes of forest management, extensive research on the prediction of erosion potential on forest roads as well as best management practices for minimizing road erosion has been conducted. Much of the recent work in road erosion modeling has involved GIS 
estimation procedures based largely on digital elevation grids. As unpaved linear management features on the landscape, forest roads have many similar characteristic to trails and the hydrology associated with each is closely related. The primary differences between roads and trails are: width, trails are generally much narrower; the level of engineering, roads are developed with mechanized excavation equipment and utilize cut slopes, ditching, and culverts where trails are primarily built with hand tools and utilize less sophisticated water control systems; use of aggregate materials to stabilize surfaces, these are seldom found on trails; and corridor use, roads have vehicular traffic as their primary use where trails have foot, horse, and bicycle traffic. Still, the investigation of trail erosion can be greatly enhanced by a familiarity with the methods and analytical approaches of forest road erosion research. While a comprehensive literature review of this topic is better suited for forest road studies, a cursory look at three specific methods is provided here to highlight how GIS approaches to forest road erosion research may be applicable to trail studies.

In a review of literature for their research, Anderson and MacDonald (1998) identify variables that are commonly studied due to their potential affect on the rate of road surface erosion: road gradient; amount, timing and type of road use; distance between drainage points; physical characteristics of the road; rainfall amounts and intensities; position on the slope; gradient and aspect of the slope across which a road is built; and micro-topography of the road surface. These are similar to variables used in the trail degradation research discussed earlier in this review. In their study of unsurfaced roads in St. John, USVI, the authors measured cross-sectional area (CSA) of 75 sample points located throughout the road networks under investigation, again an identical proxy variable as that used in many trail erosion studies. To allow for compaction, CSA was multiplied by a conservative soil density estimate to provide an estimate of soil loss. The road network was segmented into a series of drainages or continuous downhill slopes that end with a discharge point, most commonly a drain structure or a grade reversal. Road segments were digitized and entered into a GIS for further analysis. Field acquired attribute data on length, average width, average gradient, surface type, and an estimate of contributing overland flow were assigned to each segment as inputs for a modeling computer program written by the authors called ROADMOD. ROADMOD functions within GIS to calculate estimated annual sediment production of each segment and cumulative sediment for the entire network. This model only estimated sediment yield from the road surface itself and did not account for cut slope, fill slope, or ditch erosion that are commonly included in road erosion discussions. Soil erodibility and vegetative cover were also excluded from this research as study sites were close to one another and these variables were determined to be 
homogenous. Although no field verification of sediment production was done to validate the model, differences in model estimates of sediment for two watersheds with different amounts of road development corresponded well with turbidity differences in the adjacent bays. While GIS is integral to the operating ROADMOD, secondary data layers are not part of the spatial analysis and the system is used primarily for its data storage and vector connectivity capabilities in this model.

Another road erosion modeling system, WEPP:Roads (Elliot \& Hall, 1997) has been developed by the USFS as an extension of the landscape erosion estimation system Water Erosion Prediction Project (WEPP). This web based program allows forest managers to calculate road erosion estimates for single segments of road using soil type, climate, ground cover, and topographic conditions as well as road design characteristics (road design, geometry, surface characteristics, and traffic level). Users select environmental conditions and road design options from a series of drop down menus. Weighting values for the computer model are associated with each categorical selection as predetermined by the authors. While this system is useful for assessing a given section of road it does not allow for larger regional networks to be considered. To address this shortcoming, Brooks, Boll, Elliot, and Dechert (2006) created an automated approach utilizing GIS to calculate road design characteristics such as road gradient, drainage lengths (or upslope flow lengths), flow direction, and sediment delivery points. Additionally, all ground cover, soil, climate, and topographic variables used by the WEPP model are extracted from GIS data layers. Field surveys with GPS provide geo-referenced road center lines, locations of trail sections with cut slopes, fill slopes, and ditching as well as culvert and cross drain locations. This technique provides attributes for multiple road segments in a geo-database format, once attributes are assigned the system batch processes each segment through the WEPP:Roads calculations producing sediment yield estimates, thus it is named WEPP:Roads Batch.

A third model, Sediment Model 2 (SEDMODL2), developed by the Boise Cascade Corporation and the National Council for Air and Stream Improvement, more heavily integrates GIS data layers and geospatial processing capabilities (NCASI, 2005; Wold \& Dube, 1998). SEDMODL2 functions as an addon tool for ArcGIS to identify road segments with high potential for delivering sediment to streams. The system uses an elevation grid combined with road and stream information layers to produce a road surface erosion model. Automated spatial analysis provides estimates for background sediment and generation of sediment for individual road segments, finds road/stream intersections, and estimates delivery of road sediment to streams. The impetus for development of the model was a series of papers presented at the 2000 American Fisheries Society Annual Meeting that referred to the 20:80 rule for 
forest roads: $20 \%$ of the roads cause $80 \%$ of the sediment problem (NCASI, 2009). This finding is consistent with trail degradation literature which consistently finds that trail problems are isolated to small percentages of total trail mileage. Although the model can be run with only road centerline data (either actual from existing road networks or hypothetical from GIS or CADD based road plan proposals), results are greatly improved if, like the other two models, geo-referenced field data on locations of design features such as ditching and water diversion structures, vegetative cover on cut slopes, and road gradient are included. Rainfall, geology, soils information (depth and bulk density) are components of the model and are extracted from user supplied GIS data layers. An elevation grid with a minimum of 40 foot elevation intervals is integral to the modeling of road segment drainage lengths, road gradients, and overall watershed delineations computed by SEDMODL2.

These three methods represent a level of GIS integration and spatial analysis in linear route erosion modeling that far exceeds that of trail degradation studies. In a few exploratory studies the WEPP: Roads Batch model has been applied to trail erosion research (Breibart, 2007; Gaffer et al., 2008). In a field validation of the model data Gaffer et al. reported the WEPP model accurately predicted $24 \%$ of erosion rates on study trails, rates on $56 \%$ of trail sample points was overestimated by the model, and underestimated on the remaining $20 \%$. The authors included both unsurfaced roads used for foot travel and narrower traditional trails in their study. The correct prediction of erosion on $24 \%$ of trails is comparable to the regression models used for high mileage trail studies which utilize field measurements as the primary independent variables, many trails in these studies were also constructed on retired forest roads and railroad beds. Breibart utilized the WEPP: Roads Batch model to compare the erosion potential of two sets of existing trails with sets of proposed trails for the Lake Tahoe area. Model results demonstrated that with reduced maximum gradient from 16 to 10 percent, use of water diversion structures and grade reversals at a maximum 50 meter interval on steep trails, increasing buffer distances between trails and waterways, and decreasing trail width from the observed average of 1.6 meters to .6 meters, erosion was reduced with new trail designs by $98 \%$. Shortening of drainage segment lengths accounted for the highest reduction in erosion causing a $79 \%$ decline is sediment potential. Although the drainage length-erosion rate finding is consistent with the limited trail studies which have included this measurement, it may also indicate a bias in the weighting of this variable in the model.

While all GIS integrated road erosion models discussed have been field tested with forest road systems for verification, the limited use of these models with trails is inconclusive on their direct applicability. 
The reduced width, cut slope heights, ditching depths, and use of aggregates on trails may cause the weighting of these models to overestimate the amount of sediment produced. Additionally, weighting scores for environmental variables such as soils have been calculated for a limited number of categories for these models narrowing the sites to which these techniques can be implemented (Elliot et al., 2009). While limitations do exist, the active research and advancements in these GIS-based systems provides great potential for advancing trail degradation research and bringing a spatial component to this are of study.

\section{Spatial Accuracy of GIS Datasets}

Historically, prior to the invention of electronic mapping, maps served as secondary data sources in trail degradation studies providing attribute information that was not easily measured in the field. Bratton et al. (1979) derived management regions, some elevations, and geology from maps of Great Smokey Mountain National Park. Jubenville and O'Sullivan (1987) used aerial photographs to determine vegetation zones and topographic maps for slope estimates for stratifying their study sample trails. Garland (1990) derived variable values for lithology, rainfall, and slope from maps to create zonal classifications for his degradation sensitivity model. In a GIS, the process of deriving these values from other data layers is expedited through electronic queries. For example, Arrowsmith and Inbakaran (2002) computed slope, aspect, and seasonal sunlight availability from digital elevation models (DEMs), and soil and vegetation type from an ecological vegetation class layer in their study of trails in Grampian National Park, Australia.

Although efficient, the use of GIS to generate point and vector attribute values has been very limited in trail degradation research with authors citing high potential error and coarse granularity of secondary data as providing too generalized information to be useable at the site or trail level (Arrowsmith \& Inbakaran, 2002; Dixon et al., 2004). This is an unusual statement given that the scale, accuracy, and resolution of many GIS data layers are superior to that of paper maps used previously. The issue of appropriateness of GIS data to substitute for in situ data collection is one of measurability and positional accuracy at the scale of the phenomenon under investigation. For example, it would be challenging to measure maximum incisions of less than a foot for a point sample location from a geo-referenced aerial photograph but estimating bare width, multiple treads, or the number of social trails has been accomplished (Coleman, 1977; Hammitt \& Cole, 1998; Marion et al., 2006). As the scale of the 
phenomenon to be measured increases, the need for more sensitive measurement methodologies increases.

The judgment on appropriate scale and granularity of measurement is that of the researcher but the introduction of high resolution imagery, robust satellite image processing, and laser based topographic measurement systems integral to modern GIS data sets have blurred the lines. For example, high density Light Detection and Ranging (LiDAR) digital elevation models (DEMs) have been found to have sub-meter positional and elevation accuracies ranging from $10 \mathrm{~cm}$ to $80 \mathrm{~cm}$ even in densely forested mountain terrain (Reutebuch, McGaughey, Andersen, \& Carson, 2003; Vaze \& Teng, 2007). With this type of resolution, elevations, slope, aspect and other topographical variables for trails can be calculated with high confidence when combined with trail vectors of equal quality. The availability of these highresolution data sets is limited and the computing power needed to conduct analysis on large scales is prohibitive so their use may only be viable on a site scale such as in a problem analysis of specific degraded sites. Other secondary data sets such as soils, vegetation, land use, and climate variables seldom have this level of accuracy and must be evaluated separately for their appropriateness to the phenomenon under investigation (Montello, 2001).

\subsection{0: Summary}

In summary, this literature review has provided an overview of the philosophical underpinnings of recreation ecology and the major methods and findings of trail degradation research. As the focus of this study is on trail erosion, the review considers the range of degradation analyses but emphasizes the key relationships of recreational use, environmental factors, and managerial practices to the dependent erosion indicators. Expressed in the writings of prominent recreation ecologists there is a continued need to explore these relationships as they are unique to each trail setting and improvements in the predictive models and modernization of the investigation methods are needed. Inconsistencies in research findings for the relationship of trail grades, trail position, human and horse use, climate variables, elevation, and soils with erosion provide opportunity for further investigation. This study advances the field by providing another case study of trail erosion for a resource area not previously studied and explores options of adapting traditional methodologies using modern technology providing further evidence for resolving these inconsistencies. The review of GIS use in trail and forest road research identifies a gap between traditional recreation ecology field methodologies and modern 
techniques utilizing this geo-spatial approach. Although the differences of these forest pathways is noted, the methods of forest road erosion modeling provide a new approach that can link trail degradation research to broader spatial scale impact relationships, a need identified through this literature review. An understanding of previous research anchors this study within the recreation ecology field and provides a firm basis for methods and analytical approaches to guide this research. 


\section{Chapter 3: Methodology}

\section{1: Study Area}

Monongahela National Forest (MNF) is located in the eastern highlands of West Virginia in the midAtlantic region of the United States. The Forest was established in legislature by the Weeks Act of 1911 to protect the headwaters of the Potomac, Ohio, and Monongahela rivers and was officially designated in 1920. The first 7,200 acres for the Forest were purchased in 1915, and it has grown to include over 919,000 acres as of 2006 (USFS, 2006b). MNF spans ten West Virginia counties, extending approximately 112 miles from north to south. Six major river systems begin within the Forest boundaries giving the highlands a fitting nickname of the "birthplace of rivers." Elevations in the Forest range from approximately 1000 feet in the northeast corner near Petersburg, WV on the Potomac River to 4,863 feet at Spruce Knob, the highest point in the state, less than 30 miles to the southwest. Due to

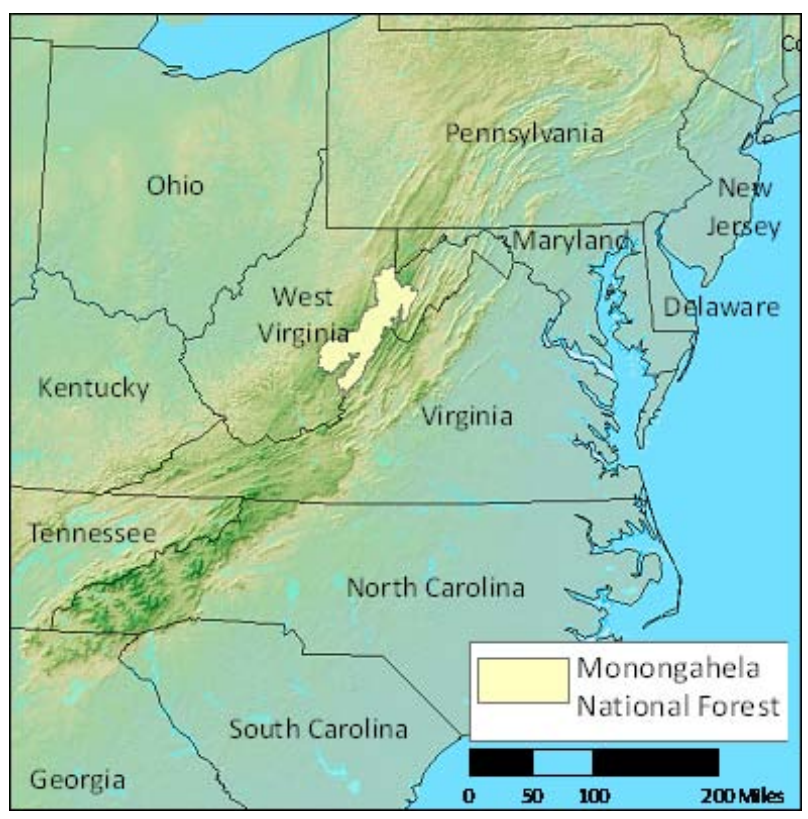

Figure 6. Location of Monongahela National Forest. the rain shadow effect of a high, central ridge system, annual precipitation rates range from 60 inches in the west central region of the Forest to less than 45 inches in the east. Much of the precipitation in the highlands falls in the form of snow with two ski areas adjacent to the Forest reporting over 200 inches of annual snowfall.

The broad ranges of precipitation and elevation combined with the latitude of the Forest provide the Monongahela with one of the most diverse plant communities of any National Forest. More than seventy species of trees can be found in MNF serving as the southern-most region for several northern boreal forest species and the northernmost region for species typical of the southern Appalachians. Black Cherry, sugar maple, and red oak are valued species for commercial production and wildlife habitat. Stands of red spruce are found in the higher elevations, mixed northern hardwoods are most common throughout the forest, and oak-white pine communities are found in the dry eastern regions. 
The geology of the Forest is roughly divided into two regions, the western Appalachian Plateau and the eastern Valley and Ridge formation. The dividing line between these regions is the Allegheny Front, a north-south ridgeline that forms the eastern edge of the Appalachian Plateau and has the highest elevations in the state, contributing to the state's nickname, "the mountain state." In the Valley and Ridge regions, valleys are primarily composed of shale and siltstone, mountain ridges resistant sandstone and limestone. The Appalachian Plateau is rich in coal, and its formation consists of cyclic sequences of sandstone, red beds, shale, limestone, and coal. Exposed sandstone at the edge of the Allegheny Front produces spectacular cliff lines and high plateaus (Lessing, 1996). Just to the east of the Allegheny Front are a series of short ridges with intermittent knife-edge protrusions composed of Tuscarora quartzite, also known as Tuscarora sandstone (Dasher, 2001). One of these ridges forms the centerpiece to the Seneca Rocks region of the Spruce Knob-Seneca Rocks National Recreation Area, a special management zone of the Forest, and a popular tourist destination for day hiking and rock climbing.

Soil structure in the Forest also varies greatly depending on the geologic sub-strata and physical geography. According to the USDA Natural Resource Conservation Service a high percentage of the soils in MNF have "very limited" suitability for path and trail development (USDA-NRCS, 2010) (Figure 7). Predominant reasons for these limitations are high water tables, steep slopes, stoniness, tendency to pond or flood, and soils prone to water erosion. Soils at higher elevations tend to be thin with high water tables due to rock substrate and fragipan morphology. Hydric soils are also found in various regions of the forest supporting bogs and wetlands.

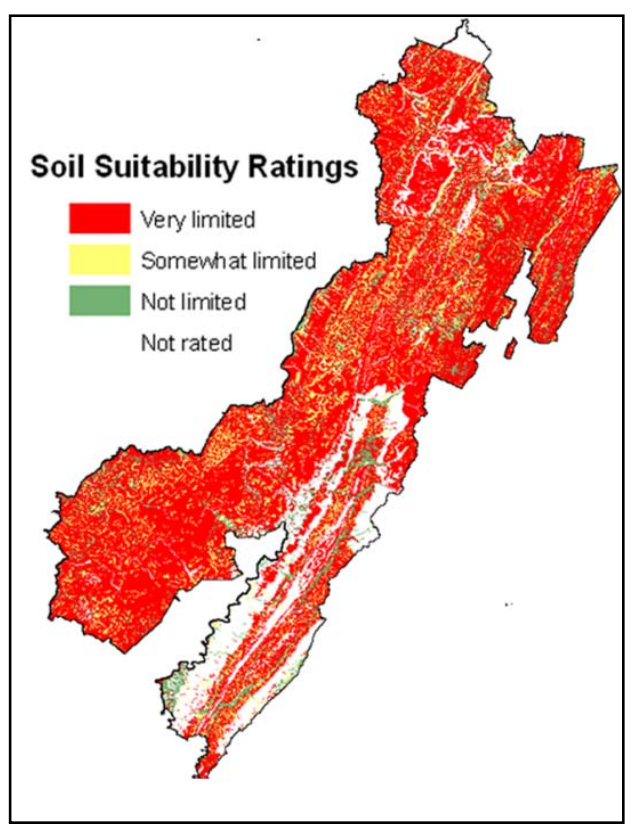

Figure 7. Suitability of soils for trail development in MNF (USDA-NRCS, 2010).

\section{Forest Management}

MNF is divided into North and South regions and six ranger districts (Figure 8). The Forest has eight congressionally designated wilderness areas totaling 115,826 acres. Five special management areas have been designated which emphasize recreation management priorities, these include: Spruce Knob - Seneca Rocks National Recreation Area (NRA), the first designated NRA on any National Forest, Cranberry Backcountry, Seneca Creek Backcountry, Canaan Mountain Backcountry and the Highland 
Scenic Highway. The Forest has some of the most remote areas of the mid-Atlantic with $21 \%$ of the acreage in the Semi-Primitive Non-motorized class of the Recreational Opportunity Spectrum (ROS). Additionally, $35 \%$ of the Forest is Semi-Primitive Motorized, $44 \%$ Roaded Natural, and less than $1 \%$ is classified as Rural or Urban.

\section{Forest Visitation}

In 2004, MNF reported 1.3 million site visits in the National Visitor Use Monitoring (NVUM) survey (USFS, 2004). Approximately 39,000 visitors participated in activities in the Forest wilderness areas. Table 5 lists the most popular recreational activities identified by the survey respondents.

Table 5

Most Popular Recreational Activities Reported by 2004 NVUM Respondents (USFS, 2004).

Activity

1. Viewing Natural Features (scenery, flowers, etc.)

2. Viewing Wildlife, Birds

3. Hiking/Walking

4. General/Other (relaxing, hanging out, escaping noise and heat)

5. Driving for Pleasure

6. Fishing

7. Nature Center Activities

8. Camping, Developed Sites

9. Picnicking

10. Downhill Skiing
Percent Population

$59 \%$

$55 \%$

$47 \%$

$46 \%$

$35 \%$

$26 \%$

$20 \%$

$15 \%$

$15 \%$

$11 \%$

Note: Bicycling (mountain biking) was 5.1\%, and horseback riding was .25\%. 


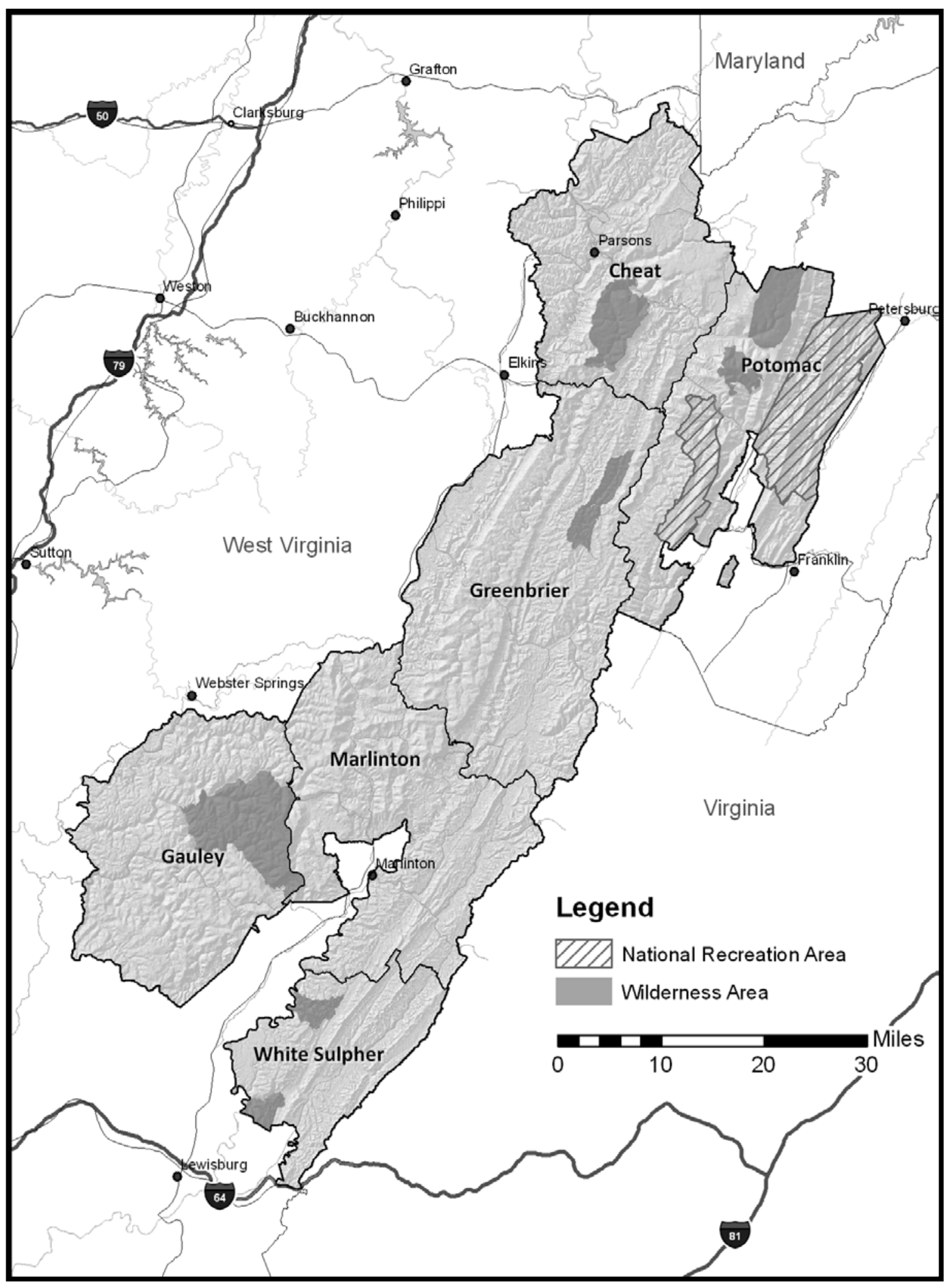

Figure 8. Monongahela National Forest Ranger Districts. 
Trails provide access for wildlife viewing, hiking, bicycling, and horseback riding constituting one of the most frequently used recreational resources in the Forest. The majority of respondents to the 2004 NVUM were from West Virginia where the MNF constitutes $52 \%$ of the publicly available recreation land in the state. As the Forest is within half a day's drive of $50 \%$ of the U.S. population, approximately three hours west of Washington, DC, many urban visitors visit the Forest for its outdoor recreation resource opportunities. In 2007, the travel and tourism industry generated $\$ 1.8$ billion in gross revenue for the state, the third largest industry for West Virginia. Visits to natural areas in the state account for $18 \%$ of all overnight leisure trips from non-West Virginians, with 10\% reporting hiking as their top activity (Runyan, 2009). Although outdoor recreation only represents a small porting of the state's gross revenues, it constitutes a large percentage of revenues in the rural counties which intersect with the Forest.

\section{Trail Infrastructure in Monongahela National Forest}

Formal trail development in the Monongahela began in 1916 with 66 miles of planned trail construction in the original Forest budget. The Civilian Conservation Corp played a major role in trail construction and development of other recreational facilities during nine-years of continuous work in the Forest beginning in 1933 (McKim, 1970). President John F. Kennedy's 1961 “Development Program for the National Forests," provided resources for trail development during its 10 year lifespan adding an additional 35 miles of trails to the transportation network of the Forest.

At the time of this study, 220 trails totaling more than 860 miles comprise the official system trails of MNF. Approximately 750 miles of trail are unsurfaced paths with the remainder either gravel, paved, or wooden boardwalk. Fifty-five percent of the trails are located in Semi-Primitive ROS class regions, 45\% in Roaded Natural, and the remainder in Urban-Rural areas.

\section{2: Study Trail Selection}

The primary source of trails evaluated in this study was a Forest-wide trail management inventory evaluation conducted on behalf of the National Forest by this researcher to assess the consistency of trail management class assignment. Thirty-six trail sections were surveyed ranging from .2 to 6 miles. Twenty-three of the trails were selected by district recreation managers to represent good examples of trails that complied with one of the six trail management classes of the Trail Condition and Assessment Survey (TRACS) system (USFS, 2006a). An additional thirteen trails were selected at random from the 
remaining trail inventory to compare with those the managers had selected. In all, 81 miles of trail were surveyed representing $10 \%$ of the total trail mileage in the Forest.

From this initial sample, those trails that had natural soil surfaces for at least $90 \%$ of the survey length were purposefully selected for this analysis. Twenty-three of the thirty-six trails met this criterion. This subset accounted for $83 \%$ of the total length surveyed and $98 \%$ of the total observed trail problems as defined in the problem census methodology. Trails sampled represented all six ranger districts within the Forest and ranged in length from .5 to 6 miles. Using manager estimates for recreational use levels, eight trails were high use, eight trails were medium use, and seven trails were low-use.

\section{3: Field Methodology}

Trail surveys were conducted during the summer of 2005 by research staff from West Virginia University Department of Recreation, Park, and Tourism Resources. Trail surveys consisted of both systematic point sampling at fixed intervals along each trail and a full census of defined problems. At the time of this research no inventory of trail degradation problems had been previously established so standard definitions from the works of Marion, Leung, and Cole were initially used with some adjustment after field testing (see Appendix A).

\section{Point Sample Method}

Sampling interval distances were established based on the length of trail being surveyed. For trails less than or equal to 2 miles the sampling interval was 300 feet; trails over 2 miles in length were sampled at 600-foot intervals. This methodology was adopted due to the time requirements for each survey, approximately one hour per nine sample points. With the ratio established, each trail could be surveyed in a single day although some were segmented into two days. Distances were established using a four foot circumference measuring wheel rolled along the trail surface starting at the most obvious trail head, generally marked with a post, or center point of a trail intersection. At each sample point, a GPS point was established with a minimum Positional Dilution of Precision (PDOP) of 6 and a minimum of 60 data points collected for each position. This standard of data quality was selected to match the U.S. Forest Service mapping standards. Positions not meeting these quality standards were excluded from the GIS analysis. The GPS unit was positioned at the edge of the trail and left to run for a minimum of 2 minutes, set to record points at 2-second intervals, or until 60 points could be established. 
Other field observations collected at each point included: trail position, trail grade, trail aspect, majority landform aspect, majority landform grade, tread width, bare soil width, clearing width, clearing height, cross trail slope, maximum incision, soil type, brush type, and overhead canopy. Maximum post construction depth along a perpendicular transect was used to measure maximum incision. Details on how each of these variables was measured are presented in the field manual found in Appendix A. In addition to these variables, two digital photographs were taken at each survey point, one looking forward down the trail and one looking down at the tread. All GPS positions, variable data, and photographs were labeled using the Forest Service trail identification numbers and the on-trail measuring wheel distance. This labeling method provided each sample point with a unique identifier and allowed the three data types to be linked in a relational database system for future analysis.

\section{Problem Census Method}

In addition to the point sample method described above, a simultaneous census of observed predefined problems, or trail degradation indicators, was also conducted. For this study, four problems were assessed:

Linear Erosion: Sections of tread $\geq 10$ feet with soil erosion exceeding 5 inches in depth within current tread boundaries running down the trail.

Lateral Erosion: Sections of tread $\geq 5$ feet with soil erosion exceeding 5 inches in depth at the upper edge of the trail (erosion onto the trail), across the tread or at the lower edge of the trail. Damaged water diversion structures were included if their downhill edge has eroded into the tread corridor.

Muddy Soil: Sections of tread $\geq 10$ feet with seasonal or permanently wet and muddy soils that show embedded foot or hoof prints $\geq 1$ inches.

Multiple Treads: Sections of trail $\geq 10$ feet that have 2 or more distinct treads or where the trail has recently been displaced from its original location due to an impact or obstruction.

For each problem, the wheel distances where the criteria for that problem began and ended were recorded. A separate log for each trail was kept so that problem references to the trail identification number could be retained.

In addition to these problem features, management features along the trail were also recorded. Recorded management features included water bars, grade reversals, switchbacks, bridges, trail surfacing material, culverts, stream crossings, and trail intersections. Water diversion structures were 
assessed for their condition and performance in serving the function of removing water from the trail. Switchbacks were categorized based on the presence or absence of drainage diversion structure.

The systematic point sample and census field methods described above were derived from those established by Dr. Jeff Marion of the U.S. Geological Survey at Virginia Polytechnic Institute and State University, Blacksburg, Virginia. These techniques are also well established in the literature as previously discussed.

\section{4: Variable Selection}

Two models of trail erosion analysis are tested in this study, one using maximum incision as a proxy measure in a point sample methodology, and one using total feet of "severe" linear erosion from the problem assessment census. Both models are tested as the literature indicates that $50 \%$ of trail erosion is missed by point samples greater than 100 meters apart where the census approach captures all instances of erosion as defined in the field guide (Leung \& Marion, 1999a). The field method utilized in this study attempted to match data collection protocols from previous trail degradation research in order to allow for data comparison. This approach was followed for the type, technique, scale, and frequency of field collected variables for both sampling methods. GIS was used to extract values of interest from geo-referenced secondary data sources (GIS Extracted) and for derivation of new variable values through a combination of GIS secondary data sources and field collected data (GIS Derived).

\section{Point Sample Analysis}

To test the hypothesis that trail erosion regression models can be improved by integrating GIS Extracted and GIS Derived data, three iterations of regression analysis were conducted from the point sample data (field collected variables only, GIS Extracted and GIS Derived variables only, and combined field and GIS variables - see Table 6 for variable list). Stepwise regression was used for each level of analysis to build models with the most significant variables.

Descriptions and measurement processes for the biophysical and managerial field collected variables are provided in Appendix A. Information on GIS extracted and GIS derived variables are provided in subsequent sections of this methodology. Recreational use estimation followed a common methodological practice of managerial estimates. Each regional recreation manager for the MNF provided an independent estimate of the relative use levels for each trail in their district. The two regional coordinators and the Forest recreation coordinator reviewed the list and made adjustments as 
appropriate. This provides a subjective estimate of trail use but was the best data available at the time of the study and is consistent with other previous trail degradation research.

Table 6

Field Collected, GIS Extracted, and GIS Derived Independent Variable List for Point Sample Analysis

\begin{tabular}{lll}
\hline Biophysical & Managerial & Recreational Use \\
\hline
\end{tabular}

Field Collected Variables

Landform Slope

Forest Canopy (Yes/No)
Trail Position

Trail Alignment

Trail Grade

Bare Width
Trail Use (Hi/Lo)

Horse Use (Yes/No)

GIS Extracted and Derived Variables

Mean Annual Rainfall

Estimated Flow Length

Mean Winter Temperature

Soil Erodibility Factor (k)

TRMI

Elevation

This combination of variables is derived from the most consistent variables used in previous studies and several less commonly used variables from previous research that were shown to be significant. Field collected management variables (trail position, trail alignment, trail grade, and bare width) and trail usage variables (use intensity, use type) are the most universal variables from previous studies. Measurement of upslope flow length from point sample locations has been conducted previously with field measurements but is applied less frequently due to the additional time required. A GIS estimation of this distance is more common in the forest road erosion research as previously discussed.

Topographical relative moisture index (TRMI) is the only variable that was not incorporated into previous research although it is closely related to the landform curvature variable used by Cakir (2005). 


\section{Linear Trail Segment Analysis}

In the majority of trail degradation literature reviewed, problem assessment census data were presented in a descriptive manner with limited attempts to establish causal relationships or predictive models. Frequency, extent, and relative location (wheel distances from trailhead) of trail degradation occurrences provide a general picture of trail condition which has strong managerial application for planning trail maintenance. By placing this information in a GIS framework and geo-referencing the locations as accurately as possible using the linear referencing tools of the ArcGIS system, additional analysis and modeling is possible. For this component of the research, each trail was divided into 600foot segments based on the wheel distances measured in the field. This length was selected as it was the common interval of the field point sample distances for all trails. A description of the linear referencing method for placement of field data, calibration, and extraction of segment data is provided below. For this analysis, the dependent variable selected was the number of feet of linear erosion in each 600-foot segment. Field collected biophysical variables were not used in this analysis as they were collected at the end of each segment and may not represent average conditions along the trail.

Management feature data collected during the trail surveys was included to assist in the derivation of upslope flow lengths (see description below). Recreational use levels from managerial estimates (high and low) were also retained for this analysis. Additional variables were extracted from secondary GIS datasets (Table 7).

Table 7

Linear Trail Segment Analysis Variables

\begin{tabular}{lll}
\hline Biophysical & Managerial & Recreational Use \\
\hline
\end{tabular}

Field Variables

Trail Use (Hi/Lo)

GIS Extracted and Derived Variables

Mean Elevation

Mean Annual Rainfall

Mean Winter Temperature

Majority Soil Erodibility Factor (k)

Majority TRMI
Feet in Designated Wilderness

Maximum Estimated Flow Length

Mean Slope 


\section{5: GPS Data Collection and Handling}

\section{Start and End Points}

In addition to the sample points, a starting point at wheel distance zero and an ending point GPS position were recorded. These positions used the same data quality standards and labeling previously stated.

\section{Trail Vector Creation}

An attempt was made to create an accurate trail vector which would match the lateral geographical position of the trail to a sub-meter confidence level. Data vertices were collected every two seconds with a minimum PDOP of 6 . As only one GPS unit was used for both point sample positions and vector recording, the unit was toggled between the point feature and linear feature functions at each stopping point. When forward movement resumed the linear feature was continued instead of creating multiple segments. Stopping linear data collection any time the surveyor stopped forward movement and maintaining a steady forward pace while moving improved the quality of the vector.

\section{GPS Data Post Processing}

All GPS data were post-processed using the Garmin GeoPathfinder Office software. All points and vectors were differentially corrected using regional online GPS base-station data from the West Virginia Department of the Environment. Additionally, vector paths were hand cleaned to remove anomalies and repetitive vertices. All point and vector data were then exported to individual ArcGIS shape files using an UTM 1983 NAD Zone 17 projection. The GPS unit used for this data collection was a Garmin GeoExplorer III with touchpad; this is a resource grade GPS unit with potential uncorrected positional accuracies of less than 1 meter diameter.

\section{Point Sample and Problem Census Data Handling}

In the field, all point sample and problem census data were recorded on waterproof paper forms printed with appropriate data cells. This information was reviewed and manually entered into a Microsoft Access relational database so that it could be linked to GIS data layers during the analysis phase. Trail number and wheel distances served as the unique identifier for each sample point and point features of the census, beginning wheel distances of linear trail features were used with trail number to identify these items. 


\section{6: GIS Methods}

Environmental Systems Research Institute (ESRI) student version ArcMap 9.3.1 with Spatial and 3D Analyst extensions was used for extraction of values from secondary GIS data sets and for derivation of estimated trail flow lengths.

\section{Secondary Data Attribute Value Extraction}

All GPS point sample data points were added to the GIS system to allow for high precision positioning of sampling points $( \pm 2.7 \mathrm{~m}, M=.78 \mathrm{~m}, \mathrm{SD}=.48)$. Secondary data sets for elevation, soils, annual precipitation, and mean winter temperature were added to the map file. Elevations were extracted from 1:4800 scale USGS Statewide Addressing and Mapping Board (SAMB) 3-meter raster grid with vertical accuracies of \pm 10 feet. Soils data were extracted from USDA Soil Survey Geographic Data Base (SSURGO) files; positional accuracies for these data are undetermined but are considered the best source available for secondary files. Precipitation and annual winter data were derived from historical records of statewide National Weather Service monitoring stations. Precipitation amounts were elevation corrected and temperature was averaged for the months of December to March to provide a mean winter average. A grid for Topographic Relative Moisture Index (TRMI) (M. G. Anderson, Merrill, \& Biasi, 1998) was calculated from the digital elevation model using flow accumulation and slope to estimate the potential amount of moisture moving from one grid cell to another.

Using the "Surface Spot" function of 3D Analyst, values from each secondary data source were extracted for each sample point. Values for elevation, precipitation, and temperature were interpolated values from the eight nearest raster grid cells to the sample point. Soils data, TRMI, and soil erosion factor ( $k$ factor) used the majority value from the eight surrounding cells. For 600 -foot linear segments of trail, zonal statistics were created for each variable using the trail segments as the zones. For elevation, precipitation, and temperature, the zonal mean was used; for TRMI and soil erosion factor, the zonal majority value was used.

\section{Linear Data Geo-Referencing}

In order to position census log data in the GIS system a procedure known as linear referencing was used. This technique is common among forest road and highway management inventories. Field recorded wheel distances were assigned to each trail to create measured trail routes. Routes were then calibrated using the GPS points and associated wheel distances. This step increases the accuracy of linear positioning of trail data by isolating ground measurement error due to surface roughness and 
obstacles between each GPS point instead of averaging the error across the entire length of trail. Once trail measurements are calibrated, point features and linear features from the Microsoft Access database are added as route event layers. These layers are then converted to point and polyline shape files with appropriate geo-referencing for use in subsequent analysis. Calculated horizontal positional errors of test points showed accuracies of \pm 20 feet.

\section{Estimated Upslope Flow Length Derivation}

On-trail flow lengths were estimated using the hydrology tools of ArcMap Spatial Analyst. These estimates are general indicators of the potential distance water can move down a trail unobstructed. The length is a calculation of continuous downward angled slope of the trail surface without encountering a diversion structure. Detailed ArcMap instructions for the derivation of these values are provided in Appendix B. Elevations used to calculate trail surface slope were extracted from 1:4800 scale digital elevation models discussed previously in the elevation extraction procedure for point samples. Management features recorded in the trail census, water bars, grade reversals, stream crossings, bridges, and switch backs with run out ditches were used as pour points for on-trail water flow. Additionally natural breaks in the topography from uphill to downhill served as dividers to continuous flow.

GIS estimated upslope flow length values were extracted to trail sample points utilizing the Spatial Analyst Extract function. Values for 600-foot trail segments were extracted from zonal statistics for each trail segment, maximum and mean flow lengths were used for analysis.

\section{Trail Section Slope Estimate}

Utilizing the trailbed elevation grids generated for calculation of the flow length model, ArcMap 3D Analyst was used to generate a slope grid. The slope tool evaluates the maximum change in elevation from each cell. Using the "Percent Rise" setting for the tool provides a measure on the same scale as that measured in the field methodology. Zonal statistics for each 600 -foot trail section were calculated from the trail slope grids. Resulting values were saved as a table in a Microsoft Access Personal Geodatabase table so they could be joined with other trail segment data for statistical analysis. Mean slope percents were used for analysis as they show the trends of each trail section.

\section{7: Statistical Analysis}

All point sample, census, and linear trail segment statistical analysis was conducted in IBM SPSS Statistics 18 software. General descriptive statistics for linear feet of observed linear erosion were 
extracted using the ArcMap Linear Referencing Overlay tool to find the intersection of linear erosion events with each 600 -foot section of trail. 


\section{Chapter 4: Results}

\section{1: Introduction}

The results presented here are divided into three main sections defined by the sampling unit used for each. The first section, Point Sample Analysis, references data collected at 569 individual sampling points systematically distributed along the length of the twenty-three study trails. Variables are organized within this section by variable type (dependent and independent) and categorically following the theoretical framework reviewed previously: recreational use, biophysical, and managerial. Descriptive statistics are provided as well as statistical analysis of the predictive relationship of independent and dependent variables utilizing analysis of variance and linear regression. Field collected variables are differentiated from data extracted from secondary geographic information system data layers. In section two, results of a second approach of trail impact research, the Problem Census Method, describing predefined impact features are presented. Descriptive statistics and relational analysis of linear erosion problems on MNF trails is provided. In section three, the results from a relatively new approach to trail impact research, linear segment sampling, are presented. Descriptive statistics for impacts on 546, 600-foot sections are provided. Results are arranged similarly to the point sample section with categorical groupings by variable type. Independent variables from extracted and derived secondary GIS data sources are regressed with linear segment impact data.

For each sampling method, variable units, measurement grouping, and statistical analyses were selected to match those found in recent recreation ecology literature. Analyses were conducted to illuminate possible patterns to support the objectives of this research:

1. Identify and characterize trail erosion patterns of purposefully selected trails in Monongahela National Forest using field data and traditional impact modeling statistical analysis;

2. Describe and model trail erosion patterns of purposefully selected trails in the Monongahela National Forest using GIS extracted data from secondary data sources and GIS derived data;

3. Model trail erosion of purposefully selected trails in the Monongahela National Forest using a combination of field data, GIS extracted data from secondary data sources, and GIS derived data; and,

4. Compare and contrast the findings and merits of field based, GIS based, and GIS-Field mixed method approaches to trail erosion modeling. 
5. Compare and contrast three sampling and field measurement methods used to model trail erosion.

Specific hypotheses that are tested for this data are:

Point Sample

- Recreational Use factors (Volume of Use and Horseback Riding) are linearly independent of maximum trail incision.

- Managerial factors (Trail Grade, Trail Alignment, Trail Position, and Estimated Upslope Flow Length) are linearly independent of maximum trail incision.

- Biophysical factors (Canopy, Landform Slope, Elevation, Mean Annual Precipitation, Mean Winter Temperatures, Soil Erodibility Factor, and TRMI) are linearly independent of maximum trail incision.

- All Recreational Use, Managerial, and Biophysical factors combined are linearly independent of maximum trail incision.

- Field collected variables and GIS extracted or derived variables explain equal amounts of variance in the dependent variable maximum trail incision.

Linear Segment Sample

- Recreational Use factors (Volume of Use and Horseback Use) are linearly independent of the cumulative linear length of erosion per trail segment.

- Managerial factors (Mean Trail Grade and Mean Estimated Upslope Flow Length) are linearly independent of the cumulative linear length of erosion per trail segment.

- Biophysical factors (Mean Land Grade, Mean Elevation, Mean Winter Temperatures, Mean Annual Precipitation, Mean Soil Erodibility Factor, and Mean TRMI) are linearly independent of the cumulative linear length of erosion per trail segment.

- All Recreational Use, Managerial, and Biophysical factors combined are linearly independent of the cumulative linear length of erosion per trail segment dependent variable. 


\section{2: Point Sample Results}

\section{Introduction}

Point samples were collected at 600-foot intervals from twenty-three trails covering a total of 63 miles. Five hundred sixty-nine individual sampling points were evaluated for maximum incision, bare width of trail, trail grade, trail alignment, landform grade, and forest canopy. Additionally, each point was georeferenced to latitude and longitude coordinates within two meters using a resource grade geographic positioning system. With sample points geo-referenced, additional data from existing electronic map sources for soils, elevation, precipitation, and average winter temperature were assigned to each point. A measure of upslope length for water traveling down the trail to the sample point was estimated for each point using landform elevation data.

\section{Dependent Variable - Maximum Incision}

Maximum incision, the deepest point below the original construction surface, serves as a proxy variable representing the dependent erosion measure for the point sample method. For the study, 569 valid cases of maximum incision, $100 \%$ of the sample points, were measured exhibiting values ranging from zero to 22 inches in depth, with a mean of 2.06 inches $(S D=1.88)$ and median of 1.5 inches. Values for this variable display positive skewness in their distribution (skewness $=4.08$, ses $=.102$ ) and are leptokuritic with a kurtosis statistic of 29.3 (sek=.204). Thirty-four cases (6\%) meet the required depth criteria ( $\geq 5$ inches) established in the problem assessment method of this study for severe erosion; fifteen cases had no measureable incision. The distribution of incision values indicates a trail system in relatively good condition with only localized severe erosion problem areas. The relatively narrow range of erosion values provides limited variance to be examined by the predictive models used in the analysis of trail erosion for the study trails.

The skewness and kurtosis analysis indicates the presence of outliers in the data. Visually it is easy to see in Figure 9 that only a handful of measurements over eight inches in depth are present. As this is the only dependent variable and will be used in various statistical tests which are sensitive to deviations from normal distributions, removal or transformation of outliers is desirable but is minimized. To maintain the most cases in the data set, only measurements greater than three standard deviations from the mean were removed, values greater than 7.7 inches. The resulting data have a mean of 1.89 $(S D=1.31)$, median $=1.50$, skewness $=1.47($ ses $=.103)$, and kurtosis $=2.42($ sek $=.206)$. Although still showing a slight positive skew and taller than a normal distribution, this subset of maximum incision 
data provides a stronger central tendency while maintaining $98 \%(n=559)$ of the field measurement data. This subset of cases is used for the remainder of the point sample analysis which reference maximum incision.

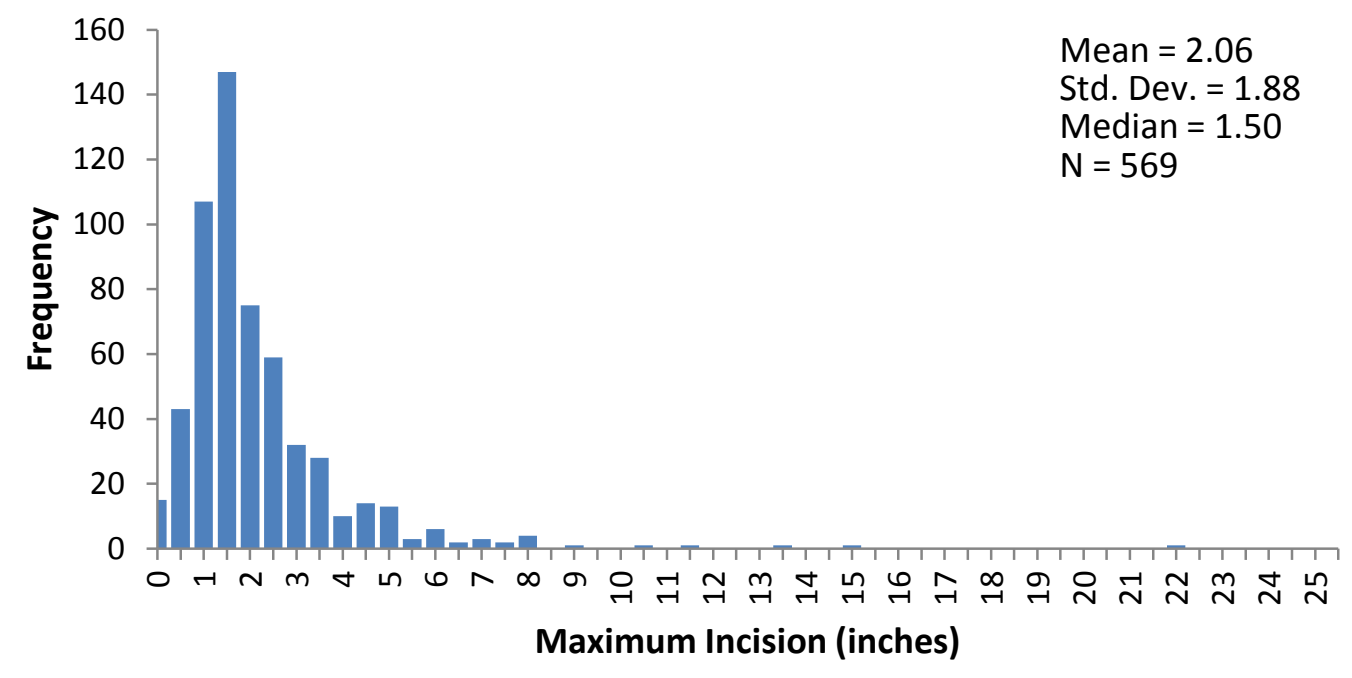

Figure 9. Distribution of Point Sample Maximum Incision values in inches for Monongahela National Forest study trails.

Table 8 provides an overview of average maximum incision values for each trail in the study; trails are sorted from highest mean incision to lowest. The table shows that some incision was observed on every trail but on average, no trail exceeded the five inch severe erosion criteria of the problem assessment method.

\section{Independent Variables}

\section{Recreational Use Variables}

Recreational use is defined by both the volume of use and the type of use. Volume was estimated by Forest trail managers and is distributed across sample trails with eight high-use trails, eight moderateuse, and seven low-use (Table 8). Managers also provided data on the types of use, foot travel, horse, and mountain bike that were found on each trail. Field observations were used to verify this information with evidence of foot prints, bicycle tracks, and hoof prints. All trails exhibited signs of human foot travel, nine trails had mountain bike travel evidence, and eight trails showed evidence of horse travel. Only three trails showed evidence of all three use types. Horse and mountain bike 
evidence correlated poorly with manager estimates so field observations were used for this analysis. No determination was made of the volume of each different mode of travel.

Table 8

Point Sample Distribution by Trail With Trail Usage and Maximum Incision

\begin{tabular}{|c|c|c|c|c|c|}
\hline \multirow[b]{2}{*}{ Trail } & \multirow{2}{*}{$\begin{array}{l}\text { Trail Usage } \\
\text { Class }\end{array}$} & \multirow{2}{*}{$\begin{array}{c}\text { \# of } \\
\text { Sample } \\
\text { Points }\end{array}$} & \multirow{2}{*}{$\begin{array}{c}\text { Trail } \\
\text { Length (Feet) }\end{array}$} & \multicolumn{2}{|c|}{$\begin{array}{l}\text { Maximum Incision } \\
\text { (inches) }\end{array}$} \\
\hline & & & & Mean & Std.Dev. \\
\hline 511 Blackbird Knob & High & 33 & 9290 & 3.60 & 3.04 \\
\hline 529 Swallow Rock & Medium & 30 & 17583 & 3.60 & 1.44 \\
\hline 104 Fire \#3 & Medium & 12 & 3920 & 3.23 & 1.44 \\
\hline 502 Landis & High & 25 & 7379 & 3.01 & 1.29 \\
\hline 350 Strip Mine & Low & 36 & 21152 & 2.70 & 2.80 \\
\hline 121 Shingletree & Medium & 38 & 23182 & 2.60 & 3.64 \\
\hline 520 Beaver Dam & Medium & 7 & 3828 & 2.29 & 1.14 \\
\hline 514 Red Creek & High & 34 & 9388 & 2.24 & 2.46 \\
\hline 438 Gauley Mountain & High & 27 & 27180 & 2.06 & 0.70 \\
\hline 143 Dobbin House & High & 25 & 14578 & 2.04 & 1.45 \\
\hline 207 Big Beechy & Medium & 36 & 36674 & 1.85 & 1.19 \\
\hline 130 Green Mountain & Low & 26 & 7813 & 1.84 & 1.39 \\
\hline 315 Camp Five & Medium & 14 & 8557 & 1.68 & 0.75 \\
\hline 684 Meadow Creek & Medium & 26 & 15480 & 1.57 & 0.71 \\
\hline 685 Virginia & High & 12 & 3406 & 1.56 & 1.19 \\
\hline 214 Tumbling Rock & Medium & 24 & 13972 & 1.47 & 1.11 \\
\hline 456 Two Lick & High & 44 & 26097 & 1.47 & 0.50 \\
\hline 212 Lick Branch & Low & 17 & 11360 & 1.40 & 0.75 \\
\hline 414 Turkey Point Connector & Low & 14 & 8407 & 1.39 & 0.70 \\
\hline 256 Barrenshe & Low & 28 & 27187 & 1.23 & 0.54 \\
\hline 131 Otter Creek & High & 25 & 14850 & 1.20 & 0.40 \\
\hline 215 Bishop Knob & Low & 22 & 13381 & 0.99 & 0.41 \\
\hline 305 Stone Camp Run & Low & 14 & 7996 & 0.73 & 0.50 \\
\hline
\end{tabular}




\section{Use Volume}

Point samples on trails of each use volume level were highest for the high volume trail estimates ( $n=219)$ and lowest for the low volume trail use estimates ( $n=157)$. Analysis of variance in mean maximum incision for each use level indicated significant differences $(F(2,566)=6.09, p<.005)$ (Table 9). Post hoc, Bonferroni test indicated that maximum incision of high-use trails $(M=2.00, S D=1.27)$ was significantly greater than and low-use trails $(M=1.43, S D=1.15)$, maximum incision on medium use trails $(M=2.14$, $S D=1.40)$ was also significantly greater than low-use trails. The pairwise comparison of high-use trails with medium use trails was non-significant.

Table 9

Analysis of Variance in Maximum Incision for Recreational Use Volume Categories

\begin{tabular}{lccc}
\hline $\begin{array}{l}\text { Manager Estimated } \\
\text { Visitor Use Level }\end{array}$ & $\mathrm{N}$ & $\begin{array}{c}\text { Mean } \\
\text { Maximum Incision }\end{array}$ & Std. Dev. \\
\hline High & 215 & 2.00 & 1.27 \\
Medium & 191 & 2.14 & 1.40 \\
Low & 153 & 1.43 & 1.15 \\
\hline Total & 559 & 1.89 & 1.31 \\
\hline
\end{tabular}

Maximum Incision Between Groups: $F(2,556)=14.25, p<.005$

\section{Creation of a Binary Use Volume Variable}

As usage estimates were made through expert opinion and not based on objective data such as field counts or other historical records of trail use, values must be considered with caution. Resolution of three use classes is even more difficult. Given there is no significant difference between high and medium recreational use estimates for the dependent variable maximum incision, in the remainder of this analysis recreational use volume is converted to a binary variable of High-Medium and Low-use categories (Table 10). 
Table 10

T-Test Results for Maximum Incision of High and Low Recreational Use Volume Categories

\begin{tabular}{lccc}
\hline $\begin{array}{l}\text { Manager Estimated } \\
\text { Visitor Use Level }\end{array}$ & $\mathrm{N}$ & Maximum Incision & Std. Dev. \\
\hline High- Medium & 406 & 2.07 & 1.33 \\
Low & 153 & 1.43 & 1.15 \\
\hline Total & 559 & 1.89 & 1.31 \\
\hline
\end{tabular}

Maximum Incision Between Groups: $t(557)=5.22, p<.005$

Use Type

Three use types were estimated for the sample, human foot travel, mountain bike, and horseback use.

The literature indicates that there is no significant difference between foot travel and mountain bike use therefore this relationship was not tested in this analysis. Horse use was observed on eight of the twenty-three study trails. Observations of the density of hoof prints indicated that the level of horse use varied by trail but no quantitative value was assigned to this variable. The field data show a significant increase in maximum incision of .32 inches on trails with horse use $(n=234, M=2.08, S D=1.43)$ when compared to those without $(n=325, M=1.76, S D=1.21), t(557)=2.88, p<.005)$.

\section{Managerial Variables}

Characteristics of the trail tread design, trail grade, trail alignment, and trail position, were measured in the field and the resulting distributions are presented here for the 559 cases. To increase comparability with previous research trail grade and alignment are also grouped into categorical variables commonly found in the literature. Similarly, an interaction between trail grade and alignment is commonly tested in trail impact research; therefore, this analysis has also been included. Finally, a variable derived from on-trail elevation data, GIS Estimated Upslope Length, is analyzed. This is an experimental variable based on similar calculations for forest roads.

\section{Trail Grade}

Trail grade values ranged from $0-46 \%$ with a mean of $7.48(S D=6.96)$. Frequency distribution shows that the majority of trail sample points, $58 \%(n=325)$, were located on flat or slightly inclined terrain, 0 - 
$6.9 \%$ grade. Steep grades of $15 \%$ or greater accounted for $14 \%$ of the sample $(n=78)$, with the remainder of cases considered moderately sloping trails (Table 11). A significant relationship is present when the variable trail grade is regressed with maximum incision but only explains $5.7 \%$ of the variance in the incision distribution $\left(R_{a d j}^{2}=.057, \mathrm{~F}(1,557)=35, p<.005\right)$.

Post-hoc Bonferroni analysis of trail grade categories show trail grades of less than $7 \%$ have significantly less incision than either moderate or high gradient trails $(p<.005)$. No significant difference exists between moderate and high gradient trails. When sample point values for grade and maximum incision are averaged by trail, some variations from this trend are observed. The two trails which exhibited the greatest mean maximum incision, 511 Blackbird Knob $(M=3.60, S D=3.04)$ and 104 Fire Trail \#3 $(M=$ $3.23, S D=1.44)$, were found in the lowest mean trail grade grouping, $6.21 \%$ and $3.91 \%$ respectively. The trail with the lowest mean maximum incision, 305 Stone Camp Run $(M=.73, S D=.50)$ had a mean trail grade of $8.07 \%(S D=5.57)$.

Table 11

Analysis of Variance of Maximum Incision for Trail Grade Categories

\begin{tabular}{lccc}
\hline Trail Grade & $\mathrm{N}$ & Mean Maximum Incision & Std. Dev. \\
\hline $0-6.9 \%$ & 325 & 1.66 & 1.10 \\
$7-14.9 \%$ & 156 & 2.11 & 1.45 \\
$>14.9 \%$ & 78 & 2.44 & 1.60 \\
\hline Total & 559 & 1.89 & 1.31 \\
\hline
\end{tabular}

$F(2,556)=14.42, p<.005$

\section{Trail Alignment}

Trail alignment values range from $0 \%$, trails parallel the topographic fall line, to $90 \%$, trails perpendicular to the topographic fall line. A large percentage of trails, $22.4 \%(n=125)$, had a trail alignment of $0 \%$, this is a potential long-term management concern as previous research suggest this trail alignment is the most susceptible to trail erosion. Regression analysis reflects this linear relationship, $b=-.009, t(556)=-$ $5.32, p<.001$, but as with other variables in the study, trail alignment explains only a small percentage of the variance, $R_{a d j}^{2}=.047, F(1,557)=28.31, p<.001$. 
Table 12

Mean Maximum Incision by Trail Alignment Categories.

\begin{tabular}{lccc}
\hline Trail Alignment & $\mathrm{N}$ & Mean Maximum Incision & Std. Dev. \\
\hline $0-22 \%$ & 161 & 2.27 & 1.54 \\
$23-45 \%$ & 80 & 2.08 & 1.49 \\
$46-67 \%$ & 114 & 1.89 & 1.23 \\
$68-90 \%$ & 204 & 1.53 & .96 \\
\hline Total & 559 & 1.89 & 1.31 \\
\hline
\end{tabular}

ANOVA results $F(3,555)=10.53, p<.001$

Categorical analysis (Table 12) also supports this relationship with a general trend of mean incision declining as trail alignments become more perpendicular to the surrounding topographic fall line. Post hoc, Bonferroni analysis shows significantly more incision, .73 inches, on sample points with $0-22 \%$ alignments when compared to those with $68-90 \%, p<.001$. Also significant was the mean difference (.58 inches) between 0-22\% alignments and $23-45 \%$ alignments, $p=.008$.

\section{Trail Grade x Trail Alignment Interaction}

The interaction of the steepness of a trail, trail grade, and the alignment of the trail to the surrounding landform slope, trail alignment, is commonly evaluated in trail impact studies. For this study, the relationship of this interaction is tested using the ANOVA (General Linear Model) statistic with soil erosion estimated by the maximum incision proxy. The plot of marginal means presented in Figure 10 illustrate a consistent decrease in soil erosion rates as trail grades are reduced for all but one of the intersection points with trail alignment categories. These data suggest a consistent relationship of the main effects with no significant interaction effect between trail grade and trail alignment. The statistical analysis indicates that the model and main effects are statistically significant (F/p-value: model $=5.4$, .000 ; trail grade $=11.23, .000$; trail alignment $=8.19, .000$; trail grade $x$ trail alignment $=.632, .705$ )

\section{Trail Position}

For point sample data in this study 188 sample points were in ridge positions, 251 midslope, and 119 in valleys. Maximum incision was found to be greatest at the midslope position $(M=2.15$ inches, $S D=$ $1.45)$, and least for the valley position $(M=1.52$ inches, $S D=.88)$. The relationship of incision to trail position for the data was significant $(F(2,555)=10.41, p<.001)$. With midslope positions significantly 
more incised than either the valley (Mean Difference $=.63$ inches, $p<.001$ ) or ridge (Mean Difference $=$ .35 inches, $p=.015)$ positions. No significant difference was found between the ridge and valley trail positions.

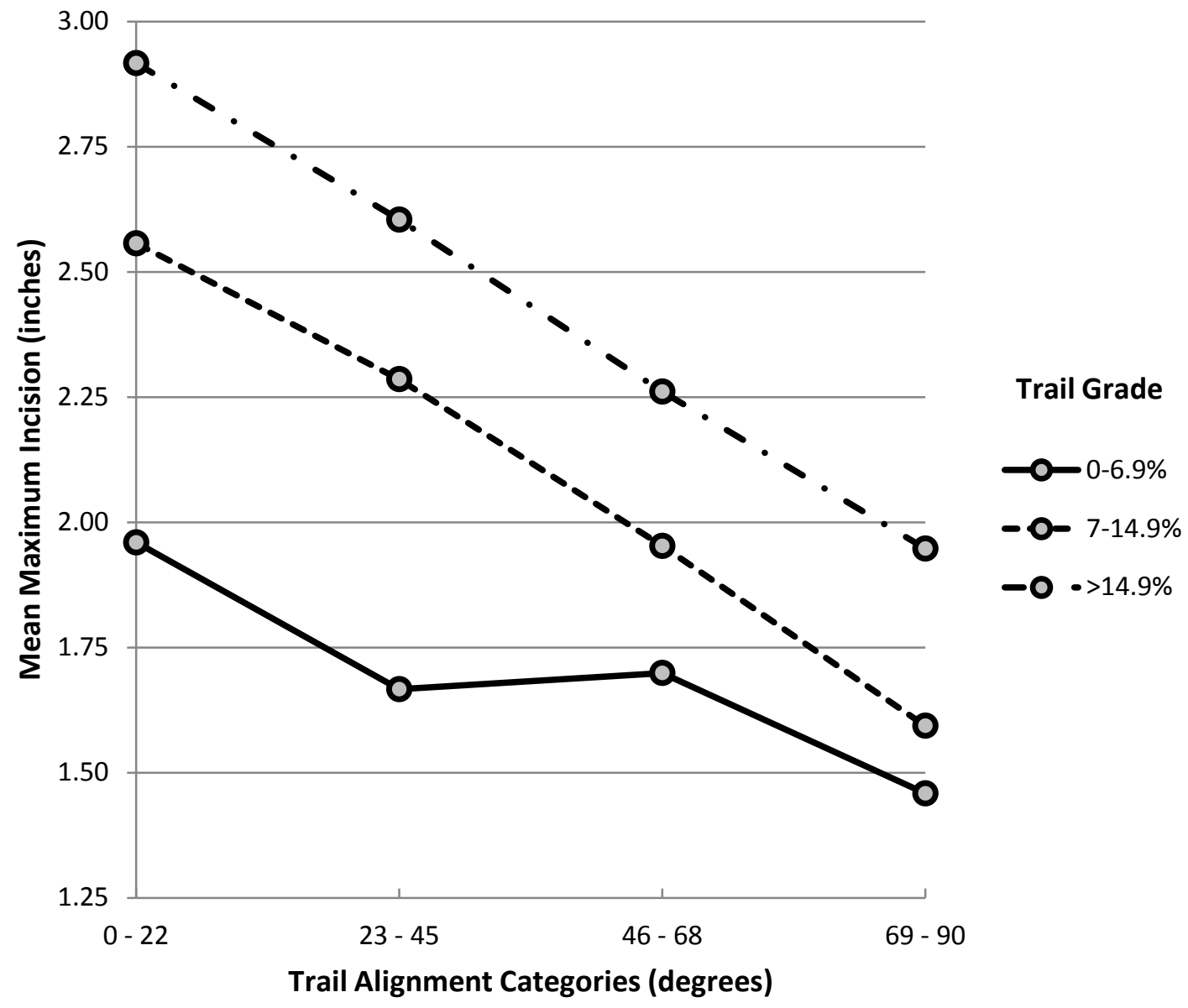

Figure 10. The influence of trail grade and trail slope alignment on soil erosion, as measured by maximum incision.

\section{GIS Estimated Upslope Flow Length}

Using the most accurate digital elevation models available for the study area, estimated upslope flow lengths (EUFL), were calculated for 552 of the 559 point sample locations. Values ranged from 3 feet to 1069 feet with the maximum EUFL found on Landis Trail in the Potomac ranger district. Ninety-five percent of the EUFL values were below 420 feet, mean EUFL = 112 feet $(S D=151.82)$, and median = 55.56 feet. The data are positively skewed (skewness $=2.77$, ses $=.104$ ) with moderate kurtosis (kurtosis $=9.78$, sek $=.208)$. 
To provide a better comparison of data from this study with previous field work, EUFL frequencies were divided into twenty-five foot categories (Table 13). No significant relationship was found between the variables although there is an observed trend of incision increasing from the 26-50 foot category to longer EUFL groups. Regression also suggests a slight positive linear relationship but given the nonnormal distribution of the data the results are inconclusive $\left(R^{2}{ }_{\text {adj }}=.006, F(1,550)=4.09, p=.044\right)$. Attempts were made to eliminate outliers and transform the EUFL variable with no increases in explained variance.

Table 13

Mean Maximum Incision by 25' Estimated Upslope Flow Length (EUFL) Groupings.

\begin{tabular}{lccc}
\hline & \multicolumn{3}{c}{ Mean Maximum } \\
Estimated Upslope Flow Length & $\mathrm{N}$ & Incision & Std. Dev. \\
\hline $0-25$ & 163 & 1.83 & 1.23 \\
$26-50$ & 95 & 1.74 & 1.00 \\
$51-75$ & 73 & 1.87 & 1.34 \\
$>75$ & 221 & 2.02 & 1.45 \\
\hline Total & 552 & 1.89 & 1.31 \\
\hline
\end{tabular}

ANOVA results: $F(3,548)=1.27, p=.285$

\section{Biophysical Variables}

General large-scale environmental processes such as geology, vegetation, and climate, categorized as biophysical variables, are presented here. The independent biophysical variables, soil type, vegetation type, forest cover, and landform slope were collected from field observations at each sample point. Additional landscape scale biophysical variables, soil erodibility, TRMI, mean annual precipitation, and average winter temperatures were extracted from secondary GIS data sets.

\section{Soil Type and Vegetation}

Soil and vegetation characteristics were measured utilizing the TRACS Productivity Factor classifications (see Appendix A). Upon review of the data, it was viewed that these measures were not comparable to other previous research. ANOVA analysis of these two categorical variables did not demonstrate any 
significant differences in mean maximum incision therefore, these variables were dropped from subsequent analysis.

\section{Forest Canopy}

An estimation of the amount of open area above the trail was conducted in the field. An open canopy contributes to erosion through increased rainfall splash detaching soils as well as drying and cracking of soils in summer due to direct sunlight. Analysis of the variance in incision for the canopy variable provides support for this impact with a significant relationship $(F(2,556)=5.42, p=.005)$, post hoc analysis indicates open canopies are significantly more incised than those with either closed (M. Dif. = .65 inches, $p<.005$ ) or partial (M. Dif. $=.62$ inches, $p<.05$ ) cover (Table 14). As the partial and closed canopies showed almost identical maximum incision values, they were grouped for subsequent analysis.

Table 14

Mean Differences in Maximum Incision by Forest Canopy Type.

\section{Mean Maximum}

\begin{tabular}{lccc} 
Canopy Type & $\mathbf{N}$ & Incision & Std. Deviation \\
\hline Closed & 411 & 1.83 & 1.23 \\
Partial & 99 & 1.86 & 1.38 \\
Open & 49 & 2.48 & 1.72 \\
\hline Total & 559 & 1.89 & 1.31
\end{tabular}

ANOVA results $F(2,556)=5.42, p=.005$

\section{Land Grade}

Study trails were built on landforms ranging from flat ground to those with a $74 \%$ grade with a mean grade of $18.9 \%(S D=15.13)$. No trends were identified which support a linear relationship between land grade and maximum incision.

\section{Elevation}

Point sample elevations ranged from 512 to 1377 meters $(M=977 \mathrm{~m}, S D=208.87$ ). Individual trail elevations ranged from the relatively flat Dobbin House trail in the Cheat ranger district at $36.7 \mathrm{~m}$ (121 feet, $M=934.5 \mathrm{~m}, S D=11.22$ ) to the steepest, Barrenshee trail in the Gauley district with a $392.1 \mathrm{~m}$ (1286 feet, $M=969 \mathrm{~m}, S D=106.7$ ) elevation change. Elevation data displayed only a slight correlation with maximum incision, $r(500)=.097, p<.05$. 


\section{Average Winter Temperature}

Average winter temperatures, a value highly correlated with elevation $(r(501)=-.833, p<.001)$, can effect erosion by increasing surface soil detachment due to frost heave. Temperatures ranged from $28.5^{\circ} \mathrm{F}-34.8^{\circ} \mathrm{F}$ with $32^{\circ} \mathrm{F}$ or lower average temperatures found above 770 meters elevation. $\mathrm{A}$ significant negative correlation exists in the data between average winter temperature and maximum incision, $r(501)=-.126, p=.005$.

\section{Mean Annual Precipitation}

Mean annual precipitation, also highly correlated with elevation $(r(499)=-.810, p<.001)$, for point samples, ranged from 43.8 to 60.7 inches per year. Gauley Mountain trail in the Gauley Ranger District was the wettest trail averaging 58.7 inches $(S D=18.2)$ of precipitation annually, and Landis Trail in the Potomac Ranger District was the driest trail averaging 44.5 inches $(S D=.97)$. Although precipitation in one of the main factors required for erosion to occur, no significant correlation was found between mean annual precipitation and maximum incision.

\section{Soil Erodibility Factor}

Soil erodibility factor, or $k$-factor, is one of the commonly used variables for determining suitability of soils for building of trails as it represents a measure of soil susceptibility to erosion. Values for soil erodibility varied from .02 to .43 feet per acre for the sample points. The lower end of the range indicates trails are built on soils which are relatively resistant to erosion such as soils with high rock content or even bedrock surfaces. At the higher end of the scale are some of the most erosive soils found in West Virginia usually containing high percentages of fine particles or silt. While the soil erodibility factor is important in estimating erosion rates for many theoretical models, no statistically significant relationship was found between this variable and the maximum incision values for point sample data in this study.

\section{Soil Moisture}

Soil moisture is represented by the relative moisture index, an estimation of soil moisture based on topography (TRMI). This unitless measure is used to compare moisture estimates between topographic locations. For the study trails, TRMI values ranged from -3.16 to $4.43(\mathrm{M}=-.89, S D=1.31)$. Values further from zero to the negative have drier soils where values to the high end of the range have moister soils. The distribution of values is slightly skewed in the positive direction (skewness $=1.11$, ses $=.109$ ), with limited kurtosis issues (kurtosis $=.97$, sek $=.22$ ) and no outliers. TRMI is significantly 
correlated with maximum incision $(r(500)=.157, p<.001)$, yet the linear relationship is weak, only explaining $2.3 \%$ of the variance $\left(R^{2}{ }_{a d j}=.023, F(1,500)=12.60, p<.001 ; b=.156, t(500)=3.55, p<.001\right)$.

\section{Ecological Land Units}

Ecological land unit (ELU) is a composite index used to classify habitats across the landscape. For this analysis, this is used only for descriptive purposes as there are too many categories to conduct robust statistical analyses given the limited sample points in each ELU. In Table 15, general trends in the data can be observed with points in steep slope land types having the greatest incision and those on narrow ridges and flat or gently sloping regions having the least.

Table 15

Mean Maximum Incision by Ecological Land Unit

\begin{tabular}{clccr}
\hline $\begin{array}{c}\text { ELU } \\
\text { Code }\end{array}$ & ELU Name & $\begin{array}{c}\text { Sample } \\
\text { Points }\end{array}$ & $\begin{array}{c}\text { Mean Maximum } \\
\text { Incision (inches) }\end{array}$ & Std. Dev \\
\hline 44 & Steep Slopes (Mountain) & 19 & 2.42 & 1.60 \\
31 & Toeslopes & 13 & 2.33 & 1.07 \\
43 & Midslope/Backslopes (Mountain) & 19 & 2.28 & .80 \\
11 & Strip Mine & 80 & 2.13 & 1.48 \\
32 & Gentle Slopes & 42 & 2.10 & 1.67 \\
50 & Cove (Draw/Hollow) & 142 & 1.94 & 1.43 \\
& Undefined & 144 & 1.94 & 1.43 \\
33 & Midslope/Backslopes & 28 & 1.94 & 1.65 \\
60 & Flood Plains & 38 & 1.72 & 1.01 \\
42 & Gentle Sideslopes (Mountain) & 23 & 1.70 & 1.16 \\
71 & Flat & 2 & 1.38 & .53 \\
10 & Narrow Ridge Top & 9 & 1.33 & .65 \\
\hline & Totals & 559 & 1.89 & 1.31
\end{tabular}

\section{Hypothesis Testing and Multiple Regression Analysis}

For this research, the performance of two groupings of variables was of interest. The first comparison was how recreational use, managerial, and biophysical variables performed in linear models. Variables in each category were tested both individually (Table 16) and together (Table 17) to assess their linear relationship with the dependent erosion variable. These categories were then combined to evaluate the performance of the multi-item model (Table 17 Model 4). In the second comparison, field collected 
variables are compared with GIS extracted and GIS derived variables to consider increases in explained variance from the GIS data (Table 18).

Table 16

Individual Independent Variables Regressed with Maximum Incision for Point Samples.

\begin{tabular}{lllllll}
\hline Independent Variables & B & Beta & Sig. & $R_{a d j}^{2}$ & F(df) & Sig.
\end{tabular}

Use Variables

\begin{tabular}{|c|c|c|c|c|c|c|}
\hline Volume of Use (High Binary) & .636 & .216 & $<.001$ & .045 & $27.25(1,557)$ & $<.001$ \\
\hline Horse Use (With Binary) & .322 & .121 & $<.005$ & .013 & $8.29(1,557)$ & $<.005$ \\
\hline \multicolumn{7}{|l|}{ Managerial Variables } \\
\hline Trail Grade (Continuous) & .046 & .243 & $<.001$ & .057 & $34.99(1,557)$ & $<.001$ \\
\hline Trail Alignment (Continuous) & -.009 & -.220 & $<.001$ & .047 & $28.31(1,557)$ & $<.001$ \\
\hline Trail Grade x Trail Alignment & $<.000$ & .044 & .294 & .000 & $1.10(1,557)$ & .294 \\
\hline Trail Position Midslope & .459 & .174 & $<.001$ & .028 & $17.34(1,556)$ & $<.001$ \\
\hline Trail Position Valley & -.480 & -.150 & $<.001$ & .021 & $12.75(1,556)$ & $<.001$ \\
\hline Est. Upslope Flow Length ${ }^{a}$ & .001 & .086 & .044 & .006 & $4.09(1,550)$ & .044 \\
\hline
\end{tabular}

Biophysical Variables

\begin{tabular}{lcccccc}
\hline Canopy (Closed Binary) & -.641 & -.138 & $<.005$ & .017 & $\mathbf{1 0 . 8 2}(\mathbf{1 , 5 5 7})$ & $<.005$ \\
Land Grade (0-100 Continuous) & .002 & .023 & .581 & .001 & $.305(1,557)$ & .581 \\
Elevation $^{\mathrm{a}}$ & .001 & .097 & .030 & .007 & $\mathbf{4 . 7 6 ( 1 , 5 0 0 )}$ & .030 \\
Avg. Winter Temperature $^{\mathrm{a}}$ & -.113 & -.126 & .005 & .014 & $\mathbf{8 . 0 8 ( 1 , 5 0 1 )}$ & .005 \\
Mean Annual Precipitation $^{\mathrm{a}}$ & .000 & .070 & .117 & .003 & $2.46(1,501)$ & .117 \\
Soil Erodibility Factor $^{\mathrm{a}}$ & -1.927 & -.082 & .087 & .004 & $2.95(1,439)$ & .087 \\
TRMI $^{\mathrm{a}}$ & .156 & .157 & $<.001$ & .023 & $\mathbf{1 2 . 6 0 ( 1 , 5 0 0 )}$ & $<.001$ \\
\hline
\end{tabular}

${ }^{\text {a }}$ GIS extracted or derived variables

BOLD indicates significant results, $p<.05$ 
Hypothesis: Recreational Use factors (Volume of Use and Horseback Riding) are linearly independent of maximum trail incision.

The null hypothesis for recreational use factors is rejected. Both the volume of use and the evidence of horse use displayed significant linear relationships with the erosion variable maximum incision. This finding is further reinforced with both variables regressed together, (Table 17, Model 1). For the multiple linear regression equation, both variables remain in the stepwise analysis, $p<.01$. While statistically significant, these variables alone or combined provide limited contribution to the explained variance of the erosion proxy.

Hypothesis: Managerial factors (Trail Grade, Trail Alignment, Trail Position, and Estimated Upslope Flow Length) are linearly independent of maximum trail incision.

The null hypothesis for managerial factors is rejected. All four of the independent variables displayed significant linear relationships with the dependent erosion variable at the $p<.05$ level. When regressed together in a stepwise analysis, three of the four variables remain as significant factors in explaining the variance of maximum incision (Table 17, Model 2). As with the recreational use variables, only limited variance in the erosion variable is explained with these individual factors. When combined the managerial variables perform the best in explaining erosion when compared to the other independent variable groupings with an explained variance of $12 \%$.

Hypothesis: Biophysical factors (Canopy, Landform Slope, Elevation, Mean Annual Precipitation, Mean Winter Temperatures, Soil Erodibility Factor, and TRMI) are linearly independent of maximum trail incision.

The null hypothesis for the biophysical factors' linear relationship with maximum incision is rejected. Four of the seven biophysical factors tested demonstrated significant linear relationships with maximum incision. Again, although the linear relationships are statistically significant, low explained variance minimizes the robustness of these findings. When compared with the recreational use and managerial multiple regression models, biophysical factors explained the least variance in the erosion variable and all but two factors dropped out of the regression model (Table 17, Model 3). 
Hypothesis: All Recreational Use, Managerial, and Biophysical factors combined are linearly independent of maximum trail incision.

The null hypothesis for a linear relationship of a combined model is rejected. The combined model (Table 17, Model 4), demonstrates a significant linear relationship with factors from all categories contributing to the model. Together the five variables from the three categories account for $23.5 \%$ of the variance found in the erosion variable maximum incision.

Table 17

Multiple Regression Model Results for Recreational Use, Managerial, Biophysical Factors, and Combined Model (Standardized Beta Coefficients) Regressed with Maximum Incision

\begin{tabular}{|c|c|c|c|c|}
\hline Variables & 1) Recreational Use & 2) Managerial & 3) Biophysical & 4) Combined \\
\hline \multicolumn{5}{|l|}{ Recreational Use } \\
\hline Use Volume (High) & .212 & & & .326 \\
\hline Horse Use (With) & .114 & & & $x x x x x x x x x$ \\
\hline \multicolumn{5}{|l|}{ Managerial } \\
\hline Trail Grade & & .167 & & .241 \\
\hline Trail Alignment & & -.243 & & -.121 \\
\hline Valley Position & & $x x x x x x x x x$ & & -.211 \\
\hline Midslope Position & & .173 & & $x x x x x x x x x$ \\
\hline Grade $x$ Alignment & & $x x x x x x x x x$ & & $x x x x x x x x$ \\
\hline Est. Upslope Flow Length* & & $x x x x x x x x x$ & & $x x x x x x x x$ \\
\hline \multicolumn{5}{|l|}{ Biophysical } \\
\hline Canopy (Closed) & & & -.100 & $x x x x x x x x x$ \\
\hline Land Grade & & & $x x x x x x x x x$ & $x x x x x x x x$ \\
\hline Elevation* & & & $x x x x x x x x x$ & $x x x x x x x x x$ \\
\hline Precipitation* & & & $x x x x x x x x x$ & $x x x x x x x x$ \\
\hline Avg. Winter Temp.* & & & $x x x x x x x x x$ & $x x x x x x x x x$ \\
\hline Soil Erodibility* & & & $x x x x x x x x x$ & $x x x x x x x x x$ \\
\hline TRMI* & & & .173 & .263 \\
\hline$R_{\text {adj }}^{2}$ & .056 & .120 & .035 & .235 \\
\hline$F(d f)$ & $27.25(2,556)$ & $25.94(3,547)$ & $13.05(2,432)$ & $27.52(5,426)$ \\
\hline Significance & $<.001$ & $<.001$ & $<.001$ & $<.001$ \\
\hline
\end{tabular}

xxxxxxxxx = variable dropped out ( $p \ln =.01, p$ Out $=.05$ )

* GIS extracted and derived variables 
Hypothesis: Field collected variables and GIS extracted or derived variables explain equal amounts of variance in the dependent variable maximum trail incision.

The hypothesis for equal performance of variables sets, field and GIS, is rejected. While both sets of variables had significant linear relationships with the dependent variable maximum incision, the GIS variable set contributed substantially less to explaining the variance of the dependent variable than the field variables (Table 18).

Table 18

Comparison of Explained Variance in Maximum Incision for Field and GIS Extracted Variables

\begin{tabular}{|c|c|c|}
\hline Variables & 1) Field Variables & 2) GIS Variables \\
\hline \multicolumn{3}{|l|}{ Field Variables } \\
\hline Use Volume (High) & .240 & \\
\hline Horse Use (With) & $\operatorname{xxxxxxxxx}$ & \\
\hline Trail Grade & .177 & \\
\hline Trail Alignment & -.215 & \\
\hline Valley Position & -.097 & \\
\hline Midslope Position & .104 & \\
\hline Grade $x$ Alignment & $x x x x x x x x x$ & \\
\hline Canopy (Closed) & -.112 & \\
\hline Land Grade & $x x x x x x x x x$ & \\
\hline \multicolumn{3}{|l|}{ GIS Variables } \\
\hline Est. Upslope Flow Length & & .109 \\
\hline Elevation & & $x x x x x x x x x$ \\
\hline Precipitation & & $x x x x x x x x x$ \\
\hline Avg. Winter Temp. & & $x x x x x x x x x$ \\
\hline Soil Erodibility & & $x x x x x x x x x$ \\
\hline TRMI & & .174 \\
\hline$R_{a d j}^{2}$ & .181 & .038 \\
\hline$F(d f)$ & $21.58(6,551)$ & $9.43(2,429)$ \\
\hline Significance & $<.001$ & $<.001$ \\
\hline
\end{tabular}




\section{3: Problem Census Results}

\section{Introduction}

Four trail impact measures were defined and assessed for the twenty-three study trails: linear erosion, lateral erosion, multiple treads, and wet soils (see Appendix A for definitions). For this analysis, only the linear erosion variable is considered, as it is comparable to the erosion proxy variable, maximum incision, used in the point sample analysis. Problem census data are best used to describe the conditions found on the trails in terms of linear feet of observed problems or percentage of total length impacted. These descriptive statistics are coarse generalizations about the entire trail length and do not incorporate the diversity of trail design and landform characteristics along the trail.

\section{Dependent Variable - Linear Erosion}

For the 63 miles of study trails, linear erosion (sections of tread $\geq 10$ feet with soil erosion exceeding 5 inches in depth) was found in $3.4 \%$ of the total length surveyed (approximately 2.1 miles). Linear erosion was found on nineteen of the twenty-three trails, with all ranger districts represented. The highest percentage of linear trail length impacted by linear erosion was $15 \%$ on Green Mountain trail, a low-use, ridge trail in Otter Creek Wilderness. Linear erosion averaged 178 feet per mile, ranging from none on three study trails to over 700 feet per mile on Blackbird Knob and Green Mountain trails. Of the 164 recorded instances of linear erosion $(M=64.09 \mathrm{feet}, \mathrm{SD}=97.44)$, Green Mountain trail also had the longest continuous length at 876 feet. The largest cumulative length of linear erosion, 2129 feet, was found on Strip Mine Trail, another low-use trail with a large percentage built on old logging roads and a reclaimed strip mine.

\section{Recreational Use}

Management estimated trail use level categories where linear erosion was observed included 5 of 8 high-use trails, all 8 medium use trails, and 6 of 7 low-use trails. Overall, the percentage of cumulative linear erosion was the greatest on low-use trails, $5 \%$, with medium use trails having $3 \%$, and high-use trails having $2 \%$ of their lengths impacted. This finding is noteworthy as it is the direct opposite of what would be expected if linear erosion was primarily a use-related impact. The eight trails with horse use had slightly less cumulative linear erosion, $3 \%$, than those without horses, $4 \%$. 


\section{Managerial Factors}

\section{Trail Grade}

Trail grade for this analysis is estimated from on-trail slope gradients calculated using the GIS digital elevation model. These data correspond poorly with field collected trail slopes and are only presented here as high-level descriptors. GIS estimated mean trail grades for the study trails ranged from $4 \%$ to $54 \%$ with a mean of $16 \%$. The general trend in the data was for both linear feet of erosion and the percentage of total eroded length to decrease as the mean trail slope increased. This is the exact opposite finding from the point sample analysis. Given the length of trails and the variety of trail slopes on each, mean trail grade at this scale is not considered a valid measure.

\section{GIS Estimated Upslope Flow Length (EUFL)}

The mean EUFL for all trails was 120.5 feet $(S D=99.8)$. A minor trend was observed with both total linear erosion and percentage of trail eroded increasing with the mean of this measure. Trails with the greatest cumulative linear erosion had slightly higher maximum EUFLs. Neither relationship was statistically significant.

\section{Biophysical Factors}

\section{Elevation}

Average trail elevation shows a moderate positive relationship with both cumulative linear erosion per trail and percentage of trail length eroded. Trails with mean elevations over 3300 feet accounted for $84 \%$ of the cumulative erosion in the study while only accounting for $47 \%$ of the total trail length, average trail elevations are 3200 feet $(S D=190)$. Again, these are based on average trail elevations over the full length of each trail.

\section{Mean Annual Precipitation}

Mean annual precipitation ranged from 44.4 inches to 58.8 inches $(M=44.9, S D=3.4)$ across all study trails. Of the variables assessed in the problem census, mean annual precipitation showed the strongest linear relationship with the erosion measures. As a trend, both cumulative linear feet and total percentage of trail eroded increased with increases in precipitation. Gauley Mountain trail was the wettest trail on average with the third highest cumulative erosion length, and Landis trail was the driest 
with the second lowest amount of erosion, twenty feet. The four trails displaying no measureable erosion had less than 51 inches of mean annual precipitation.

\section{Mean Winter Temperature}

As an interpolated GIS variable corrected for linear relationships with elevation, this variable is highly correlated with elevation. Average winter temperatures (December through March) for the twentythree trails ranged from $28.9^{\circ} \mathrm{F}$ to $34.2^{\circ} \mathrm{F}(\mathrm{M}=31.4, \mathrm{SD}=1.4)$. On average, trails with lower winter temperatures exhibited the greatest cumulative linear erosion and to a lesser extent higher total percentages of eroded trail length. Trails averaging less than $30^{\circ} \mathrm{F}$ accounted for $47 \%$ of the total cumulative erosion while only accounting for $30 \%$ of the total trail length. Gauley Mountain trail, in addition to being the wettest trail, was also the coldest trail. Landis trail had the highest GIS estimated average winter temperature, was also the driest, and had the second lowest amount of erosion.

\section{Soil Erodibility Factor}

The mean for soil erodibility was calculated for each trail $(M=.28, S D=.04)$. Very little variance was found for this measure with only four trails having more than one erodibility value, $.2(n=3), .3(n=16)$ and mixed $(n=4)$. No trends were apparent between this and the two erosion variables.

\section{Topographic Relative Moisture Index (TRMI)}

The unitless TRMI measure ranged from -1.95 to $0.42(\mathrm{M}=-.08, \mathrm{SD}=0.7)$ as an average measure for each trail. A visual inspection of the data distribution indicates no visible relationship of this measure to either cumulative linear erosion or total percentage of trail eroded. No statistical analysis was conducted given the limited number of trails.

\section{Land Grade}

The mean percent grade for the area adjacent to each trail was calculated, $(M=19.6 \%, S D=7.3)$. High values for both cumulative eroded trail length and percentage of trail eroded were relatively even in their distribution across the slope range. The trail with the highest land grade, Red Creek at 33.7\%, had only 292 linear feet of erosion compared to Strip Mine trail with the highest linear feet of erosion at 2129 with a mean slope of $19.4 \%$. This measure does not reflect the trail surface itself but rather the surrounding landform. Averaging this value across miles of trail provides limited explanatory capability due to the variability in terrain. 


\section{Ecological Land Units (ELU)}

This categorical measure was evaluated for the majority landform type (ELU) for each trail. Only two categories were observed as majority, Gentle Slopes on 18 trails, and Strip Mine for the remaining 5 trails. No pattern was observed for this variable's relationship to erosion although the Strip Mine trail with majority landform type "Strip Mine" had the highest cumulative erosion total.

Utilizing the dynamic segmentation abilities of the GIS route events, individual linear instances of trail erosion were categorized by landform type, results presented in Table 19. "Cove" landform types accounted for the greatest erosion amounts in cumulative eroded length, percentage of all erosion length, and percentage of total trail length eroded. Trails in Flat and Flood Plain landforms had the largest percentage of their length eroded.

Table 19

Cumulative Lengths and Percentages of Trail Erosion in Major Ecological Land Unit Categories

\begin{tabular}{lrrrrr} 
& $\begin{array}{r}\text { Trail } \\
\text { Length } \\
\text { (feet) }\end{array}$ & $\begin{array}{r}\text { Linear } \\
\text { Erosion } \\
\text { (feet) }\end{array}$ & $\begin{array}{r}\text { \% of Trail } \\
\text { Length } \\
\text { Eroded }\end{array}$ & $\begin{array}{r}\text { \% of Total } \\
\text { Trail Length } \\
\text { Eroded }\end{array}$ & $\begin{array}{r}\text { \% of Total } \\
\text { Linear } \\
\text { Erosion }\end{array}$ \\
\hline Cove (Draw/Hollow) & 93091 & 3354 & $3.6 \%$ & $1.0 \%$ & $30.7 \%$ \\
Strip Mine & 59848 & 1922 & $3.2 \%$ & $0.6 \%$ & $17.6 \%$ \\
Flood Plains & 27986 & 1785 & $6.4 \%$ & $0.5 \%$ & $16.3 \%$ \\
Gentle Slopes & 46037 & 1693 & $3.7 \%$ & $0.5 \%$ & $15.5 \%$ \\
Gentle Sideslopes (Mountain) & 21906 & 843 & $3.8 \%$ & $0.2 \%$ & $7.7 \%$ \\
Steep Slopes (Mountain) & 14647 & 434 & $3.0 \%$ & $0.1 \%$ & $4.0 \%$ \\
Midslope/Backslopes (Mountain) & 9650 & 389 & $4.0 \%$ & $0.1 \%$ & $3.6 \%$ \\
Midslope/Backslopes & 50357 & 310 & $0.6 \%$ & $0.1 \%$ & $2.8 \%$ \\
Flat & 1056 & 97 & $9.2 \%$ & $<0.1 \%$ & $0.9 \%$ \\
Toeslopes & 4044 & 72 & $1.8 \%$ & $<0.1 \%$ & $0.7 \%$ \\
Narrow Ridge Top & 9923 & 33 & $0.3 \%$ & $<0.1 \%$ & $0.3 \%$ \\
Alluvial Fan & 305 & 10 & $3.3 \%$ & $<0.1 \%$ & $0.1 \%$ \\
Peak (Mountain Top) & 733 & 0 & $0.0 \%$ & $0.0 \%$ & $0.0 \%$ \\
Ponds/Lakes/Rivers & 316 & 0 & $0.0 \%$ & $0.0 \%$ & $0.0 \%$ \\
\hline Total & $\mathbf{3 3 9 8 9 8}$ & $\mathbf{1 0 9 4 3}$ & & $\mathbf{3 . 2 \%}$ & $\mathbf{1 0 0 . 0 \%}$
\end{tabular}




\section{4: Linear Segment Sample Results}

\section{Introduction}

In order to improve the ability to model patterns of erosion identified in the problem census for the twenty-three study trails, each trail was divided into 600-foot segments maintaining the associated measure of linear erosion for each. This process created 547 valid cases to evaluate, 109 cases that exhibited erosion and 438 without. Twenty of the twenty-three trails had segments with measureable linear erosion (Table 20). With these segments, it is possible to conduct zonal analysis of comparable trail lengths and create zonal statistics in GIS that are more sensitive to landscape scale characteristics than either the micro sample point data or the macro full trail length problem census assessments. As zonal statistics are generalizations, this method is for intermediate level analysis providing consideration of larger areas than can be measured in the field. This approach also provides an opportunity to conduct a problem analysis of areas of the trail exhibiting various predefined trail problems. The thirtyfour sample points with greater than five inches of incision from the point sample method provide limited statistical power if used in a problem analysis due to their limited frequency. Although the 164 individual instances of linear erosion from the problem census could be evaluated in the GIS, due to the differences in their length and associated geographic areas this analysis was also considered limiting. Evaluating the 109 linear trail segments, or $20 \%$ of the total trail length, provides a more robust analysis of possible trends in erosion due to its increased frequency, intermediate landscape scale lengths, and consistent geographic areas.

With $80 \%$ of the linear segments not exhibiting the dependent variable, it is not appropriate to conduct statistical analyses which assume a normal distribution for the full sample. Two options are considered for treatment of the data. The first option is to divide the sample into a binary variable, cases which exhibit linear erosion $(n=109)$ and those which do not $(n=438)$. Using the binary, significant differences in independent variables between the groups can be explored. The second option is to only consider those cases which exhibit erosion. This subset is closer to a normal distribution with a mean of 97.6 feet of linear erosion $(S D=64)$, skewness $=2.21$ (ses $=.23)$, and kurtosis $=6.06($ sek $=.45)$. This approach limits the generalizability of the results but may provide significant insights into the commonalities of eroded segments. Both analysis options are presented in the following section.

As with the point sample and problem census analyses, independent variables in this section are separated into recreational use, managerial, and biophysical factors for ease of comparison. Although 
all variables in this section are extracted from secondary data sources, or derived from existing data using computational methods, attempts were made to create comparable variables as those used in the point sample field method.

Table 20

Distribution of Eroded Segments by Trail (Mean All Segments)

\begin{tabular}{|c|c|c|c|c|c|c|}
\hline Trail & $\begin{array}{c}\text { Total } \\
\text { Trail } \\
\text { Segments }\end{array}$ & $\begin{array}{c}\text { Eroded } \\
\text { Segments }\end{array}$ & $\begin{array}{l}\% \text { Eroded } \\
\text { Segments }\end{array}$ & $\begin{array}{l}\text { Mean } \\
\text { Erosion } \\
\text { Length } \\
\end{array}$ & $\begin{array}{r}\text { Trail Eroded } \\
\text { Segments / } \\
\text { Total Eroded } \\
\text { Segments } \\
\end{array}$ & $\begin{array}{r}\text { Trail Eroded } \\
\text { Segments / All } \\
\text { Segments }\end{array}$ \\
\hline 130 Green Mountain (w) & 13 & 4 & $30.8 \%$ & 88.8 & $3.70 \%$ & $0.70 \%$ \\
\hline 511 Blackbird Knob (w) & 15 & 12 & $80.0 \%$ & 73.2 & $11.00 \%$ & $2.20 \%$ \\
\hline 414 Turkey Pt. Connect & 14 & 7 & $50.0 \%$ & 60.1 & $6.40 \%$ & $1.30 \%$ \\
\hline 520 Beaver Dam & 6 & 3 & $50.0 \%$ & 50.0 & $2.80 \%$ & $0.50 \%$ \\
\hline 350 Strip Mine & 35 & 10 & $28.6 \%$ & 49.1 & $9.20 \%$ & $1.80 \%$ \\
\hline 529 Swallow Rock & 29 & 13 & $44.8 \%$ & 47.1 & $11.90 \%$ & $2.40 \%$ \\
\hline 438 Gauley Mountain & 45 & 13 & $28.9 \%$ & 45.0 & $11.90 \%$ & $2.40 \%$ \\
\hline 104 Fire \#3 & 6 & 5 & $83.3 \%$ & 45.0 & $4.60 \%$ & $0.90 \%$ \\
\hline 212 Lick Branch & 19 & 6 & $31.6 \%$ & 37.1 & $5.50 \%$ & $1.10 \%$ \\
\hline 214 Tumbling Rock (w) & 23 & 6 & $26.1 \%$ & 31.5 & $5.50 \%$ & $1.10 \%$ \\
\hline 514 Red Creek (w) & 15 & 5 & $33.3 \%$ & 17.6 & $4.60 \%$ & $0.90 \%$ \\
\hline 684 Meadow Creek & 26 & 4 & $15.4 \%$ & 8.5 & $3.70 \%$ & $0.70 \%$ \\
\hline 121 Shingletree & 38 & 6 & $15.8 \%$ & 7.3 & $5.50 \%$ & $1.10 \%$ \\
\hline 305 Stone Camp Run (w) & 13 & 3 & $23.1 \%$ & 6.2 & $2.80 \%$ & $0.50 \%$ \\
\hline 207 Big Beechy (w) & 61 & 6 & $9.8 \%$ & 4.3 & $5.50 \%$ & $1.10 \%$ \\
\hline 315 Camp Five $(w)$ & 14 & 2 & $14.3 \%$ & 4.2 & $1.80 \%$ & $0.40 \%$ \\
\hline 143 Dobbin House & 24 & 2 & $8.3 \%$ & 2.8 & $1.80 \%$ & $0.40 \%$ \\
\hline 502 Landis & 12 & 1 & $8.3 \%$ & 1.7 & $0.90 \%$ & $0.20 \%$ \\
\hline 256 Barrenshe & 45 & 1 & $2.2 \%$ & 0.9 & $0.90 \%$ & $0.20 \%$ \\
\hline 131 Otter Creek (w) & 24 & 0 & $0.0 \%$ & 0.0 & $0.00 \%$ & $0.00 \%$ \\
\hline 215 Bishop Knob & 22 & 0 & $0.0 \%$ & 0.0 & $0.00 \%$ & $0.00 \%$ \\
\hline 456 Two Lick & 43 & 0 & $0.0 \%$ & 0.0 & $0.00 \%$ & $0.00 \%$ \\
\hline 685 Virginia & 5 & 0 & $0.0 \%$ & 0.0 & $0.00 \%$ & $0.00 \%$ \\
\hline Totals & 547 & 109 & $19.9 \%$ & 19.5 & $100.00 \%$ & $19.90 \%$ \\
\hline
\end{tabular}




\section{Dependent Variable - Feet of Linear Erosion per 600' Segment}

For linear segment analysis, the dependent variable is the length of each 600 -foot trail segment that displays linear erosion as assessed during the problem census field work. Linear erosion was found in 109 of the 547 trail segments with cumulative lengths ranging from 0 to 600 feet $(M=19.5, S D=60.37)$. In eleven instances, linear erosion lengths were divided between two trail segments and in one instance, the 876-foot continuously eroded segment of Green Mountain trail, three segments. This clipping effect was considered negligible and all segments were included for this analysis. The distribution of eroded segments by trail is presented in Table 20 . Fire \#3 trail had the highest percentage of eroded segments, 83.3\%. Green Mountain trail, had the greatest mean erosion length per segment, $M=88.8$ feet $(S D=$ 191.24). Both of these low to moderate use trails were relatively short and straight with continuous gradual downhill slopes. Swallow Rock and Gauley Mountain trails accounted for the highest frequency of eroded segments, 13 each, as well as the highest percentage of eroded segments, $11.9 \%$, and accounted for the largest percentage of eroded segments from all 547 trail segments, $2.4 \%$. Two Lick trail had the most trail segments without linear erosion, 43 , one of four study trails displaying no linear erosion along their entire length.

\section{Analysis of Linear Segments with Binary Dependent Variable}

In the first analysis of linear segments, trail segments displaying no linear erosion $(n=438)$, are compared to those with erosion $(n=109)$.

\section{Recreational Use}

\section{Use Volume}

Both recreational use variables are categorical, binary variables as is the dependent variable for this analysis. For manager estimated volume of use, in the high-medium use category, 308 cases had no erosion, and 78 displayed erosion. In the low-use category, 130 segments had no erosion and 31 displayed erosion. Chi square analysis indicates that the percentage of trail segments with linear erosion did not differ significantly from those without, $\chi^{2}(1, N=547)=0.07, p=.80$.

Use Type

Displayed evidence of horse traffic on trails is also a binary variable. For the study trails with horse use, 205 segments had no erosion and 35 displayed erosion. On trails with no horse use, 233 cases had no 
erosion, and 74 displayed erosion. Analysis shows the percentage of trails with erosion was significantly higher on trails without horse use, $\chi^{2}(1, N=547)=7.65, p=.006$. Although this is a positive result for horseback riders and trail managers, types of impact other than linear erosion, particularly mud development, need to be assessed to determine impact on and suitability of trails for horse travel. This result is supported by the problem census data but differs from the findings of the point sample regression analysis.

\section{Managerial Factors}

For the linear segment analysis, only trail grade and GIS estimated upslope flow length were calculated from the secondary GIS data.

\section{Trail Grade}

Trail grade was estimated from a linear analysis of elevations along the trail tread in ArcGIS. Values used in this analysis are the mean slopes for each 600-foot trail segment. Trail grade for all study trail segments ranged from zero to $41.3 \%\left(22.4^{0} ; M=11 \%, S D=7.39\right)$. Trail segments with erosion had a mean trail grade of $11.69 \%$ (SD $=7.5$ ) and those without a mean of $10.84 \%$ (SD $=7.36$ ). The difference in mean trail grades for eroded and non-eroded segments was not statistically significant, $t(545)=1.07, p=$ .286 .

GIS Estimated Upslope Flow Length (EUFL)

The same map coverage for EUFL was used for this analysis as in that for the other two methods. The values used for comparison are the mean EUFL for each 600-foot trail segment. For trails without erosion, EUFL values ranged from 30 to 1069 feet $(M=194.3, S D=161.53)$, and for trail segments with erosion 44 to 636 feet $(M=191.3, S D=132.00)$. As with trail grade no significant difference was found between the mean EUFL values for each erosion group, $t(545)=-.177, p=.86$.

\section{Biophysical Factors}

\section{Land Grade}

As with the problem census treatment of this variable, land grade was derived from the digital elevation models and the mean maximum grade for the trail corridor of each trail segment was calculated. Values are presented as slope percentages and range from zero to $200 \%$ (zero to $63.4^{0} ; \mathrm{M}=33.53, \mathrm{SD}=23.78$ ). 
Shingletree trail had the highest mean land grade for segments at 62.1\% (SD = 32.39), and Strip Mine had the least sloped terrain on average at $9 \%(S D=7.89)$. For trail segments with erosion the mean maximum land grade was $32.79 \%$ (SD $=20.27)$, and for those without erosion $33.72 \%(S D=24.59)$, no significant difference was found between these two groups, $t(545)=-.36, p=.72$.

\section{Other Biophysical Variables}

Significant differences between trail segments with and without erosion were found for the remaining GIS extracted biophysical variables: Elevation, Average Winter Temperature, Mean Annual Precipitation, Soil Erodibility Factor, and TRMI (Table 21). For the independent variable elevation, trails with erosion were found at higher elevations than those without (Mean Difference $=356.9$ feet). As previously mentioned, mean winter temperature is closely related to elevation, with lower temperatures found at higher elevations. Correspondingly a significant relationship was found for mean annual temperatures and erosion with trail segments having erosion being at lower temperatures than those without (Mean Difference $\left.=.96^{\circ} \mathrm{F}\right)$.

Table 21

Biophysical Variable with Significant Differences for Trail Segments with and Without Erosion

\begin{tabular}{lrrr}
\hline Independent Variable & \multicolumn{1}{c}{$\begin{array}{c}\text { Trail Segments } \\
\text { with Erosion }\end{array}$} & \multicolumn{1}{c}{$\begin{array}{c}\text { Trail Segments } \\
\text { without Erosion }\end{array}$} & \multicolumn{1}{c}{$t(d f), p$} \\
\hline Mean Elevation (feet) & $3569.08(\mathrm{SD}=604.95)$ & $3212.19(\mathrm{SD}=723.32)$ & $t(545)=4.75, p<.001$ \\
Mean Winter Temperature $\left({ }^{0} \mathrm{~F}\right)$ & $30.68(\mathrm{SD}=1.22)$ & $31.64(\mathrm{SD}=1.61)$ & $t(545)=-5.81, p<.001$ \\
Mean Annual Precipitation (inches) & $55.01(\mathrm{SD}=3.72)$ & $52.92(\mathrm{SD}=4.05)$ & $t(535)=4.88, p<.001$ \\
Majority Soil Erodibility Factor & $.30(\mathrm{SD}=.04)$ & $.31(\mathrm{SD}=.03)$ & $t(545)=-3.35, p=.001$ \\
TRMI & $-.52(\mathrm{SD}=1.78)$ & $-1.08(\mathrm{SD}=1.00)$ & $t(545)=5.04, p<.001$ \\
\hline
\end{tabular}

Mean annual precipitation, and the landscape derived TRMI, both operate as expected. Significantly higher mean precipitation amounts for trail segments with erosion (Mean Difference $=2.09$ inches), as well as significantly higher TRMI values (Mean Difference $=.54$ ). Although the difference in mean soil erodibility factor values is significant for the two groups, the relationship is the opposite of what would be expected with higher mean erodibility values for trail segments with no erosion (Mean Difference = .01). The limited variability in soil erodibility values makes this variable of limited use as a predictor of soil erosion for this analysis method. 


\section{Ecological Land Units (ELU)}

The ELU for each trail segment was determined by the zonal majority statistic effectively returning the mode category for each segment. Values were distributed in thirteen defined landform categories and one undefined group (Table 22). Differences in the distribution of segments with and without erosion are minimal with a few exceptions. The percentage of trail segments with erosion found on Gentle Slopes (11.9\%) was almost double the percentage of trail segments without erosion (5.5\%). Also no segments with erosion were found in Midslope/Backslope (Mountain), Peak (Mountain Top), and Toeslopes.

Table 22

Distribution of Linear Segment Erosion Categories by Ecological Land Unit

\begin{tabular}{lrrrrrr}
\hline & \multicolumn{2}{c}{$\begin{array}{c}\text { Trail Segments } \\
\text { With Erosion }\end{array}$} & \multicolumn{2}{c}{ Wrail Segments } & \multicolumn{2}{c}{ Totals } \\
\cline { 2 - 7 } Ecological Land Unit & Count & Percentage & Count & Percentage & Count & Percentage \\
\hline Cove (Draw/Hollow) & 34 & $31.2 \%$ & 111 & $25.3 \%$ & 145 & $26.5 \%$ \\
\hline Not Classified & 20 & $18.3 \%$ & 110 & $25.1 \%$ & 130 & $23.8 \%$ \\
\hline Strip Mine & 18 & $16.5 \%$ & 74 & $16.9 \%$ & 92 & $16.8 \%$ \\
\hline Gentle Slopes & 13 & $11.9 \%$ & 24 & $5.5 \%$ & 37 & $6.8 \%$ \\
\hline Midslope/Backslopes & 9 & $8.3 \%$ & 28 & $6.4 \%$ & 37 & $6.8 \%$ \\
\hline Flood Plains & 5 & $4.6 \%$ & 17 & $3.9 \%$ & 22 & $4.0 \%$ \\
\hline Steep Slopes (Mountain) & 5 & $4.6 \%$ & 13 & $3.0 \%$ & 18 & $3.3 \%$ \\
\hline Flat & 2 & $1.8 \%$ & 0 & $0.0 \%$ & 2 & $0.4 \%$ \\
\hline Gentle Sideslopes (Mountain) & 2 & $1.8 \%$ & 26 & $5.9 \%$ & 28 & $5.1 \%$ \\
\hline Narrow Ridge Top & 1 & $0.9 \%$ & 12 & $2.7 \%$ & 13 & $2.4 \%$ \\
\hline Midslope/Backslopes (Mountain) & 0 & $0.0 \%$ & 14 & $3.2 \%$ & 14 & $2.6 \%$ \\
\hline Peak (Mountain Top) & 0 & $0.0 \%$ & 1 & $0.2 \%$ & 1 & $0.2 \%$ \\
\hline Ponds/Lakes/Rivers & 0 & $0.0 \%$ & 3 & $0.7 \%$ & 3 & $0.5 \%$ \\
\hline Toeslopes & 0 & $0.0 \%$ & 5 & $1.1 \%$ & 5 & $0.9 \%$ \\
\hline Total & 109 & & 438 & & 547 & \\
\hline
\end{tabular}

\section{Analysis of Linear Segments with Linear Erosion}

The final analysis of this study investigates the relationships of recreational use, managerial factors, and biophysical factors with the cumulative length of linear erosion found in the 600-foot trail segments that exhibit measureable erosion. Using these lengths as continuous measures allows for linear regression analysis to be conducted, testing for the presence of linear relationships in the data. All managerial and biophysical factors for this analysis were extracted or derived from existing secondary GIS datasets. 
Frequencies of erosion per segment and cumulative length of linear erosion per segments exhibiting linear erosion are presented in Table 23.

Table 23

Distribution of Eroded Segments by Trail (Mean Eroded Segments Only)

\begin{tabular}{|c|c|c|c|c|c|}
\hline Trail & $\begin{array}{l}\text { Total Trail } \\
\text { Segments }\end{array}$ & $\begin{array}{c}\text { Eroded } \\
\text { Segments }\end{array}$ & $\begin{array}{l}\text { Mean } \\
\text { Erosion } \\
\text { Length } \\
\end{array}$ & $\begin{array}{l}\text { Trail Eroded } \\
\text { Segments / } \\
\text { Total Eroded } \\
\text { Segments } \\
\end{array}$ & $\begin{array}{c}\text { Trail Eroded } \\
\text { Segments / All } \\
\text { Segments } \\
\end{array}$ \\
\hline 130 Green Mountain (w) & 13 & 4 & 288.5 & $3.70 \%$ & $0.70 \%$ \\
\hline 350 Strip Mine & 35 & 10 & 172.0 & $9.20 \%$ & $1.80 \%$ \\
\hline 214 Tumbling Rock (w) & 23 & 6 & 120.8 & $5.50 \%$ & $1.10 \%$ \\
\hline 414 Turkey Pt. Connect & 14 & 7 & 120.1 & $6.40 \%$ & $1.30 \%$ \\
\hline 212 Lick Branch & 19 & 6 & 117.3 & $5.50 \%$ & $1.10 \%$ \\
\hline 529 Swallow Rock & 29 & 13 & 105.0 & $11.90 \%$ & $2.40 \%$ \\
\hline 520 Beaver Dam & 6 & 3 & 100.0 & $2.80 \%$ & $0.50 \%$ \\
\hline 511 Blackbird Knob (w) & 15 & 12 & 91.5 & $11.00 \%$ & $2.20 \%$ \\
\hline 438 Gauley Mountain & 45 & 13 & 90.0 & $11.90 \%$ & $2.40 \%$ \\
\hline 684 Meadow Creek & 26 & 4 & 55.5 & $3.70 \%$ & $0.70 \%$ \\
\hline 104 Fire \#3 & 6 & 5 & 54.0 & $4.60 \%$ & $0.90 \%$ \\
\hline 514 Red Creek (w) & 15 & 5 & 52.8 & $4.60 \%$ & $0.90 \%$ \\
\hline 121 Shingletree & 38 & 6 & 46.3 & $5.50 \%$ & $1.10 \%$ \\
\hline 207 Big Beechy (w) & 61 & 6 & 43.8 & $5.50 \%$ & $1.10 \%$ \\
\hline 256 Barrenshe & 45 & 1 & 39.0 & $0.90 \%$ & $0.20 \%$ \\
\hline 143 Dobbin House & 24 & 2 & 34.0 & $1.80 \%$ & $0.40 \%$ \\
\hline 315 Camp Five $(w)$ & 14 & 2 & 29.5 & $1.80 \%$ & $0.40 \%$ \\
\hline 305 Stone Camp Run (w) & 13 & 3 & 26.7 & $2.80 \%$ & $0.50 \%$ \\
\hline 502 Landis & 12 & 1 & 20.0 & $0.90 \%$ & $0.20 \%$ \\
\hline 131 Otter Creek (w) & 24 & 0 & 0.0 & $0.00 \%$ & $0.00 \%$ \\
\hline 215 Bishop Knob & 22 & 0 & 0.0 & $0.00 \%$ & $0.00 \%$ \\
\hline 456 Two Lick & 43 & 0 & 0.0 & $0.00 \%$ & $0.00 \%$ \\
\hline 685 Virginia & 5 & 0 & 0.0 & $0.00 \%$ & $0.00 \%$ \\
\hline Totals & 547 & 109 & 97.6 & & $19.9 \%$ \\
\hline
\end{tabular}

w = Wilderness Area Trail

\section{Recreational Use Variables}

Use Volume

Utilizing the binary use volume categorization from the point sample analysis, high-medium and lowuse, it was found that eroded linear trail segments were most prevalent for high-medium volume trails 
$(n=78)$. Contrary to this finding, mean cumulative linear erosion per segment was almost double on low-use trails $(M=146.39$ feet, $S D=136.68)$ compared to high-medium use trails $(M=78.23$ feet, $S D=$ 9.08). A test of the difference in mean distributions confirmed that this difference was statistically significant, $t(107)=3.23, p<.005$. This finding is noteworthy, as it does not follow previous findings. One possible reason for this is the occurrence of regionalized severe rain events on low-use trails which show evidence of scouring. Another is that low-use trails are used enough to remove vegetation and to become entrenched but not enough to develop hardened pan structure from compaction. Limited maintenance over extended time periods would allow erosion to develop unchecked. A number of the trails in this category which displayed extensive erosion were relatively straight with continuous gradual downhill grades.

\section{Horse Use}

Horse use was observed on eight of the twenty study trails which exhibit measureable linear erosion. Sixty-eight percent of the eroded segments $(n=74)$ were found on trails without horse use. No significant differences were found between the mean cumulative linear erosion lengths on trails with (M $=101.40$ feet, $S D=109.52)$ and without horse use $(M=95.82$ feet, $S D=101.36), t(107)=-.26, p=.794$.

\section{Managerial Variables}

\section{Trail Grade}

Trail grade was averaged for each linear segment and values ranged from 1.8 to $39.1 \%(M=11.69, S D=$ 7.50). The majority of trail segments had a mean grade of $7-14.9 \%(n=50,46 \%)$, no significant differences between the mean cumulative erosion lengths of categorical trail grade groupings were observed (Table 24). Regression analysis also showed no linear relationship between mean trail grade and cumulative erosion for each trail segment $(F(1,107)=.383, p=.538)$. 
Table 24

Cumulative Linear Feet of Erosion per 600' Trail Section x Mean Grade of 600' Trail Section

\begin{tabular}{lrrr}
\hline & \multicolumn{3}{c}{ Mean Linear } \\
Trail Grade Class & $N$ & Erosion (feet) & Std. Dev. \\
\hline $0-6.9 \%$ & 33 & 87.39 & 96.74 \\
$7-14.9 \%$ & 50 & 101.60 & 120.27 \\
$\geq 15 \%$ & 26 & 102.92 & 76.24 \\
\hline Total & 109 & 97.61 & 103.57 \\
\hline$F(2,106)=.229, p=.796$ & & &
\end{tabular}

GIS Estimated Upslope Flow Length (EUFL)

The mean EUFL was calculated for each trail segment, values ranged from 15.4 to 524.1 feet $(M=$ $106.74, \mathrm{SD}=110.52)$. The data distribution is positively skewed (skewness $=1.93$, ses $=.231$ ) with moderate kurtosis (kurtosis $=3.18$, sek $=.46$ ) but less so than the point sample distribution for this variable.

Table 25 ANOVA Results for Mean Differences in Trail Segment Cumulative Linear Erosion by 25' Estimated Upslope Flow Length (EUFL) Groupings

\begin{tabular}{lccr}
\hline Estimated Upslope Flow Length & $\mathrm{N}$ & Incision & Std. Dev. \\
\hline $0-25$ & 9 & 64.22 & 49.94 \\
$26-50$ & 37 & 73.78 & 69.04 \\
$51-75$ & 14 & 99.93 & 97.36 \\
$>75$ & 49 & 121.08 & 127.94 \\
\hline Total & 109 & 97.61 & 103.57 \\
\hline
\end{tabular}

$F(3,105)=1.85, p=.143$

For comparison, mean EUFLs were categorized by 25 -foot lengths. As with point sample analysis no significant relationships were observed for the categories (Table 25) although trails with over 75 feet of mean EUFL had the highest mean cumulative erosion lengths $(M=121.08 \mathrm{feet}, \mathrm{SD}=127.94)$. When regressed with mean cumulative linear erosion, a significant linear relationship was observed accounting 
for $13.6 \%$ of the explained variance in the erosion variable $\left(R^{2}{ }_{a d j}=.136, F(1,107)=18.00, p<.001 ; b=\right.$ $.356, t(107)=4.64, p<.001)$. This is the highest explained variance of any independent variable in the study, more than double the $R^{2}$ adj found for trail grade $\left(R^{2}{ }_{a d j}=.057, F(1,557)=34.99, p<.001\right)$ in the point sample analysis.

\section{Biophysical Variables}

\section{Continuous Variables}

Mean values for each of the biophysical variables were calculated for all linear segments exhibiting erosion. A correlation test between each variable and the cumulative length of linear erosion per segment was conducted (Table 26). Results show mean TRMI as the only measured biophysical variable with a significant correlation to the dependent variable $(r(107)=.265, p=.005)$.

Table 26

Pearson Correlations for Environmental Variables with Cumulative Length of Erosion per 600' Trail Segment (Eroded Segments Only)

\begin{tabular}{lcc}
\hline & \multicolumn{2}{c}{ Pearson Correlation Coefficients } \\
\cline { 2 - 3 } Independent Variable & $\mathrm{R}$ & Significance \\
\hline Mean Elevation & .164 & .089 \\
Mean Winter Temperature & -.155 & .109 \\
Mean Soil Erosion Factor & -.504 & .577 \\
Mean Land Grade & -.037 & .700 \\
Mean TRMI & .265 & .005 \\
\hline
\end{tabular}

\section{Ecological Land Units (ELU)}

Majority values for ELUs were computed for each eroded trail segment. "Cove" $(n=34)$, "Strip mine" ( = 18), and "Gentle slope" ( $n=13$ ) landforms accounted for $60 \%$ of the 109 eroded segments (Table 27). No erosion was found in "Midslope/Backslopes (Mountain)", "Peak (Mountain Top)", or "Toeslope” landforms, although trail segments in these areas only account for $4 \%$ of the trail segments. Eighteen percent of the eroded trail segments fall into unclassified zones which limits the usefulness of this GIS measure as this accounts for a substantial portion of the eroded segments. 
Mean cumulative linear erosion was greatest for trail segments with "Gentle Slopes" (defined as slopes of 6 to 25 degrees) as the majority ecological land unit ( $M=126.31 \mathrm{feet}, \mathrm{SD}=85.02)$. "Steep Slope" and "Cove" landform also had notably longer mean cumulative linear erosion lengths than other landforms. As too few cases are represented in each category, statistical analysis of this distribution is inconclusive. Use of this descriptive analysis might be useful in stratification strategies for future sampling design.

Table 27

Distribution and Mean Length of Eroded Trail Segments by Ecological Land Unit

\begin{tabular}{lrrrr}
\hline & \multicolumn{2}{c}{$\begin{array}{c}\text { Trail Segments } \\
\text { With Erosion }\end{array}$} & \multicolumn{2}{c}{$\begin{array}{c}\text { Cumulative Linear Erosion } \\
\text { per 600' Trail Segment }\end{array}$} \\
\cline { 2 - 6 } Ecological Land Unit & Count & Percentage & Mean (feet) & \multicolumn{1}{c}{ SD } \\
\hline Cove (Draw/Hollow) & 34 & $31.2 \%$ & 107.44 & 131.75 \\
\hline Not Classified & 20 & $18.3 \%$ & 91.05 & 68.07 \\
\hline Strip Mine & 18 & $16.5 \%$ & 93.06 & 88.70 \\
\hline Gentle Slopes & 13 & $11.9 \%$ & 126.31 & 85.02 \\
\hline Midslope/Backslopes & 9 & $8.3 \%$ & 74.56 & 91.55 \\
\hline Flood Plains & 5 & $4.6 \%$ & 52.80 & 39.54 \\
\hline Steep Slopes (Mountain) & 5 & $4.6 \%$ & 115.40 & 195.89 \\
\hline Flat & 2 & $1.8 \%$ & 93.50 & 103.95 \\
\hline Gentle Sideslopes (Mountain) & 2 & $1.8 \%$ & 58.50 & 26.16 \\
\hline Narrow Ridge Top & 1 & $0.9 \%$ & 33.00 & \\
\hline Midslope/Backslopes (Mountain) & 0 & $0.0 \%$ & 0 & - \\
\hline Peak (Mountain Top) & 0 & $0.0 \%$ & 0 & - \\
\hline Ponds/Lakes/Rivers & 0 & $0.0 \%$ & 0 & - \\
\hline Toeslopes & 0 & $0.0 \%$ & 0 & 103.57 \\
\hline Total & 109 & & 97.61 & \\
\hline
\end{tabular}

\section{Hypothesis Testing and Multiple Regression Analysis}

To allow for comparison of this linear segment method with the point sample method, the linear relationship of the dependent erosion variable and recreational use, managerial, and biophysical independent variables were tested for both. In this model, the erosion variable proxy was the cumulative length of observed erosion greater than or equal to five inches in depth per 600-foot section of trail. As stated, this analysis only considers trail segments which display the erosion variable. Each independent variable was regressed alone (Table 28) with the erosion variable, together with other variables of the same category (Table 29, Models 1-3), and finally in a composite with all study variables (Table 29, Model 4). 
Table 28

Individual Independent Variables Regressed with Cumulative Linear Feet of Erosion on 600-foot Eroded Linear Segments.

\begin{tabular}{lllllll}
\hline Independent Variables & B & Beta & Sig. & $R_{\text {adj }}^{2}$ & F(df) & Sig. \\
\hline
\end{tabular}

Use Variables

\begin{tabular}{lrrrrrr}
\hline Volume of Use (Hi Binary) & -68.16 & -.298 & $<.005$ & .080 & $\mathbf{1 0 . 4 5}(1,107)$ & $<.005$ \\
Horse Use (Yes/No Binary) & 5.58 & .025 & .794 & -.009 & $.07(1,107)$ & .794
\end{tabular}

Managerial Variables

\begin{tabular}{lrrrrrr}
\hline Mean Trail Grade & .824 & .060 & .538 & -.006 & $.383(1,107)$ & .538 \\
Mean Est. Upslope Flow Length & .356 & .380 & $<.001$ & .136 & $\mathbf{1 8 . 0 0 ( 1 , 1 0 7 )}$ & $<.001$
\end{tabular}

Biophysical Variables

\begin{tabular}{lrrrrrr}
\hline Mean Land Grade & -.191 & -.037 & .700 & -.008 & $.49(1,107)$ & .700 \\
Mean Elevation $^{\mathrm{a}}$ & .028 & .164 & .089 & .018 & $2.94(1,107)$ & .089 \\
Mean Avg. Winter Temperature $^{\mathrm{a}}$ & -13.11 & -.155 & .109 & .015 & $2.62(1,107)$ & .109 \\
Mean Annual Precipitation $^{\mathrm{a}}$ & .044 & .158 & .100 & .016 & $2.75(1,107)$ & .100 \\
Mean Soil Erodibility Factor $^{\mathrm{a}}$ & -160.09 & -.054 & .577 & -.006 & $.313(1,107)$ & .577 \\
Mean TRMI & $\mathbf{2 3 . 3 5}$ & .265 & .005 & .062 & $\mathbf{8 . 1 0 ( 1 , 1 0 7 )}$ & .005 \\
\hline
\end{tabular}

${ }^{a}$ GIS extracted or derived variables

BOLD indicates significant results, $p<.05$

Hypothesis: Recreational Use factors (Volume of Use and Horseback Use) are linearly independent of the cumulative linear length of erosion per trail segment.

The null hypothesis for recreational use factors is rejected. The trail manager estimate for volume of use on trails significantly predicted erosion, $b=.298, t(108)=3.23, p<.005$. Volume of use also explained a significant proportion of the variance in erosion lengths, $R^{2}{ }_{a d j}=.08, F(1,107)=10.45, p<.005$. No significant relationship was found between horse use and erosion for this method. These relationships were consistent when both recreational use variables were regressed together with erosion (Table 29, Model 1). 
Hypothesis: Managerial factors (Mean Trail Grade and Mean EUFL) are linearly independent of the cumulative linear length of erosion per trail segment.

The null hypothesis for managerial factors is rejected. For the GIS derived variable, mean EUFL, a significant linear relationship exists between this independent variable and the dependent erosion variable, $b=.380, t(108)=4.24, p<.001$, and a significant portion of the variance is also explained, $R^{2}{ }_{a d j}$ $=.136, F(1,107)=18, p<.001$. No significant relationship was found between mean trail grade and the dependent linear segment erosion variable. Mean EUFL also remained the only variable to be significant in a stepwise regression when regressed together with mean trail grade (Table 29, Model 2).

Hypothesis: Biophysical factors (Mean Land Grade, Mean Elevation, Mean Winter Temperatures, Mean Annual Precipitation, Mean Soil Erodibility Factor, and Mean TRMI) are linearly independent of the cumulative linear length of erosion per trail segment.

The null hypothesis for biophysical factors is rejected. Of the six GIS extracted biophysical variables, only mean TRMI significantly predicted erosion for the study trail segments, $b=.265, t(108)=2.85, p=$ .005 . This variable only explained a limited amount of the variance in the dependent erosion variable, $R_{\text {adj }}^{2}=.062, F(1,107)=8.1, p=.005$. No additional relationships were identified when all biophysical variables were regressed together with the erosion variable (Table 29, Model 3).

Hypothesis: All Recreational Use, Managerial, and Biophysical factors combined are linearly independent of the cumulative linear length of erosion per trail segment.

The null hypothesis for a linear relationship of a combined model is rejected. Three independent variables (Volume of Use, Mean EUFL, and Mean TRMI), one from each category, remained significant in a stepwise regression analysis when regressed with cumulative linear length of erosion (Table 29, model 4). A significant amount of variance in the dependent variable was explained by these combined variables $\left(R_{\text {adj }}^{2}=.264, F(3,105)=13.91, p<.001\right)$, a $2.9 \%$ increase in the explained variance of the maximum incision dependent variable in the point sample regression model. 
Table 29

Multiple Regression Model Results for Recreational Use, Managerial, Biophysical Factors, and Combined Model (Standardized Beta Coefficients) Regressed with Mean Cumulative Linear Erosion per 600' Trail Segment.

\begin{tabular}{|c|c|c|c|c|}
\hline Variables & 1) Recreational Use & 2) Managerial & 3) Biophysical & 4) Combined \\
\hline \multicolumn{5}{|l|}{ Recreational Use } \\
\hline Visitor Use (High) & -.298 & & & -.314 \\
\hline Horse Use (With) & $\operatorname{xxxxxxxxx}$ & & & $\operatorname{xxxxxxxxx}$ \\
\hline \multicolumn{5}{|l|}{ Managerial } \\
\hline Mean Trail Grade & & $x x x x x x x x x$ & & $x x x x x x x x x$ \\
\hline Mean EUFL & & .380 & & .335 \\
\hline \multicolumn{5}{|l|}{ Environmental } \\
\hline Mean Elevation & & & .184 & $x x x x x x x x x$ \\
\hline Mean Precipitation & & & $\operatorname{xxxxxxxxx}$ & $x x x x x x x x x$ \\
\hline Mean Avg. Winter Temp. & & & $x x x x x x x x x$ & $x x x x x x x x x$ \\
\hline Mean Landform Slope & & & $\operatorname{xxxxxxxxx}$ & $x x x x x x x x x$ \\
\hline Mean Soil Erodibility & & & $x x x x x x x x x$ & $x x x x x x x x x$ \\
\hline Mean TRMI & & & .279 & .240 \\
\hline$R_{\text {adj }}^{2}$ & .080 & .136 & .087 & .264 \\
\hline$F(d f)$ & $10.45(1,107)$ & $18.00(1,107)$ & $6.148(2,106)$ & $13.91(3,105)$ \\
\hline Significance & $<.005$ & $<.001$ & $<.005$ & $<.001$ \\
\hline
\end{tabular}

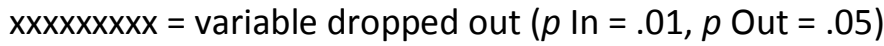




\section{Chapter 5: Discussion and Implications}

\section{1: Introduction}

For this study, three sampling methods were utilized to explore the patterns and relationships of trail erosion to recreational use, biophysical conditions, and managerial practice in the Monongahela National Forest (MNF). The first two methods, point sample and problem assessment, are well documented in the literature and the results of this study provide comparative examples of each approach. In an effort to leverage the capabilities of geographic information systems (GIS) to advance trail degradation research, new variables were introduced to these methods that were wholly extracted from existing GIS datasets. The effort here was to compliment and expand the understanding of linear relationships in available data and not to test the validity of replacing field measurements with GIS derived data as considered in previous research (Cakir, 2005). This approach accepted the inherent limitations in these GIS datasets to provide an exploratory analysis of potential landscape level relationships of managerial and biophysical variables to the dependent erosion variables. A third sampling method, linear segment, is utilized in this research as an extension of the problem assessment method. Although similar linear segment sampling methods have been defined previously (Bratton et al., 1979; Dixon et al., 2004; T. F. Farrell \& Marion, 2002; Summer, 1980), the method has not been widely applied. As this study heavily integrates the linear modeling capabilities of GIS to geo-position assessment data on the landscape, a process not well integrated into previous research, it is to be considered exploratory. This approach provides intermediate scale segments of equal size that can be attributed with GIS extracted data in post processing of field data. This is believed to be an improvement of the trail level assessments of previous studies as it allows for a more accurate characterization of the landscape scale biophysical conditions within these smaller units. This is of particular relevance to trail research in mountainous terrain as trails can vary greatly along their length in elevation, landform position, moisture, grade, and a multitude of other potential impact influencing factors.

This dissertation presents the results of each of these methods in detail to allow for a comparison of the approaches to data collection and analysis inherent in each. The following discussion first provides a comparative overview of the sampling method results, and then considers in detail the patterns of erosion displayed by each method as compared with other studies utilizing similar field methodologies. Managerial implications, research implications, and conclusions are presented which emphasize the 
integration of this modern tool of natural resource management, GIS, as an important element of future recreation ecology research.

\section{2: Comparison of Sampling Methods}

For this study, two distinct types of field data on trail erosion were collected; maximum incision at 600foot sampling intervals, and a census of continuous linear sections of erosion of five inches or more which exceeded ten feet. Dynamic segmentation of the census data in GIS provides a third treatment of the field data providing an intermediate scale erosion variable, cumulative linear erosion per 600 -foot segment. Each data set presents a different view of the trail erosion conditions and provides unique opportunities for analysis.

\section{Descriptive Analysis}

From a descriptive level of analysis, each data set considers a different scale of topography (Table 30). Census data allows for analysis at the trail level with erosion by trail unit or feet of erosion per mile of trail. At this scale, two extremes of trail erosion conditions are apparent; $73.9 \%$ of all study trails have severe erosion impacts but these impacts only account for $3.4 \%$ of the overall length of trails. An interpretation of these values would indicate that erosion is dispersed across many trails in the study but is isolated to a relatively small number of problem locations.

The treatment of data in 600-foot trail sections provides a clearer picture of the geographic location of problem erosion. This level of analysis is considered an intermediate scale as it incorporates smaller topographic areas than the full trail length of the census method, and larger areas than individual sampling points. Similar to the relationship of trails to trail lengths, a comparison of linear segment and point samples impacted by severe erosion shows $19.9 \%$ of segments impacted with $5.9 \%$ of point samples impacted. If linear segments alone were considered, interpretation of the trail conditions at this scale would show a moderate percentage of degradation due to erosion. Sample point information provides the finest scale of data and as shown can be averaged for a trail or taken as a single data set. Like trail length, these data show a low percentage of trail area impacted by severe erosion.

Of the thirty-four point samples that exhibited depths greater than five inches, only seventeen (50\%) intersected with sections of linear erosion identified in the problem census. The remaining fifty percent were isolated areas where 5 inch maximum incision depth was shorter than ten feet in length. With these limited cases, the point sample method missed approximately ninety percent $(89.6 \%)$ of the erosion found on the study trails. 
Table 30

Percentage of Observed Erosion Greater Than 5 Inches by Sample Type

\begin{tabular}{lccrrr}
\hline Sample Type & Unit & Scale & Total Samples & Eroded Samples & Erosion \% \\
\hline Trails & Trail & Macro & 23 & 17 & $73.9 \%$ \\
Trail Length & Feet & Macro & 331,534 & 11,166 & $3.4 \%$ \\
$600^{\prime}$ Trail Segments & Segment & Intermediate & 547 & 109 & $19.9 \%$ \\
Point Samples & Point & Micro & 569 & 34 & $5.9 \%$ \\
\hline
\end{tabular}

At the trail level, each erosion variable showed slight variations in the results for the most impacted trail (Table 31). The one commonality of four of the most impacted trails is their position on high plateaus or ridges. These trails were also in regions with the highest mean annual precipitation and the coldest average winter temperatures. Swallow Rock trail is an exception to this pattern as it starts low in the valley, climbs over a high ridge and descends the other side. Gauley Mountain and Blackbird Knob trails are two of the highest use trails in the study and Green Mountain and Strip Mine are two of the lowest. Swallow Rock is a high-use trail but also has a substantial level of horse use. As point samples miss such a large percentage of the severe erosion accounted for in the census method, it is understandable that different trails are most impacted for each method although Blackbird Knob trail was in the top three most impacted trails for the all sample types. Four trails consistently showed no indication of problem erosion.

\section{Regression Model Analysis}

Two of the sampling methods, point sample and linear segment, provide continuous dependent erosion variables that are suitable for regression analysis with erosion (Table 32). As the linear segment regression model excludes segments with no erosion, it should be considered a problem analysis approach. The point sample model considers the full sample and provides a more comprehensive model of erosion trends. Volume of use appears significant in both models with higher use trails having a positive relationship to the respective erosion variables. Managerial variables vary greatly between 
Table 31 Comparison of observed erosion of $>5$ inches for problem census, point sample, and linear segment methods

\begin{tabular}{|c|c|c|c|c|c|c|c|c|c|c|c|c|c|c|}
\hline & \multicolumn{4}{|c|}{ Problem Assessment Census } & \multicolumn{5}{|c|}{ Point Sample } & \multicolumn{5}{|c|}{ Linear Segments (LS) } \\
\hline Trail & $\begin{array}{l}\text { Wheel } \\
\text { Length }\end{array}$ & $\begin{array}{c}\text { Linear } \\
\text { Erosion } \\
\text { (feet) }\end{array}$ & $\begin{array}{c}\% \text { of } \\
\text { Trail } \\
\text { Length } \\
\text { Eroded }\end{array}$ & $\begin{array}{c}\% \\
\text { Eroded } \\
\text { / All } \\
\text { Length }\end{array}$ & $\begin{array}{c}\text { \# of } \\
\text { Sample } \\
\text { Points }\end{array}$ & $\begin{array}{l}\text { Points } \\
\text { w/Max } \\
\text { Incision } \\
\text { > } 5 \text { in. }\end{array}$ & $\begin{array}{c}\% \text { of } \\
\text { Trail } \\
\text { Points }\end{array}$ & $\begin{array}{c}\% \text { of } \\
\text { All } \\
\text { Trail } \\
\text { Points }\end{array}$ & $\begin{array}{c}\text { Mean } \\
\text { Max } \\
\text { Incision }\end{array}$ & $\begin{array}{c}\text { Total } \\
\text { Trail } \\
\text { LS }\end{array}$ & $\begin{array}{c}\text { Eroded } \\
\text { LS }\end{array}$ & $\begin{array}{c}\% \\
\text { Eroded } \\
\text { LS }\end{array}$ & $\begin{array}{c}\% \\
\text { Eroded } \\
\text { LS / All } \\
\text { LS }\end{array}$ & $\begin{array}{c}\text { Mean } \\
\text { Eroded } \\
\text { Length/ } \\
\text { LS }\end{array}$ \\
\hline 350 Strip Mine & 21152 & 2129 & $10.1 \%$ & $0.6 \%$ & 36 & 7 & $19.4 \%$ & $1.2 \%$ & 2.70 & 35 & 10 & $28.6 \%$ & $1.8 \%$ & 172.0 \\
\hline 529 Swallow Rock & 17583 & 1365 & $7.8 \%$ & $0.4 \%$ & 30 & 6 & $20.0 \%$ & $1.1 \%$ & 3.60 & 29 & 13 & $44.8 \%$ & $2.4 \%$ & 105.0 \\
\hline 438 Gauley Mountain & 27180 & 1170 & $4.3 \%$ & $0.4 \%$ & 27 & 0 & $0.0 \%$ & $0.0 \%$ & 2.06 & 45 & 13 & $28.9 \%$ & $2.4 \%$ & 90.0 \\
\hline 130 Green Mountain (w) & 7813 & 1154 & $14.8 \%$ & $0.3 \%$ & 26 & 1 & $3.8 \%$ & $0.2 \%$ & 1.84 & 13 & 4 & $30.8 \%$ & $0.7 \%$ & 288.5 \\
\hline 511 Blackbird Knob (w) & 9290 & 1123 & $12.1 \%$ & $0.3 \%$ & 33 & 9 & $27.3 \%$ & $1.6 \%$ & 3.60 & 15 & 12 & $80.0 \%$ & $2.2 \%$ & 91.5 \\
\hline 414 Turkey Pt. Connect & 8407 & 841 & $10.0 \%$ & $0.3 \%$ & 14 & 0 & $0.0 \%$ & $0.0 \%$ & 1.39 & 14 & 7 & $50.0 \%$ & $1.3 \%$ & 120.1 \\
\hline 214 Tumbling Rock (w) & 13972 & 725 & $5.2 \%$ & $0.2 \%$ & 24 & 1 & $4.2 \%$ & $0.2 \%$ & 1.47 & 23 & 6 & $26.1 \%$ & $1.1 \%$ & 120.8 \\
\hline 212 Lick Branch & 11360 & 716 & $6.3 \%$ & $0.2 \%$ & 17 & 0 & $0.0 \%$ & $0.0 \%$ & 1.40 & 19 & 6 & $31.6 \%$ & $1.1 \%$ & 117.3 \\
\hline 520 Beaver Dam & 3828 & 300 & $7.8 \%$ & $0.1 \%$ & 7 & 0 & $0.0 \%$ & $0.0 \%$ & 2.29 & 6 & 3 & $50.0 \%$ & $0.5 \%$ & 100.0 \\
\hline 514 Red Creek (w) & 9388 & 292 & $3.1 \%$ & $0.1 \%$ & 34 & 2 & $5.9 \%$ & $0.4 \%$ & 2.24 & 15 & 5 & $33.3 \%$ & $0.9 \%$ & 52.8 \\
\hline 121 Shingletree & 23182 & 278 & $1.2 \%$ & $0.1 \%$ & 38 & 4 & $10.5 \%$ & $0.7 \%$ & 2.60 & 38 & 6 & $15.8 \%$ & $1.1 \%$ & 46.3 \\
\hline 104 Fire \#3 & 3920 & 270 & $6.9 \%$ & $0.1 \%$ & 12 & 1 & $8.3 \%$ & $0.2 \%$ & 3.23 & 6 & 5 & $83.3 \%$ & $0.9 \%$ & 54.0 \\
\hline 207 Big Beechy (w) & 36674 & 263 & $0.7 \%$ & $0.1 \%$ & 36 & 1 & $2.8 \%$ & $0.2 \%$ & 1.85 & 61 & 6 & $9.8 \%$ & $1.1 \%$ & 43.8 \\
\hline 684 Meadow Creek & 15480 & 222 & $1.4 \%$ & $0.1 \%$ & 26 & 0 & $0.0 \%$ & $0.0 \%$ & 1.57 & 26 & 4 & $15.4 \%$ & $0.7 \%$ & 55.5 \\
\hline 305 Stone Camp Run (w) & 7996 & 103 & $1.3 \%$ & $0.0 \%$ & 14 & 0 & $0.0 \%$ & $0.0 \%$ & 0.73 & 13 & 3 & $23.1 \%$ & $0.5 \%$ & 26.7 \\
\hline 143 Dobbin House & 14578 & 97 & $0.7 \%$ & $0.0 \%$ & 25 & 1 & $4.0 \%$ & $0.2 \%$ & 2.04 & 24 & 2 & $8.3 \%$ & $0.4 \%$ & 34.0 \\
\hline 315 Camp Five (w) & 8557 & 59 & $0.7 \%$ & $0.0 \%$ & 14 & 0 & $0.0 \%$ & $0.0 \%$ & 1.68 & 14 & 2 & $14.3 \%$ & $0.4 \%$ & 29.5 \\
\hline 256 Barrenshe & 27187 & 39 & $0.1 \%$ & $0.0 \%$ & 28 & 0 & $0.0 \%$ & $0.0 \%$ & 1.23 & 45 & 1 & $2.2 \%$ & $0.2 \%$ & 39.0 \\
\hline 502 Landis & 7379 & 20 & $0.3 \%$ & $0.0 \%$ & 25 & 1 & $4.0 \%$ & $0.2 \%$ & 3.01 & 12 & 1 & $8.3 \%$ & $0.2 \%$ & 20.0 \\
\hline 131 Otter Creek (w) & 14850 & 0 & $0.0 \%$ & $0.0 \%$ & 12 & 0 & $0.0 \%$ & $0.0 \%$ & 1.56 & 5 & 0 & $0.0 \%$ & $0.0 \%$ & 0.0 \\
\hline 215 Bishop Knob & 13381 & 0 & $0.0 \%$ & $0.0 \%$ & 44 & 0 & $0.0 \%$ & $0.0 \%$ & 1.47 & 43 & 0 & $0.0 \%$ & $0.0 \%$ & 0.0 \\
\hline 456 Two Lick & 26097 & 0 & $0.0 \%$ & $0.0 \%$ & 25 & 0 & $0.0 \%$ & $0.0 \%$ & 1.20 & 24 & 0 & $0.0 \%$ & $0.0 \%$ & 0.0 \\
\hline 685 Virginia & 3406 & 0 & $0.0 \%$ & $0.0 \%$ & 22 & 0 & $0.0 \%$ & $0.0 \%$ & 0.99 & 22 & 0 & $0.0 \%$ & $0.0 \%$ & 0.0 \\
\hline Totals & 332660 & 11166 & $3.4 \%$ & *Sort & 569 & 34 & $6.0 \%$ & & 2.06 & 547 & 109 & $19.9 \%$ & & 97.6 \\
\hline
\end{tabular}


the two models. Trail alignment was not calculated for linear segments due to the variety within segments. GIS derived values for trail grade were used in the linear segment model but did not display a significant linear relationship with erosion. A comparison of field and GIS derived values show limited consistency for the point sample locations.

Table 32

Comparison of Point Sample and Linear Segment Regression Models

\section{Point Sample}

$Y_{1}=\left(.326 \times X_{1}\right)+\left(.241 \times X_{2}\right)+\left(-.121 \times X_{3}\right)$

$+\left(-.211 \times X_{4}\right)+\left(.263 \times X_{5}\right)$

$Y_{1}=$ Maximum Incision (inches)

$\mathrm{X}_{1}=$ Volume of Use (High)

$\mathrm{X}_{2}=$ Trail Grade (percent)

$X_{3}=$ Trail Alignment Angle (degrees)

$\mathrm{X}_{4}=$ Valley Trail Position

$X_{5}=$ TRMI

$R_{\text {adj }}^{2}=.235, F(5,426)=27.52, p<.001$

\section{Linear Segment}

$Y_{2}=\left(-.314 \times X_{6}\right)+\left(.335 \times X_{7}\right)+\left(.240+X_{8}\right)$

$\mathrm{Y}_{2}=$ Cumulative Length of Linear Erosion (feet)

$\mathrm{X}_{6}=$ Volume of Use (High)

$\mathrm{X}_{7}=$ Mean Estimated Upslope Flow Length (feet)

$\mathrm{X}_{8}=$ Mean TRMI

GIS estimate upslope flow length was positively correlated with erosion in the linear segment. This GIS estimation technique is a new to the study of trail degradation and reflects a calculation that is difficult to make in the field while conducting rapid assessments of large trail inventories. As it is interpolated from a digital elevation model, it is better suited for segment analysis than discrete point analysis which is reflected in these results. For the biophysical category, the TRMI variable appears in both models. This GIS derived variable is a composite of slope and aspect. Although not a direct measure of soil moisture, this variable does provide a relative index of the amount of overland moisture available and various topographic positions. The positive value of this relationship indicates that areas where moisture is concentrated by the topography (depressions, coves, or collecting landform curvature) have higher erosion values. The explained variance for the two models is very similar. 


\section{3: Point Sample Method}

The point sample method is one of the most commonly used sampling techniques found in the literature for high mileage trail impact assessments. Previous research presents this method as best suited for high precision and accuracy, particularly for measurement of trail width, tread incision, and tread composition (Jewell \& Hammitt, 2000; Marion \& Leung, 2001). This precision is evident in the results of this study with measurements of maximum incision in quarter inch increments. While this provides useful information for long-term monitoring of specific locations and estimates of statistical means for trail width and depth, it is less useful from a trail maintenance standpoint. As this method missed approximately ninety percent (89.6\%) of the occurrences of erosion greater than 5 inches found on the study trails, it would not be effective in informing managers of the extent and severity of potential erosion conditions. A commonly cited reference suggests that sampling intervals between 100 and 500 meters should provide accurate representations of the linear extent of trail impact problems, noting a $50 \%$ accuracy loss at these sampling distances (Leung \& Marion, 1999a). Supporting evidence for this recommendation from this study is inconclusive. While the 200 meter sampling distance used in this study missed the majority of severe erosion occurrences, the overall percentages of incision greater than five inches only varied by two and one half percent between the point sample (5.9\%) and problem assessment (3.4\%) methods. Given these variations in findings, future research should strongly consider both short and long-term management and research objectives of a trail assessment before committing to this time consuming method. One important benefit for combining this method with the problem assessment census discussed in the next section is the recording of high quality GPS data points at each point sample location. These data points allow for calibration of trail vector distances greatly improving the geographic accuracy of linear trail data placement for GIS analysis.

For the point sample analysis, this study used a proxy variable of maximum incision to approximate erosion severity on MNF trails. While this has been a common practice, cross-sectional area (CSA) of soil loss at sampling points has predominated recent studies. Maximum incision is a rapid assessment measurement requiring limited field tools, but CSA provides a more comprehensive view of the volume of soil being displaced from the trail tread. Other considerations for maximum incision not incorporated in this study are the differentiation of incision depths from the original constructed surface and current surface (T. F. Farrell \& Marion, 2002), and the difference of compacted soil versus eroded soils (Godwin, 2000). The maximum incision values and distribution indicate the MNF study trails on average have limited erosion with some depths over five inches found in isolated areas, mean = 2.06 inches, SD = 1.88. 
When compared with similar studies in other resource management areas, the mean and percentage of sample points incised greater than or equal to 5 inches (5.9\%) for MNF trails are comparatively low. While White et al. (2006) reported a lower mean of 1.48 inches with a maximum of 10 inches for mountain bike trails in Arizona and New Mexico, several other studies reported deeper average incision: Cakir (2005) reported 32\% of sample points greater than or equal to 5 inches in depth with a mean of 4.3 inches in a single trail evaluated in North Carolina; Cole (1991) reported an average depth of 5.5 inches $(14 \mathrm{~cm} \pm 2 \mathrm{~cm}$ ) for trails in Selway-Bitterroot Wilderness, Montana; Dixon et al. (2004) had a mean range of maximum depths from 2.9 inches to 9.6 inches $(7.4 \mathrm{~cm}$ to $24.5 \mathrm{~cm})$ in Tasmania; and Farrell and Marion (2002) found means of 3.1 inches on low-use, 4.3 inches on moderate-use, and 5.9 on high-use trails in Torres del Paine, Chile. Even Aust et al. (2005) reported all trails with gravel surfacing for armoring against erosion in Hoosier National Forest had mean maximum incision values greater than 2.5 inches for all use levels, ungraveled trails averaged greater than 3.5 inches.

The relationships of maximum incision with each of the theoretical groupings of independent variables included in the point sample method - recreational use, biophysical, and managerial - also showed similarities and differences with previous research.

\section{Recreational Use}

Two recreational use variables were defined for this study, use volume and use type, specifically horse use versus non-horse use. MNF trail data showed significant differences between manager estimated low-use trails and both medium and high-use trails. Means for medium and high-use level trails were not statistically different and in fact mean trail incision for high-use trails was lower than medium use trails. Relying on manager judgment for trail usage is common in trail studies but given the persistent influence of use volume in this and other studies, an objective measure for this variable would increase the validity of use-impact relationships and provide a quantitative measure for comparing between studies. It is unclear whether it is appropriate to compare these results with those of other study areas for this measure given potential use volume differences. For example, the mean incision for trails in Torres del Paine, Chile, low-use (< 500 visitors/year) mean incision 3.1 inches, medium-use (501-1,000 visitors/year) mean incision 4.3 inches, and high-use (>1,000 visitors/year) mean incision 5.9 inches, with annual visitation of 50,392 (T. F. Farrell \& Marion, 2002), seems unlikely to be receiving the same level of visitor impact as the MNF with 1.3 million annual visitors (low-use mean incision 1.4 inches, medium 2.1 inches, and high-use 2 inches). For the MNF, many of the ultra-high-use trails were not included in the sample because they have received some level of surfacing such as pavement, 
boardwalk, or extensive gravel; this study focused only on natural surface trails. As many of the sample trails were more remote, it is possible that their use volumes were similar to Torres del Paine trails as a 2004 estimate lists MNF wilderness trail users at approximately 34,000. Only through standardization of use volume estimation techniques will findings of use-impact relationships be meaningful to managers and researchers; this sentiment is reflected in the literature by Cole (2006) and others. Regardless, eight of twelve studies reviewed found similar significant positive relationships between impacts, including erosion, and increases in trail use; three of six descriptive studies also reported this relationship (see Table 3 in literature review).

Horse use was found to significantly increase the maximum incision of MNF study trails but mean values varied by less than one-half inch. No consideration was made of the volume of horse use on study trails. These findings add to the growing body of literature noting the increased incision due to horse travel (Aust et al., 2005; Bratton et al., 1979; Dale \& Weaver, 1974; Deluca et al., 1998; Leung \& Marion, 1999b; Pickering et al., 2009; Törn et al., 2009). Yet, as noted in the literature review, research by Summer $(1980,1986)$, and Weaver and Dale (1978) do not reach the same conclusion, pointing to biophysical and trail design variables as having a larger influence. As horse use is not significant in the final regression model for this sampling method, this study would lend support to the findings of Summer and Weaver and Dale from a strict consideration of trail erosion. Trail widening and mud development are also commonly reported trail problems related to horse use but were not considered in this analysis.

\section{Managerial Variables}

All of the managerial variables considered for this method were trail design factors. Each individual managerial variable for the point sample displayed significant linear relationships with trail erosion. Combined they predicted $12 \%$ of the variance in maximum incision, although EUFL dropped out of the multiple regression model. Given the expense to construct or relocate trails, as well as the diminished maintenance budgets for recreation resource areas such as MNF, thoughtful trail design considering these variables is a clear investment in the long-term sustainability of recreational trails.

\section{Trail Grade}

As a single variable, trail grade accounted for the highest percentage of variance in maximum incision $(5.7 \%)$ of any independent variable in the point sample method. In addition, trail grade played an 
influential role in multiple regression erosion prediction models when combined with other managerial variables, recreational use, and biophysical factors. When divided categorically, trail grades of less than $7 \%$ had significantly less incision than those greater than $7 \%$. Throughout the literature trail grade has demonstrated a significant influence in rates of erosion and is one of the most commonly included variables in trail degradation research. Bratton et al. (1979) also found trail grade to be the most important physical factor related to trail degradation of all types. Jubenville and O'Sullivan (1987), and Godwin (2000) reported much higher explained variance for trail grade than this study with adjusted $r$ squared values over .3 although each used CSA as their dependent variable. Olive and Marion (2009) found similarly low explained variance in their Hoosier National Forest trail study with trail grade explaining $2 \%$ of the variance in CSA.

The categorical groupings for trail grade in this study matched categories selected by Jubenville and O'Sullivan (1987) and Sutherland et al. (2001). Although mileage for these three studies was substantially different, similar trends were found in the relationships of trail grade categories to erosion variables. For each, lower gradient categories had the least erosion and highest gradients the most. The Jubenville and O'Sullivan study was unique in its treatment of trail grade as the sample for the study was stratified so as to compare gradients by vegetation type. Although other studies considered the interaction of grade with other variables, few have designed a stratified model to test it as in the Jubenville and O'Sullivan study. This methodology is one potential explanation of the higher explained variance for this variable. The dependent variable used to indicate erosion by Sutherland, the Saleh Roughness Factor (Saleh, 1993), is substantially different from other trail erosion measurements common to trail degradation research. Although the Saleh chain method was experimented with in this and other trail studies, it is unclear of the relationship of this measurement to maximum incision or CSA and therefore the explained variance in the Sutherland study is limited in its value for comparison.

\section{Trail Alignment}

Trail alignment, or the angle of the trail in relationship to the slope of the land, explained the second highest amount of variance in maximum incision, $4.7 \%$. Like trail grade, the trail alignment variable in this study is a strongly significant predictor of maximum incision with relatively low explanatory power. Olive and Marion (2009), Aust, Marion and Kyle (2005), Gager and Conacher (2001), and Bratton et al. (1979) all found trail alignment to be a significant factor in predicting erosion as a standalone variable. Bryan (1977) did not present statistical analysis of the relationship of alignment water diversion and erosion but notes: 
"Topography is significant primarily in relation to trail orientation. Where trails follow the fall-line, severe water erosion hazard exists, regardless of slope angle. When trails parallel contours little damage will occur unless incision is sufficient to divert runoff."

In this investigation it was found that incision deep enough to "divert runoff," as described by Bryan, was found at all sample points. As such, these trails act similarly to ephemeral streams during rain events as described by Chatterjae (2007) in her trail research in Singapore. In theory, perpendicular alignment of trails to slope, high alignment angles, enables easy removal of water from trails with functional water bars and water dips which reduce both the volume and velocity of water moving down the incised trail (Olive \& Marion, 2009). Thirty-one functional water bars and 114 water dips were identified on the MNF study trails. Only on one or two of the trails did the density of these features meet the Forest Service recommendations based on trail grade. With limited maintenance and less than optimal frequency of these structures, only limited benefit in reducing erosion on MNF trails was observed.

\section{Trail Grade and Trail Alignment}

The interaction and potential amplification of erosion on trails closely aligned with the topography and having steeper trail grades is commonly investigated in the trail degradation literature. Findings from this study indicate no interaction effect between the two variables for MNF trails but do show that maximum incision increases in parallel as alignment angles decrease and trail grade increases. It would be expected that if amplification of the influence of one variable on the other was occurring, a regression model with both variables together would explain a greater amount of variance in the dependent variable. This is not the case for this data set, in fact the cumulative impact is slightly less than the sum of each individual variable (Trail Grade: $R^{2}{ }_{\text {adj }}=.057, F(1,557)=35, p<.005$; Trail Alignment: $R_{\text {adj }}^{2}=.047, F(1,557)=28.31, p<.001$; Combined: $\left.R_{\text {adj }}^{2}=.092, F(1,556)=29.22, p<.001\right)$.

A comparison of the results of this study with the Olive and Marion (2009) study of trail impacts in the Big South NRA of Tennessee shows very similar relationships in the trend lines for the estimated marginal means of erosion variables for each independent variable (Figure 11). Data for MNF trails show a more downward linear trend than the Big South data for the $7-14.9 \%$ and $>14.9 \%$ trail grades. 


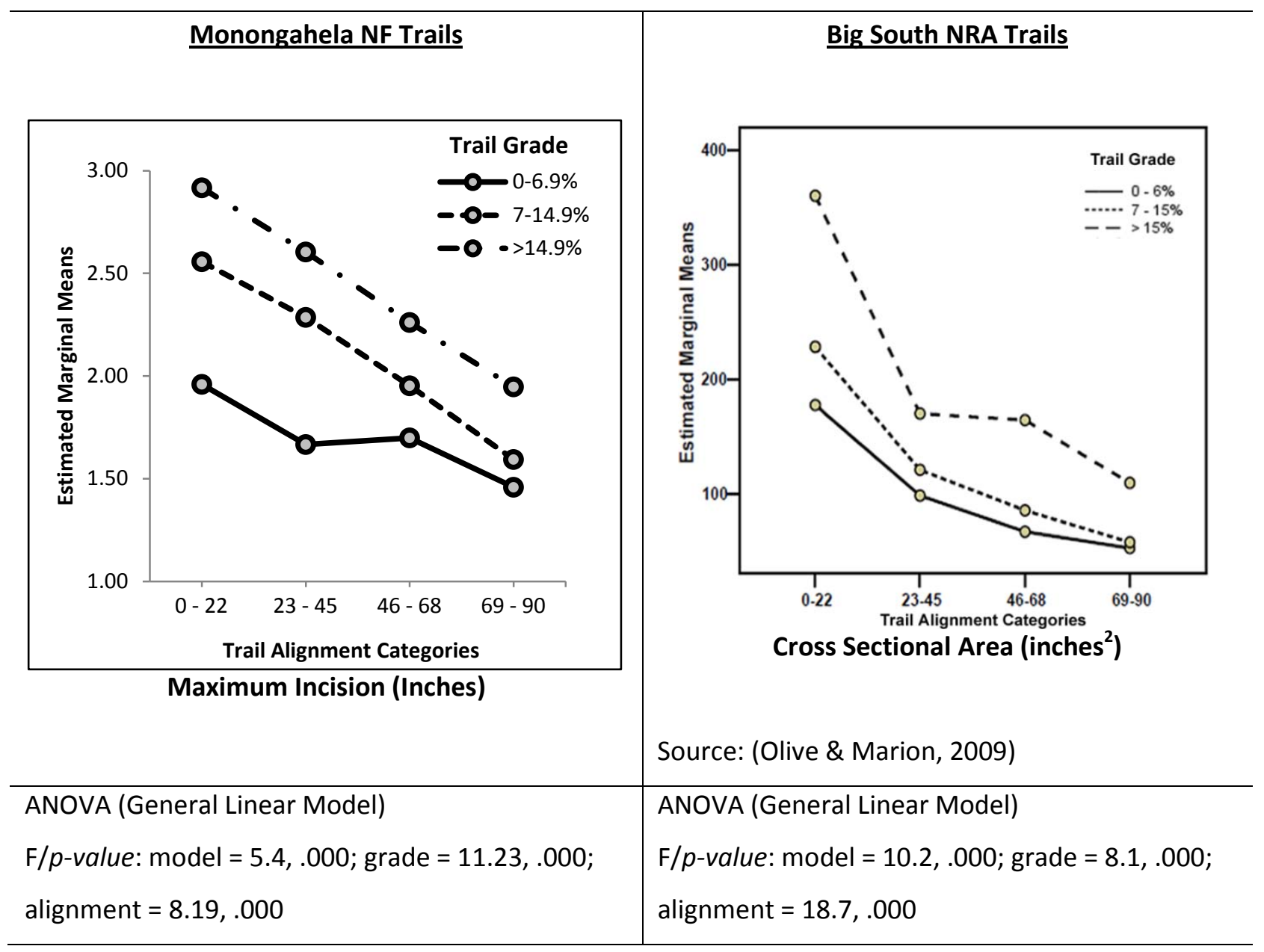

Figure 11. Comparison of trail alignment and trail grade relationships with erosion indicators on MNF and Big South National Recreation Area (NRA) trails.

Erosion indicator behavior at the 46-67 degree alignment has some inconsistencies in both data sets although at different trail gradients. Trail grade had slightly more influence over erosion in this study than on Big South NRA trails where alignment had a greater influence. Regardless, these results provide further evidence that trail alignment and trail grade are highly correlated and, erosion varies linearly with trail grade similarly for each alignment category. Leung and Marion (1996) speculate that the importance of slope alignment angle increases in its significance as trail grade increases; Bratton et al. (1979) take a similar position. Evidence to support this hypothesis would show a curvilinear relationship in the trend line with proportionally higher maximum incision or CSA indicated at the low alignment angle and high grade. While the Big South NRA study supports this relationship, the findings of this study do not. Differences in maximum incision are relatively constant for each alignment and grade intersection with the lowest grade sample points exhibiting greater erosion and high alignment angles. 
One potential explanation for this inconsistency in findings is that the study trails in MNF have received little maintenance and all are incised, also few functional water diversion features are found on the majority of trails. As trail incision allows water to flow down long lengths of relatively low grade trails, erosion rates are relatively high. Also, a number of trails with the highest grades were built in areas with low rainfall and soils that are more porous. Only through more targeted sampling approaches to filter out intervening variables can these explanations for the alignment-grade relationship to erosion be tested.

\section{Trail Position}

Where trail tread is located on the landscape can significantly change the trail user experience. Ridge trails with open view points or valley trails adjacent to streams or other bodies of water are attractive but the literature shows that midslope, or contour trails are more resistant to erosion and other impacts (AMC, 2008; Aust et al., 2005; Felton, 2004; Hammitt \& Cole, 1998; Leung \& Marion, 1996). Contrary to this literature, midslope positioned sample points in this study displayed significantly deeper maximum incision than those in either ridge or valley positions. These findings align with Coleman's early study of English Lake District trails (Coleman, 1981) where ridge trails exhibited less erosion than midslope trails. Coleman accounted for this finding by suggesting that midslope positioned trails accumulate larger amounts of water from upslope watersheds and that it is "channeled" down the path increasing erosion. As noted in the literature review, no strong research support exists for the consistent influence of trail position on erosion. While midslope positions have a lower potential for erosion, this can only be realized if effective maintenance of water diversion structures is implemented. This level of maintenance is not in place on the majority of trails in this study. With reduced maintenance budgets for Federal land management agencies increasing erosion on midslope trails may become more evident in all Federal recreation resource areas.

\section{GIS Estimated Upslope Flow Length}

One of the first GIS derived variables that are considered in this discussion, estimated upslope flow length (EUFL), was found to be a significant predictor of maximum incision but explained a limited amount of variance $\left(R^{2}{ }_{a d j}=.006\right)$. This finding supports trail design literature which prescribes limiting the length of on-trail water flow as a primary mechanism to reduce erosion potential (AMC, 2008; Demrow \& Salisbury, 1998; Hesselbarth et al., 2007; T. S. Parker, 2004). As this variable is time consuming to measure in the field due to the need to backtrack at each sampling point, it is not commonly included in large scale trail impact assessments, Olive and Marion (2009), Aust et al. (2005), 
and Gager and Conacher (2001) are exceptions. Each study also found a significant relationship between the erosion at a sample location and the distances to functioning upslope water diversion structures. Difficulty in accurately calculating this value in GIS for a single point may be part of the limited predictive power here as it does perform better in the linear segment method of this study which incorporates larger areas. EUFL is estimated in GIS from topographic elevation data using interpolation and also relies on accurate assessments of water diversion structures found in the field (see Appendix B). As there are inherent errors in the elevation data of \pm 10 feet, short linear distances are more likely to display error values than longer distances where these values tend to be smoothed out through interpolation. If more accurate elevation data were available, such as that based on Light Detection and Ranging (LiDAR) scans with vertical errors of \pm 1 foot or less, there is the potential for improved predictive performance of these estimates. Due to the large area covered by this trail study, it is unlikely that LiDAR derived data would be available for all study trails in the near future. Even if they were available, the required computing power to consider these data would limit the feasibility of conducting analysis of an area the size of MNF. This level of analysis would be better suited for single trails such as that conducted in Cakir's research (Cakir, 2005) or small regional trail studies. Additionally, future research comparing field calculated upslope distances and GIS EUFL would provide a level of validation not incorporated into this study, providing useful evidence to support continuation of this methodology in trail degradation studies.

\section{Biophysical Variables}

\section{Soil and Vegetation}

Field measurements of soil and vegetation types used in this investigation are not compatible with previous research. As this trail erosion assessment was a component of a broader study to evaluate the compliance of trail corridors with USFS trail design standards, USFS soil and vegetation productivity standard measurements were collected (see Appendix A). For this reason, the statistics for soil and vegetation field variables have not been incorporated into this analysis. This gap in field data as compared to other studies can potentially limit the explanatory power of this study. Two GIS-based continuous soil variables, soil erodibility and relative soil moisture (TRMI), are included as they are easily derived from existing data sources, and are highly compatible with the regression modeling approach. 


\section{Soil Erodibility}

Extracted from USDA soil type GIS layers, this variable provides a generalized assessment of the potential for erosion of specific soil types. Map scale soil typing has been largely excluded from trail studies due to map errors particularly in edge zones where different soil types meet although limited studies do exist. For example, Arrowsmith and Inbakaran (2002) computed slope, aspect, and seasonal sunlight availability from digital elevation models (DEMs), and soil and vegetation type from an ecological vegetation class GIS layer in their study of trails in Grampian National Park, Australia. Trail models which utilize the Universal Soil Loss Equation, such as the Gaffer et al. (2008) study of military training trails in Indiana, also derive the soil erodibility scores from map scale data sources. For this study, soil erodibility showed no significant linear relationship with maximum incision. This result is expected as the range of erodibility values is limited and the majority of soils in the Forest have high erodibility rates making them all highly susceptible. This finding lends support to erosion being accelerated or moderated by forces other than the inherent binding capacity and resistance of the soils. The historical origins of study trails may provide another reason for this disconnect with map soil erodibility values. Many of the trails are built on logging roads or old narrow gauge railroad beds which have a certain level of engineering not typical of purpose designed or volunteer trails. Historic hardening of these trailbed surfaces or importation of less erosive soils which do not match the soil map designations is possible. To fully test these hypotheses, studies stratified by different map extracted soil types of interest or the inclusion of field and laboratory based soil classification and testing of on and off trail surfaces would be required. Given these findings, inclusion of this variable in future trail studies offers limited value unless utilizing USLE or WEPP GIS models which require the variable.

\section{Soil Moisture - Topographical Relative Moisture Index (TRMI)}

While intended to be a proxy for soil moisture, the topographical relative moisture index (TRMI) is based on a surface water flow model typically used in the delineation of ecological regions (M. G. Anderson et al., 1998). As the formula considers the availability of water from the upslope catchment area and the speed at which the water can flow through the raster cell on a GIS surface based on slope, it measures the potential for water to move through or collect into the sample area. This is very similar to the landform curvature model considered by Cakir (2005) which looks at each raster cell as one that catches moisture or spreads moisture. Cakir found significant linear relationships between both incision and trail width when curvature interacted with trail grade. Although minimal in its predictive power, TRMI was a significant predictor of incision for this study as well. Additionally, cove landforms which have 
correspondingly high TRMI values when compared with other landform units, also accounted for the highest percentage of linear erosion in this study providing further evidence of this relationship.

The inability of measuring water flow at any given study point has been noted as a frustration by previous researchers (Coleman, 1981). While not a specific field measurement, this GIS based variable may provide a consistent tool to approximate the potential for water to flow through a given sample point. While Parker (2004) includes upslope areas as part of a trail watershed in his trail design text, he contends that under normal conditions $90 \%$ of water moving down a trail is from the trail surface itself. Exceptions to this are during abnormally high precipitation or run-off events. In these instances, areas with high TRMI values or curvatures which concentrate flow direct off-trail water moving too quickly to be absorbed or water moving over saturated soils down-slope and potentially onto trails increasing erosion rates. As this GIS-based variable has only been used in a limited number of studies, further investigation is needed to evaluate its effectiveness as a predictor of erosion but these and Cakir's findings are promising.

\section{Forest Canopy}

Previous research has shown that an open canopy contributes to erosion through increased rainfall splash detaching soils as well as drying and cracking of soils in summer due to direct sunlight (Bryan, 1977; Dissmeyer \& Foster, 1981; Hammitt \& Cole, 1998; Harden, 2001). For this study, sample points with open canopies had .63 inches greater maximum incision than those with partial or closed canopies providing further evidence of this relationship. Determining the degree of openness of the canopy is subjective given this field methodology which makes consistent application of this measurement difficult. Utilizing a more systematic measurement such as a GIS vegetative cover analysis described by Dissmeyer \& Foster (1981) would provide a more objective measure. From a practical perspective, trails in open areas should expect higher erosion rates and thus greater maintenance requirements.

\section{Land Grade}

Land grade surrounding sample points did not have a significant influence on maximum incision patterns for this study. As presented in the literature review, landform grade has a greater influence on trail width and mud development than erosion so this finding is complimentary to other research. Other variables regarding the orientation of the trail to the land's grade, trail position and trail alignment, are more important to degradation modeling. 


\section{Elevation, Average Winter Temperature, and Mean Annual Rainfall}

These three variables are grouped here due to their close correlations both in a practical sense and in their actual values. Elevation by itself displayed a limited correlation to maximum incision but plays a critical role in determining temperatures and rainfall throughout the Forest. Thermoclines which influence vegetation, winds, frost, and snowfall are present throughout the MNF as elevations vary from 1000 feet to 4800 feet. High elevation ridge lines form barriers to persistent weather patterns separating the Forest into wet and dry areas. Trails over 2500 feet experienced greater snow amounts and frost levels than those below 2500 feet. Additionally, certain geologic and soil attributes were only exposed as potential trail surfaces when certain elevations were reached. From a computational standpoint, values for average winter temperature and mean annual rainfall were calculated from fixed weather stations and interpolated across the landscape utilizing elevation as a correction factor. Elevation data was also critical in determining slopes, TRMI, land grade, and in estimating upslope flow lengths (EUFL). The multitude of relationships of elevation to the land and to the GIS layers in this study make it a critical element to the research but due to the complexity of these relationships it does not stand alone in its direct influence on maximum incision.

Average winter temperature was the only one of these elevation dependent variables that exhibited a significant linear relationship with maximum incision. Decreases in average winter temperature varied linearly with increases in maximum incision. Two probable reasons for this relationship can be gleaned from previous research. First, frost heave, and the formation of sub-surface needle ice at higher elevations and lower temperatures increase the detachment of surface materials increasing the potential for erosion (Coleman, 1981; S. K. Nepal, 2003; Whinam \& Chilcott, 2003; Yoda \& Watanabe, 2000). Second, spring snow melt can provide a catastrophic water flow event for trails at higher elevations (Bryan, 1977; Yoda \& Watanabe, 2000). Due to the snowmelt, soils at higher elevation are wetter later into the spring when hikers begin to use the trails. In other parts of the U.S. trail use is prohibited during this time but no such restrictions exist in MNF. Wet trails have been closely linked to trail widening as trail users attempt to avoid mud or standing water in the tread and wider trails mean more runoff and thus more erosion. Few studies look at the relationship between width and erosion as both are deemed dependent variables but exposed soil is a requirement of most erosion models and the relationship should be investigated further.

Lack of a linear relationship between mean annual rainfall and maximum incision is unexpected as precipitation is a key element in erosion. Trails were not selected to test the influence of this variable 
and the majority of sample points fell in a relatively narrow band of rainfall totals with Landis Trail in the dry North Mountain region being the exception. No information was collected on the timing or intensity of precipitation events. Heavy rain events are known to scour trails and to create deep gully erosion as was observed in a few isolated locations on the MNF trails. Although limited, these washout sections of trail appear to be historic again pointing to the accumulation of limited maintenance and repair regimens as an influential factor in the cumulative impacts observed. As rainfall was an interpolated value derived from a discreet set of observation points, it is possible that microclimates of increased rainfall intensity are present in the Forest. From these findings, a suitability model such as that proposed by Garland (1990) for the Drakensberg range in South Africa would perform poorly as rainfall accounts for a large percentage of the index. Combining rainfall with a broader set of variables such as in the USLE or WEPP models may perform better for this region as rainfall interacts with other more influential factors.

\section{Regression Model}

Stepwise regression analysis for the point sample data revealed that variables from each category of independent variable, recreational use, biophysical, and managerial, contributed significantly to the explained variance in maximum incision. The amount of explained variance was $23.5 \%$ for the complete multi-regression model which includes the use volume, trail grade, trail alignment, valley position, and soil moisture independent variables. Managerial variables performed best as a group explaining half of the variance in maximum incision.

Two reviewed studies used similar statistical analysis methods for assessing the explained variance in a maximum incision variable. Coleman (1981) found that use volume interacting with slope, cross-trail slope (landform slope), ridge position, and soil type combined to predict $46 \%$ of the variance in the maximum incision variable for his study of English Lake District footpaths. All use for this region was hiking and use volume was compared for a period of weeks with data coming from self reporting registers at each of 25 trail heads. Vegetation type, trail grade, altitude, aspect, and trail surface were all recorded for this study as well but were not significant in the model. The predictive power of the Coleman study is almost double that of this research which used very similar field measurements. The region and diversity of trails in the Coleman study were both more limited than those surveyed in the MNF and the measure of use pressure was of much greater accuracy. Cakir (2005) also conducted regression analysis on the relationship of maximum incision to field and GIS based variables. As her study was intended to try to create a predictive model which substituted field observations for GIS 
derived variables, the recreational use variables were omitted. The Cakir study was conducted on a single $5 \mathrm{~km}$ trail segment with fairly consistent environmental conditions and use limited to hiking only. Measurement intervals were 50 meters apart as compared to the 200 meter frequency of this study. These differences present a much more homogenous setting for conducting this type of relational analysis and the results, $63 \%$ explained variance (42\% from field collected data only), provide a much higher confidence in the predictive relationships. The most prominent independent variables which comprised Cakir's incision model were landform curvature, valley bottom trail position, landform slope, and trail grade.

Additional studies which used cross sectional area (CSA) as the dependent variable also showed higher predicted variance than this study: Jubenville and O'Sullivan (1987) were able to explain $32.5 \%$ of the variance in CSA from trail slope in a sample stratified by vegetation type; Olive and Marion (2009) 31\% with trail valley position, explaining $11 \%$ of the total variance, trail alignment, and use type (hiking vs. horse); and, Gager and Conacher (2001) were able to explain $48.2 \%$ of the variance in CSA with trail slope alone and $49.5 \%$ with slope and upslope trail length (a field measurement of upslope flow length to eroded test segment). Aust, Marion, and Kyle (2005) did not report the explained variance in CSA but did indicate that distance to drainage features (a field estimate of upslope flow length to sample point) was the most influential variable in their regression model which also included trail alignment and percent gravel cover on trail. Garland et al. (1985) were unsuccessful in their erosion models in the North Drakensberg region of South Africa, explaining only limited variability in cross-sectional path area. Garland notes several possible reasons for the poor performance including inappropriate statistical method, inaccuracy in measurement of the dependent variable, lack of information about the path use, or lack of information about variation in rainfall intensity.

The point sample findings here do not improve the predictive power of the point sample model. While the explained variance is comparable to a few studies it is still relatively low and as shown is less than previous research utilizing similar techniques and variables. As recreational use levels were prominent in several of the models, the subjective nature of the volume estimates used in this study are one potential reason for the more limited predictive power although this was a significant contributor to the regression equation. The diversity of environmental settings is another differentiating characteristic of this study which may have diminished its predictive power. As a baseline analysis of trail conditions in the MNF, future work using smaller homogenous regions or stratified sampling techniques of vegetative communities, soil types, or trail grade categories identified and mapped in this study might improve the 
model. These differences also reinforce the assertion by Hammitt and Cole (1998) that observed trail degradation relationships are highly site specific and that the MNF may well have other important factors influencing erosion rates that are not well represented utilizing this standardized approach.

Only one GIS derived variable, topographic relative moisture index (TRMI), remained in the final regression model. There is some question as to the field level equivalent of this measure. The definition infers it is a proxy for soil moisture but it appears to be more aligned with the potential delivery of overland water flow to the point sample region. In the latter approach it behaves more similarly to the water shedding - water collecting landform variable used by Cakir (2005) which she found to be significant in her predictive model as well. Inclusion of this variable is important as it is not something easily observed in the field making this GIS derivation an addition to the measurement tools used in the predictive models.

\section{4: Problem Census}

The problem census of study trails provides a descriptive model of the presence and distribution of erosion across the Forest. As the study trails range in length from .6 to 7 miles in length, characterization of the setting to establish relationships with environmental and management variables is difficult given the heterogeneity of these variables along the trail lengths. While limited in this way from a research perspective, this approach is most consistent with current trail inventory systems that look at management infrastructure and trail maintenance providing a high practical utility for trail maintenance planning as found by Jewell and Hammitt (2000) in their survey of trail management experts. With only $3.4 \%$ (approximately 2.1 miles or $178 \mathrm{feet} / \mathrm{mile}$ ) of the total surveyed trail length displaying linear erosion as defined in this study (sections of tread ( $\geq 10 \mathrm{ft}$ ) with soil erosion exceeding 5 inches depth), the study trails collectively are generally in good condition in regards to erosion. As trail problem assessment research has traditionally defined the dimensions for erosion and mud to meet the needs of the management agency and to match the expected degradation conditions of the resource management area under consideration, there is only limited standardization of what is considered linear erosion which makes comparison of these finding with previous studies difficult. For instance, Nepal and Nepal (2004) in their trail study at Mt. Everest categorized erosion into severity classes of 0 - 6, 6 12, 12 - 18, 18 - 24, and greater than 24 inches. Similarly, Marion and Leung (2001) created categories of $1-2,2-3$, and greater than 3 feet for their study of a 15 mile segment of the Appalachian Trail. No 
such categorization was done for this study although qualitative descriptions were collected for occurrences of linear erosion which show representation in each of the erosion categories from either study. For the Marion and Leung study, $7.1 \%$ of the 15 mile trail segment displayed the erosion problem, or an average of 400 feet of erosion per mile, no similar calculation was available from the Nepal and Nepal study due to the way they segmented their study trails. Three published studies used the same erosion problem definition as used here which is an emerging standard in recognition of the need to make data comparable between resource areas. Aust, Marion, and Kyle (2005) found that $9 \%$ of the 36 miles of horse trails under investigation in the Hoosier National Forest displayed the defined erosion problem at a density of 455 feet per mile; Farrell and Marion (2001) studied five trails from different protected areas in Costa Rica and Belize reporting 14\% of one trail was eroded (791 feet per mile), with the other four having less than $2 \%$ of their length eroded; and Manning, Jacobi, and Marion (2006) found only 320 yards of erosion on the 20 miles of trail (.003\% or 18 feet per mile) on Acadia's Isle au Haut trails. Marion (1994) surveyed 328 miles of trail in Great Smokey Mountain National Park and found $4.5 \%$ eroded deeper than 1 foot, 14.6 miles or 239 feet/mile. Although each of these trail systems are set in unique environmental conditions, receive a variety of use levels and types, and are managed differently, the comparison does show that trails on MNF are on the lower end of the impact scale. All studies demonstrate that this level of analysis is very coarse and offers a limited view of the causal factors influencing erosion rates.

A more detailed look at the individual MNF study trails reveals that erosion is non-existent on four of the study trails and exceeds $500 \mathrm{feet} / \mathrm{mile}$ on four trails. Two deviations from previous research are characterized by this data: 1) three of the four trails with the greatest erosion are low-use trails and three of the four trails displaying no erosion are high-use trails; and 2) trails with relatively low gradients displayed some of the highest densities of trail erosion. These findings will be discussed further in the recreational use and biophysical variable sections below.

\section{Recreational Use}

Although it has been demonstrated that different environmental conditions and management practices can minimize erosion rates influenced by recreational use, use is still a key element in the erosion equation. Generally, it is accepted that this is a curvilinear relationship where impacts increase with initial use then level off as the site is hardened. What is unusual in this data set is that the erosion impacts found on three low-use trails are disproportionate to that found on all but one high-use trail. 
The trails in question are long established hiking routes that receive minimal annual visitation. By comparison, only one of eight study trails in the Aust, Marion, and Kyle (2005) study with erosion distribution greater than 500 feet per mile was in the low-use category, although they did have one high and one low-use trail in the "no erosion" group. Dixon et al. (2004) display a similar relationship with low-use trails demonstrating much greater maximum incision than the high usage trails over a 40-year period although they do not note this to be a significant finding. While recreational use is a significant predictor in all models presented in this study, this finding suggests that it has a more limited influence on erosion. The trails in question, Green Mountain, Strip Mine, and Turkey Point Connector are very different in their physical layout, origins, and geographic regions. Green Mountain trail is a remote wilderness trail on a high ridge, the erosion appears to be historical, perhaps dating back to the severe hurricane damage of the late 1980s or other catastrophic rain, or snow melt event as the trail is moderately gullied in some sections. This trail is remote, centered in Otter Creek Wilderness approximately 15 miles from the nearest trailhead, and very little maintenance such as brush trimming or water bar maintenance was observed. Another indicator that erosion on Green Mountain trail is historical is that unlike high-use trails, the erosion area is narrow and much of the trail is coved with leaf litter. Strip Mine trail was one of the longer trails in the study and traverses a wide range of land types including two distinct surface mining reclamation areas and several long steep slopes on abandoned timber roads. Disturbed soils and engineered drainage systems are probable contributors to the high erosion rates on this trail although it also receives little tread maintenance. More than half of the length of Turkey Point Connector trail is built on an old logging road with machine cut drainage including water bars and side trenching. A tremendous amount of water was observed on this trail which is deeply entrenched due to the original road design. Trail tread beyond the road bed displays very little erosion which again points to disturbed soils as primary contributor to problems on this trail. As discussed in trail design literature (T. S. Parker, 2004) and previous research (Coleman, 1981), cross-slope trails have the risk of intercepting sub-surface water flow in addition to capturing surface flow with their incised treads, both sources of water appear to be present on this trail. Erosion on all three trails appears to be ongoing and worsening supporting the concept that erosion is "non-self-limiting" (Hammitt \& Cole, 1998; Hill \& Pickering, 2009). The low levels of estimated and observed recreational use on these trails have been enough to remove vegetation from a central tread but limited incision of non-eroded tread indicate a lack of compaction of the trail surface. Although compaction reduces infiltration and increase the speed of water flow it also provides a level of protection for the trail surface through hardening. 
Inclusion of surface bulk density tests with a field penetrometer could be used to confirm this hypothesis in future studies of these trails.

\section{Managerial Variables}

Only two managerial factors were calculated for the full lengths of the study trails for consideration with the problem census approach, trail grade and estimated upslope flow length (EUFL). Both of these variables were derived from GIS elevation grids and were averaged for the entire length of each trail. Given the diversity of terrain which some of the longer study trails traverse, the average values are limited in providing a meaningful picture of the topography and layout of the trails. The lack of alignment of GIS derived trail slopes and field observations has been previously introduced in the trail degradation research (Cakir, 2005; S. K. Nepal \& Nepal, 2004) noting calculation methods utilizing grids, interpolation, and differences in exact topographical positioning as probable sources of differences. As trail vector mapping introduces greater error than point sampling due to more limited GPS points per vertex and the straightening of trail vectors between vertices in the GIS depiction, this finding is not unexpected. Another potential problem in using GIS for these calculations is that the width of trails is most often narrower than a raster cell used, this problem is amplified on steep side-slopes where slope can vary greatly depending on where in the cell you are positioned. On the interpolated elevation grids used in this study, although they are the best available, some engineered trail bed surfaces such as old railroad grades and logging roads are not represented in the data. As these structures change the slope of the land significantly their omission further limits the ability of GIS to model on-trail processes and may have contributed to the lack of significance of these topographic dependent variables in this and other methods in this study.

\section{Biophysical}

When considering trail erosion on a regional scale, as necessitated by consideration of the full length of each study trail, biophysical variables were strong contributors to understanding the differences in erosion problem frequencies. Elevation and elevation related climate variables, mean annual precipitation and average winter temperatures, were all significant predictors of the density of erosion problems on the trails. These variables were all GIS derived and averaged for each trail. As these variables are representative of larger geographic areas than on-trail slope or estimated upslope flow length, they perform better in this type of regional analysis. It is possible that micro-climates, not represented by these interpolated data sets, may exist within the highly varied topography of the Forest 
but the probability of this influencing the data on such a large scale is minimal. The potential colinearity of these three variables found in the other two methods requires further investigation into which variable is the most influential. As mean annual precipitation is not closely related to mean winter temperatures elevation is the variable in question. Past research is also conflicted in this analysis although several studies have pointed to rainfall amounts as a significant predictor of erosion (Arrowsmith \& Inbakaran, 2002; Dixon et al., 2004; Garland, 1990). Bratton et al. (1979) found that elevation was strongly correlated with erosion levels but surmised that this was a function of forest type and greater rainfall on high ridges. Elevation is clearly an influencing factor but it may be an indirect one. Mean annual winter temperature has not been a variable considered frequently in trail erosion literature although it is included in some landscape and forest road erosion models. The influence of this variable on the formation of snow pack and related spring runoff as well as the previously mentioned formation of frost heave and needle ice have been noted. Its significance here where winter temperatures below 32 degrees Fahrenheit account for $47 \%$ of the cumulative trail erosion is noteworthy and requires further investigation in similar mid-latitude trail systems with high elevation variability.

\section{5: Linear Segment}

The final sampling method for this study, linear segment analysis, utilizing route linear segmentation GIS functions and field GPS points to geo-reference field wheel distances is new to trail degradation research. This method is most similar to that employed by Bratton, Hickler, and Graves (1979) where traditional paper based maps where utilized prior to field surveys to segment trails into $.5 \mathrm{~km}$ sections. What is unclear in the Bratton et al. study is how they identified mapped sample points in the field as GPS was not readily available and no mention was made of a measuring wheel. There are a number of noteworthy differences between this study and the Bratton et al. study, first, the linear segments for this study were post processed, i.e. segments were characterized in the computer lab after the field work was completed based on high quality start and end GPS points increasing the confidence in positional accuracy. Secondly, Bratton et al. used subjective estimates of erosion percentage per segment and this study used measured length of a single erosion problem type, this subjective assessment was noted as a limitation by Bratton et al. in their report. Segments in this study were also much shorter, 600 feet versus 1640 feet, providing a more homogenous trail segment for consideration. Finally, point samples at the end of each trail segment in the Bratton et al. study were used to help 
characterize the erosion on the previous segment of trail; this method was also replicated by Obua and Harding (1997). As this and other studies provide evidence that point samples miss a large percentage of occurrences of erosion in trail surveys, the usefulness of this methodology is marginalized. Although the uni-dimensional variable of length of erosion per segment utilized in this study is more objective, it fails to capture the extent of soil removed from the trail, treating each occurrence the same whether five or twenty-four inches in depth with no calculation for width. Categorizing erosion by depth such as Marion and Leung's (2001) Appalachian Trail study may improve the results but it also limits the use of regression analysis as it becomes a categorical variable.

Linear segment analysis was also used by Wilkerson and Whitman (2009) and Nepal and Nepal (2004) but each study treated trail segments uniquely. Wilkerson and Whitman had two varying segment lengths, $2 \mathrm{~km}$ and $5 \mathrm{~km}$, and used frequency of occurrence of erosion problem variable per kilometer instead of actual lengths, a more sensitive measure, as the dependent variable. Nepal and Nepal used a combination of field and lab analyses to segment trails into varying lengths of 50 to several hundred meters based on the presence of common tread impacts, environmental setting, resource condition, and maintenance features. Additionally, Nepal and Nepal utilized a condition class schema similar to Bratton et al. to compute a composite impact score which included erosion and muddiness making it more difficult to delineate erosion impacts separately. Nepal and Nepal also utilized GPS and GIS in their analysis but noted difficulty in matching field wheel distances to linear lengths in the GIS. Similar to this study they utilized field GPS point data to scale trail sections that had longer field measured lengths than GIS lengths due to large changes in elevation. The Nepal and Nepal research would have benefited from collecting more frequent high-quality GPS points as in this study which utilized over 500 GPS points for 63 miles of trail as compared to Nepal and Nepal who used 65 GPS points to calibrate lengths on 55 miles of trail. Ad hoc analysis of this calibration method for this study showed linear variations of 20 to over 100 feet of point data along various trails. Thus, this method vastly improved the positional accuracy of trail features and segment positioning for use in the relational analysis. Linear segments are also used in forest road erosion modeling but segments are based on road drainage lengths (D. M. Anderson \& MacDonald, 1998; Elliot \& Hall, 1997). As similar lengths were calculated for EUFL, this approach may be feasible for future research but was not incorporated here.

Since this method is not comparable to other trail degradation studies, results must be interpreted more generally with regards to use, biophysical, and management variable relationships to trail erosion. The 
19.9\% of trail segments exhibiting erosion is much higher than either the point sample $(5.9 \%)$ or problem census (3.4\%) methods utilized in this study. Additionally, when compared to other trail erosion studies of all types, this number is substantially higher (see Problem Census discussion), so care must be taken when considering these data, and this analysis should be treated as exploratory.

\section{Recreational Use}

When considering all linear segments there were no significant relationships with use volume and presence of erosion. For segments which exhibited erosion, low-use trails exhibited greater erosion than high-medium-use trails as in the problem census method. As this method produces a census of erosion for each segment this consistency reinforces that segments better reflect the patterns of erosion than the point sample method. Still the inconsistency of having the point sample data displaying significantly deeper incision for high-medium trails is problematic. This finding again demonstrates limitations of each method in representing a snapshot of trail degradation. While the results for linear segment data are significant for recreational use, they do not add to the understanding of erosion distribution that was established from the problem census method. For trails exhibiting erosion, the linear segment analysis slightly amplifies the results of the problem census method; for linear segments low-use trails (148 feet/segment) show 2.1 times the amount of mean erosion length than high-medium use trails (71 feet/segment), the census method was only 1.7 times larger (low-use $375 \mathrm{feet} / \mathrm{mile}$ and high-use $217 \mathrm{feet} / \mathrm{mile}$ ). As expected the linear segment results for horse use were similar to the problem census findings, trails with horse use had less eroded segments. These consistent findings indicate that these two methods are measuring the same relationships for use volume and horse use.

\section{Managerial Variables}

Trail grade and GIS estimated upslope flow length are the only two managerial variables included in the linear segment analysis. Unlike point sample data, average segment trail grade was not a significant predictor of erosion for MNF trails. As trail grade is one of the stronger predictors of erosion across the trail degradation literature and is demonstrated to exist in MNF with the results of the point sample method, the inability of this method to demonstrate the relationship is limiting. Gradient fluctuations along a trail segment appear to mask the relationship, or the extraction of average trail grades from a GIS elevation surface introduces too much error to demonstrate the relationship. It is also feasible that trail erosion operates on a smaller scale than 600 -foot trail segments where short steep sections of trail 
produce disproportionate levels of erosion. This hypothesis is better tested using a field-based problem analysis methodology such as that employed by Gager and Conacher (2001) which looks at specific impacted areas and independent variables in the direct vicinity of the site.

Although GIS estimated upslope flow length (EUFL) is derived from elevation grids it differs from segment trail grade in that it is a measure of continuous downhill grade independent of the degree of gradient. Mean EUFL values had the highest explained variance of any independent variable in the study at $13.6 \%$. While exploratory, this finding supports both the research and the trail design literature with a replicable, objective, quantitative measure showing that the longer water moves along a trail the greater its erosional impact on the trail. Using field methodologies Gager and Conacher (2001) and Aust et al. (2005) both demonstrated this same relationship although to a lesser degree. Gager and Conacher found that tail grade and upslope trail length explained $49.5 \%$ of the variance in soil loss of their on-trail study plots. Although upslope trail length only contributed a small amount to the predictive model, it was strongly significant and these were the only two variables to remain in a stepwise regression analysis. Trail alignment, trail width, off-trail granite outcroppings, and several soil properties all dropped from the equation and were labeled as erosion "influencing" rather than "controlling" variables. Aust et al. measured distances from sample points to the closest uphill "tread drainage feature", such as a functioning water bar, limiting their maximum measurement to 100 feet. They found the distance to these features to be the most influential factor in predicting soil loss at their sample points (no $R_{a d j}^{2}$ value was provided). Both studies noted the presences of water diversion structures that were non-functioning which could have reduced the upslope flow lengths, this was also found to be the case in MNF emphasizing the importance of maintenance on these structures. The importance of functioning water diversion structures on trails is also emphasized in recent trail erosion modeling conducted by the USFS Stream System Technology Center which found that in the WEPP:Roads Batch model, installing water diversion structures every 50 meters on steep sections of study trails decreased the erosion potential by $67 \%$ (Breibart, 2007). Given previous findings and the significance of this variable in the prediction of maximum incision and eroded lengths of trail segments in this study it is worthwhile to consider in future research. As this value is derived from secondary data, it is also possible to calculate EUFL for previous trail studies to assess its potential influence. The derivation of EUFL can be further improved utilizing higher resolution elevation data and emerging zonal statistical computations available in the evolving GIS software. 


\section{Biophysical Variables}

The results of the influence of biophysical variables on cumulative length of erosion per segment conflict for this study. When looking at eroded segments versus non-eroded, significant patterns are displayed for elevation, mean annual rainfall, mean winter temperature, and topographic relative moisture index (TRMI). The finding that erosion rates increase with elevation and annual rainfall is supported by the literature as previously discussed. Consideration of mean winter temperatures and TRMI are new to trail degradation research so there is no point for comparison. When analyzing eroded segment data exclusively utilizing regression statistics, only the relationship of erosion with TRMI remains significant. This finding implies that trail segments with erosion behave differently than those without. To fully test this finding, balanced sampling would be required to insure equal representation of select biophysical conditions as well as a range of eroded segment lengths.

Although ecological land unit analysis is limited in this study due to insufficient representation of data points in the fourteen landform categories, it does show promise as a potential variable in creating a sensitivity index for planning new trails or for trail re-routing. The data suggests that trails in cove, midslope, and strip mine areas are more susceptible to erosion than trails in other landform types. As previously mentioned cove areas concentrate surface and ground water increasing soil moisture level which makes soils more susceptible to erosion as well as increasing the water available to erode trails. Midslope trail positions when incised intercept water and when water diversion structures are not maintained can accumulate large quantities of water moving down the incised tread for long distances. Strip mine locales have altered drainage systems, disturbed soils, and open canopies which make them highly susceptible to both mud development and erosion.

\section{Regression Analysis}

Like the point sample analysis, regression analysis of linear segments with erosion displayed significant relationships with at least one variable from each independent variable category, recreational use, biophysical, and managerial. The linear segment regression combined model performed slightly better than the point sample model $\left(R_{a d j}^{2}=.235\right)$ explaining $27.4 \%$ of the variance in the cumulative length of erosion per segment. Recreation use volume and the biophysical variable TRMI performed similarly in both models. The primary difference was the inability to model management variables for trail segments, specifically trail alignment and relative position of the segments. In addition to these two variables, further experimentation with the capabilities of GIS spatial analysis tools for biophysical 
variables such as forest cover (Chatterjea, 2007; Gaffer et al., 2008), vegetation communities (Bratton et al., 1979; Törn et al., 2009) and a more sensitive indicator of soil texture could further improve this model. Consideration of GIS data layers for this type of analysis is expanding with the integration of GIS in general landscape and forest road erosion modeling and consultation of this broader literature would be of benefit to trail erosion studies. The importance of trail design and maintenance, both management variables, is emphasized again in this model by the strong contribution of EUFL. This variable alone accounted for $51 \%$ of the explained variance in cumulative erosion lengths in the segment analysis, performing slightly better than the combination of trail grade, trail alignment, and midslope position management variables in the point sample analysis.

\section{6: Managerial Implications}

For the Monongahela National Forest, this study provides baseline data on the frequency, severity, and distribution of erosion on sample trails from across the Forest. Generalized findings show that the trails are in good condition relative to other large trail inventories with severe erosion focused on a few "hotspots." Observations and data on the frequency and conditions of water control features show that they are below USFS standards for frequency and are in generally poor condition on the majority of study trails. The resulting increase in on-trail flow lengths is causing increased erosion particularly on midslope trails that run obliquely to landform slopes with low trail grades. As is common with trail use, original out-sloping of these trails have been compromised and incised trails now transport water freely down the trail treads. Although currently in fair condition, these changes in the trail structure threaten the sustainability of the trail treads particularly with major rainfall events. Additionally, due to convenience and reduced cost of construction, many trails in the Forest are constructed on historic logging roadbeds and retired railroad grades. The long, unbroken shallow grades and altered drainage of these surfaces have shown to be susceptible to erosion particularly when water diversion structures are not present or are poorly maintained. New trails and trail reroutes should consider alternate locations to existing roadbeds and railroad grades. These trails should be built with long-term impacts in mind incorporating modern trail building techniques for water removal such as lower maintenance grade reversals to create shorter on-trail flow lengths.

For eroded sections of trail, the finding that low-use trails are exhibiting erosion at disproportionately higher levels than high-moderate-use trails impacts trail maintenance prioritization. In an environment 
of reduced maintenance budgets trail managers must weigh the trade-offs of repairing trails that have higher visibility and high recreational use against restoring or decommissioning less visible low-use trails that may be causing greater resource and environmental impacts. As it has been documented that erosion is non-self-limiting and will continue introducing sediments into adjacent waterways or creating muddy on-trail sediment dumps unless action is taken to remediate these problems, mitigation of these problems on MNF trails require intervention. This problem is of specific concern in Wilderness areas which require a higher level of care in protecting the resource from human induced impacts such as recreational trail use.

While trails are in good condition, recreational use is consistently found to impact trail conditions. For MNF it appears to be a distribution of use issue and not an overall volume issue as many of the study trails displayed limited use, in fact in three months of mid-week travel by the researcher fewer than a dozen travelers where seen on all study trails combined. Use is concentrated on trails in the high elevation, high precipitation, and low winter temperature spine of the Forest. All of these variables were found to be significant contributors to soil loss in the study. The seldom visited eastern side of the Forest is slightly lower in elevation and is in a rain shadow of the central mountains making trails there much more resistant to erosion. Further development of trails in this region which offer attractive overlooks, historical themes, or which take advantage of water features should be considered. Investigating other amenities and resources to encourage use of these more sustainable trails is also required to help shift the public's consideration of them as viable options. These trails are particularly well suited in spring when higher elevation trails are most sensitive to high impact trail use behaviors caused by the desire to avoid wet trail surfaces such as hiking outside the trail tread. The lack of drinking water on many of the eastern trails due to the drier climate is an issue for longer distance travel and the addition of water stations at trail heads or the mapping of springs with access trails could also encourage use.

Horse use of trails was not found to be causing significant erosion problems for the study trails in this investigation. This is a positive finding for the continued use of MNF by horseback riders but it is not consistent with the majority of findings from other trail degradation studies. Caution must be exercised in the expansion of horse use to trails which are poorly designed for this mode of travel. For example, the field survey of Shingletree trail in the Cheat Ranger District which has sections of narrow hillside trails with tight switchbacks displayed evidence of a single or possibly a pair of horseback riders using the trail. From this limited use, substantial damage to the downhill edge of this trail was observed. 
Swallow Rock trail in the Seneca Creek Backcountry area of the Potomac District had some of the highest horse use observed on study trails. High occurrences of deep mud, deep incision, increased width, and the frequent presence of horse feces and urine have greatly impacted this trail. These are similar to horse related impacts observed at other resource areas such as the Great Smokey Mountain National Park, Big South Recreation Area, Hoosier National Forest, and Rocky Mountain National Park. While these are expected impacts from horse use, certain trails are better suited to resists or absorb these and higher maintenance is often required. Conflicts between horseback riders and hikers have also been noted as a common issue at other resource areas although it has not been investigated in MNF. Limiting horse use to trails which can absorb these impacts and partnering with the horseback riding community to assist with education of riders, development of trail guides to appropriate trails, installation of trail head and on-trail tie stations, and volunteer programs to help with the increased trail maintenance required of horse trails have shown to be positive steps in establishing sustainable horseback riding trail systems. Clear signage of horse use trails and alternate routes without horse use in the same regions can help alleviate potential user conflicts as well.

From a longer-term perspective, this baseline study provides MNF with a benchmark to compare future trail conditions and can serve as a foundation for a trail impact assessment and monitoring system. If a visitor impact monitoring program were to be employed across the Forest, the methodologies used in this study have established a number of measurements that could be used as indicators of change in trail conditions. Some examples used in other resource areas are: from the problem census, the number of linear feet of erosion per mile; from the point sample, the percentage of sample points with incision greater than five inches; and from the linear segment analysis, the number of 600-foot trail segments with erosion greater than 5 inches or the number of segments with linear erosion greater than 20 percent of their length. The benefit of the point sample and linear segment indicators is that, with the utilization of the GIS methodology employed in this study, the distribution and density of these impacts can also be observed. Additionally, the geo-location of impacts using the route segmentation function of GIS meshes well with emerging trail inventory management systems and mapping of trail infrastructure. This method can assist in planning of trail maintenance and in directing field crews to problem sites. As this research integrates on-trail factors in the erosion models, the resulting regression equations are not directly suitable for development of a general landscape sensitivity grid to aid managers in making trail alignment decisions. These equations could be used to evaluate other trails in the Forest for erosion potential as well as assess proposed trail alignments similarly to Breibart's (2007) application of the WEPP:Roads Batch model. Field verification of these findings and comparison of 
results with USDA soil suitability grids are recommended to see if this research provides a more accurate and sensitive planning framework for trail locations. If additional applied research is funded on trail erosion for MNF, this baseline study and associated geo-referenced maps of erosion occurrences can also enable more advanced sampling methodologies which can compare eroded and non-eroded trail segments.

\section{7: Research Implications}

This study contributes to a broad body of literature on trail erosion modeling within recreation ecology. As it is recognized that the influences effecting erosion and the characteristics of erosion occurrences vary by region, this study provides another viewpoint from which to consider universal trends in trail erosion processes. While the point sample and problem census methodologies attempted to follow the most common practices in trail assessment field protocols for ease of comparing results, this study also introduced a new method of considering landform scale variables through the use of GIS technology into the discussion as has been called for by leaders in the recreation ecology discipline.

As the explained variance for the regression models calculated through this analysis is limited, consistent with previous high mileage trail impact assessments, this study fails to illuminate further on the complexity of the relationships between recreational use, biophysical variables, and management practices. The findings are supportive of previous findings that each variable category plays a role in erosion and that the location, design, and maintenance of trails have a strong role in their resistance to erosion. In reviewing these findings and that of previous assessments of varying trail distances, a number of possibilities are apparent for future research to refine the understanding of erosional processes on trails.

Sampling method appears to be one alternate approach. Large scale trail studies consider highly varied environmental condition including elevation, precipitation, temperature, forest cover, and land form. Smaller scale studies consider much more homogenous environmental conditions and consistently explain more variance in the dependent erosion variables by the same independent variables used in larger studies. More advanced stratified sampling designs which attempt to isolate trails into homogenous environmental settings with common biophysical influences may yield improved results. 
Micro-topography appears to have a strong influence on trail erosion, as problems are isolated to small areas which have similar macro-topography to non-eroded trail segments. The GIS derived topographic relative moisture index (TRMI) of this study and landform curvature variables investigated by Cakir (2005) provide possible methods for measuring and incorporating micro-topographic features into future studies. These elevation derived variables appear to be sensitive enough to capture site scale drainage patterns that influence trail erosion rates dependent on the scale of the elevation raster data. Experimentation with higher resolution LiDAR data has promise for improved characterization of microtopography but at the time of this publication is still limited to small scale projects. For other landscape scale variables, the size of the region to consider as influential is still not answered by this research. For example, are precipitation rates from a regional interpolated map adequate when considering a specific erosion problem area or are more localized data sources needed to identify micro-climates or localized catastrophic precipitation events? Problem analysis studies, such as those conducted by Gager and Conacher (2001), implemented on a broader scale are needed to better understand the appropriate scale to consider for each variable.

The dimensioning of trail watersheds, as described by Parker (2004), was a primary focus of the GIS computations for this study. Estimated upslope flow length (EUFL) performed well in the predictive model for erosion on 600 -foot linear segments but explained limited variance in predicting maximum incision at individual sample points. Research by Olive and Marion (2009), Aust et al. (2005), and Gager and Conacher (2001) also included upslope trail drainage length variables but utilized time consuming field techniques with limited distances to measure this variable. If used in future research, field validation of the accuracy of the GIS EUFL derivations is needed as the interpolation of raster data and the stair-stepping of trail vectors crossing slopes obliquely has the strong potential to introduce error. Still with refinement, this GIS approach may add an important dimension to trail erosion models that is currently being employed in the modeling of forest road erosion (E. S. Brooks et al., 2006).

More recent trail erosion studies have favored the use of cross-sectional area (CSA) as the proxy dependent variable for measuring erosion rather than the maximum incision variable used here. The long-standing metric of maximum incision is being questioned as a valid measure as it fails to consider the amount of soil removed from a sample site. CSA is questioned as well as it combines two recreational impacts, tread incision and tread width, into one value (Marion et al., 2006). A recent study by Olive and Marion (2009) measured both but authors have not published a comparison of the relational models using each dependent variable. Increasing the linear area sampled at each sampling 
point, as done by Dixon, Hawes, and McPherson (2004), also provides potential increase in accuracy of erosion prediction and could be used with both maximum incision and CSA.

Another movement in trail erosion research is to try to separate compaction (Godwin, 2000) and historic erosion (T. F. Farrell \& Marion, 2002) from the observed maximum incision values. Each of these methods improves upon the sensitivity of the erosion proxy variable in measuring active erosion but will again make this and other studies incompatible with their findings. Observations in MNF, particularly at higher elevations with sensitive soils and high water tables and on trails with relatively high use, showed considerable incision that appeared to be more of a function of compaction than erosion. Low-use trails in these same areas appeared to be incised or gullied by erosion with only limited compaction contributing to maximum incision. Future studies should consider these differences in approach as each has substantially different methodological considerations and narrows the scope of comparable results. The addition of a penetrometer for assessing soil bulk density or the inclusion of the Saleh Roughness Scale have been experimented with in large scale studies as other ways of differentiating compaction from incision but with mixed results. These methods warrant further investigation for their ability to model trail tread morphology.

The theoretical model of the curvilinear relationship between use and impacts generally shows that the type and degree of impacts are greatest at initial use of a site and level off at higher levels of use. The results from this study support this model although the findings show that sites with historic low use have a disproportionately greater amount of erosion than trails in comparable environmental settings, Dixon, Hawes, and McPherson (2004) reported similar findings for trails in Tasmania. This finding points to the consideration of compaction or bulk density of the trail surface as well as reduced maintenance on low-use trails but this would need to be confirmed with more in-depth problem analysis studies of these trails.

As discussed in the literature review, while the body of literature is broad for trail degradation research there is limited consistency in the methodologies used, how variables are defined, and in the statistical analyses used to consider results. A number of specific recommendations would improve this and future recreation ecology studies:

- As recreational use is consistently shown to be a strong influence in trail degradation, there is a great need for more objective recreational use measures that are easily replicable and financially feasible for management agencies. 
- While there are strides being made to improve communications within the recreation ecology research community, the need for standardization of survey methods so studies can be compared across resource areas is still paramount.

- Methodologies which utilize GIS should no longer considered "novel" ways of presenting data and must be integrated into modern recreation ecology studies to match other natural resource management practices.

- Consideration of landscape scale phenomenon measured in GIS based systems can improve the understanding of trail impacts but the relationship of micro-scale phenomenon to these variables requires further investigation.

- Testing of GIS-based forest road erosion models for their applicability to trail erosion is needed as these models are more broadly utilized in forest management and apply the spatial impact consideration called for by leading recreation ecologists.

\section{Conclusions}

This study was established to characterize the patterns of trail erosion on study trails in Monongahela National Forest utilizing two standard and one experimental sampling methodology, and to conduct exploratory analysis of promising GIS-based derivations which might assist in the understanding of trail erosion processes. The results of the study demonstrate that MNF has a trail system in relatively good condition with trail erosion limited to a small section of trails. Patterns were apparent although inconsistencies were exhibited between the three sampling methods. Trail design and maintenance, particularly low gradient trails with long unbroken downhill segments, appear to be problematic on the Forest.

As other research has shown, each method used in this study provided unique information about the trails. As erosion was the primary variable of interest for this study, the problem census and linear segment analysis proved to be critical to this understanding due to the facts that the point sample method had limited variability in the maximum incision erosion proxy variable and this method missed $83 \%$ of the instances of severe erosion on the study trails. Combining these methods has become the norm in high mileage trail degradation research and served this study well. The addition of recording high quality GPS points at each point sample location added little time to the process but greatly increased the ability to utilize field data with GIS reliably. 
The GIS techniques used in this study proved to be useful in adding to the explanatory power of the erosion models. These techniques provide replicable, objective computational methods which can be utilized in other trail degradation research and provide additional information to phenomenon that are not easily measured or observed with field techniques alone. Additionally, these techniques mesh well with agency trail management systems and required GIS trail inventories adding useable knowledge of resource impacts to these established systems.

While this study showed statistically significant relationships that were able to explain the variance of erosion occurrences in approximately one third of the cases, the predictive power of the relationships between recreational use, biophysical variables, and management practices is still low. Findings were consistent with existing research that demonstrate similar explanatory power. Future work on isolating trail segments into homogenous subsets for paired comparisons is a suggested improvement to advance this research. 


\section{Bibliography}

Aguirre, J. A. (2009). Sustainable Trail Management in Costa Rica National Park: The use of photography in trail surface decisions under tropical rainforest conditions. Pasos, 7(1), 29.

AMC. (2008). Complete guide to trail building and maintenance (4th ed.). Boston, MA: Appalachian Mountain Club Books.

Anderson, D. M., \& MacDonald, L. H. (1998). Modeling road surface sediment production using a vector geographic information system. Earth Surface Processes and Landforms, 23(2), 95-107.

Anderson, M. G., Merrill, M. D., \& Biasi, F. B. (1998). Connecticut River watershed: Natural communities and neotropical migrant birds, final report. The Nature Conservancy, Boston, MA.

Arrowsmith, C., \& Inbakaran, R. (2002). Estimating environmental resiliency for the Grampians National Park, Victoria, Australia: A quantitative approach. Tourism Management, 23(3), 295-309.

Aust, M. W., Marion, J. L., \& Kyle, K. (2005). Research for the development of best management practices to minimize horse trail impacts on the Hoosier National Forest (Final Research Report). Blacksburg, VA: Virginia Tech, Department of Forestry.

Avery, M., Clements, R., Harrison, G., Hughey, K. F., \& Thompson, M. (1997). A GIS based walkway management system. In R. T. Pascoe (Ed.), Proceedings of the Second Annual Conference on GeoComputation 97 (pp. 15 - 23). Dunedin, New Zealand: University of Leeds.

Bailey, G. D., \& Pilgrim, S. A. L. (1983). Soils of the White Mountains of New Hampshire and their suitability for recreational development. Mountain Research and Development, 3(1), 53-60.

Bayfield, N. G. (1973). Use and deterioration of some Scottish hill paths. Journal of Applied Ecology, 10(2), 635-644.

Birkby, R. C. (2006). Lightly on the land: The SCA trail building and maintenance manual (2nd ed.). Mountaineers Books. 
Boers, B., \& Cottrell, S. (2007). Sustainable tourism infrastructure planning: A GIS-supported approach. Tourism Geographies, 9(1), 1.

Bratton, S. P., Hickler, M. G., \& Graves, J. H. (1979). Trail erosion patterns in Great Smoky Mountains National Park. Environmental Management, 3(5), 431-445.

Breibart, A. (2007). The WEPP road batch model: A tool for reducing erosion from trails. Stream Notes, USFS Stream Systems Technology Center Quarterly, (July, 2007), 1-6.

Brooks, E. S., Boll, J., Elliot, W. J., \& Dechert, T. (2006). Global Positioning System/GIS-based approach for modeling erosion from large road networks. Journal of Hydrologic Engineering, 11, 418.

Brooks, K. N., Ffolliott, P. F., Gregersen, H. M., \& DeBano, L. F. (2003). Hydrology and the management of watersheds (3rd ed.). Wiley-Blackwell.

Bryan, R. B. (1977). The influence of soil properties on degradation of mountain hiking trails at Grövelsjön. Geografiska Annaler. Series A. Physical Geography, 49-65.

Buckley, R. (Ed.). (2004). Environmental impacts of ecotourism. Oxford: CAB International.

Burden, R. F., \& Randerson, P. F. (1972). Quantitative studies of the effects of human trampling on vegetation as an aid to the management of semi-natural areas. Journal of Applied Ecology, 9(2), 439-457.

Cakir, J. F. (2005, August 1). Modeling trail degradation using field and GIS methodologies: A comparative study (Ph.D. dissertation). North Carolina State University, United States - North Carolina. Retrieved from http://www.lib.ncsu.edu/theses/available/etd-07152005-143654/

Chatterjea, K. (2007). Assessment and demarcation of trail degradation in a nature reserve, using GIS: Case of Bukit Timah Nature Reserve. Land Degradation \& Development, 18(5), 500-518.

Cole, D. N. (1983). Assessing and monitoring backcountry trail conditions (Research Paper No. INT-303). Ogden, UT: U.S. Department of Agriculture, Forest Service, Intermountain Research Station. 
Cole, D. N. (1989). Recreation ecology: What we know, what geographers can contribute. The Professional Geographer, 41(2), 143-148.

Cole, D. N. (1991). Changes on Trails in the Selway-Bitterroot Wilderness, Montana, 1978-89 (Research Paper No. RP-INT-450). Ogden, UT: U.S. Department of Agriculture, Forest Service, Intermountain Research Station.

Cole, D. N. (2004). Impacts of hiking and camping on soils and vegetation: A review. In R. Buckley (Ed.), Environmental impacts of ecotourism (pp. 41-60). Oxford: CAB International.

Cole, D. N. (2006). Visitor and recreation impact monitoring: Is it lost in the gulf between science and management. The George Wright Forum (Vol. 23, pp. 11-16).

Coleman, R. A. (1977). Simple techniques for monitoring footpath erosion in mountain areas of northwest England. Environmental Conservation, 4(02), 145-148.

Coleman, R. A. (1981). Footpath erosion in the English Lake District. Applied Geography, 1(2), 121-131.

Cordell, H. K. (2008). The latest on trends in nature-based outdoor recreation. Forest History Today, (Spring), 4-10.

Dale, D., \& Weaver, T. (1974). Trampling effects on vegetation of the trail corridors of north Rocky Mountain forests. Journal of Applied Ecology, 11(2), 767-772.

Dasher, G. (2001). The caves and karst of Pendleton County. West Virginia Speleological Society Bulletin, $15,160$.

Deluca, T. H., Patterson, W. A., Freimund, W. A., \& Cole, D. N. (1998). Influence of llamas, horses, and hikers on soil erosion from established recreation trails in western Montana, USA. Environmental Management, 22(2), 255-262.

Demrow, C., \& Salisbury, D. (1998). Complete guide to trail building and maintenance (3rd ed.). Boston, MA: Appalachian Mountain Club Books. 
Dissmeyer, G. E., \& Foster, G. R. (1981). Estimating the cover-management factor (C) in the universal soil loss equation for forest conditions. Journal of Soil and Water Conservation, 36(4), 235.

Dixon, G., Hawes, M., \& McPherson, G. (2004). Monitoring and modeling walking track impacts in the Tasmanian Wilderness World Heritage Area, Australia. Journal of Environmental Management, 71(4), 305-320.

Dorwart, C., Moore, R., \& Leung, Y. F. (2010). Visitors' perceptions of a trail environment and effects on experiences: A model for nature-based recreation experiences. Leisure Sciences, 32(1), 33-54.

Elliot, W. J., \& Hall, D. E. (1997). Water Erosion Prediction Project (WEPP) forest applications. General Technical Report. USDA Forest Service, Intermountain Research Station, Ogden, Utah.

Elliot, W. J., Foltz, R. B., \& Robichaud, P. R. (2009). Recent findings related to measuring and modeling forest road erosion. In R. S. Anderssen, R. D. Braddock, \& L. T. Newham (Eds.), Conference Proceedings of the 18th World IMAC/MODSIM Congress 4078-4084. Cairns, Australia.

Fancy, S. G., Gross, J. E., \& Carter, S. L. (2009). Monitoring the condition of natural resources in US national parks. Environmental Monitoring and Assessment, 151(1), 161-174.

Farrell, T. A., \& Marion, J. L. (2001). Identifying and assessing ecotourism visitor impacts at eight protected areas in Costa Rica and Belize. Environmental Conservation, 28(03), 215-225.

Farrell, T. F., \& Marion, J. L. (2002). Trail impacts and trail impact management related to visitation at Torres del Paine National Park, Chile. Leisure/Loisir, 26(1-2), 31-59.

Felton, V. (2004). Trail solutions: IMBA's guide to building sweet singletrack. Boulder, CO: International Mountain Bicycling Association.

Foresman, T. W. (Ed.). (1998). The history of geographic information systems: Perspectives from the pioneers. Prentice Hall.

Foth, H. D. (1990). Fundamentals of soil science. Wiley. 
Gaffer, R. L., Flanagan, D. C., Denight, M. L., \& Engel, B. A. (2008). Geographical information system erosion assessment at a military training site. Journal of Soil and Water Conservation, 63(1), 1.

Gager, P., \& Conacher, A. (2001). Erosion of access tracks in Kalamunda National Park, Western Australia: Causes and management implications. Australian Geographer, 32(3), 343-357.

Garland, G. G. (1990). Technique for assessing erosion risk from mountain footpaths. Environmental Management, 14(6), 793-798.

Garland, G. G., Hudson, C., \& Blackshaw, J. (1985). An approach to the study of path erosion in the Natal Drakensberg, a mountain wilderness area. Environmental Conservation, 12(04), 337-342.

Giles, A. (2002). Exploring the social, environmental and economic aspects of trail surfacing decisions. Unpublished master's thesis, University of Waterloo, Waterloo, Ontario.

Gimblett, H. R. (2005). Modelling human-landscape interactions in spatially complex settings: Where are we and where are we going? In M. H. Hamza (Ed.), MODSIM 2005: Proceedings of the International Congress on Modeling and Simulation (pp. 11 - 15).

Godwin, C. . (2000). Physiographic components of trail erosion (Unpublished master's thesis). Montana State University, Bozeman, MT.

Goeft, U., \& Alder, J. (2001). Sustainable mountain biking: A case study from the southwest of Western Australia. Journal of Sustainable Tourism, 9(3), 193-211.

Graefe, A. R., Kuss, F. R., \& Vaske, J. J. (1987). Recreation impacts and carrying capacity: $A$ visitor impact management framework. Washington, D.C.: National Parks and Conservation Association.

Graefe, A. R., Kuss, F. R., \& Vaske, J. J. (1990). Visitor impact management: The planning framework. Washington, D.C.: National Parks and Conservation Association.

Greer, R. C., Wu, J. Q., Singh, P., \& McCool, D. K. (2006). WEPP simulation of observed winter runoff and erosion in the U.S. Pacific Northwest. Vadose Zone Journal, 5(1), 261-272. 
Gül, A., Örücü, M. K., \& Karaca, Ö. (2006). An approach for recreation suitability analysis to recreation planning in Gölcük Nature Park. Environmental Management, 37(5), 606-625.

Hammitt, W. E., \& Cole, D. N. (1998). Wildland recreation: Ecology and management. John Wiley \& Sons Inc.

Harden, C. P. (2001). Soil erosion and sustainable mountain development: Experiments, observations, and recommendations from the Ecuadorian Andes. Mountain Research and Development, 21(1), 77-83.

Harris, L. K., Gimblett, R. H., \& Shaw, W. W. (1995). Multiple use management: Using a GIS model to understand conflicts between recreationists and sensitive wildlife. Society \& Natural Resources, $8(6), 559-572$.

Hartley, E. (2000). Thirty-year monitoring of subalpine meadow vegetation following a 1967 trampling experiment at Logan Pass, Glacier National Park, Montana. In D. N. Cole, S. F. McCool, W. T. Borrie, \& J. O'Loughlin (Eds.), Proceedings: Wilderness Science in a Time of Change (Vol. 5, pp. 124-132). Missoula, MT: U.S. Department of Agriculture, Forest Service, Rocky Mountain Research Station.

Hendee, J. C., Stankey, G. H., \& Lucas, R. C. (1990). Wilderness management. Golden, CO: North American Press.

Hesselbarth, W., Vachowski, B., \& Davies, M. A. (2007). Trail construction and maintenance notebook (2007th ed.). Missoula, MT: USDA Forest Service, Missoula Technology and Development Program.

Hickey, R. (2000). Slope angle and slope length solutions for GIS. Cartography, 29(1), 1-8.

Hill, W., \& Pickering, C. M. (2009). Evaluation of impacts and methods for the assessment of walking tracks in protected areas (1st ed.). Australia: CRC for Sustainable Tourism Pty Ltd. 
Jewell, M. C., \& Hammitt, W. E. (2000). Assessing soil erosion on trails: A comparison of techniques. In D. N. Cole, S. F. McCool, W. T. Borrie, \& J. O'Loughlin (Eds.), Proceedings: Wilderness Science in a Time of Change (Vol. 5, pp. 133-140). Missoula, MT: U.S. Department of Agriculture, Forest Service, Rocky Mountain Research Station.

Jubenville, A., \& O'Sullivan, K. (1987). Relationship of vegetation type and slope gradient to trail erosion in interior Alaska. Journal of Soil and Water Conservation, 42(6), 450.

Kim, M. K., Ednie, A. J., \& Daigle, J. J. (2006). Detecting vegetation change using multi-temporal aerial photographs at Cadillac Mountain in Acadia National Park, Maine. In J. G. Peden \& R. M. Schuster (Eds.), Proceedings of the 2005 Northeastern Recreation Research Symposium, Gen. Tech. Rep. NE-341 (pp. 300 - 306). Newtown Square, PA: U.S. Department of Agriculture, Forest Service, Northestern Research Station.

Kliskey, A. (2000). Recreation terrain suitability mapping: A spatially explicit methodology for determining recreation potential for resource use assessment. Landscape and Urban Planning, 52(1), 33-43.

Koehler, R. D., Sowers, J. M., Mileham, F., \& Golec, C. T. (2000). An assessment of trails, watercourses, soils, and Redwood forest health in Joaquin Miller Park, Oakland, California, with recommendations for management. Oakland, CA: City of Oakland, Office of Parks and Recreation. Retrieved from http://www.btceb.org/pdf/jmp_report.pdf

Kuss, F. R. (1983). Hiking boot impacts on woodland trails. Journal of Soil and Water Conservation, 38(2), 119.

Kuss, F. R., \& Morgan, J. M. (1986). A first alternative for estimating the physical carrying capacities of natural areas for recreation. Environmental Management, 10(2), 255-262.

Lal, R., livari, T., \& Kimble, J. M. (2003). Soil degradation in the United States: Extent, severity, and trends. Boca Raton, FL: CRC Press. 
Lanehart, E. (1998). Backcountry Trails Near Stream Corridors: An Ecological Approach To Design (Unpublished master's thesis). Virginia Polytechnic Institute and State University, United States Virginia.

Lawson, S. R., Itami, R. M., Gimblett, H. R., \& Manning, R. E. (2004). Monitoring and managing recreational use in backcountry landscapes using computer-based simulation modeling. In T. Sievänen, J. Erkkonen, J. Jokimäki, J. Saarinen, S. Tuulentie, \& E. Virtanen (Eds.), Proceedings of the Second International Conference on Monitoring and Management of Visitor Flows in Recreational and Protected Areas (pp. 107-113). Rovaniemi, Finland: Finnish Forest Research Institute.

Lawson, S. R., Itami, R. M., Gimblett, H. R., \& Manning, R. E. (2006). Benefits and challenges of computer simulation modeling of backcountry recreation use in the Desolation Lake Area of the John Muir Wilderness. Journal of Leisure Research, 38(2), 187.

Lee, B., \& Graefe, A. R. (2004). GIS: A tool to locate new park and recreation services. Parks \& Recreation, 39.

Lessing, P. (1996, July). WVGES geology: Physiographic provinces. West Virginia Geological \& Economic Survey. Retrieved June 28, 2010, from http://www.wvgs.wvnet.edu/www/geology/geolphyp.htm

Leung, Y. F. (1998). Assessing and evaluating recreation resource impacts: spatial analytical approaches (Ph.D. dissertation). Virginia Polytechnic Institute and State University, Blacksburg, VA.

Leung, Y. F., \& Marion, J. L. (1996). Trail degradation as influenced by environmental factors: A state-ofthe-knowledge review. Journal of Soil and Water Conservation, 51(2), 130.

Leung, Y. F., \& Marion, J. L. (1999a). The influence of sampling interval on the accuracy of trail impact assessment. Landscape and Urban Planning, 43(4), 167-179. 
Leung, Y. F., \& Marion, J. L. (1999b). Assessing trail conditions in protected areas: Application of a problem-assessment method in Great Smoky Mountains National Park, USA. Environmental Conservation, 26(04), 270-279.

Leung, Y. F., \& Marion, J. L. (2000). Recreation impacts and management in wilderness: A state-ofknowledge review. In D. N. Cole, S. F. McCool, W. T. Borrie, \& J. O'Loughlin (Eds.), Proceedings: Wilderness Science in a Time of Change (Vol. 5, pp. 23-27). Missoula, MT: U.S. Department of Agriculture, Forest Service, Rocky Mountain Research Station.

Leung, Y. F., \& Neller, R. J. (1995). Trail degradation along the Pat Sin Range: An example of environmental geomorphology. Hong Kong Geologist, 1, 79-87.

Leung, Y. F., Shaw, N., Johnson, K., \& Duhaime, R. (2002). More than a database: Integrating GIS data with the Boston Harbor Islands carrying capacity study. The George Wright Forum (Vol. 19, pp. 69-78).

Liddle, M. (1997). Recreation Ecology - The Ecological Impact of Outdoor Recreation (1st ed.). Springer.

Liddle, M. J., \& Greig-Smith, P. (1975). A survey of tracks and paths in a sand dune ecosystem. Journal of Applied Ecology, 12(3), 893-908.

Luce, C. H., \& Black, T. A. (2001). Spatial and temporal patterns in erosion from forest roads. Water Science and Application, 2, 165-178.

Lynn, N. A., \& Brown, R. D. (2003). Effects of recreational use impacts on hiking experiences in natural areas. Landscape and Urban Planning, 64(1-2), 77-87.

Manning, R. E. (1979). Impacts of recreation on riparian soils and vegetation. Water Resource Bulletin, 15(1), 30-43.

Manning, R. E. (2001). Visitor experience and resource protection: A framework for managing the carrying capacity of national parks. Journal of Park and Recreation Administration, 19(1), 93108. 
Manning, R. E., Jacobi, C., \& Marion, J. L. (2006). Recreation monitoring at Acadia National Park. The George Wright Forum (Vol. 23, pp. 59-72).

Manning, R. E., Lawson, S., Newman, P., Budruk, M., Valliere, W., Laven, D., Bacon, J., et al. (2004). Visitor perceptions of recreation-related resource impacts. Environmental impacts of ecotourism, 259-272.

Manning, R. E., Leung, Y. F., \& Budruk, M. (2005). Research to support management of visitor carrying capacity of Boston Harbor Islands. Northeastern Naturalist, 12, 201-220.

Marion, J. L. (1994). An assessment of trail conditions in Great Smoky Mountains National Park. US Dept. of Interior, National Park Service, Great Smoky Mountains National Park, Division of Resource Management and Science.

Marion, J. L. (1998). Recreation ecology research findings: Implications for wilderness and park managers. Proceedings of the National Outdoor Ethics Conference (pp. 188-196). Gaithersburg, MD: Izaak Walton League of America.

Marion, J. L., \& Leung, Y. F. (2001). Trail resource impacts and an examination of alternative assessment techniques. Journal of Park and Recreation Administration, 19(3), 17-37.

Marion, J. L., \& Leung, Y. F. (2004). Environmentally sustainable trail management. In R. Buckley (Ed.), Environmental impacts of ecotourism (pp. 229-243). Oxford: CAB International.

Marion, J. L., \& Olive, N. D. (2006). Assessing and understanding trail degradation: Results from Big South Fork National River and Recreation Area (NPS Research/resources Mgmt Report). Oneida, TN: U.S. Department of the Interior: Big South Fork National River and Recreation Area.

Marion, J. L., \& Reid, S. (2007). Minimizing visitor impacts to protected areas: The efficacy of low impact education programs. Journal of Sustainable Tourism, 15(1), 5-27.

Marion, J. L., Leung, Y. F., \& Nepal, S. K. (2006). Monitoring trail conditions: New methodological considerations. The George Wright Forum (Vol. 2, pp. 36-49). 
Mayhew, S. (2009). A Dictionary of Geography (3rd ed.). USA: Oxford University Press.

McHarg, I. (1995). Ian McHarg reflects on the past, present and future of GIS. GIS World, (8), 46-49.

McKim, C. R. (1970). 50 year history of the Monongahela National Forest. Unpublished manuscript, . Retrieved from http://ir.library.oregonstate.edu/dspace/bitstream/1957/10096/1/50_Yea_His_Mon_Nat_For.p $\mathrm{df}$

Meyer, K. G. (2002). Managing degraded Off-Highway Vehicle trails in wet, unstable, and sensitive environments (NPS OHV Management No. 2E22A68). Missoula, MT: USDA, Forest Service, Technology and Development Program.

Middleton, D. M., Cseke, J., Gershman, M., \& Sherry, J. (2009). Trail condition monitoring, Boulder open space and mountain parks: West Trail study area. Boulder, CO: City of Boulder, Open Space and Mountain Parks Department. Retrieved from http://www.bouldercolorado.gov/files/openspace/pdf_TSA_general/westtsa_report_recreation .pdf

Montello, D. R. (2001). Scale in geography. In N. J. Smelser, P. B. Baltes, J. Altmann, \& O. Ashenfelter (Eds.), International encyclopedia of the social \& behavioral sciences (pp. 13501-13504). Amsterdam: Elsevier.

Monz, C. A., \& Leung, Y. F. (2006). Meaningful measures: Developing indicators of visitor impact in the National Park Service inventory and monitoring program. The George Wright Forum (Vol. 23, pp. 17-27).

Monz, C. A., Cole, D. N., Leung, Y. F., \& Marion, J. L. (2009). Sustaining visitor use in protected areas: Future opportunities in recreation ecology research based on the USA experience. Environmental Management, 45(3), 551-562. 
Naber, M. D., \& Leung, Y. F. (2006). Research update: Technology lends a helping hand. Parks \& Recreation, 41(7), 24.

NCASI. (2005). Technical documentation for SEDMODL version 2.0 road erosion/delivery model. National Council for Air and Stream Improvement, Inc. Retrieved from http://www.ncasi.org/support/downloads/Detail.aspx?id=5

NCASI. (2009). Forest watersheds - Predictive forest hydrology tools. National Council for Air and Stream Improvement, Inc. Retrieved September 25, 2011, from http://www.ncasi.org/programs/areas/forestry/watershed/predictive_tools.aspx

Nepal, S. K. (2003). Trail impacts in Sagarmatha (Mt. Everest) National Park, Nepal: A logistic regression analysis. Environmental management, 32(3), 312-321.

Nepal, S. K., \& Nepal, S. A. (2004). Visitor impacts on trails in the Sagarmatha (Mt. Everest) National Park, Nepal. AMBIO: A Journal of the Human Environment, 33(6), 334-340.

Newsome, D., Cole, D. N., \& Marion, J. L. (2004). Environmental impacts associated with recreational horse-riding. In R. Buckley (Ed.), Environmental impacts of ecotourism (pp. 61-82). Oxford: CAB International.

Obua, J., \& Harding, D. M. (1997). Environmental impact of ecotourism in Kibale National Park, Uganda. Journal of Sustainable Tourism, 5(3), 213-223.

Olive, N. D., \& Marion, J. L. (2009). The influence of use-related, environmental, and managerial factors on soil loss from recreational trails. Journal of Environmental Management, 90(3), 1483-1493.

Parker, P. (2008). Geologies: Webster's quotations, facts, and phrases. ICON Group International, Inc.

Parker, T. S. (2004). Natural surface trails by design: Physical and human design essentials of sustainable, enjoyable trails. Boulder, CO: Natureshape.

Pettebone, D., \& Newman, P. (2008). Breckenridge trail condition report. Unpublished report, Town of Breckenridge, Breckenridge, $\mathrm{CO}$. 
Pettebone, D., Newman, P., \& Theobald, D. (2009). A comparison of sampling designs for monitoring recreational trail impacts in Rocky Mountain National Park. Environmental Management, 43(3), $523-532$.

Pickering, C. M., Hill, W., Newsome, D., \& Leung, Y. F. (2009). Comparing hiking, mountain biking and horse riding impacts on vegetation and soils in Australia and the United States of America. Journal of Environmental Management, 91, 551 - 562.

Pierskalla, C. D., Siniscalchi, J. M., Academy, U. S. C. ., Hammitt, W. E., Smaldone, D. A., \& Storck, S. J. (2006). Identifying predictors for quality and quantity restorative character of wilderness: using events as an analysis unit. In R. Burns \& K. Robinson (Eds.), Proceedings of the 2006 Northeastern Recreation Research Symposium (Vol. 14, pp. 497 - 508). Newtown Square, PA: U.S. Department of Agriculture, Forest Service, Northern Research Station.

Reutebuch, S. E., McGaughey, R. J., Andersen, H. E., \& Carson, W. W. (2003). Accuracy of a highresolution LiDAR terrain model under a conifer forest canopy. Canadian Journal of Remote Sensing, 29(5), 527-535.

Rinehart, R. P., Hardy, C. C., \& Rosenau, H. G. (1978). Measuring trail conditions with stereo photography. Journal of Forestry, 76(8), 501-503.

Roggenbuck, J. W., Williams, D. R., \& Watson, A. E. (1993). Defining acceptable conditions in wilderness. Environmental Management, 17(2), 187-197.

Runyan, D. (2009). Economic impact of travel on West Virginia, 2000-2008 detailed state and county estimates. South Charleston, WV: West Virginia Department of Commerce, Division of Tourism. Saleh, A. (1993). Soil roughness measurement: Chain method. Journal of Soil and Water Conservation, 48(6), 527. 
Schumacher, J. V., Redmond, R. L., Hart, M. M., \& Jensen, M. E. (2000). Mapping patterns of human use and potential resource conflicts on public lands. Environmental Monitoring and Assessment, 64(1), 127-137.

Serengil, Y., \& Özhan, S. (2006). Effects of recreational activities on the soil and water components of a deciduous forest ecosystem in Turkey. International Journal of Environmental Studies, 63(3), 273-282.

Stankey, G. H., Cole, D. N., Lucas, R. C., Petersen, M. E., \& Frissell, S. S. (1985). The limits of acceptable change (LAC) system for wilderness planning (General Technical Report No. INT-176). Ogden, UT: USDA, Forest Service, Intermountain Forest and Range Experimental Station.

Starr, M. J., Gratzer, M. A., \& Lewis, A. R. (1999). The use of GIS in recreational planning: The application of spatial analysis to find suitable locations for recreational trails. In G. Kyle (Ed.), Proceedings of the 1999 Northeastern Recreation Research Symposium (pp. 391 - 396). Bolton Landing, NY.

Summer, R. M. (1980). Impact of horse traffic on trails in Rocky Mountain National Park. Journal of Soil and Water Conservation, 35(2), 85-77.

Summer, R. M. (1986). Geomorphic impacts of horse traffic on montane landforms. Journal of Soil and Water Conservation, 41(2), 126.

Sun, D., \& Liddle, M. J. (1993). A survey of trampling effects on vegetation and soil in eight tropical and subtropical sites. Environmental Management, 17(4), 497-510.

Sutherland, R. A., Bussen, J. O., Plondke, D. L., Evans, B. M., \& Ziegler, A. D. (2001). Hydrophysical degradation associated with hiking-trail use: A case study of Hawai'iloa Ridge Trail, Oahu, Hawaii. Land Degradation \& Development, 12(1), 71-86.

Swift, L. W. (1984). Soil losses from roadbeds and cut and fill slopes in the Southern Appalachian Mountains. Southern Journal of Applied Forestry, 8(4), 209-216. 
Törn, A., Tolvanen, A., Norokorpi, Y., Tervo, R., \& Siikamäki, P. (2009). Comparing the impacts of hiking, skiing and horse riding on trail and vegetation in different types of forest. Journal of Environmental Management, 90(3), 1427-1434.

Trail. (2003).Merriam-Webster's collegiate dictionary. Merriam-Webster, Inc.

USDA-NRCS. (2010). Soil data mart. Retrieved June 1, 2010, from http://soildatamart.nrcs.usda.gov/ USFS. (1991). Forest Service handbook (Handbook No. FSH 2309.18). Washington, D.C.: USDA, Forest Service.

USFS. (2004). National visitor use monitoring results, June 2004. Region 9, Monongahela National Forest. Elkins, WV: USDA, Forest Service: Monongahela National Forest.

USFS. (2006a). Makin' TRACS: Forest Service guide to trail assessment and condition surveys. Washington, D.C.: USDA, Forest Service.

USFS. (2006b). Monongahela National Forest land and resource management plan. USDA Forest Service, Monongahela National Forest.

USFS. (2011). National Forest system statistics FY 2010 (Brochure No. FS-905 (10)). Washington, D.C.: USDA, Forest Service.

Vaske, J. J., Graefe, A. R., \& Dempster, A. B. (1982). Social and environmental influences on perceived crowding. In F. Boteler (Ed.), Wilderness Psychology Group. Third Annual Conference Proceedings (pp. 211-227).

Vaze, J., \& Teng, J. (2007). High-resolution LiDAR DEM: How good is it? In L. Oxley \& D. Kulasiri (Eds.), MODSIM 2007: Preceedings of the International Congress on Modelling and Simulation. Retrieved from www.mssanz.org.au/MODSIM07/ papers/12_s27/HighResolution_s27_Vaze_.pdf

Wagar, J. A. (1964). The carrying capacity of wild lands for recreation. Forest Science, 10(Supplement 7), a0001-24. 
Wall, G., \& Wright, C. (1977). The environmental impact of outdoor recreation. Dept. of Geography, Faculty of Environmental Studies, University of Waterloo.

Watson, A. E., Cole, D. N., Turner, D. L., \& Reynolds, P. S. (2000). Wilderness recreation use estimation: A handbook of methods and systems (General Technical Report No. RMRS-GTR-56). Ogden, UT: U.S. Department of Agriculture, Forest Service, Rocky Mountain Research Station.

Weaver, T., \& Dale, D. (1978). Trampling effects of hikers, motorcycles and horses in meadows and forests. Journal of Applied Ecology, 451-457.

Whinam, J., \& Chilcott, N. M. (2003). Impacts after four years of experimental trampling on alpine/subalpine environments in western Tasmania. Journal of Environmental Management, 67(4), 339351.

White, D. D., Waskey, M. T., Brodehl, G. P., \& Foti, P. E. (2006). A comparative study of impacts to mountain bike trails in five common ecological regions of the southwestern US. Journal of Park and Recreation Administration, 24(2), 21-41.

Wilkerson, E., \& Whitman, A. A. (2009). Recreation trails in Maine and New Hampshire: A comparison of motorized, non-motorized, and non-mechanized trails. In C. LeBlanc \& C. Vogt (Eds.), Proceedings of the 2009 Northeastern Recreation Research Symposium, Gen. Tech. Rep. NRS-P14 (pp. 25-45). Newtown Square, PA: U.S. Department of Agriculture, Forest Service, Northern Research Station.

Wilson, J. P., \& Seney, J. P. (1994). Erosional impact of hikers, horses, motorcycles, and off-road bicycles on mountain trails in Montana. Mountain Research and Development, 14(1), 77-88.

Wing, M., \& Shelby, B. (1999). Using GIS to integrate information on forest recreation. Journal of Forestry, 97(1), 12-16. 
Wold, W. L., \& Dube, K. V. (1998). A tool to estimate sediment production and delivery from roads. In ESRI (Ed.), Conference Proceedings of the 1998 ESRI User Conference. Redlands, CA: Environmental Systems Research Institute.

Wood, K. T., Lawson, S., \& Marion, J. L. (2006). Assessing recreation impacts to cliffs in Shenandoah National Park: Integrating visitor observation with trail and recreation site measurements. Journal of Park and Recreation Administration, 24(4), 86-110.

Xiang, W. N. (1996). A GIS based method for trail alignment planning. Landscape and Urban Planning, 35(1), 11-23.

Yoda, A., \& Watanabe, T. (2000). Erosion of mountain hiking trail over a seven-year period in Daisetsuzan National Park, Central Hokkaido, Japan. In D. N. Cole, S. F. McCool, W. T. Borrie, \& J. O’Loughlin (Eds.), Proceedings: Wilderness Science in a Time of Change (Vol. 5, pp. 172-180). Missoula, MT: U.S. Department of Agriculture, Forest Service, Rocky Mountain Research Station.

Yoder, D. C., Foster, G. R., Weesies, G. A., Renard, K. G., McCool, D. K., \& Lown, J. B. (2001). Evaluation of the RUSLE soil erosion model. Southern Cooperative Series Bulletin, Agricultural Non-Point Source Water Quality Models: Their Use and Application, 398, 107. 


\section{Appendices}

\section{Appendix A: Trail Assessment Field Manual}

\section{Monongahela National Forest Trail Survey Handbook}

This manual is based on the work of Dr. Jeff Marion, Virginia Polytechnical Institute, Blacksburg, Virginia (2005). The original manual was designed for the Daniel Boone National Forest and was shared with WVU by Dr. Marion. Any publications utilizing data collected from this method must recognize Dr. Marion as the creator of this system.

Starting/Ending Point: Record a brief but accurate description of the starting and ending points of the survey. Choose identifiable and permanent locations that others can identify in the future, like intersections with other trails, roads, or permanent trailhead signs.

Measuring Wheel Procedures: At the trail segment starting point, select a random number from 0 to your sample interval (normally $300 \mathrm{ft}$ ). Record this number on the first row of the form. This will be the first sample point, from which all subsequent sample points will be located at whatever your interval is. This procedure ensures that all points along the trail segment have an equal opportunity of being selected. * Once you get to the first sample point, reset the wheel counter and use it to stop at points separated by your sample interval distance thereafter.

Push the measuring wheel along the middle of the tread so that it does not bounce or skip in rough terrain. Lift the wheel over logs and larger rocks, adding distance manually where necessary to account for horizontal distances. Your objective is to accurately measure the distance of the primary (most heavily used) trail tread. Monitor the wheel counter and stop at your sample intervals to conduct the sampling point measures. If you go over this distance, you can back the wheel up to the correct distance. If the wheel doesn't allow you to take distance off the counter then stop immediately and conduct your sampling at that point, recording the actual distance from the wheel, not the "missed" distance. Continue to the next "correct" sample point (as though you had not missed the last one).

Rejection of a sample point: Given the survey's objective, there will be rare occasions when you may need to reject a sampling point due to the presence of boulders, tree falls, trail intersections, roadcrossings, stream-crossings, bridges, or other odd "uncharacteristic" situations. The data collected at sample points is intended to be roughly "representative" of the $150 \mathrm{ft}$ sections of trail on either side of the sample point. Use your judgment but be conservative when deciding if a sample point should be relocated. Do not relocate a point to avoid longer or common sections of bog bridging, turnpiking, or other trail tread improvements. The point should be relocated by moving forward along the trail an additional 30 feet, this removes the bias of subjectively selecting a point. If the new point is still problematic then add another $30 \mathrm{ft}$, and so on. Record the distance of the actual point and continue on to the next "correct" point (as though you did not need to move the last one).

For the following data, in the field or office: If an indicator cannot be assessed, e.g., is "Not Applicable" code the data as -9 , code missing data as -1 . 
1. Distance: Measuring wheel distance ( $\mathrm{ft}$ ) from the beginning of the trail segment to the sample point.

2. Trail Position (TP): Use the descriptions below to determine the trail position of the sampling point. Record the corresponding letter code in the TP column.

R - Ridge: Ridge-top or high plateau position

CB - Cliff base

M - Midslope/Sideslope: Mid-slope positions

V - Valley Bottom: Flatter valley bottom terrain

3. Trail Grade (TG): The two field staff should position themselves on the trail $5 \mathrm{ft}$ either side of the transect. A clinometer is used to determine the grade (\% slope) by sighting and aligning the horizontal line inside the clinometer with a spot on the opposite person at the same height as the first person's eyes. Note the percent grade (right-side scale in clinometer viewfinder) and record.

4. Trail Alignment (TA): Assess the trail's alignment angle to the prevailing land-form in the vicinity of the sample point. Sight a compass along the trail from a point about $5 \mathrm{ft}$ before the transect to about $5 \mathrm{ft}$ past the transect, record the compass azimuth (0-360, not corrected for declination) on the left side of the column (it doesn't matter which direction along the trail you sight). Next face directly downslope, take and record another compass azimuth - this is the aspect of the local landform. The trail's alignment angle $\left(<90^{\circ}\right)$ can be computed by these two azimuths.

5. Landform Grade (LG): Assess an approximate measure of the landform slope in the vicinity of the sample point. Turn the clinometer perpendicular to the ground with the window facing your eye. Next orient the bottom of the clinometer in alignment with the prevailing landform slope (placing the clinometer on your clipboard and orienting the bottom of the clipboard may improve your accuracy). Record the \% slope to the nearest percentage.

6. Secondary Treads (ST): Count the number of trails that parallel the main tread at the sample point. Count all treads regardless of their length, excluding the main tread.

7. Tread Width (TW): From the sample point, extend a line transect in both directions perpendicular to the trail tread. Identify the endpoints of this trail tread transect as the most pronounced outer boundary of visually obvious human disturbance created by trail use (not trail maintenance like vegetation clearing). These boundaries are defined as pronounced changes in ground vegetation height (trampled vs. untrampled), cover, composition, or, when vegetation cover is reduced or absent, as pronounced changes in organic litter (intact vs. pulverized) (see photo illustrations in Figure 1, placed at the end of the manual). The objective is to define the trail tread that receives the majority (>95\%) of traffic, selecting the most visually obvious outer boundary that can be most consistently identified by you and future trail surveyors. In places where the trail boundary is indistinct at the sample point project the boundary to the sample point from immediately adjacent areas. Include the widths of any secondary treads (see \#8) crossed by the transect, excluding widths of any undisturbed areas between treads (as defined by the tread boundary definition). Measure and record the length of the transect (the tread width) to the nearest inch (don't record feet and inches).

8. Bare Width: Measure the width of bare soil or bare soil covered by a thin layer of leaf litter on the main tread. 
9. Cross Width: With a line attached to a stake on the high side of the trail, extend the line to the opposite side of the trail roughly perpendicular to the main tread. Attach a line level to the line and level. Measure the height of the line from the ground on the low side. Subtract the height of the line from the ground on the high side (can be set at ground level to avoid this step). Record your results in inches and draw an arrow to indicate the direction of slope. If a berm exists in the middle of the trail put a "B" in the data position.

10. Max Incision: Position the transect line at the tread edges. Holding a tape measure or plumb bob find the maximum depth from the line to the ground and record this number.

11. Soils: Characterize the soil adjacent to the transect point and in the trail using the categories provided in the attached form from TRACS productivity levels.

12. Brush: Characterize the vegetation in the trail corridor adjacent to the transect point using the categories provided in the attached form from TRACS productivity levels.

13. Canopy: Look up and assess the amount of cover provided by the tree canopy at full leaf-out. If there are no trees record " $\mathrm{O}$ " for open. If the canopy has large gaps record " $\mathrm{P}$ " for partial coverage. If the trees are dense with few open gaps record " $\mathrm{C}$ " for closed.

Collect all equipment and move onto the next sample point. Be sure to record information on indicators $\mathbf{2 7}$ - $\mathbf{3 0}$ as you proceed to the next sample point. These indicators are assessed continuously as pre-defined trail tread problems and when found, surveyors either tally or record begin and end distances (from the start of the survey) on the Problem Assessment Form. Note: after data entry and before analysis the data for these indicators need to be corrected to add in the $1^{\text {st }}$ randomly selected interval distance so that location data is accurate. In particular, examine any indicators that may begin before and end after the first sample point.

\section{Trail Impact Log Procedures}

Informal Trails (IT): Count and keep a running tally of the number of informal or "visitor-created" trails that intersected the survey trail segment as you proceed to the next sample point. Sum and record the total at each sample point. This indicator is intended to provide an approximation of the extensiveness of unofficial, visitor-created trails associated with survey trail. Do not count formal trails, roads of any type, extremely faint trails, trails $<10 \mathrm{ft}$ long, or trails that have been effectively blocked off by managers. Informal trails are trails that visitors have created to access streams, scenic attraction features, camping areas, or other features, to cut switchbacks, to avoid mud-holes, rutted treads, steep obstacles, or downed trees, or that simply parallel the main trail. Count both ends of any informal trails $\geq 10$ feet long that loop out and return to or parallel the survey trail. Include any distinct animal or game trails as these are generally indistinguishable from human trails and their true origin is likely unknown.

Linear Erosion (LNE): Sections of tread ( $\geq 10 \mathrm{ft}$ ) with soil erosion exceeding $5 \mathrm{in}$. depth within current tread boundaries running down the trail. Record beginning and ending distances on the Problem Assessment form. 
Lateral Erosion (LTE): Sections of tread ( $\geq 10 \mathrm{ft}$ ) with soil erosion exceeding $5 \mathrm{in}$. depth at the upper edge of the trail (erosion onto the trail), across the tread or at the lower edge of the trail. Include damaged water diversion structures if their downhill edge has eroded into the tread corridor. Record beginning and ending distances on the Problem Assessment form.

Muddy Soil (MS): Sections of tread ( $\geq 10 \mathrm{ft}$ ) with seasonal or permanently wet and muddy soils that show imbedded foot or hoof prints ( $\geq 1 \mathrm{in}$ ). Omit temporary muddiness created from a recent rain. This should generally include any longer mud-holes or treads with running water. The objective is to include only tread segments that are frequently wet or muddy enough to divert trail users around the problem, often leading to an expansion of trail width.

Water in Trail Sections of tread ( $\geq 10 \mathrm{ft}$ ) that contain running water or standing water. Record the type (running/standing) and the probable source of the water. Record beginning and ending distances on the Problem Assessment form.

Multiple Treads Sections of trail ( $\geq 10 \mathrm{ft}$ ) that have 2 or more distinct treads or where the trail has recently been displaced from its original location due to an impact or obstruction. Record beginning and ending distances on the Problem Assessment form. 


\section{TRACS Productivity Factor Codes}

(Updated 4/1/2004)

\begin{tabular}{|c|c|c|}
\hline \multicolumn{2}{|c|}{ Typical Soil Type } & \multirow{2}{*}{$\begin{array}{l}\text { Engineering soil composition and texture } \\
\text { Soils with uniform fine texture with little or no rock content. May be dark } \\
\text { with high organic content. Demonstrates low carrying capacity, especially } \\
\text { when wet. Trenches easily, highly dusty when dry, highly erosive. }\end{array}$} \\
\hline ST01 & Fine/Organics & \\
\hline ST02 & Sand & $\begin{array}{l}\text { Material with uniform sand-grain texture with few fines. Refuses to } \\
\text { compact when dry. Highly susceptible to erosion. }\end{array}$ \\
\hline ST03 & Pumice & $\begin{array}{l}\text { Broken-up pumice cobbles with few or no fines. Refuses to compact. } \\
\text { Highly susceptible to erosion, particularly with ability to float in water. }\end{array}$ \\
\hline ST04 & Common & $\begin{array}{l}\text { Material with a good mixture of fines and small rock. May be loose or } \\
\text { highly compacted. Compacts well. Good erosion resistance. }\end{array}$ \\
\hline ST05 & $\begin{array}{l}\text { Common w/ } \\
\text { Larger Rock }\end{array}$ & $\begin{array}{l}\text { Material with a good mixture of soil and small rock intermixed with larger } \\
\text { cobbles or small boulders. May be loose or highly compacted. Methods for } \\
\text { removal of larger rock may include digging out or breaking in-place. }\end{array}$ \\
\hline ST06 & Talus or Boulders & $\begin{array}{l}\text { Material that is mostly rock of uniform or varying sizes containing little or } \\
\text { no soil. Removal may include hand, machine, or blasting methods. }\end{array}$ \\
\hline ST07 & Bedrock & $\begin{array}{l}\text { Bedrock or very large boulders (larger than a VW Bug) where blasting is } \\
\text { generally the only method of removal. }\end{array}$ \\
\hline \multicolumn{2}{|c|}{$\begin{array}{l}\text { Typical Vegetation: } \\
\text { Brush \& Regeneration }\end{array}$} & All brush and tree regeneration less than 4 " diameter within Trail Corridor \\
\hline BR01 & None & No brush or regen within Trail Corridor \\
\hline BR02 & Extra Light & $\begin{array}{l}\text { Grasses, light perennials, or other non-woody plants. Capable of being } \\
\text { worked with hand sickles, mowers or weed whips. }\end{array}$ \\
\hline BR03 & Light & $\begin{array}{l}\text { Small regen shorter than knee height; slow-growing woody brush that } \\
\text { typically grows to knee height. Diameters typically no greater than } 1 / 2 " \text {. } \\
\text { Capable of being worked with a hand sickle or for regen being pulled by } \\
\text { hand. }\end{array}$ \\
\hline BR04 & Medium & $\begin{array}{l}\text { Faster growing woody brush or regen with diameters typically between } \\
1 / 2 " \text { and } 1 " \text { and heights lower than chest high. Typically would be worked } \\
\text { with hand nippers, sandiks, machetes or chainsaws. }\end{array}$ \\
\hline BR05 & Heavy & $\begin{array}{l}\text { Fast-growing brush or regen above head height with typical diameters } \\
\text { greater than 1". Typically would be worked with sandiks, machetes or } \\
\text { chainsaws. }\end{array}$ \\
\hline BR06 & Extra Heavy & $\begin{array}{l}\text { Very dense and fast-growing brush or regen above head height with typical } \\
\text { diameters greater than 1". Typically would be worked with sandiks, } \\
\text { machetes, or chainsaws. }\end{array}$ \\
\hline
\end{tabular}




\section{Appendix B: Estimated Upslope Flow Length (EUFL) Derivation in ArcGIS}

The following instructions are for the development of an estimate of on-trail watershed lengths in ESRI ArcMap version 9.3.1. This calculated estimate is limited in accuracy by the following assumptions and generalizations:

- All trails have an incised trail surface that will transport some amount of water in a downhill direction. Crowned or outsloped trail surfaces with no incision are treated the same as incised trail surfaces.

- $100 \%$ of on-trail water will be removed from the trail at good condition water bars, grade reversals (water dips), stream crossings, bridges, and switchbacks with run-out ditches. These features are labeled as pour points.

- Trailbed elevations are based on terrain elevations from digitized elevation models. Elevations of raised trailbeds such as those on historic railroad grades or roadbeds will only be represented if these features are large enough to be represented in the digital elevation data sets.

ArcMap Spatial Analyst has a set of hydrology tools for calculating flow direction and flow lengths from digital elevation models (DEM). In order to utilize these tools for the trailbed a DEM for the trail surface must be created as the plane of the trail has a different slope direction than the slope of the landscape, see Figure 1. 
Figure 1: Graphical comparison of landscape slope and trailbed slope on a cross-slope trail alignment.

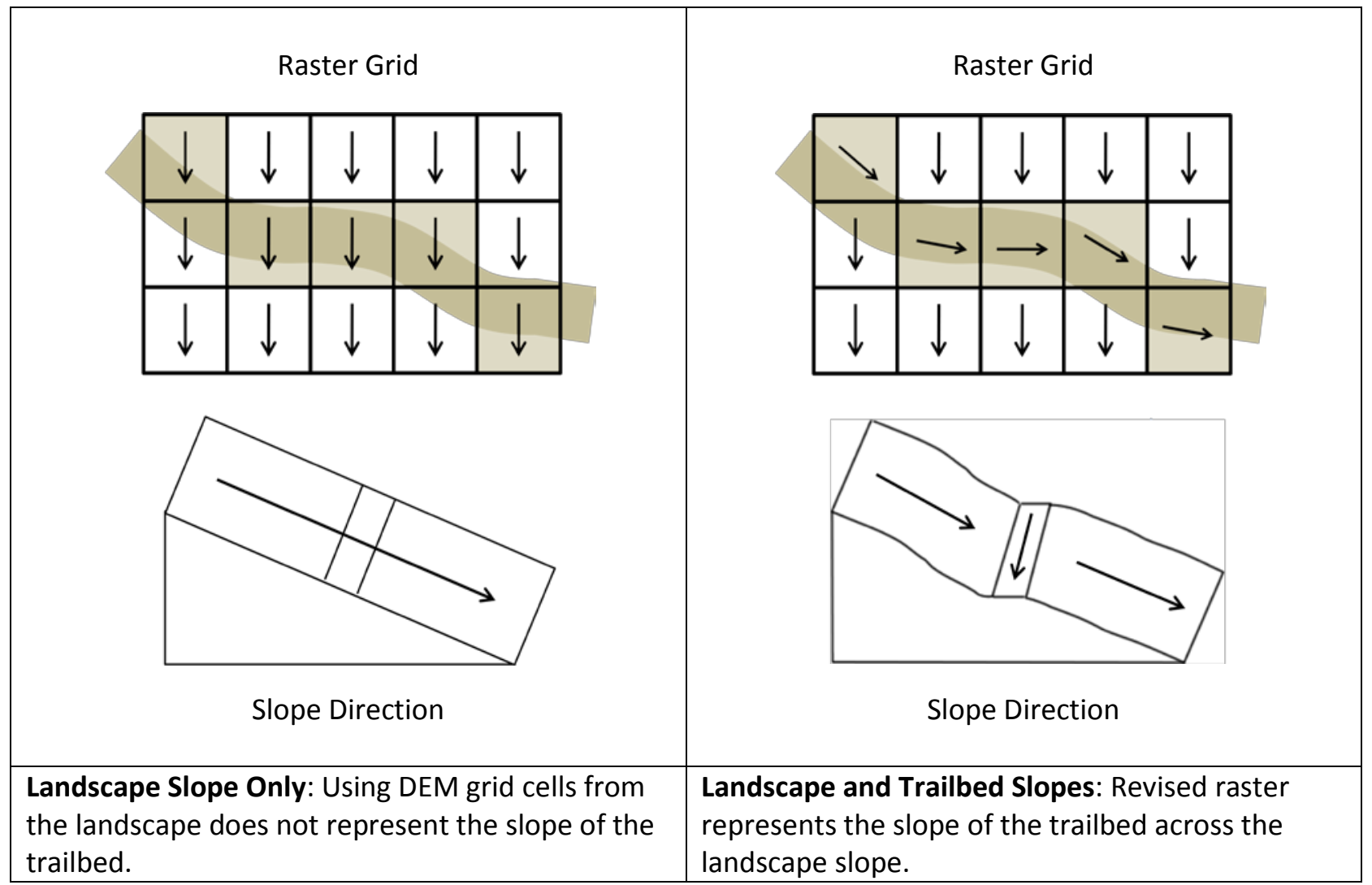

The "Flow Direction" grid is a key element of determining "Flow Length." While trails running up and down slopes (low trail alignments) have a similar slope profile to the landscape, trails running across hill slopes (high trail alignments) have a very different profile and often result in a "zig-zag" or "stairstepped" profile when converted to raster. These steps produce high and low elevations that average to the trail line. Each low point interrupts the calculation of the flow direction model creating short flow length segments. To smooth out this stair stepping the trail surface must be interpolated across its length to improve the model, making it function more like the real world trail surface. This process averages low and high elevation raster cells by considering the elevation values of the cells provided in a point feature data set.

Figure 2 provides an example of the effect of interpolation on a short segment of trail extracted from a real world data set for elevations, flow direction, and flow length. 
Figure 2. Effects of Interpolation on trail flow length calculations.

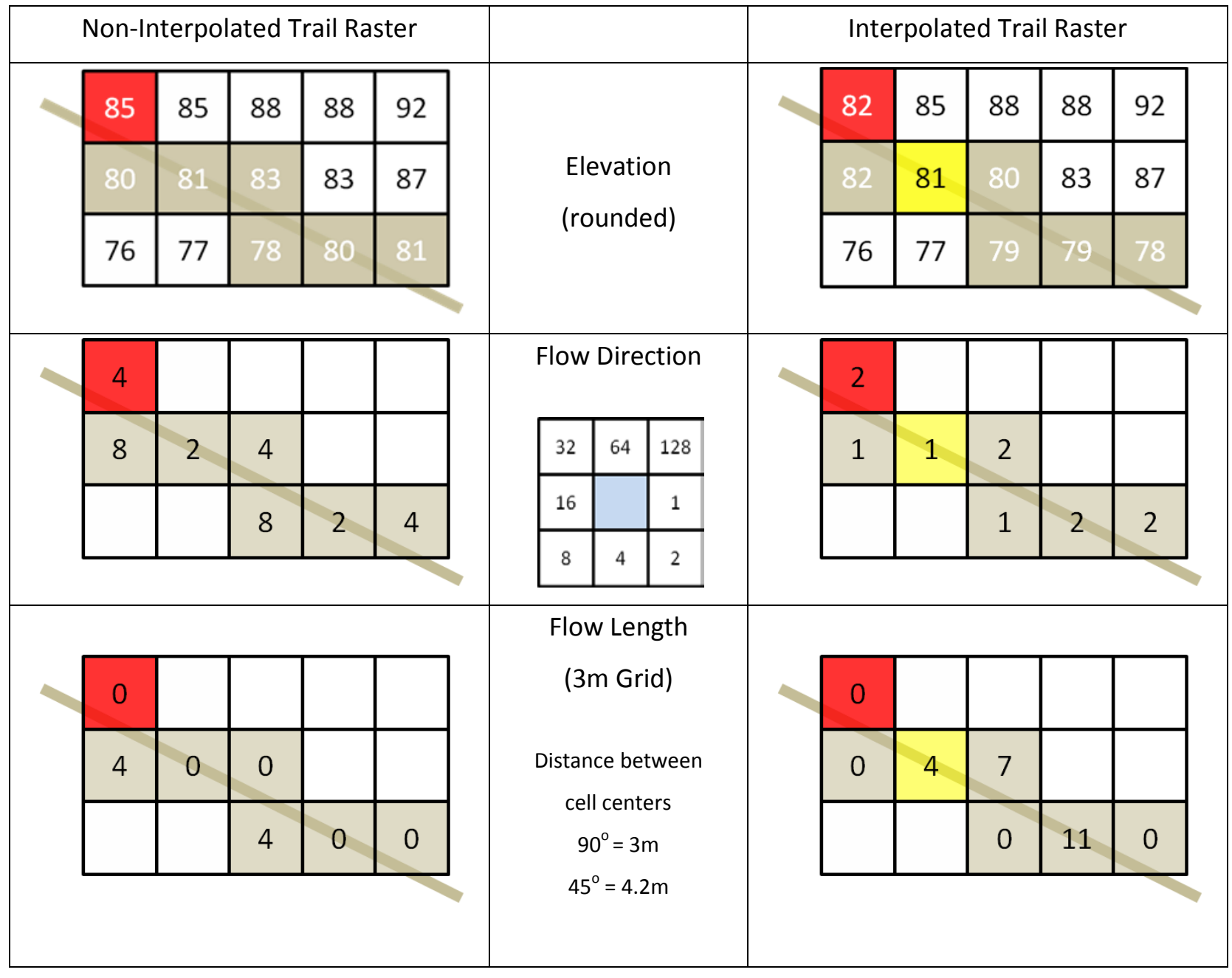

$=$ Trail Vector (shaded raster cells represent trail)

$=$ Highest elevation raster cell for trail

$=$ Cell for discussion below

\section{Flow Direction: Non-Interpolated vs. Interpolated Trail Rasters}

Upon examination of the elevations, flow direction, and flow lengths of these short sections of trail the flow length of the Non-Interpolated trail raster grid is much smaller than on the Interpolated grid. For the Non-Interpolated grid each time the trail raster steps down the value jumps 5 meters downhill, then gradually moves uphill as it moves to the right then drops again. This downward jump creates a sink at each step which does not allow the model to flow in the correct direction as the difference between the 
vertical drop and the starting cell is greater than the starting cell and the next lower cell on the diagonal. This sink causes multiple, discontinuous, short flow lengths which do not represent real world trail flows. Through the interpolation process these sinks are smoothed out by an averaging process that considers the trail point elevations extracted from the depressionless DEM. The resulting trail raster now allows higher-level steps to pour diagonally into lower steps without the creation of sinks. Thus in the Interpolated Trail Raster grid higher flow lengths are derived improving the model of trailbed water flow connectivity.

\section{Flow Direction Calculation: Perpendicular vs. Diagonal}

The yellow cell in the Interpolated Trail Raster grids (right column), appears to have an anomaly in the calculation of the Flow Direction grid. Instead of the flow direction going to the cell with elevation 79 (Direction 2), it goes to the cell with an elevation of 80 (Direction 1). To understand why this is not an anomaly you must understand how the Flow Direction is calculated. From each cell, Spatial Analyst looks to see what is the greatest change in slope from the center cell to each of its 8 neighboring cells. The direction with the greatest slope is assigned the raster value designating that direction (see Flow Direction key above). Slope is calculated using the following formula:

$$
\text { Slope }=\text { change in z-value } / \text { distance } * 100
$$

In the case of the yellow cell, the elevations are .3 feet apart. As Spatial Analyst uses the distance between cell centers as the distance value, for the 3-meter cells, the distance between perpendicular cell centers is 3 meters ( 9.84 feet) and the distance between cell centers at $45^{\circ}$ angles is 4.2 meters (13.78 feet). Therefore, using the un-rounded values from the elevation grid we can see that direction 1 is correct:

Slope for Direction 1: $80.99-79.68 / 9.84 \mathrm{ft} * 100=13.3$

Slope for Direction 2: $80.99-79.31 / 13.78 \mathrm{ft} * 100=12.2$ 


\section{ArcMap Trail Flow Length Derivation Procedure:}

The following procedure for calculating a slope grid for the trail was adapted from Brooks, Boll, Elliot, \& Dechert (2006) used for estimating forest road slopes for use in the Watershed Erosion Prediction Project (WEPP) roads module.

Required GIS data files:

- Forest trail shape file

- $3 \mathrm{~m}$ Depressionless DEM Statewide mosaic (USGS Statewide Addressing and Mapping Board (SAMB) 1:4800, accuracy \pm 10 ; source West Virginia GIS Technical Center, West Virginia University)

- Shapefile of defined pour points. This file was generated from linear referenced survey logs on trail routes calibrated with field measured GPS points to $\pm 1 \mathrm{~m}$ accuracy at least every $1000^{\prime}$ along surveyed trails.

Note: Due to the large file size of the $3 m$ Depressionless DEM it may be necessary to clip the mosaic around trails of interest to reduce the time and computer resources needed to process trail flow length calculations.

ArcMap Requirements:

Derivation utilizes:

- ArcMap Desktop

- 3D Analyst

- Spatial Analyst

- XTools Pro ArcGIS Extension (http://www.xtoolspro.com; If full version of ArcEditor is available XTools Pro is not needed).

Procedure:

1. Create new map file in ArcMap

2. Add with depressionless DEM to establish grid, extent, and projection.

3. Add trail shape file.

4. Use data management tool to copy trails of interest to new shapefile. 
5. Use "Analysis Tools/Proximity/Buffer" to create polygon shapefile of trails with $1.5 \mathrm{~m}$ buffer. This file will be used as an analysis mask with total width of $3 \mathrm{~m}$ matching the raster cell size.

6. Using "XTools/Feature Conversion/Convert Features to Points" function, convert trail polylines to points - set Equidistant Points Interval $=10 \mathrm{~m}$.

7. Using "3D Analyst/Functional Surface/Surface Spot" calculate elevations for each point utilizing the depressionless DEM as the raster surface.

Note: Compared Surface Spot, Extract, and Calculation of $\mathrm{z}$ in table advanced field calculator and found that the interpolated Surface Spot and Calculation of $z$ values provided the same value. This value provides the best trail surface model for this calculation.

8. Use "3D Analyst/Raster Interpolation/IDW" function to create raster surface from trail point file.

- Set $Z$ value Field to use field from trail point file containing elevations.

- Set Options Mask = $1.5 \mathrm{~m}$ buffered trail shapefile.

- $\quad$ Set Extent $=1.5 \mathrm{~m}$ buffered trail shapefile.

- Set Cell Size same as Depressionless DEM (3m).

- Set Snap Raster same as Depressionless DEM (3m).

- Set Search Radius Settings, Maximum Distance to $10 \mathrm{~m}$. Will use 3 points to interpolate trail surface elevations on most straight sections of trail.

9. Create new long integer field, "rastervalue", in Pour Point shape file and assign a value of -5 to each row using the field calculator.

10. Use "Point to Raster" conversion tool to convert Pour Point shapefile to Raster (use same Mask, Extent, Snap raster, and Cell Size values as step 8. Field value is assigned to field created in step 9, "rastervalue" (-5).

11. Use "Spatial Analyst/Reclassify" tool to reclassify Pour Point raster file values:

- Values: NoData $=0 ;-5=-5$.

- Options Mask $=1.5 \mathrm{~m}$ buffered trail shapefile.

- Extent: $1.5 \mathrm{~m}$ buffered trail shapefile.

- Cell Size same as Depressionless DEM (3m).

- Snap Raster same as Depressionless DEM (3m).

12. Use "Raster Math/Plus" to add reclassified Pour Point raster file to Trail DEM.

13. Use "Spatial Analyst/Hydrology/Flow Direction" to create flow direction grid of Trail DEM.

14. Use "Spatial Analyst/Hydrology/Flow Length" tool to create Flow Length grid of Trail DEM. 
15. Use "Spatial Analyst/Neighborhood Statistics" tool to create a Maximum Flow Length grid of Trail DEM.

- Set statistic type to Maximum

- Neighborhood Settings: Height $=3$, Width $=3$.

The resulting grid file contains cumulative flow length values for each $3 \mathrm{~m}$ grid cell which represents the trail vector. Use the Extract function to transfer these values to your sample point shape file or use spatial statistics to extract maximum flow length values for each trail segment length of interest.

Note: Use of this calculation for on-trail watershed lengths is only suitable for trails that follow the natural contours of the topography. Trails with significant trail-bed construction, such as trails on old railroad or road beds, where the final landform contours are not captured in the digital elevation model cannot be accurately modeled using this method.

References:

Brooks, E. S., Boll, J., Elliot, W. J., \& Dechert, T. (2006). Global positioning system/GIS-based approach for modeling erosion from large road networks. Journal of Hydrologic Engineering, 11, 418. 
Method 1: Produces stair steps on cross-slope trails - cells aligned to landscape slope

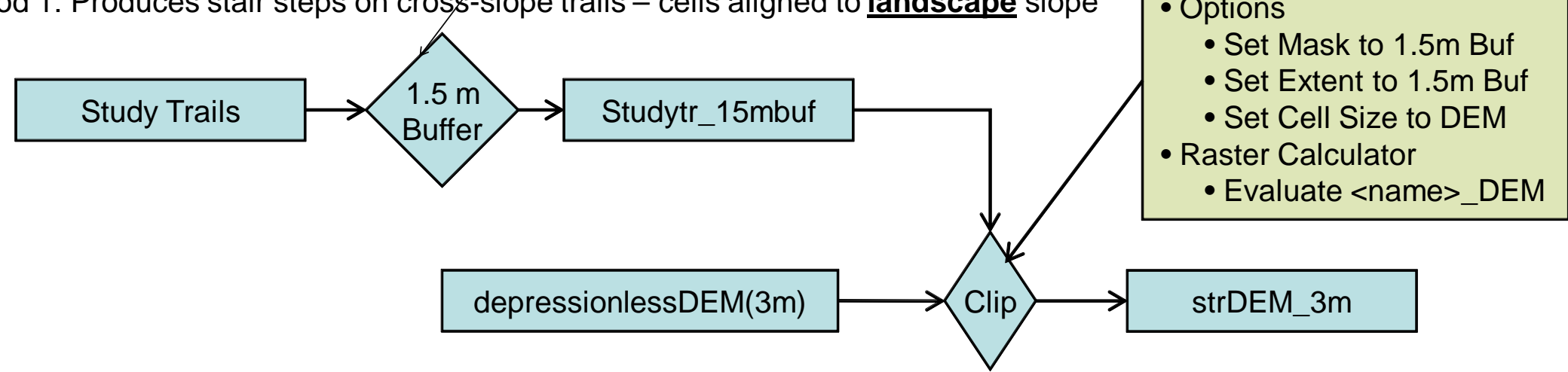

Method 2: Limits stair steps on cross-slope trails - cells aligned to trail slope

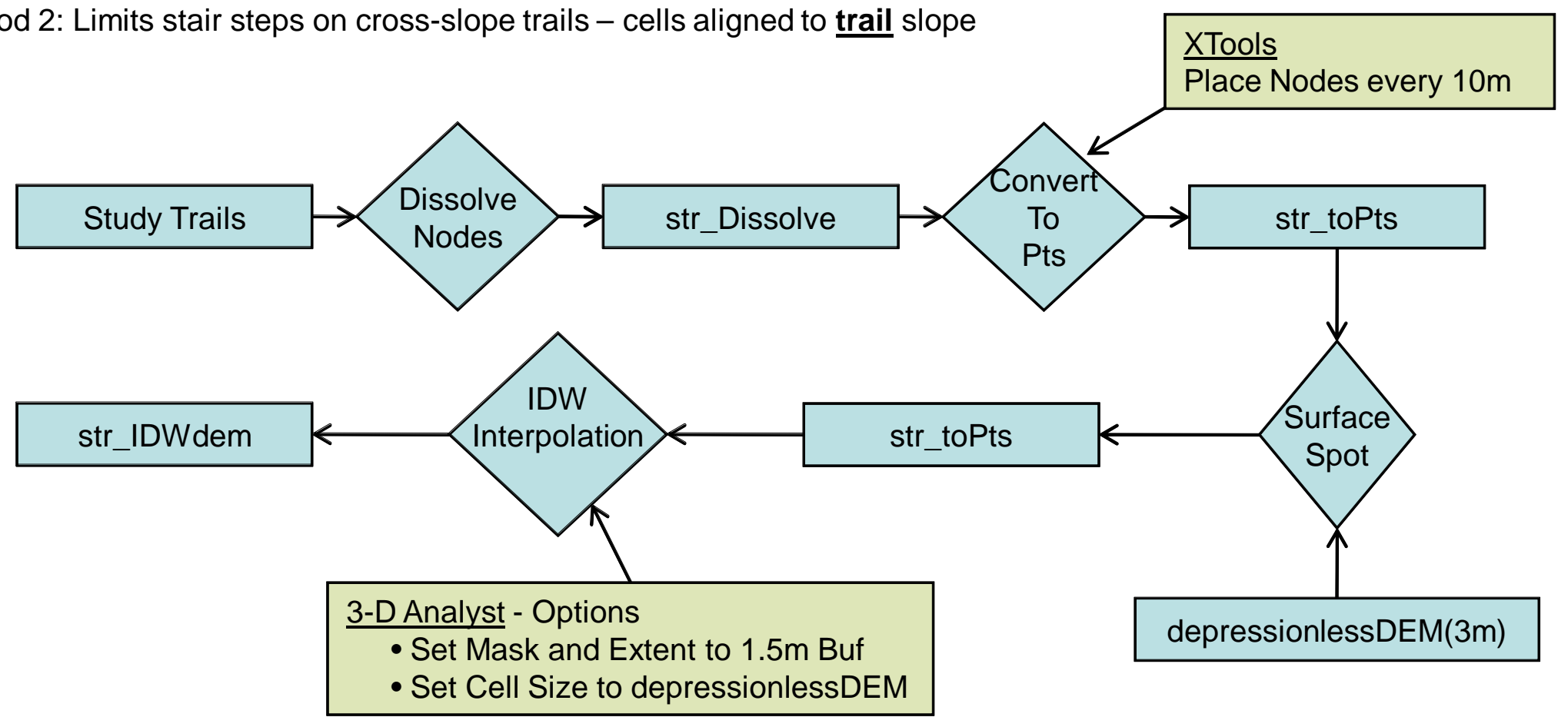




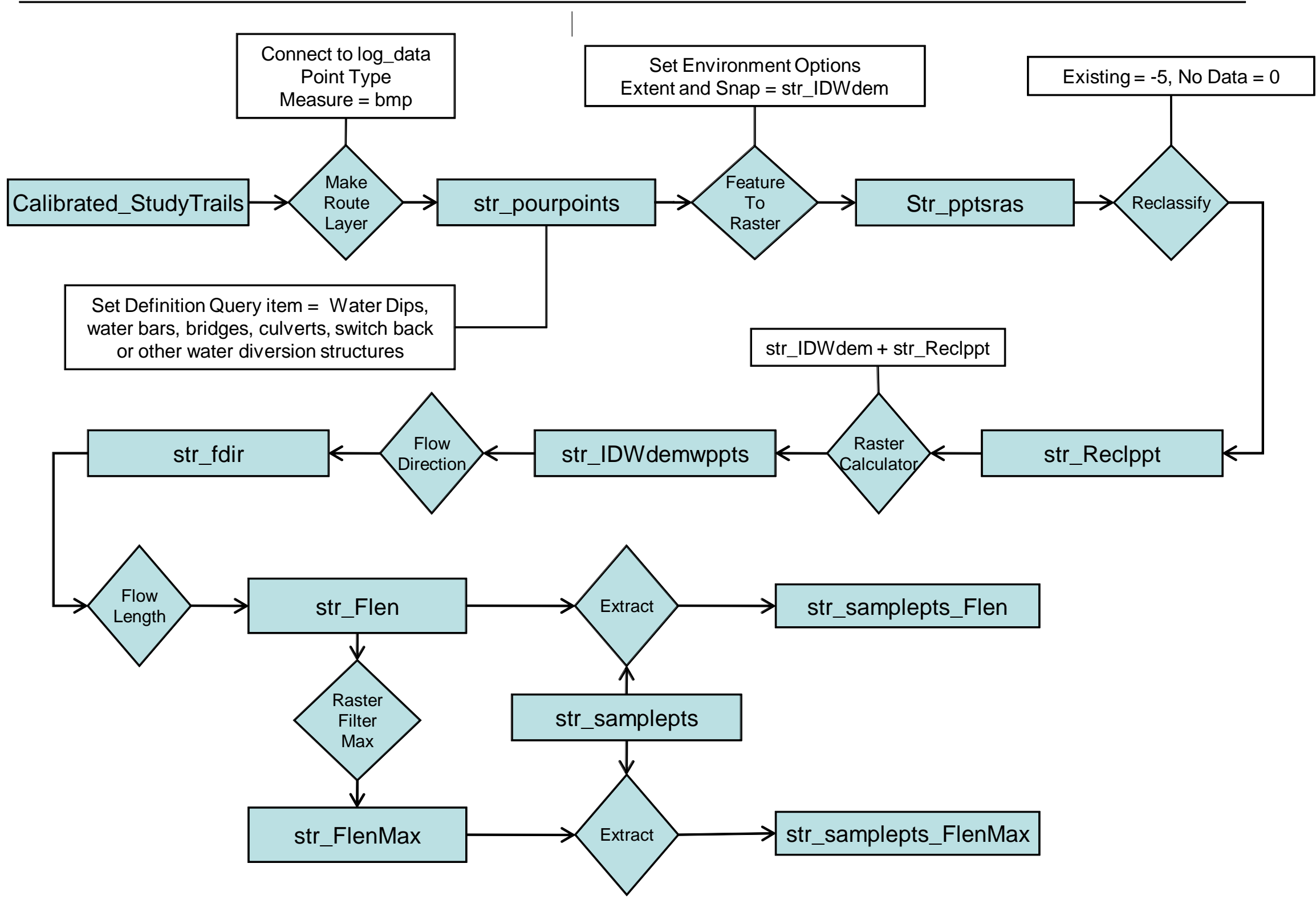

